\title{
Técnicas de Orientação a Objetos para Projeto de Sistemas Adaptáveis
}

\author{
Uirá Kulesza
}

Dissertação de Mestrado apresentada ao Instituto de Matemática e Estatística da Universidade de São Paulo como requisito para obtenção do grau de mestre em Ciência da Computação.

Curso: Mestrado em Ciência da Computação Área de concentração: Engenharia de Software Orientadora: Profa. Dra. Dilma Menezes da Silva

Durante a elaboração deste trabalho o aluno recebeu apoio financeiro da FAPESP.

São Paulo - SP / Julho - 2000 


\title{
Técnicas de Orientação a Objetos para Projeto de Sistemas Adaptáveis
}

\author{
Este exemplar corresponde à redação \\ final da dissertação devidamente corrigida \\ e defendida por Uirá Kulesza \\ e aprovada pela comissão julgadora.
}

São Paulo, 26 de Setembro de 2000.

Banca Examinadora:

- Profa. Dra. Dilma Menezes da Silva (orientadora) (DCC-IME-USP)

- Prof. Dr. Hernán Astudillo (DCC-IME-USP)

- Profa. Dra. Cecilia Mary Fischer Rubira (IC-UNICAMP) 
Dedicada à painho e mainha. 


\section{Agradecimentos}

\section{Acadêmicos}

À Dilma pela excelente e enérgica orientação durante todas as fases de elaboração deste trabalho (desde o início do mestrado quando ajudou a situar-me na área de projeto de software orientado a objetos e na definição do tópico do trabalho, até as fases finais quando teve bastante paciência nas repetidas leituras do texto que aqui se encontra); pelos ensinamentos (diretos e indiretos) sobre como proceder no desenvolvimento de uma pesquisa; e finalmente, por ter topado me orientar mesmo quando o tema de trabalho não era alvo direto de suas pesquisas.

Ao professor Hernán Astudillo pelos valiosos ensinamentos compartilhados de sua experiência acadêmica e industrial sobre projeto de software e orientação a objetos; pela atenção dedicada ao trabalho e a minha pessoa; e finalmente por nos ter indicado "caminhos" para o desenvolvimento da pesquisa e verificação de seus resultados.

À professora Cecilia Rubira pelos excelentes comentários apresentados na defesa da dissertação que certamente contribuíram para a melhoria da redação final da dissertação aqui apresentada e que também permitiram aprender e refletir ainda mais sobre os resultados da pesquisa e os problemas que circundam a área de projeto de software.

Ao professor Alan Durham pelas dicas trazidas durante a realização do exame de qualificação.

Aos demais professores do Departamento de Ciência da Computação do Instituto de Matemática e Estatística da USP, que tive contato direto através de disciplinas e seminários, e que enriqueceram o mestrado mostrando as diversas facetas da ciência da computação. Em especial a: Ana Cristina Melo, Cristina Fernandes, Flávio Soares, Francisco Reverbel, Marcelo Finger, Markus Endler e Paulo Feofiloff.

À todos os funcionários das dependências (biblioteca, CPG, secretaria, café, segurança) do IME/USP, que dão diariamente excelente condições e muita simpatia que facilitam em muito o desenrolar do nosso trabalho. 


\section{Pessoais}

"Esta dissertação foi fruto de um trabalho que requereu esforços próprios, mas cujos resultados certamente não seriam alcançados se não fosse a presença, apoio e energia da familia e dos amigos"

À tia Irene, por ter me acolhido em seu lar, pela dedicação durante esses dois anos e meio, pela força positiva, pela excelente companhia e aprendizados mútuos, pelo amor e carinho. "Sem você tia, o desenvolvimento da dissertação teria sido muito mais penoso".

À Roberta por ter me motivado a vir para São Paulo mesmo não sendo esse seu maior desejo, pela "presença" e força constante, por ter suportado junto comigo os meses difíceis de separação, por todo o amor, paciência e atenção intensos que tem dedicado. "Amor, agora podemos ficar juntinhos!! (;-*”

Aos meus amigos inseparáveis Ricardo e Said, que me fizeram aprender muito mais do que conhecimentos científicos nesses anos de IME, me fizeram perceber ainda mais o quanto é importante a amizade! E não quero agradecer a vocês apenas pelas companhias no futebol (de Sábado e Quinta), mas também pela dedicação e atenção nos almoços, durante o curso das disciplinas, nas preparações para qualificação e defesa, nas discussões de trabalho, pelos sorrisos matinais que trazia sempre muita energia e nos excelentes programas culturais que fizemos juntos pela grande São Paulo.

À tia Lica, tio Sérgio, Chayene e Walace pelo apoio desde a minha chegada até o meu retorno, pelos adoráveis encontros de final de semana, pelos sorrisos e carinhos, e pelas palavras de conforto.

À minha maninha Maité pela força na reta final da dissertação, pelos conselhos, e pela dedicação transparente e sincera.

À painho e mainha pelos conselhos sábios, pela tranquilidade e força emocional que me trazem.

À Raoni e Yuri pelos sorrisos e amor. E pelos ensinamentos conjuntos que passamos um para os outros.

À toda a familia Kulesza por todo o carinho dedicado, e pelos muitos papos e encontros descontraídos de final de semana.

À Franklin, Gustavo, Rodriguinho e Tácito que sempre trouxeram bastante carinho e conselhos amigos.

Para uma extensa lista de amigos que fiz no mestrado e que junto com Said e Ricardo, tornaram os dias acadêmicos mais enriquecedores, bonitos, alegres e festivos. 
"Gente sentirei saudade de cada um vocês e de cada um dos momentos legais que compartilhamos juntos". Em especial a: Ademir, Alexandre, Ana Paula, Ane, Antonio, Ariane, Carlos Maia, Clara, Eduardo, Emmanuel, Fábio "Beleza" e Val, Franklin, Lorena, Lucy, Luiz Carlos, Marcel, Marcelo Brito, Marco Aurélio, Maria do Carmo, Marquinho, Roberto Toscano, Sandro, Santos, Sirley, Téo, Verinha, Washington.

Para os amigos do DreamTeam (Alejo, Ana Karla, Claudiana, Edcleide, Flávia, Giggio, Greg, Guga, Joseane, Livia, Natasha, Raissa, Sérgio, Starch, Uélber) que perto ou longe sempre estiveram presentes e transmitindo força e carinho, através de telefonemas, e-mails descontraídos e de corpo presente. 


\section{Resumo}

O paradigma de orientação a objetos se consolidou ao longo da década de 90 e tem demonstrado grande potencial em facilitar o tratamento de questões de evolução e mudanças em sistemas. Entretanto, diversos problemas ainda são encontrados na manutenção de sistemas construídos sob a ótica dos conceitos e abstrações presentes neste paradigma. Recentemente novos enfoques para projeto orientado a objetos têm sido propostos com o intuito de favorecer requisitos de manutenibilidade $\mathrm{e}$ reutilização/evolução de sistemas orientados a objetos.

Este trabalho descreve um estudo comparativo do impacto das técnicas de programação orientada a aspectos e programação adaptativa com relações de contexto no projeto de sistemas com requisitos de adaptação estática e dinâmica. O estudo foi conduzido através da reengenharia do projeto dos sistemas: JAWS - um servidor Web adaptativo - e SPIN - um sistema operacional extensível. Nosso objetivo foi analisar e avaliar a aplicabilidade das técnicas no projeto de sistemas mais flexíveis a mudanças futuras.

O estudo demonstra que a aplicação dos preceitos de programação orientada a aspectos e programação adaptativa com relações de contexto pode trazer diversos benefícios para o projeto de sistemas adaptáveis, entre eles: separação de interesses e facilidades na reutilização, na evolução estática, na configuração dinâmica e no entendimento progressivo da estrutura e comportamento do sistema.

O trabalho propõe ainda uma categorização para os tipos de adaptações encontrados em sistemas de software. 


\section{Abstract}

The object paradigm has been consolidated during the last decade. It has been shown that this paradigm facilitates the management of evolution and change in systems. However, some difficulties still occur in the course of maintaining object-oriented systems. Recently, new design techniques have been proposed to address object-oriented maintainability requirements.

This dissertation describes a comparative study that analyzes the impact of two techniques (aspect-oriented programming and adaptive programming with context relations) in the design of systems with static and dynamic adaptation requirements. The case study has been carried out by reengineering the design of two systems: JAWS - an adaptive Web server - and SPIN - an extensible operating system. Our goal was to analyze and assess the applicability of the techniques in the design of flexible systems.

The study demonstrated that the use of aspect-oriented programming and adaptive programming with context relations can bring about several benefits in the design of adaptable systems, such as: separation of concerns, facility in reuse, static evolution, dynamic configuration, and progressive understanding of the system.

The dissertation also proposes a categorization for the different adaptation types found in software systems. 


\section{Sumário}

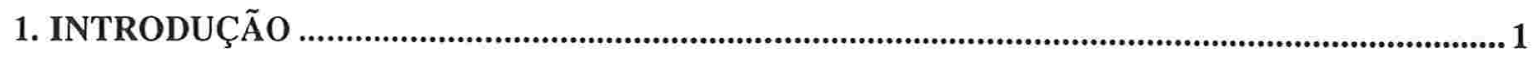

1.1 MotIVAÇÃO

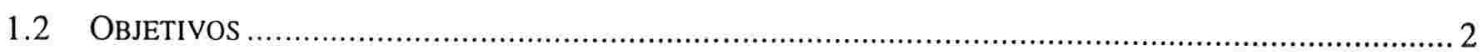

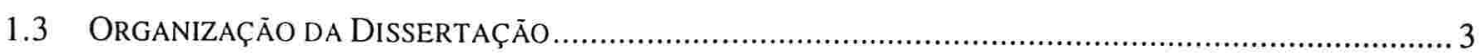

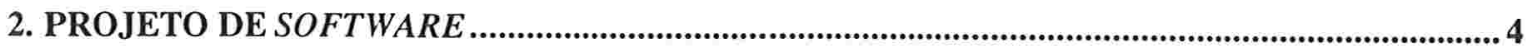

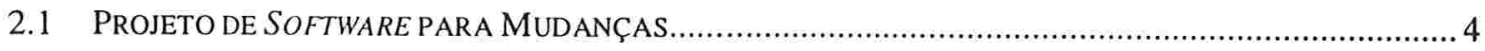

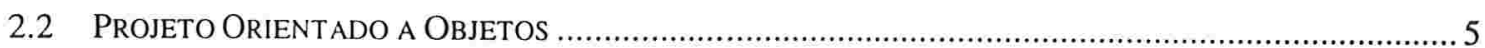

2.3 TÉCNICAS DE PROJETO PaRa Sistemas FlexíVEIS.................................................................... 7

2.3.1 Padrōes de Arquitetura e Projeto .................................................................................... 7

2.3.2 Programação Orientada a Assunto .................................................................................. 8

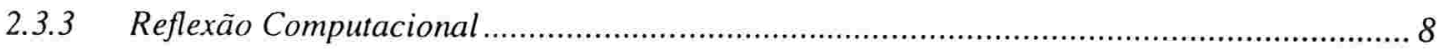

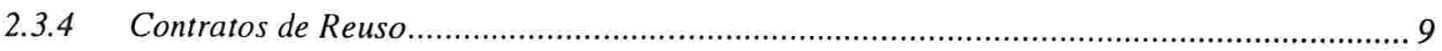

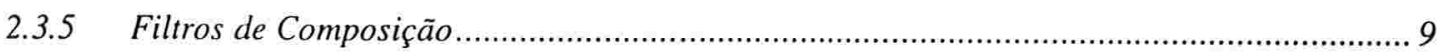

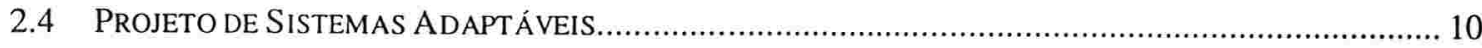

2.5 ADAPTAÇÃo E RECONFIGURAÇÃo DinÂMICA DE SISTEMAS ……................................................. 12

3. TÉCNICAS DE PROJETO PARA SISTEMAS ADAPTÁVEIS....................................................... 14

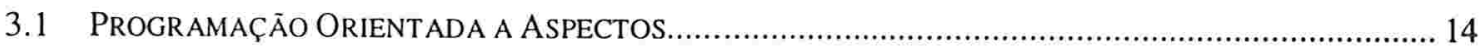

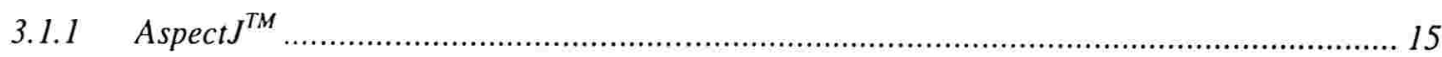

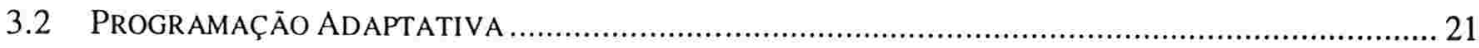

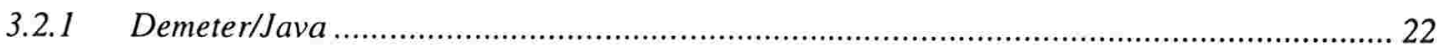

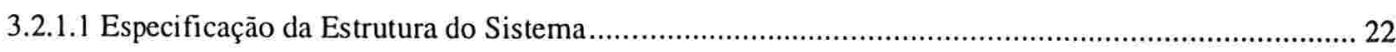

3.2.1.2 Especificação do Comportamento do Sistema ............................................................................ 25

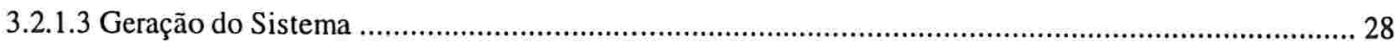

3.2.1.4 Evolução da Estrutura e Comportamento do Sistema................................................................... 28

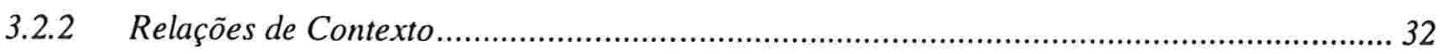

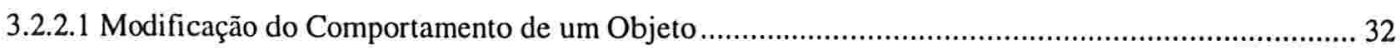

3.2.2.2 Modificação do Comportamento de um Grupo de Objetos............................................................... 36

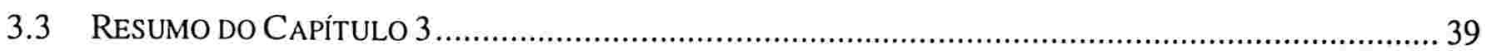




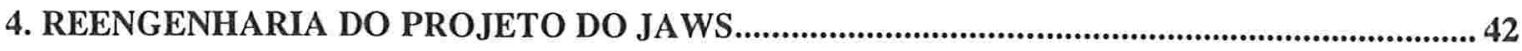

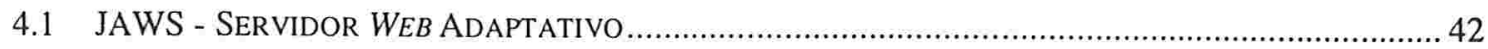

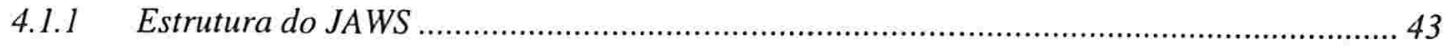

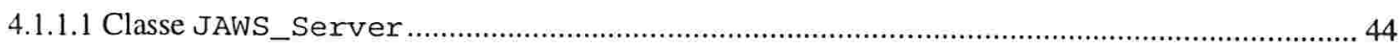

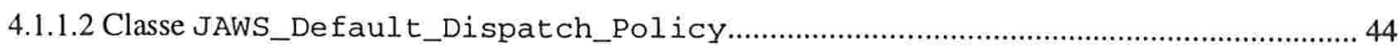

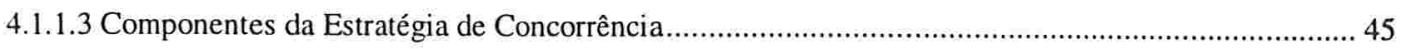

4.1.1.4 Componentes da Estratégia de Aceitação de Conexões.................................................................. 47

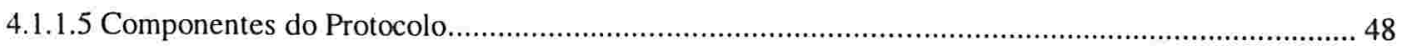

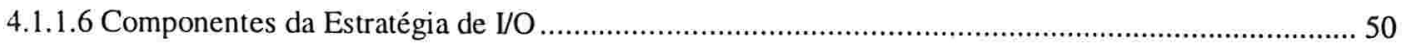

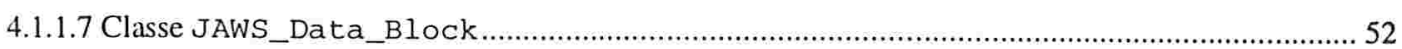

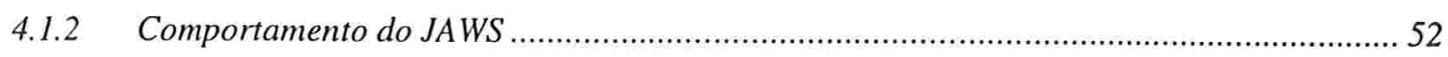

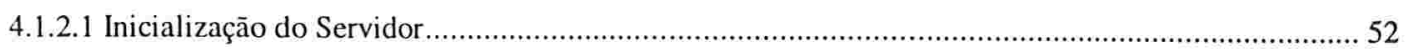

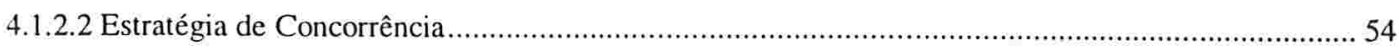

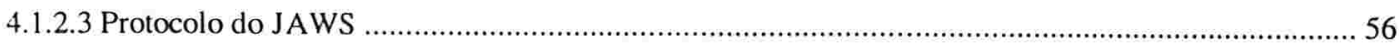

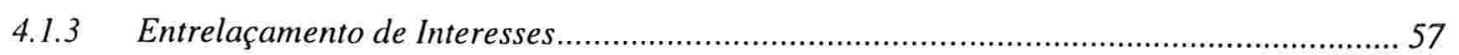

4.2 ReEngenharia do Projeto do JAWS com ProgramaÇão Orientada a AsPeCtos................. 60

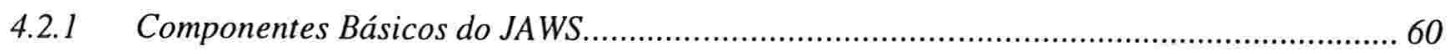

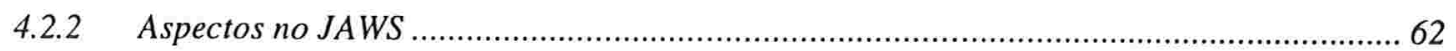

4.2.2.1 Estratégia de Concorrência...................................................................................................... 63

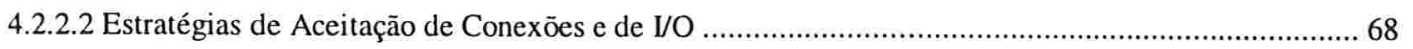

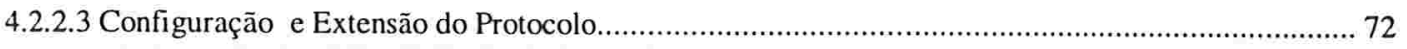

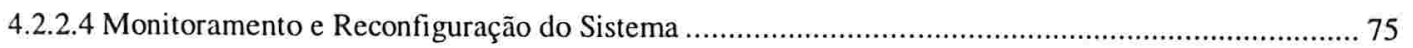

4.2.3 Análise do Projeto do JAWS com Programação Orientada a Aspectos................................ 80

4.3 ReEngenharia do Projeto do JaWS com ProgramaÇão Adaptativa e Relações de

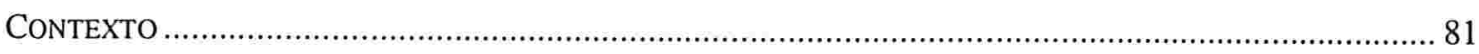

4.3.1 Projeto do JAWS com Programação Adaptativa................................................................ 81

4.3.1.1 Projeto do Servidor com Programação Adaptativa ......................................................................... 81

4.3.1.2 Projeto do Protocolo do JAWS com Programação Adaptativa ......................................................... 87

4.3.2 Projeto das Estratégias do JAWS com Relações de Contexto ............................................ 89

4.3.2.1 Projeto da Estratégia de Concorrência .......................................................................................... 89

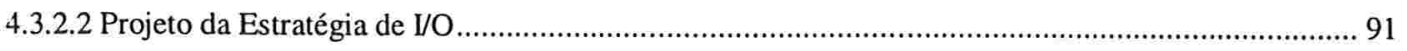

4.3.2.3 Projeto da Estratégia de Aceitação de Conexōes ...................................................................... 92

4.3.2.4 Projeto da Estratégia de Configuração do Protocolo ...................................................................... 94

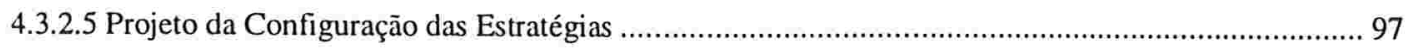

4.3.3 Análise do Projeto do JAWS com Programação Adaptativa e Relações de Contexto ......... 98

4.4 COMPARAÇÃo DO ESTUDO DE REENGENHARIAS DO JAWS ....................................................... 99 


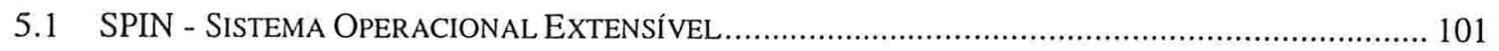

5.1.1 Modelo de Extensão do SPIN ..................................................................................... 102

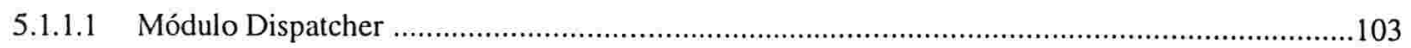

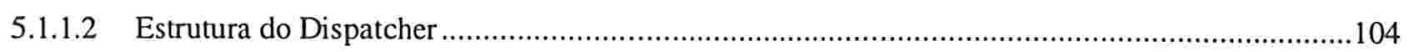

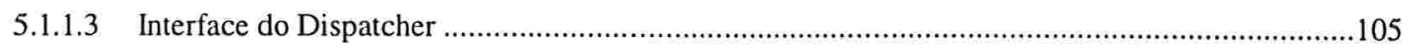

5.2 Reengenharia do Projeto do Dispatcher com ProgramaÇão Orientada a Aspectos .... 109

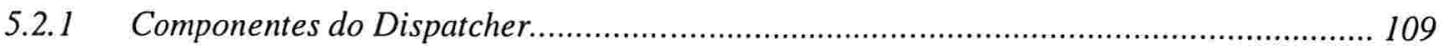

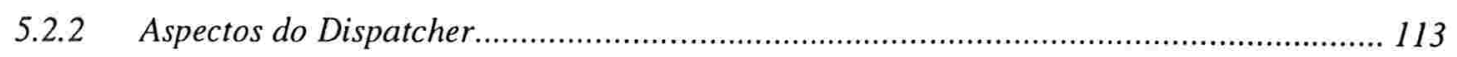

5.2.2.1 Instalação de Imposed Guards e Handlers Default/Result ........................................................114

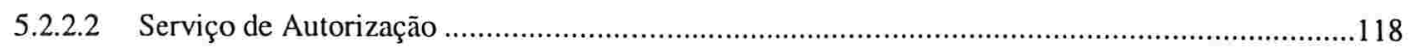

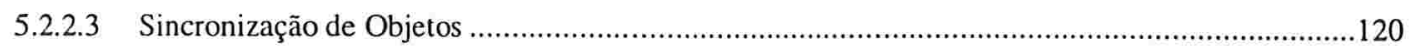

5.2.2.4 Verificação de Tipos ...................................................................................................124

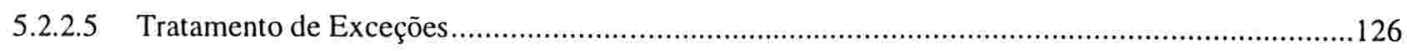

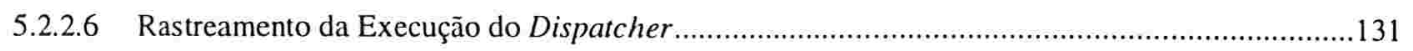

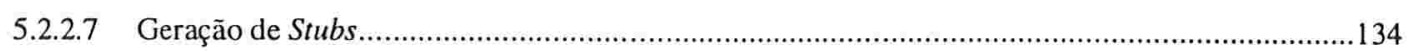

5.2.3 Análise do Projeto do Dispatcher com Programação Orientada a Aspectos.................... 136

5.3 Reengenharia do Projeto do Dispatcher com Programação AdaPtativa e Relaçōes de

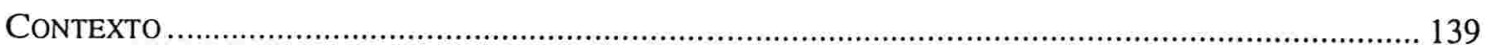

5.3.1 Projeto do Dispatcher com Programação Adaptativa ..................................................... 139

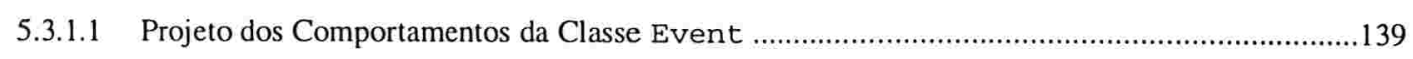

5.3.1.2 Projeto de Imposed Guards e Handlers Default/Result..............................................................141

5.3.2 Projeto do Dispatcher com Relaçōes de Contexto............................................................ 144

5.3.3 Análise do Projeto do Dispatcher com Programação Adaptativa e Relações de Contexto 147

5.4 COMPARAÇÃO DO ESTUdO DE REENGENHARIAS DO DISPATCHER/SPIN ……................................. 147

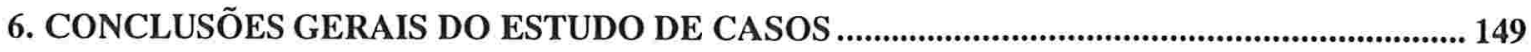

6.1 Aplicabilidade de ProgramaÇão Orientada a AsPectos .................................................... 149

6.1.2 Método para Projeto Orientado a Aspectos.................................................................. 151

6.2 Aplicabilidade de ProgramaÇão Adaptativa e Relaçōes de Contexto.......................... 152

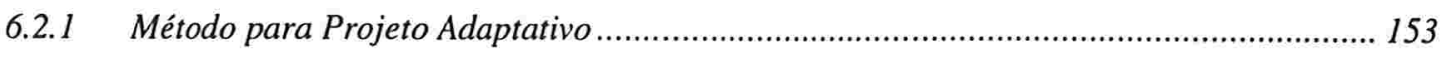

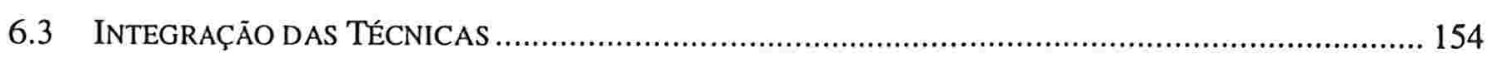

6.3.1 Integração entre Programação Orientada a Aspectos e Programação Adaptativa .......... 154

6.3.2 Integração entre Programação Orientada a Aspectos e Relações de Contexto ................. 156

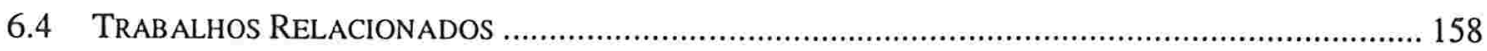


7. CATEGORIZAÇÃO DE ADAPTAÇÕES EM SISTEMAS........................................................... 162

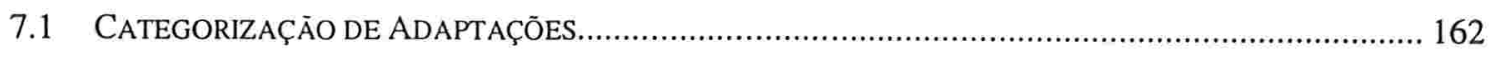

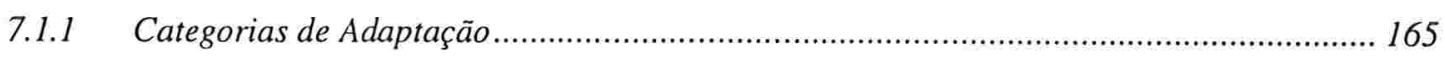

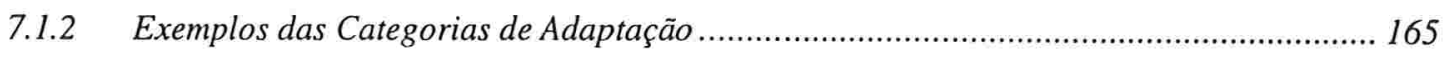

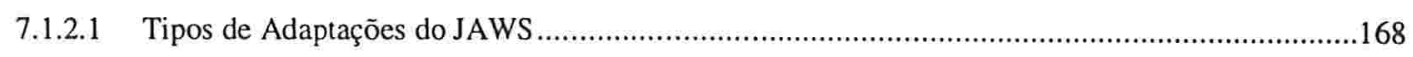

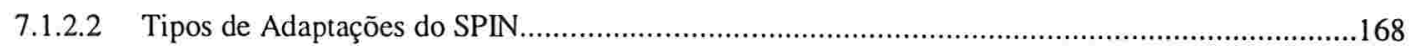

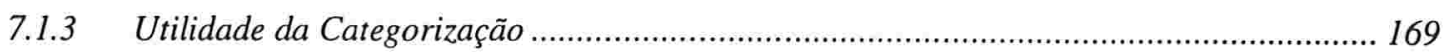

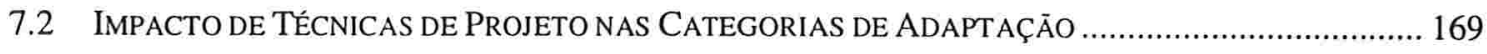

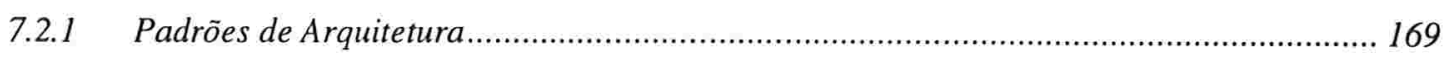

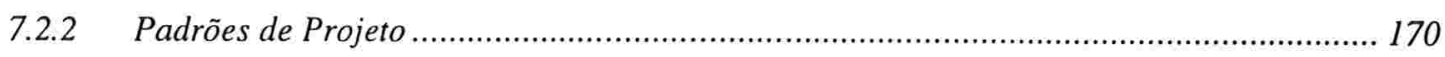

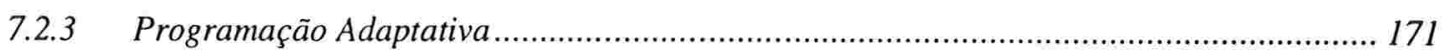

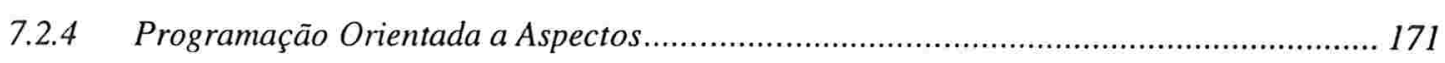

7.2.5 Tabela com o Impacto das Técnicas ......................................................................... 172

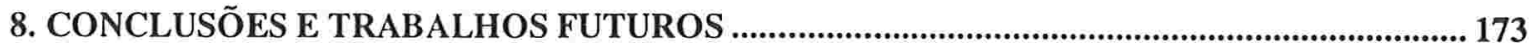

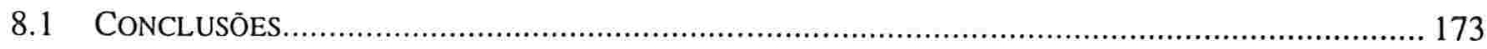

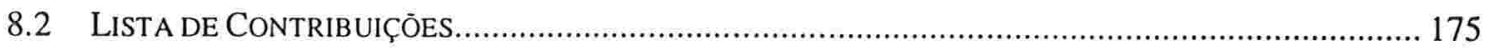

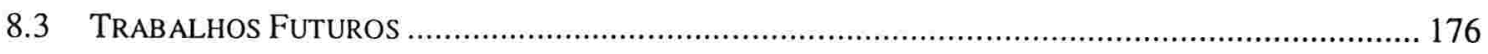

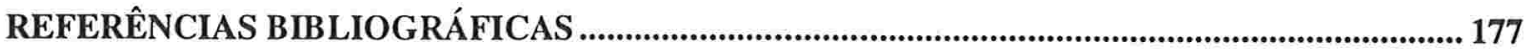




\section{Lista de Figuras}

Figura 3.1: Diagrama de Classes/Aspectos do ShowAcCesses... 17

Figura 3.2: Diagrama de Classes/AsPectos do ShowACCESSESEXTENDED .................................... 18

Figura 3.3: Diagrama DE ClassEs/ASPECTOS do SHOWACCESSESANDSETTERS ................................ 19

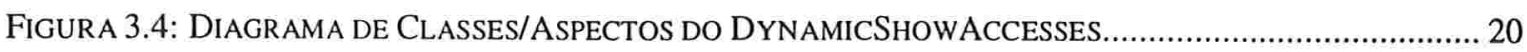

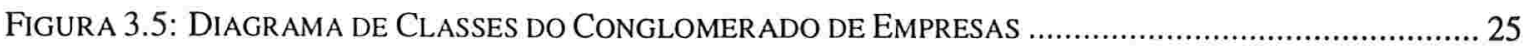

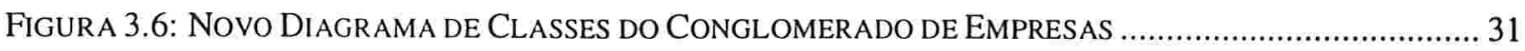

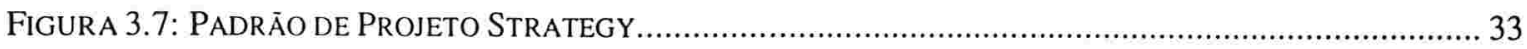

Figura 3.8: Padrão de Projeto Strategy modelado com RelaÇões de ConteXto ..........................34

FIGURA 3.9: DiAgRAMA DE ClASSES UML PARA EQUIPAMENTOS DE COMPUTADORES .............................. 37

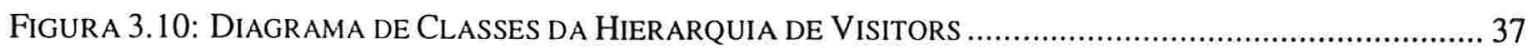

Figura 3.11: Diag. DE Classes PARA EQUIP. DE COMPUTADORES UTILIZANDO RELAÇÕES DE CONTEXTO. 38

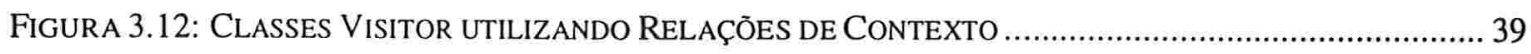

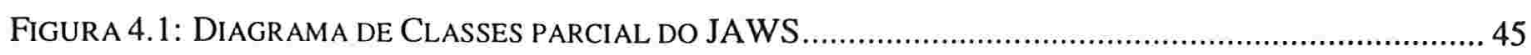

FIgURA 4.2: Diagrama dE ClasSES DA ESTRATÉGIA DE CONCORRÊNCIA DO JAWS ...............................47

Figura 4.3: Diagrama de Classes da EstratÉgia de ACEITAÇÃo de Conexões do JAWS .................48

FIgURA 4.4: Diagrama dE ClasSES Da ESTRATÉGIA do Protocolo do JAWS ................................... 50

FIGURA 4.5: DIAGRAMA DE CLASSES DA ESTRATÉGIA DE I/O DO JAWS ............................................... 51

FIGURA 4.6: DiAGRAMA DE SEQÜÊNCIA DO MÉTODO INIT ( ) DA CLASSE JAWS_SERVER .......................... 53

FIgURA 4.7: Diagrama dE SEQÜÊNCIA dO MÉTOdO open ( ) DA CLASSE JAWS_SERVER ........................... 53

FIGURA 4.8: Diagrama de SEQÜÊNCIA do MÉTOdo sVC ( ) DA ClASSE JAWS_CONCURRENCY_BaSE.......... 54

FIgURA 4.9: Diagrama de SEQÜÊNCIA do MÉTOdo svc_loop ( ) DA ClASSE JAWS_CONCURRENCY_BASE 55

FIgura 4.10: Diagrama de SEQÜÊNCIA DO MÉTOdO SVC_hOOK ( ) DA ClASSE JAWS_CONCURRENCY_BASE

FIgURA 4.11: Diagrama dE SEQÜÊNCIA DO MÉTOdo put () DA CLASSE JAWS_Pipeline_ACCCEPt_TASK

Figura 4.12: Diagrama dE SEQÜÊNCIA DO MÉTODO handLE_put ( ) DA CLASSE JAWS_PIPELINE_ACCCEPT_TASK.

Figura 4.13: DiaG. DE ClaSSES PARCIAL do JAWS INDICANDO ENTRELAÇAMENTOS DE INTERESSES ....... 59

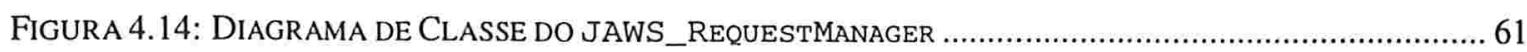

Figura 4.15: Diagrama de Classes e Aspectos da EstratÉGIA DE CONCORRÊNCIA ...........................64 64

Figura 4.16: Diagrama de Classes e Aspectos da EstratéGia de ACEITAÇĀo de ConeXões e I/O ... 69 
Figura 4.17: Diagrama de Classes e Aspectos da Configuração do Protocolo

FiguRA 4.18: Diag. DE CLASSES/ASPECTOS DOS INTERESSES dE MONITORAMENTO E CONFIGURAÇĀO do

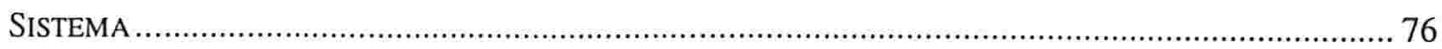

FIGURA 4.19: DiAGRAMA DE CLASSES DO PROJETO DO JAWS COM PROGRAMAÇÃO ADAPTATIVA................. 83

Figura 4.20: Diagrama DE ClaSSES DO PROJETO DO PROTOCOLO DO JAWS COM PROGRAMAÇãO

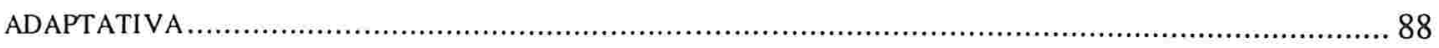

Figura 4.21: MANUTENÇÃO No Protocolo Do JAWS COM PROGRAMAÇão ADAPTATIVA.......................... 89

Figura 4.22: EstratéGIA DE CONCORRÊNCIA COM RELAÇÕES DE CONTEXTO............................................. 90

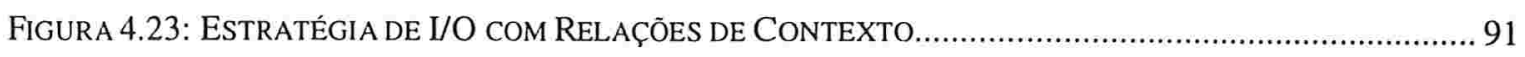

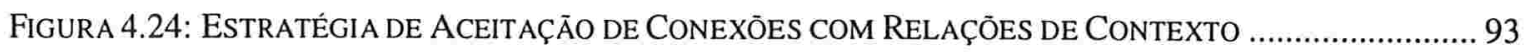

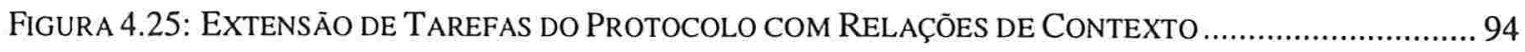

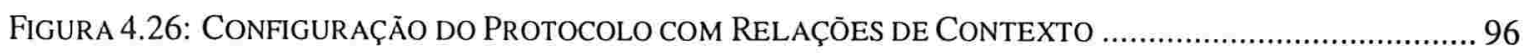

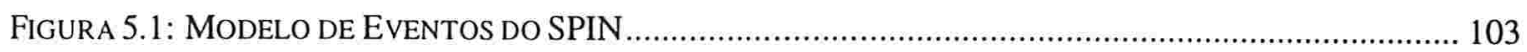

Figura 5.2: Diagrama DE ClasSES Da ESTRUTURA ORIGINAL Do DisPaTCHER ……............................... 104

Figura 5.3: Diagrama de Classes do Projeto do Dispatcher com POA …….................................. 110

Figura 5.4: Diagrama de SEQÜÊnCia do mÉTOdo DebugDispatch ( ) DA CLASSE Dispatcher............. 111

Figura 5.5: Diagrama de ASPeCtOS E ClasSES dos Elementos DinÂMicos...................................... 115

Figura 5.6: Diagrama de ASPeCtos E ClasSES do SER VIÇO de AutorizaÇão....................................... 119

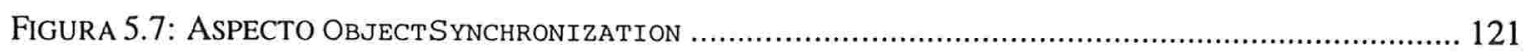

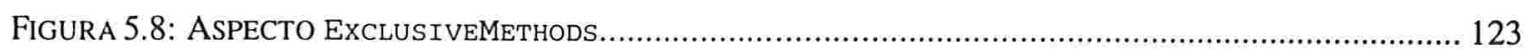

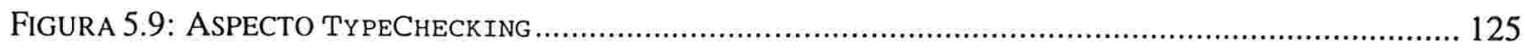

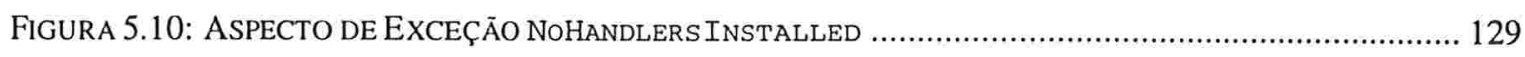

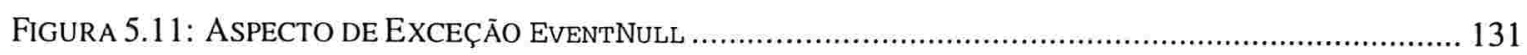

FIGURA 5.12: ASPECTO TRACING (RASTREAMENTO DO MÉTODO INSTALL_STUB) ....................................... 133

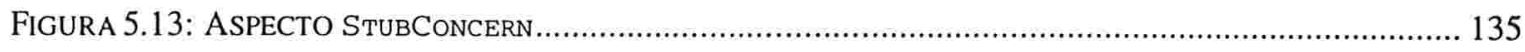

FIGURA 5.14: DiAGRAMA DE DEPENDÊNCIA ENTRE ASPECTOS ……....................................................... 138

FiguRA 5.15: Diagrama de Classes do Modelo de CoMPonENTES FunCIONAIS EXTENDIDO................ 142

Figura 5.16: Diagrama de CLASSES Do DiSPATCHER COM RELAÇÕES DE CONTEXTO............................... 146

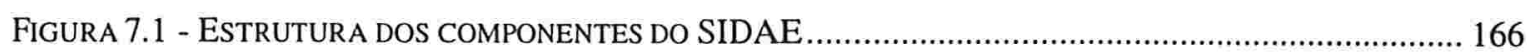




\section{Introdução}

Este trabalho descreve um estudo conduzido com o intuito de avaliar o impacto de novos enfoques da abordagem orientada a objetos no projeto de sistemas adaptáveis. Neste capítulo inicial, apresentamos a motivação para realização do trabalho, seus objetivos e descrevemos a sua organização.

\subsection{Motivação}

Apesar do amadurecimento das pesquisas em engenharia de software, manutenção de software permanece como um problema central à área. O processo de manutenção [GJM91] envolve não apenas a correção de erros, mas sobretudo a adequação do sistema para a integração de novas tecnologias e novos requisitos. O alto custo associado a estas adequações [CALO94, Gra94] estimula o desenvolvimento de sistemas mais flexíveis a mudanças futuras. Outros fatores que também motivam o desenvolvimento de sistemas mais flexíveis são:

- a dificuldade na especificação e entendimento dos requisitos de determinados domínios de aplicação (ex: sistemas de tempo real ou tolerante a falhas);

- a possibilidade de funcionamento por tempo prolongado [GJM91];

- a tendência a constantes e rápidas mudanças nos requisitos de classes específicas de sistemas, como por exemplo, aplicações financeiras;

- a possibilidade de reutilização da estrutura do sistema para a construção de similares [FS97, FJS99];

- a crescente demanda por aplicações que executem sobre o ambiente de execução heterogêneo, constantemente modificado e altamente dinâmico, que é a Internet.

Uma das abordagens propostas para tratar questões de evolução e mudança em software é construí-lo com base em uma arquitetura e projeto concebidos de forma a serem adaptáveis. Um sistema adaptável pode ser definido "como um sistema que pode ser facilmente modificado" [LL95], ou "um sistema que permite adaptar facilmente sua estrutura completa ou partes específicas devido a mudanças nos requisitos" [TA97]. Pesquisadores têm destacado o paradigma orientado a objetos como sendo promissor para o desenvolvimento de sistemas adaptáveis [FC96].

O paradigma de orientação a objetos (OO) se consolidou ao longo da década de 90, e estudos [HH93, Mey97, Sch98, WMH93] têm demonstrado as facilidades que ele pode trazer para o processo de manutenção de software. Entretanto, diversos problemas ainda são encontrados durante a evolução estática e dinâmica destes sistemas, entre eles: entrelaçamento de código relacionado a diferentes interesses [KLM+97]; dificuldade no entendimento de colaborações entre classes [ML98, WMH93]; e aumento da 
complexidade do sistema com a construção de extensas hierarquias de classes [Sch98]. Com o objetivo de favorecer requisitos de manutenibilidade de sistemas OO, a comunidade de engenharia de software vem propondo nos últimos anos diversas técnicas de projeto de software, tais como: padrões [BMR+96, GHJV95], programação orientada a domínio [HO93, OKH+95], programação adaptativa [Lie96, LX93] e programação orientada a aspectos [KLM+97]. Apesar dos autores destes novos enfoques para projeto orientado a objetos destacarem os benefícios que as técnicas podem trazer, torna-se necessário a elaboração de estudos para comprovação da aplicabilidade das mesmas no desenvolvimento de sistemas reais [KPP95, MWB99]. Estudos têm sido conduzidos recentemente com o intuito de avaliar a usabilidade e utilidade de algumas destas técnicas [KM99, LL99, MWB99, QR97, Sch95, WBM99].

Paralelamente, as comunidades de sistemas configuráveis distribuídos e de sistemas operacionais vêm estudando e desenvolvendo há bastante tempo diversas implementações de sistemas que incorporam aspectos de adaptação [KM85, Is197]. Este trabalho investiga o impacto das técnicas de programação orientada a aspectos e programação adaptativa com relações de contexto na reconstrução do projeto de dois destes sistemas. O objetivo foi avaliar as técnicas em relação as suas utilidades e vantagens no projeto de sistemas com requisitos de adaptação estática e dinâmica.

\subsection{Objetivos}

Neste trabalho são exploradas as relações existentes entre o projeto de software e a obtenção de sistemas flexíveis. Foram estudados dois novos enfoques para projeto orientado a objetos: programação orientada a aspectos e programação adaptativa com relações de contexto. Demos ênfase especial para as abordagens AspectJ [Asp00] de programação orientada a aspectos e Demeter/Java [LO00] de programação adaptativa.

O objetivo central do trabalho foi estudar e comparar o impacto de novas técnicas de projeto orientado a objetos no desenvolvimento de sistemas adaptáveis, em que: (1) serviços possam ser adicionados ou retirados da interface de um componente ${ }^{1}$; e (2) o sistema possa ser configurado (estatica e dinamicamente) para atuar de diferentes formas.

Para proceder a avaliação das técnicas foram inicialmente escolhidos dois sistemas adaptáveis: JAWS [HS99] - um servidor Web adaptativo - e SPIN [BSP+95] um sistema operacional extensível. Em seguida, nosso estudo foi conduzido através da reengenharia do projeto de partes específicas destes dois sistemas, relacionadas com seus interesses de adaptação, usando os conceitos e abstrações presentes nas abordagens das técnicas sendo investigadas. Os projetos gerados para cada sistema foram comparados

\footnotetext{
1 Ao longo desta dissertação é assumida a seguinte definição de componentes [KLM+97]: "unidades oriundas da decomposição funcional do sistema e que podem ser expressas e compostas nas linguagens de programação atuais". Como a dissertação trata de sistemas orientados a objetos na maioria dos casos, seguindo a definição acima, um componente será considerado como sendo uma classe ou conjunto de classes inter-relacionadas.
} 
com o seu projeto original no que diz respeito a diversas características, tais como, facilidade de manutenção, reutilização e evolução estática e dinâmica do sistema.

\subsection{Organização da Dissertação}

Esta dissertação está organizada em nove capítulos. O presente capítulo apresenta as motivações para a realização do trabalho, além dos seus objetivos e organização.

O capítulo 2 ressalta a importância do projeto do software em trazer facilidades para a futura evolução e mudança do sistema. São abordados os benefícios e problemas que o paradigma de orientação a objetos pode trazer para o projeto de softwares mais flexíveis a mudanças futuras, assim como apresentadas diversas técnicas de projeto que privilegiam requisitos de manutenibilidade de sistemas. Em uma das seções deste capítulo são apresentados conceitos e definições relacionados ao tema de adaptabilidade em sistemas.

O capítulo 3 apresenta as técnicas de projeto investigadas nesta dissertação: programação orientada a aspectos e programação adaptativa com relações de contexto. São descritas em maiores detalhes as abordagens de cada uma das técnicas (AspectJ e Demeter/Java) usadas no nosso estudo de casos.

Os capítulos 4 a 6 relatam o estudo de casos conduzido para avaliação do impacto das técnicas de programação orientada a aspectos e programação adaptativa no projeto de sistemas adaptáveis. Os capítulos 4 e 5 descrevem as características, estrutura e comportamento dos sistemas JAWS e SPIN, assim como as respectivas reengenharias do projeto destes sistemas usando os conceitos e abstrações das técnicas investigadas na dissertação. O capítulo 4 é dedicado ao JAWS e o capítulo 5 ao SPIN. Métodos empregados e modelos resultantes do processo de reengenharia do projeto dos sistemas estão também dispostos ao longo dos capítulos 4 e 5, assim como análises comparativas do projeto original de cada sistema com os novos projetos gerados usando as abordagens de AspectJ de programação orientada a aspectos e Demeter/Java de programação adaptativa. O capítulo 6 traz as conclusões gerais do estudo de casos e o confronta com trabalhos relacionados.

O capítulo 7 apresenta uma proposta para categorização dos tipos de adaptações que um software pode sofrer e uma breve análise do impacto das técnicas de projeto programação orientada a aspectos, programação adaptativa com relações de contexto e padrões (de arquitetura e projeto) sobre as categorias de adaptação.

Finalmente, o capítulo 8 traz as conclusões da dissertação, a lista de contribuições e propostas para a realização de trabalhos futuros. 


\section{Projeto de Software}

Neste capítulo ressaltamos a importância do projeto do software em propiciar facilidades para evolução e mudança do sistema. Os benefícios e problemas trazidos pelo paradigma de orientação a objetos para o projeto de softwares flexíveis são abordados. Técnicas de projeto propostas para a produção de sistemas mais fáceis de evoluir e manter são apresentadas. Em uma das seções do capítulo discorremos sobre o projeto de sistemas adaptáveis, são apresentados conceitos e definições relacionados ao tema de adaptabilidade encontrados na literatura, e as implicações no desenvolvimento de sistemas com tais características. Finalmente, uma breve seção é dedicada a apresentar o domínio dos sistemas configuráveis, usados no estudo dessa dissertação.

\subsection{Projeto de Software para Mudanças}

A fase de projeto do ciclo de vida de desenvolvimento de software [Som92, Pres95] é de vital importância para determinar as possibilidades e facilidades de sua futura evolução. Enquanto na fase de análise o objetivo é entender os requisitos do sistema e estabelecer uma especificação dos requisitos que este deverá endereçar, na fase de projeto o objetivo principal é determinar "como" o software alcançará tal especificação. Toda a estrutura interna do software é estabelecida e documentada durante a fase de projeto, e esta organização interna acaba tendo um forte impacto sobre as posteriores evoluções que ele sofrerá ao longo do seu ciclo de vida.

Duas atividades principais são identificadas durante a fase de projeto [Som92, Pres95]: (1) projeto arquitetural (ou projeto de alto nível) - que consiste na especificação da arquitetura do software, através de um conjunto de subsistemas que estão interrelacionados, cada um responsável por determinadas funções do sistema; e (2) projeto detalhado (ou projeto de baixo nível) - que especifica a estrutura interna de cada subsistema, através da descrição de um conjunto de módulos com funções mais detalhadas e específicas.

Para promover a evolução do software é fundamental que ele seja projetado para acomodar futuras mudanças. É necessário que durante a fase de análise sejam especificados não apenas os requisitos, serviços e funções que o sistema necessita atender no momento, mas também sejam identificadas futuras mudanças que o software poderá sofrer. Com tais informações documentadas (antecipação de mudanças), o projetista pode então elaborar uma arquitetura e projeto detalhado que favoreçam a adequação de determinadas mudanças dentro do sistema, tornando estruturas internas específicas mais flexíveis. Alguns tipos de mudanças que podem ser considerados durante a análise e projeto do software e que são muitas vezes encontrados durante a sua manutenção são [GJM91, GHJV95]: mudanças nos algoritmos, mudanças na representação dos dados, 
mudanças nos sistemas de hardware e software com que o sistema interage, mudanças no ambiente social do cliente do sistema, mudanças nos requisitos funcionais e nãofuncionais do sistema.

Existem alguns princípios para o projeto de software que, quando adotados pelos métodos e técnicas usados para o seu desenvolvimento, podem também auxiliar no processo de suas futuras evoluções. A modularização do sistema, promovendo módulos com baixo acoplamento e alta coesão, pode facilitar a capacidade de entendimento de cada parte separadamente e a sua conseqüente modificação. A distinção entre a interface e implementação de cada módulo e o seu encapsulamento pode diminuir o impacto de mudanças na implementação interna de cada um deles. O princípio de separação de interesses $^{2}$ pode auxiliar no tratamento dos diferentes requisitos funcionais e nãofuncionais a serem alcançados pelo sistema, auxiliando o projetista no estabelecimento de políticas de modularização do sistema que facilitem a posterior localização e manutenção de partes específicas do software, responsáveis pela implementação destes requisitos.

\subsection{Projeto Orientado a Objetos}

O paradigma de orientação a objetos (OO) se consolidou ao longo da década de 90, e estudos [HH93, Mey97, Sch98, WMH93] têm demonstrado as vantagens que ele pode trazer para o processo de desenvolvimento e manutenção de software, tais como: facilidades de reuso através de relações de herança e composição de classes; encapsulamento de decisões de implementação; associação direta, em muitos casos, de entidades do mundo real com os objetos do domínio; transição "suave" e gradual entre as fases do ciclo de vida de desenvolvimento de software através do uso da abstração de objetos na análise, projeto, implementação e manutenção do sistema.

Mesmo com todas as vantagens trazidas pelo paradigma $\mathrm{OO}$, o projeto resultante de muitos sistemas OO não tem apresentado um grau de flexibilidade aceitável. Diversos problemas ainda são encontrados durante a evolução estática e dinâmica destes sistemas, entre eles:

- entrelaçamento de código relacionado a diferentes interesses do sistema [KLM+97, TOHS99] - a decomposição de um sistema OO privilegia a modelagem dos objetos relacionados diretamente a sua funcionalidade. Código referente aos interesses não-funcionais, tais como, persistência, concorrência e distribuição, ficam entrelaçados e difusos ao longo dos objetos funcionais definidos para o sistema. Este entrelaçamento e difusão de código relacionado aos diferentes interesses funcionais e não-funcionais do sistema trazem dificuldades para o entendimento, manutenção, evolução e reutilização dos seus interesses de projeto;

\footnotetext{
${ }^{2}$ Ao longo desta dissertação é assumida a seguinte definição de interesse [ОТ00]: "parte do software que é relevante para um conceito, objetivo ou propósito particular". Assumimos também que um interesse funcional está diretamènte relacionado aos requisitos funcionais do sistema e um interesse não-funcional está diretamente relacionado aos requisitos não-funcionais do sistema.
} 
- dificuldade no entendimento de colaborações entre classes [ML98, WMH93] - a implementação de cada funcionalidade do sistema em um projeto OO envolve usualmente a colaboração de um grande número de objetos das diferentes classes da sua estrutura. Esta forma de implementação do comportamento de sistemas OO dificulta o seu entendimento, manutenção, evolução e reutilização;

- aumento da complexidade do sistema com a construção de extensas hierarquias de herança e uso de polimorfismo/ligação dinâmica [Sch98] - extensas hierarquias de herança podem dificultar o entendimento de quais comportamentos das classes que se localizam perto do topo da hierarquia são utilizados por classes que se localizam na parte inferior da hierarquia; o entendimento pode envolver a navegação pelos métodos das classes da hierarquia. A modificação de uma classe que faz parte de uma extensa hierarquia de herança pode ocasionar a propagação indesejada destas mudanças para todas as classes que direta ou indiretamente derivam desta. $O$ uso de polimorfismo/ligação dinâmica força o programador durante o desenvolvimento e manutenção do sistema a testar as diferentes possibilidades de ligação dinâmica que chamadas de métodos polimórficos podem assumir.

Métodos de análise e projeto de sistemas orientados a objetos, tais como, OMT [RBP+91], Booch [Boo94], Fusion [CAB+94] e OOSE [JCJ92] foram propostos durante a última década. Estes métodos fornecem um conjunto de diretrizes e passos gerais para a construção de sistemas $\mathrm{OO}$, definindo um processo para o seu desenvolvimento. Na fase de análise orientada a objetos, estes métodos auxiliam na modelagem dos objetos do domínio e seus relacionamentos, produzindo diversos modelos estáticos e dinâmicos do sistema. Na fase de projeto, a ênfase é definir uma solução lógica baseada nos modelos gerados durante a fase de análise; os métodos focam, em geral, na definição e descoberta das colaborações e responsabilidades dos objetos do domínio.

Escolher um método OO e aplicá-lo no desenvolvimento de um sistema não é, entretanto, suficiente para garantir a sua qualidade. No desenvolvimento da arquitetura e projeto detalhado de um sistema de software é necessário um esforço razoável, por parte dos projetistas, na descoberta da estrutura, comportamento e interligações dos componentes do sistema, de forma a satisfazer não apenas os seus interesses funcionais, mas também refletir uma série de outros aspectos não-funcionais desejáveis (reusabilidade, flexibilidade, manutenibilidade, eficiência). Os métodos OO não endereçam diretamente estes aspectos não-funcionais.

Com o objetivo de favorecer requisitos de manutenibilidade e reusabilidade de sistemas $\mathrm{OO}$, a comunidade de engenharia de software vem propondo nos últimos anos diversas técnicas de projeto, entre elas: padrões [BMR+96, GHJV95], programação orientada a domínio [HO93, OKH+95], programação adaptativa [Lie96, LX93], programação orientada a aspectos [KLM+97], filtros de composição [AT88, Ber94], contratos de reuso [SLMD96] e reflexão computacional [Mae87]. Estudos têm sido conduzidos recentemente com o intuito de avaliar a usabilidade e utilidade de alguma destas técnicas [KM99, LL99, MWB99, QR97, Sch95, WBM99]. 
Nosso trabalho investiga o impacto das técnicas de programação orientada a aspectos e programação adaptativa no projeto de sistemas adaptáveis. Estas técnicas são descritas detalhadamente no capítulo 3.

\subsection{Técnicas de Projeto para Sistemas Flexíveis}

Nesta seção descrevemos técnicas de projeto que foram desenvolvidas com o intuito de favorecer os requisitos de manutenibilidade e reusabilidade de sistemas orientados a objetos, e trazer facilidades para a sua evolução. Várias destas técnicas estendem o modelo convencional de orientação a objetos.

A maioria destas técnicas (inclusive as investigadas nesta dissertação) procuram privilegiar a especificação separada dos interesses não funcionais (concorrência, persistência, distribuição, tratamento de exceções) do sistema do interesse diretamente relacionado a sua funcionalidade. Diversos autores argumentam que esta separação traz facilidades para o processo de entendimento e evolução do software [KLM+97, TOHS99, HL95].

\subsubsection{Padrões de Arquitetura e Projeto}

A partir do desenvolvimento de diversos projetos de software orientado a objetos, alguns projetistas têm levantado diversas estruturas de projeto (conjunto de classes e objetos) que podem ser reaplicadas para a concepção de novos projetos que encarem problemas similares. Essas estruturas ou padrões resolvem problemas específicos e tornam o projeto de software orientado a objetos mais flexível e em geral mais reutilizável. Acabam funcionando, portanto, como uma forma de se aplicar diretamente experiências de sucesso de projetos anteriores na concepção de novos sistemas. Embora esses padrões sejam comumente reusados pelos projetistas que os capturam, eles em geral não são registrados e publicados de forma a auxiliar projetistas que venham a se deparar com o mesmo problema. Padrões de arquitetura [BMR+96] e padrões de projeto [GHJV95] têm justamente esta finalidade.

Padrões de arquitetura [BMR+96] descrevem a estrutura fundamental de organização de um sistema de software, apresentando um conjunto de subsistemas, cada um com sua responsabilidade, que colaboram a fim de oferecer a funcionalidade desejada. Esses padrões especificam, portanto, as propriedades estruturais do sistema inteiro, sendo em geral aplicados no início da fase de projeto do software.

Padrões de projeto [GHJV95] são estruturas de projeto que podem ser aplicadas para resolver algum problema recorrente encontrado no refinamento dos subsistemas ou módulos de um sistema de software. São, em geral, úteis durante toda a fase de projeto de um sistema.

Um padrão é descrito através de um contexto no qual se aplica, dentro de um problema recorrente encontrado no projeto de software e oferece uma possível solução 
(conjunto de componentes inter-relacionados, com um determinado comportamento dinâmico) para a resolução de tal problema. Os padrões têm baseado suas descrições nesta estrutura básica formada por contexto, problema e solução. Esta descrição tem, no entanto, sido estendida com outros aspectos (ex: aplicabilidade e conseqüência de utilização do padrão) que facilitam a escolha e entendimento do padrão e a sua comparação com outros padrões [GHJV95].

\subsubsection{Programação Orientada a Assunto}

Programação Orientada a Assunto (Subject Oriented-Programming) [HO93, $\mathrm{OKH}+95$ ] é uma técnica que estende o modelo convencional de orientação a objetos com o intuito de permitir a manipulação de diferentes perspectivas subjetivas que objetos podem assumir em diferentes domínios. O objetivo é permitir criar extensões em sistemas OO de formas não previstas na sua concepção original.

Em programação orientada a assunto, cada perspectiva é expressa por meio de um subject. Um subject é definido como um conjunto de classes relacionadas através de herança, agregação e associação. Subjects podem ser compostos para determinar novas perspectivas, através de regras de: (1) correspondência - utilizadas para especificar correspondências entre conjunto de classes, métodos e atributos de subjects diferentes; e (2) combinação - utilizadas para especificar como atributos e métodos de duas classes serão combinados (sobreposição, ordem de execução) para formar uma nova perspectiva. Dessa forma é possível expressar evoluções de um conjunto de classes, através da combinação entre o subject que representa este conjunto e um novo subject que realiza adaptações necessárias ao primeiro.

\subsubsection{Reflexão Computacional}

Reflexão computacional [Mae87, KdRB91] vem sendo amplamente reconhecida como um mecanismo poderoso para implementação de sistemas que demandem mudanças dinâmicas na sua estrutura e comportamento. Um sistema reflexivo mantém estruturas para representar a si próprio. No modelo de objetos, reflexão pode ser usada para interceptação e modificação do comportamento de operações básicas, tais como, criação de classes/objetos e invocação de métodos.

A arquitetura de um sistema reflexivo [BMR+96] é formada por dois componentes principais: o meta-nível e o nível base. O meta-nível define, através dos meta-objetos, a própria representação da estrutura e comportamento do sistema. Os metaobjetos representam informações do sistema, tais como, estrutura de tipos e mecanismos de chamadas de funções. Já o nível base define a própria aplicação lógica do sistema; na sua implementação são utilizados os meta-objetos. Se um meta-objeto é alterado estática ou dinamicamente (através de um protocolo meta-objeto), a parte da implementação no nível base que utiliza os serviços ou informações deste meta-objeto também sofre alterações no que diz respeito a sua funcionalidade. O protocolo meta-objeto funciona como uma interface externa do meta-nível, através da qual aplicações podem especificar modificações para os meta-objetos. 
Diversos trabalhos têm demonstrado o potencial de reflexão computacional para a separação dos interesses relacionados diretamente à funcionalidade da aplicação daqueles referentes a seus interesses não-funcionais, tais como, sincronização [WY90], controle de localização [OI94], distribuição [OB98], tolerância a falhas [BRL97] e migração de objetos [Yok92].

\subsubsection{Contratos de Reuso}

Visando resolver o problema da propagação de mudanças, ou seja, que a evolução de um dos componentes do sistema possa causar impacto em outros componentes que dependam dele, Tom Mens et al da Vrije Universiteit Brussel propõem um mecanismo, denominado contratos de reuso [SLMD96]. A idéia central por trás deste mecanismo é que a evolução de componentes é suportada por um contrato explícito entre o provider de um componente e seu evolver, o qual modifica tal componente. Ambos (o provider e o evolver) acabam assumindo obrigações contratuais. $\mathrm{O}$ provider documenta as propriedades do componente que podem ser confiadas a outros componentes. Já o evolver é obrigado a documentar as alterações que realiza sobre determinado componente, através da especificação de cláusulas de reuso e um tipo de contrato. O tipo de contrato especifica a forma como um componente evolui e impõe obrigações, permissões e proibições para o evolver. Em desenvolvimento orientado a objetos, por exemplo, os tipos de contrato mais comuns são extensão, cancelamento, refinamento e sobreposição. Cada componente pode participar de diferentes contratos de reuso, cada um endereçando um diferente aspecto. Os autores argumentam que o mecanismo proposto traz um formalismo básico para a evolução de software, através da documentação da especialização e evolução dos componentes e permite assim a detecção dos conflitos de evolução relacionados a componentes.

\subsubsection{Filtros de Composição}

A técnica de filtros de composição [AT88, Ber94] define um modelo que permite integrar diferentes interesses não funcionais no projeto de sistemas OO. Os autores de filtros de composição argumentam que o tratamento de interesses não funcionais no projeto de sistemas que são implementados usando o modelo convencional $\mathrm{OO}$, usualmente, incorre em problemas como entrelaçamento de código relacionado aos interesses [KLM+97] e anomalia de herança [MY93]. A técnica de filtros de composição vem sendo utilizada para implementar interesses de sincronização [Ber94], tempo real [ABSB94], transações atômicas [ABV92] e verificação de erros baseado em précondições [Ber94].

No modelo definido pela técnica de filtros de composição, um objeto consiste de um objeto-núcleo e uma camada de interface. O objeto-núcleo representa o próprio conceito de objeto, tal como definido por linguagens $\mathrm{OO}$ convencionais como Java ou $\mathrm{C}++$. A camada de interface, por sua vez, contém um conjunto arbitrário de filtros de mensagens de entrada e saída. Mensagens enviadas para um objeto do modelo de filtros de composição passam inicialmente através dos filtros de entrada e no retorno de tais 
mensagens passam pelos filtros de saída. Os filtros podem modificar a semântica das mensagens de várias formas. Diferentes tipos de filtros podem ser definidos de acordo com a ação a que se propõem. Alguns tipos pré-definidos de filtros definidos no modelo são: (a) filtros de delegação - que delegam mensagens para outros objetos (internos ou externos à camada de interface); (b) filtros de espera - que armazenam mensagens; e (c) filtros de erro - que permitem o lançamento de exceções. A modificação da semântica da mensagem pelo filtro pode opcionalmente depender da própria mensagem e do estado do objeto-núcleo.

\subsection{Projeto de Sistemas Adaptáveis}

Considerar aspectos possíveis de mudança futura em software durante o seu desenvolvimento vem se tornando cada vez mais relevante. Uma das abordagens propostas para tratar questões de evolução e mudança em software é construí-lo com base em uma arquitetura e projeto concebidos de forma a serem adaptáveis. Um sistema adaptável pode ser definido "como um sistema que pode ser facilmente modificado" [LL95], ou "um sistema que permite adaptar facilmente sua estrutura completa ou partes específicas devido a mudanças nos requisitos" [TA97]. O rápido avanço das tecnologias do ambiente de execução de sistemas e o mutável ambiente social no qual ele está inserido estimulam o seu desenvolvimento, desde o início de sua concepção, através do favorecimento da qualidade de adaptabilidade.

Em [FC96], Fayad \& Cline estabelecem quatro fatores para um sistema ser caracterizado como adaptável: extensibilidade, flexibilidade, ajuste de desempenho e facilidade de conserto. Dois dos fatores estão relacionados a mudanças de alto nível (extensibilidade e flexibilidade) e os outros dois a mudanças de baixo nível (ajuste de desempenho, facilidade de conserto). Extensibilidade é a qualidade que um sistema tem de mudar sua capacidade em quantidade mas não em tipo; um exemplo de um sistema extensível seria aquele que permite a adição de suporte a novos dispositivos gráficos além dos já existentes. Flexibilidade é a qualidade que um sistema tem de mudar suas capacidades em tipo; um exemplo seria transformar a interface gráfica de um sistema em uma nova interface baseada em sensores ou sons. Um sistema adaptável no que se refere ao ajuste de desempenho é aquele que pode ser facilmente modificado de forma a causar impacto em sua execução. Um sistema adaptável no que se refere a facilidade de conserto é aquele que permite que ajustes/correções sejam feitos numa determinada parte do sistema sem corromper a estrutura e funcionamento de outras partes relacionadas.

As atividades das etapas de análise e projeto do ciclo de vida de desenvolvimento de software [Som92, Pres95] têm uma grande importância na obtenção final de um sistema dito adaptável. A fase de análise pode contribuir para identificação dos requisitos funcionais e não-funcionais do sistema que estão mais sujeitos a mudanças e impactos futuros, e na identificação desses possíveis tipos de mudanças. Na fase de projeto deve-se estimular a obtenção de uma arquitetura flexível e inserir, dentro dos módulos de cada subsistema da arquitetura, estruturas alternativas para oferecer suporte às mudanças futuras identificadas durante a etapa de análise. Tanto os requisitos sujeitos a mudanças 
futuras quanto as estruturas alternativas que suportam tais mudanças devem ser devidamente documentados.

Segundo [TA97], existem duas abordagens para proceder a adaptação de um sistema: (a) adaptação de transformação - que procura adaptar o sistema através da modificação da sua especificação e/ou implementação de forma a atender os requisitos que estão sendo alterados; e (b) adaptação de composição - que trata a adaptação de um sistema através do uso de técnicas de composição de componentes de forma a atender os requisitos requeridos para o software. Já em [LL95], as abordagens para adaptação em sistemas são divididas em: (a) pró-ativas - que são aquelas que buscam projetar o software favorecendo desde o início de sua concepção a qualidade de adaptabilidade (exemplos: programação adaptativa, programação orientada a aspectos, padrões, programação orientada a assuntos); e (b) re-ativas - que são aquelas que tentam automatizar ou realizar manualmente a adaptação quando ela acontece (exemplo: refactoring [Opd92, Fow99]).

Tekinerdogan mostra em [Tek96] três atividades básicas para adaptação em sistemas orientados a objetos: (I) substituição - processo de troca de um componente por outro; (II) composição - processo de combinação modular de dois ou mais componentes; e (III) modificação - processo de alteração interna da semântica de um componente. Com base na combinação destas atividades são apresentadas técnicas básicas de adaptação para desenvolvimento de software orientado a objetos. Embora se reconheça as vantagens que as tecnologias de orientação a objetos podem trazer para o desenvolvimento de software adaptável, seu uso indiscriminado não garante necessariamente o alcance de tal característica [FC96].

As técnicas de projeto investigadas nesta dissertação, programação orientada a aspectos e programação adaptativa, fazem parte de um conjunto de técnicas [KLM+97, TOHS99, HL95] que estendem o modelo orientado a objetos e encaram o problema de desenvolvimento de sistemas adaptáveis através do favorecimento do princípio de separação de interesses [GJM91]. Por trazer benefícios para o entendimento, reutilização e manutenção dos diferentes interesses envolvidos no projeto de um sistema, tanto no nível conceitual quanto de implementação, acredita-se que tal favorecimento possa facilitar a composição e integração de diversos interesses, inclusive aqueles não previstos inicialmente.

O projeto de um sistema geralmente envolve contrabalancear um conjunto razoável de atributos de qualidade. Assim, a adaptabilidade de um sistema não deve desfavorecer a obtenção de qualidades igualmente desejáveis, como:

- manutenibilidade: o enfoque em adaptabilidade durante a análise, projeto e implementação não deve aumentar o esforço exigido na localização, reparo de erros no sistema e extensão de suas características;

- corretude: a validação e verificação do sistema deve levar em conta os aspectos de adaptabilidade que o sistema fornece. A elaboração dos planos de teste deve considerar as possíveis adaptações dinâmicas que o sistema pode sofrer, gerando se preciso as condições necessárias para o seu disparo; 
- eficiência: a capacidade de adaptação em tempo de execução em geral incorre em custos que devem ser analisados. É desejável que só sejam penalizadas com tais custos as instâncias do software que estejam diretamente associadas ao componente sendo alterado dinamicamente;

- integridade conceitual do projeto e reusabilidade: a introdução de adaptabilidade não deve resultar em uma estruturação indesejada do sistema. Deve-se estimular o desenvolvimento de componentes coesos e com baixo acoplamento, melhorando assim a qualidade do projeto e favorecendo conseqüentemente a reutilização de alguma(s) de suas partes;

- confiabilidade: a adaptação de um sistema a novas condições de execução exige que os fatores relacionados a robustez do sistema sejam cuidadosamente estudados.

Uma técnica para comparação e seleção de alternativas do projeto de um sistema baseado nos fatores de qualidade de adaptabilidade e desempenho é apresentada em [AT00], onde é proposto um processo para a atividade de projeto de software que transforma a especificação de requisitos em um conjunto alternativo de modelos orientado a objetos que oferecem diferentes níveis de adaptabilidade e desempenho. A técnica é especificada formalmente e implementada por um conjunto de ferramentas. $\mathrm{O}$ processo para proceder o projeto de sistemas adaptáveis desta técnica consiste dos seguintes passos:

(1) encontrar os conceitos envolvidos no domínio do software a partir da sua especificação de requisitos;

(2) extensão do conjunto de conceitos obtidos no passo anterior usando análise de domínio [Arr94];

(3) classificação dos conceitos como sendo adaptáveis ou fixos. O engenheiro de software pode considerar diferentes alternativas para um mesmo conceito, assim como deve atribuir um grau de adaptabilidade para cada alternativa;

(4) mapeamento de cada conceito para uma abstração do modelo orientado a objetos (classe, método ou atributo) considerando cada conceito como sendo adaptável ou fixo;

(5) identificação das relações entre os conceitos com base na adaptabilidade requerida.

Ao fim deste processo obtém-se um conjunto alternativo de modelos orientados a objetos ordenados de acordo com seu grau de adaptabilidade. O engenheiro de software é responsável pela seleção de um destes modelos, a partir do qual o sistema será implementado.

\subsection{Adaptação e Reconfiguração Dinâmica de Sistemas}

As comunidades de sistemas configuráveis distribuídos [ICCDS94, ICCDS96, ICCDS98] e sistemas operacionais [SOSP95, SOSP97, SOSP99] têm ao longo dos últimos anos desenvolvido diversas implementações de sistemas que incorporam aspectos de adaptação. Estes sistemas podem ser definidos como aqueles que possibilitam a alteração de alguma(s) de suas partes (funções, serviços, objetos, subsistemas), 
principalmente durante a sua execução. Este tipo de abordagem vem sendo utilizada para o desenvolvimento de sistemas que demandem alta disponibilidade e flexibilidade, e que usualmente objetivam o atendimento de requisitos de tolerância a falha, adaptação dinâmica à carga imposta ao sistema, otimização da utilização dos recursos disponíveis ou monitoramento do sistema. Diferentes mecanismos têm sido propostos para permitir a reconfiguração dinâmica destes sistemas de acordo com os seus requisitos [SE97].

Nesta dissertação é investigado o impacto e aplicabilidade que novos enfoques para projeto orientado a objetos têm no desenvolvimento de sistemas adaptáveis. Os sistemas configuráveis JAWS (servidor Web adaptativo) e SPIN (sistema operacional extensível) tiveram partes específicas do seu projeto reconstruídas utilizando os conceitos e abstrações das abordagens de AspectJ de programação orientada a aspectos e Demeter/Java de programação adaptativa. O objetivo foi analisar os benefícios que estas novas técnicas podem trazer para o projeto de sistemas adaptáveis. 


\section{Técnicas de Projeto para Sistemas Adaptáveis}

Este capítulo descreve as técnicas de projeto investigadas nesta dissertação: programação orientada a aspectos e programação adaptativa com relações de contexto. São apresentados os principais conceitos e mecanismos oferecidos pelas técnicas para a atividade de projeto de software, além das abordagens AspectJ [Asp00] e Demeter/Java [LO00] de cada uma delas (usadas em nosso estudo de casos).

\subsection{Programação Orientada a Aspectos}

Programação Orientada a Aspectos é uma técnica que propõe, segundo seus autores, um novo paradigma para o desenvolvimento de sistemas [KLM+97]. Segundo pesquisadores do Xerox Palo Alto Research Center (PARC), as linguagens de programação atuais permitem apenas a construção de estruturas (procedimentos, funções, objetos) associadas diretamente à funcionalidade da aplicação. Outras propriedades gerais de interesse ao sistema (concorrência, distribuição, manipulação de falhas, alocação de memória, persistência) decorrentes de decisões de projeto ficam entrelaçadas e difusas ao longo destas estruturas, dificultando seu desenvolvimento, localização e futura manutenção. Também as metodologias de projeto procuram quebrar o sistema em unidades funcionais que juntas colaboram para o atendimento dos requisitos do sistema. Assim, tanto as metodologias quanto as linguagens de programação atuais focam sua atenção principal na decomposição funcional do sistema.

O objetivo de programação orientada a aspectos é promover a especificação separada dos interesses funcionais e não-funcionais de sistemas, com a promessa de que esta separação traga facilidades para o processo de entendimento, evolução e futura manutenção do software [TOHS99].

Em programação orientada a aspectos, um sistema é composto de:

- um conjunto de componentes - unidades oriundas da decomposição funcional do sistema e que podem ser expressas e compostas nas linguagens de programação atuais. Exemplos: entidades do domínio da aplicação, interface gráfica da aplicação, bibliotecas de funções utilitárias;

- um conjunto de aspectos - propriedades gerais do sistema relacionadas a seus interesses não-funcionais e que afetam o seu desempenho ou a semântica dos componentes de uma forma sistemática. Para especificar e compor este conjunto de aspectos que afetam os componentes do sistema, propõe-se a utilização de linguagens 
específicas. Exemplos de aspectos são: sincronização de objetos concorrentes, manuseio de falhas e exceções, estratégias de comunicação, otimização de alocação de memória, persistência.

Em programação orientada a aspectos, o sistema é construído através de uma clara separação entre componentes e aspectos, e em tempo de compilação ou execução estes elementos são combinados e compostos, através de um compilador (aspect weaver), para produção do sistema completo.

Nos trabalhos iniciais do grupo de programação orientada a aspectos do Xerox $P A R C$ foram desenvolvidas diferentes linguagens para a especificação e composição de aspectos para domínios ou interesses específicos. Cool foi desenvolvida para o projeto/programação de aspectos de sincronização de objetos [LK97, Lop97]. Ridl é uma linguagem de aspectos para especificar estratégias de transferência de dados entre ambientes remotos [LK97, Lop97]. $A M L$ é uma linguagem orientada a aspectos para o domínio de computação de matrizes esparsas que trata os interesses de tempo de execução, representação de dados e estabilidade numérica separadamente [IL+97]. $R G$ é uma linguagem de aspectos usada para o domínio de processamento de imagens [MK+97]. Posteriormente o grupo vem desenvolvendo a linguagem de aspectos de propósito geral AspectJ [Asp00, KL99], que foi a utilizada em nosso estudo de casos.

\subsubsection{AspectJ AM $^{\mathrm{TM}}$}

AspectJ [Asp00, KL99] é uma extensão orientada a aspectos para Java ${ }^{\mathrm{TM}}$. Ela permite especificar "aspectos" que afetam classes e objetos de um programa escrito em Java.

Assim como uma classe Java, um aspecto em Aspect $\mathrm{J}^{3}$ possui um nome e pode declarar atributos e métodos com diferentes visibilidades. Cada aspecto pode ainda definir três construções adicionais: (a) crosscut - indica métodos específicos de classes que terão sua implementação afetada pelo aspecto; (b) introduction - que permite inserir novos atributos e métodos em classes do sistema; e (c) advice - que permite inserir código que será executado no início (before) ou final (after) de métodos de classes do sistema caso não ocorra alguma exceção, código que será executado incondicionalmente após execução de um dado método (finally), e código que será executado caso ocorra uma exceção específica (catch).

Vamos supor a existência de uma classe Point, contendo dois atributos inteiros $\mathrm{x}$ e y, e dois métodos públicos, getx() e gety (), para acesso a tais atributos. No exemplo abaixo está definido um aspecto que afeta esta classe Point da seguinte forma: (1) são adicionados um novo atributo (extraAtributte) e um novo método (extramethod) em tal classe; e (2) os métodos getx() e gety() da classe Point são afetados por uma construção advice que especifica: comandos para indicar a entrada e saída da execução de tais métodos, através de cláusulas before e after, respectivamente; a atualização do

\footnotetext{
${ }^{3}$ A versão 0.6 da linguagem e ferramenta AspectJ foi usada nesta dissertação.
} 
atributo nexecutions do aspecto sempre que os métodos afetados forem executados, através da cláusula finally; e a captura de exceções do tipo Exception em tais métodos, através da cláusulas catch.

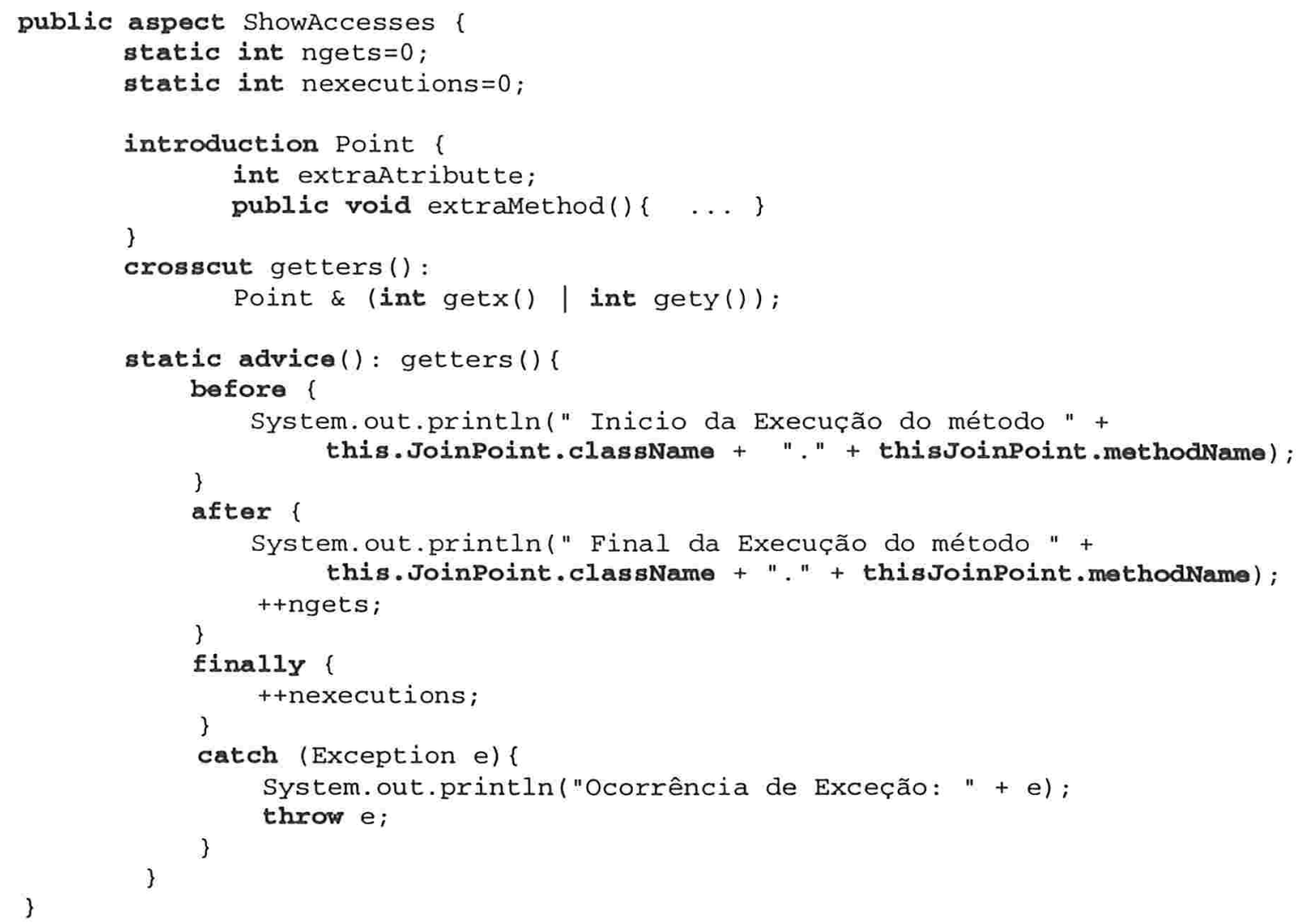

Para representar a abstração de aspectos de AspectJ em UML (Unified Modeling Language) [BRJ99] durante a elaboração de diagramas de classes/aspectos resultantes da reengenharia do projeto de sistemas adaptáveis com programação orientada a aspectos, nós utilizamos o estereótipo <<aspect>> para representar cada aspecto e relações de dependência com o estereótipo <<affect $>>$ para indicar que um determinado aspecto afeta a implementação de uma ou mais classes do sistema. Cada aspecto pode ainda definir seu conjunto próprio de construções introduction e advice.

A figura 3.1 apresenta um diagrama de classes/aspectos contendo o aspecto ShowAccesses e a classe point. 


\begin{tabular}{|c|c|c|}
\hline Point & & $\begin{array}{c}\text { <<aspect>> } \\
\text { ShowAccesses }\end{array}$ \\
\hline $\begin{array}{l}\text { Bjint } x \\
\text { Buint } y\end{array}$ & $<<$ affect $>>$ & 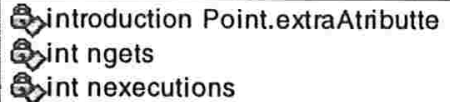 \\
\hline $\begin{array}{l}\text { Aint getx() } \\
\text { Aint gety() }\end{array}$ & & $\begin{array}{l}\text { Hintroduction Point.extraMethod() } \\
\text { static advice Point.getx() } \\
\text { static advice Point.gety() }\end{array}$ \\
\hline
\end{tabular}

Figura 3.1: Diagrama de Classes/Aspectos do ShowAccesses

\section{Aspecto afetando Classes}

Um aspecto pode afetar mais de uma classe. O aspecto ShowAccesses acima pode ser modificado para alterar também uma classe Line, que tem como atributos dois objetos (A e B) do tipo Point, e dois métodos públicos, getA() e getB(), para acesso a tais atributos. Abaixo apresentamos o aspecto ShowAccessesExtended especificado com tal propósito.

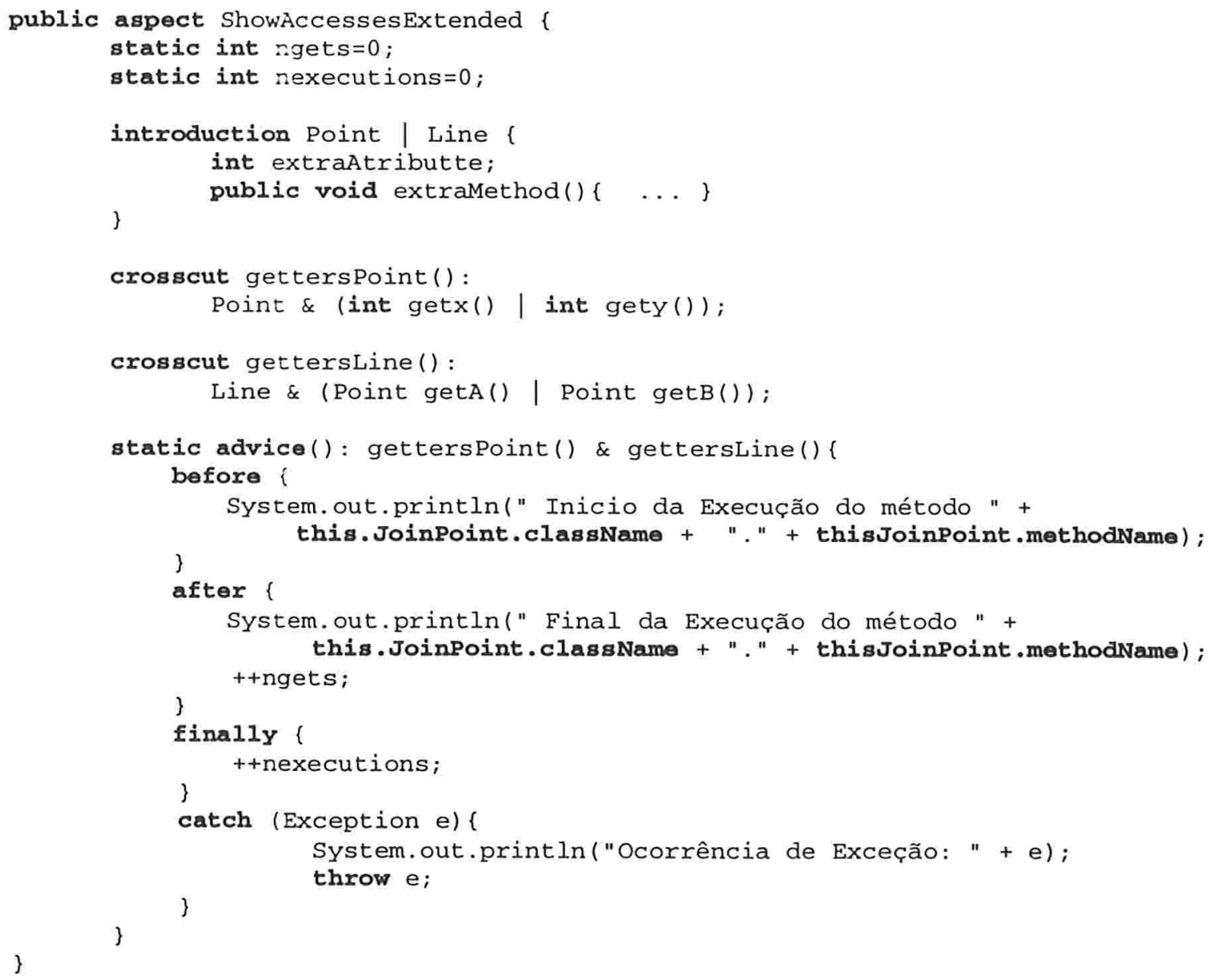


A figura 3.2 apresenta diagrama de classes/aspectos contendo o aspecto ShowAcessesExtended.

\begin{tabular}{|c|c|c|}
\hline Point & & \multirow{3}{*}{\begin{tabular}{|l|}
\multicolumn{1}{|c|}{ ShowAccessect»> } \\
Soxtended \\
Quintroduction (Point I Line).extraAttribute \\
Q Dint ngets \\
Q int nexecutions
\end{tabular}} \\
\hline $\begin{array}{l}\text { Boint } x \\
\text { Q bint } y\end{array}$ & \multirow{3}{*}{$<<$ affect $>>$} & \\
\hline $\begin{array}{l}\text { Sint getx() } \\
\text { Wint gety() }\end{array}$ & & \\
\hline Line & & \multirow{3}{*}{$\begin{array}{l}\text { Pintroduction (Point I Line).extraMethod() } \\
\text {-static advice Point.getx() } \\
\text {-static advice Point.gety() } \\
\text { static advice Line.getA() } \\
\text { \$static advice Line.getB() }\end{array}$} \\
\hline $\begin{array}{l}\text { Bopoint A } \\
\text { \&Point B }\end{array}$ & \multirow[t]{2}{*}{$\leftarrow \quad<<$ affect $>$} & \\
\hline $\begin{array}{l}\text { PPoint getA() } \\
\text { SPoint getB() }\end{array}$ & & \\
\hline
\end{tabular}

Figura 3.2: Diagrama de Classes/Aspectos do ShowAccessesExtended

\section{Contexto do crosscut de um Aspecto}

Dentro das cláusulas (before, after, finally e catch) de uma construção advice de um aspecto, podem ser acessados os atributos internos do aspecto assim como ser invocados os métodos que ele define. Nos exemplos anteriores, os atributos inteiros ngets e nexecutions eram incrementados dentro da construção advice dos aspectos. Além de poder acessar os atributos e invocar os métodos de um aspecto, as cláusulas de uma construção advice podem também acessar os parâmetros definidos pelos seus crosscuts. Nos aspectos apresentados anteriormente as construções crosscut não definiam parâmetros. Abaixo apresentamos um exemplo com tal definição.

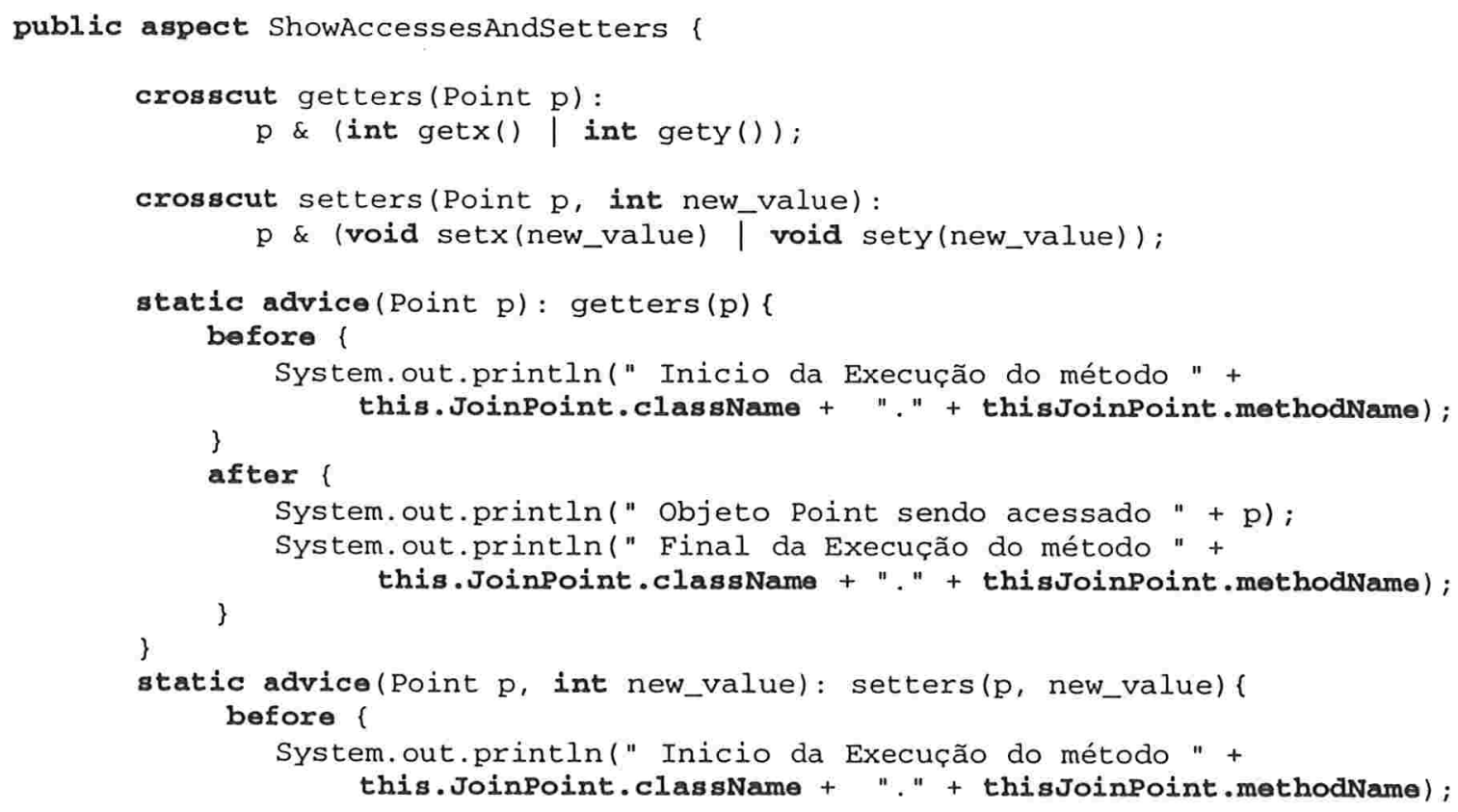




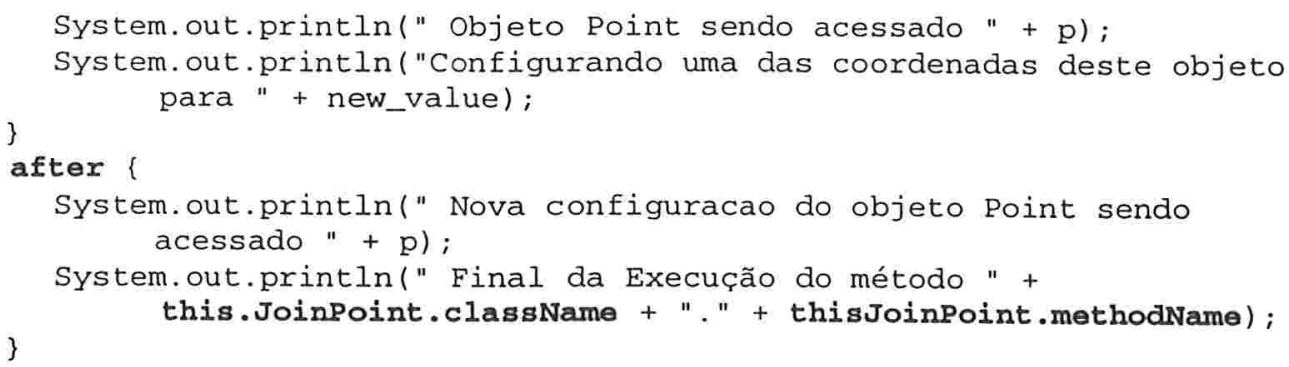

No aspecto ShowAccessesAndSetters acima são definidas duas construções crosscut: getters e setters. Em ambas são definidos parâmetros que poderão ser acessados nas construções advice relacionadas. No crosscut getters é definido como parâmetro o objeto $\mathrm{p}$ do tipo Point, este parâmetro será o mesmo objeto que receberá, durante a execução do sistema, as mensagens getx() e gety() definidas para o crosscut. Na construção advice associada ao crosscut getters este objeto é acessado na sua cláusula after.

$\mathrm{O}$ crosscut setters define para o seu contexto dois parâmetros o objeto $\mathrm{p}$ do tipo point e o atributo new_value do tipo int. Conforme pode ser verificado na definição do crosscut estes parâmetros são, respectivamente, o objeto que receberá as mensagens setx() e sety () e o novo valor a ser configurado durante a chamada de tais métodos. Estes parâmetros são acessados na construção advice associada ao crosscut setters.

A figura 3.3 apresenta diagrama de classes/aspectos, contendo o aspecto ShowAccessesAndsetters e a classe Point.

\begin{tabular}{|c|c|c|}
\hline Point & \multirow{2}{*}{ <<affect $>>$} & \\
\hline $\begin{array}{l}\text { Osint } x \\
\text { Boint } y\end{array}$ & & $\begin{array}{c}\quad<<a s p e c t>> \\
\text { ShowAccessesAndSetters }\end{array}$ \\
\hline $\begin{array}{l}\text { Wint getx() } \\
\text { Pint gety }() \\
\text { Osetx (int } x)() \\
\text { Osety (int } y)()\end{array}$ & $<$ & $\begin{array}{l}\text { static advice Point.getx() } \\
\text { static advice Point.gety() } \\
\text { static advice Point.setx0 } \\
\text { static advice Point.sety0 }\end{array}$ \\
\hline
\end{tabular}

Figura 3.3: Diagrama de Classes/Aspectos do ShowAccessesAndSetters

\section{Aspectos Dinâmicos}

As inserções de atributos e métodos de construções introduction de AspectJ são sempre realizadas sobre classes e em tempo de compilação. Assim, todas as instâncias de uma classe afetada por um aspecto incorporam as extensões de construções introduction. Já a construção advice pode afetar uma classe (conseqüentemente todas suas instâncias serão estendidas) ou apenas um conjunto específico de objetos, através da 
definição de construções advice não-estáticas. Neste último caso, tem-se o conceito de aspecto dinâmico que deve ser associado explicitamente aos objetos a serem estendidos.

Abaixo o aspecto ShowAccesses é redefinido para que a construção advice getters () passe a ser dinâmica e assim possa afetar apenas instâncias específicas. O código de associação de objetos point a uma instância do aspecto DynamicShowAccesses é também apresentado logo abaixo. Apenas após esta associação é que os objetos passam a incorporar as extensões da construção getters ( ).

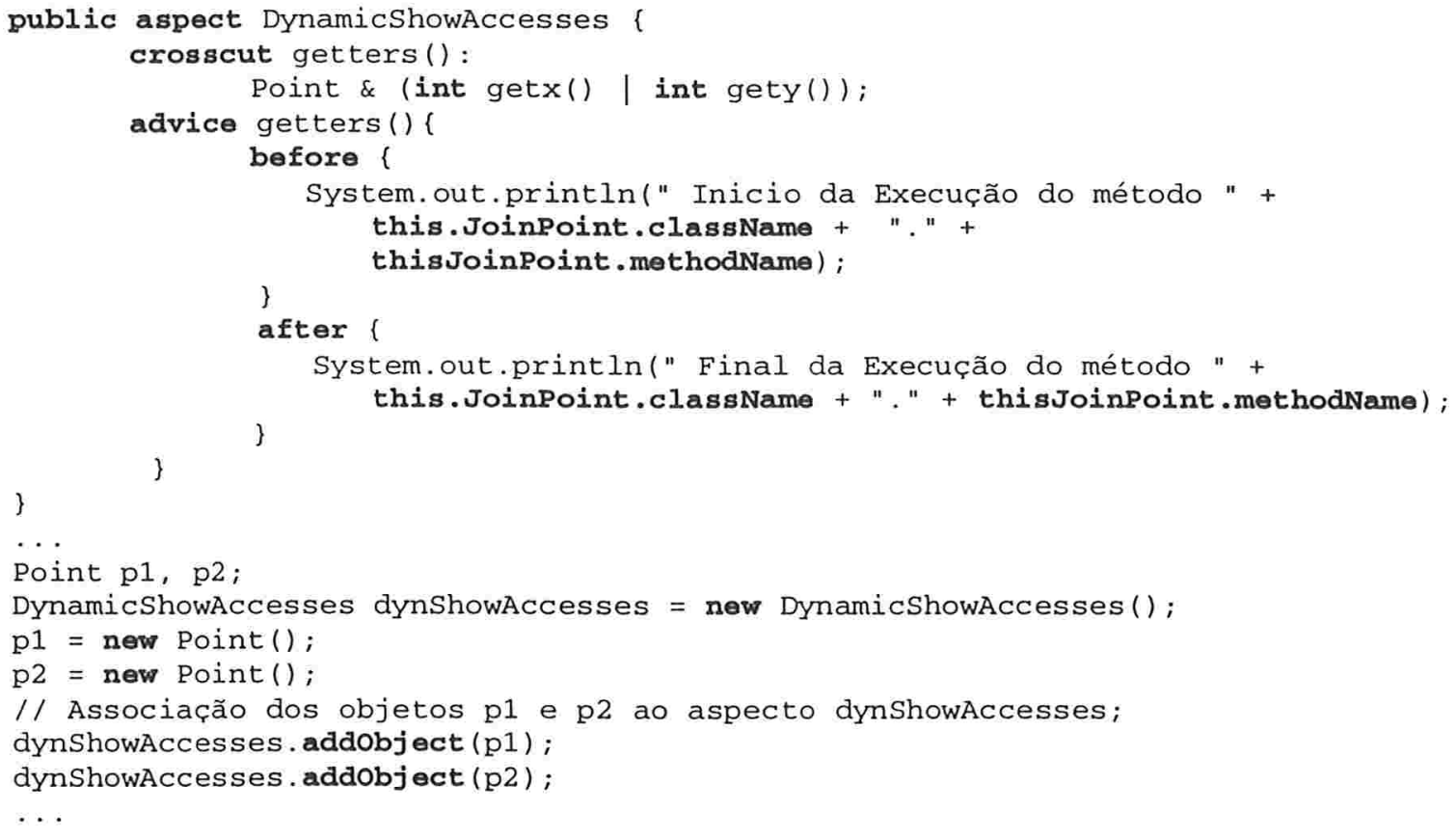

A figura 3.4 apresenta diagrama de classes/aspectos, contendo o aspecto DynamicShowAccesses.

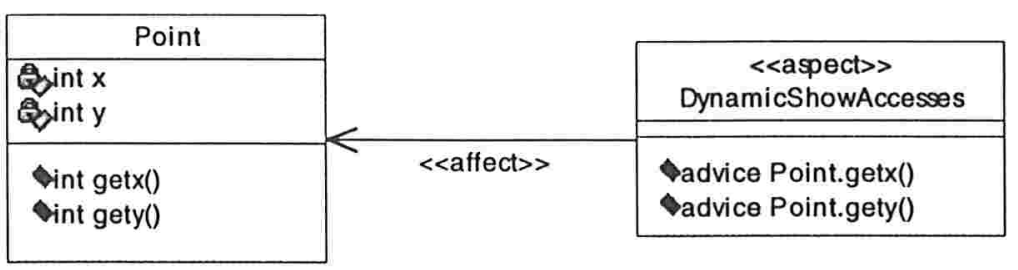

Figura 3.4: Diagrama de Classes/Aspectos do DynamicShowAccesses 


\subsection{Programação Adaptativa}

Programação Orientada a Objetos Adaptativa é uma extensão à programação orientada a objetos convencional que permite expressar o comportamento da aplicação sem o seu comprometimento para uma estrutura de classes específica [Lie96, LX93].

Em programação orientada a objetos convencional, a estrutura da aplicação é expressa como um conjunto de classes relacionadas através de herança, agregação e associação, e o seu comportamento é especificado através de métodos descritos detalhadamente, cada um deles pertencendo a alguma das classes presentes na estrutura. Na técnica de programação adaptativa do método Demeter, a estrutura de classes da aplicação pode ser inicialmente descrita apenas parcialmente, e posteriormente pode sofrer evoluções e modificações que em muitos casos não afetam o comportamento especificado anteriormente. O comportamento do sistema no método Demeter é descrito de forma bastante geral para facilitar sua adaptação para futuras modificações na estrutura de classes.

Programação Adaptativa se fundamenta em um princípio de projeto denominado Lei de Demeter [LX93]. Este princípio impõe que para cada método $\mathrm{M}$ de um objeto $\mathrm{O}$ do sistema, poderão ser invocados dentro dele apenas métodos: (1) do próprio objeto O; (2) dos objetos passados como argumentos para o método M; (3) de objetos criados pelo método M; e (4) de objetos que fazem parte do objeto O. O efeito da Lei de Demeter é forçar a comunicação e troca de mensagens apenas entre objetos relacionados diretamente, diminuindo o conhecimento dentro de métodos sobre a estrutura e comportamento de diferentes classes do sistema. Abaixo apresentamos um exemplo de um conjunto de classes, codificadas em Java, que possui um método que não obedece a Lei de Demeter.

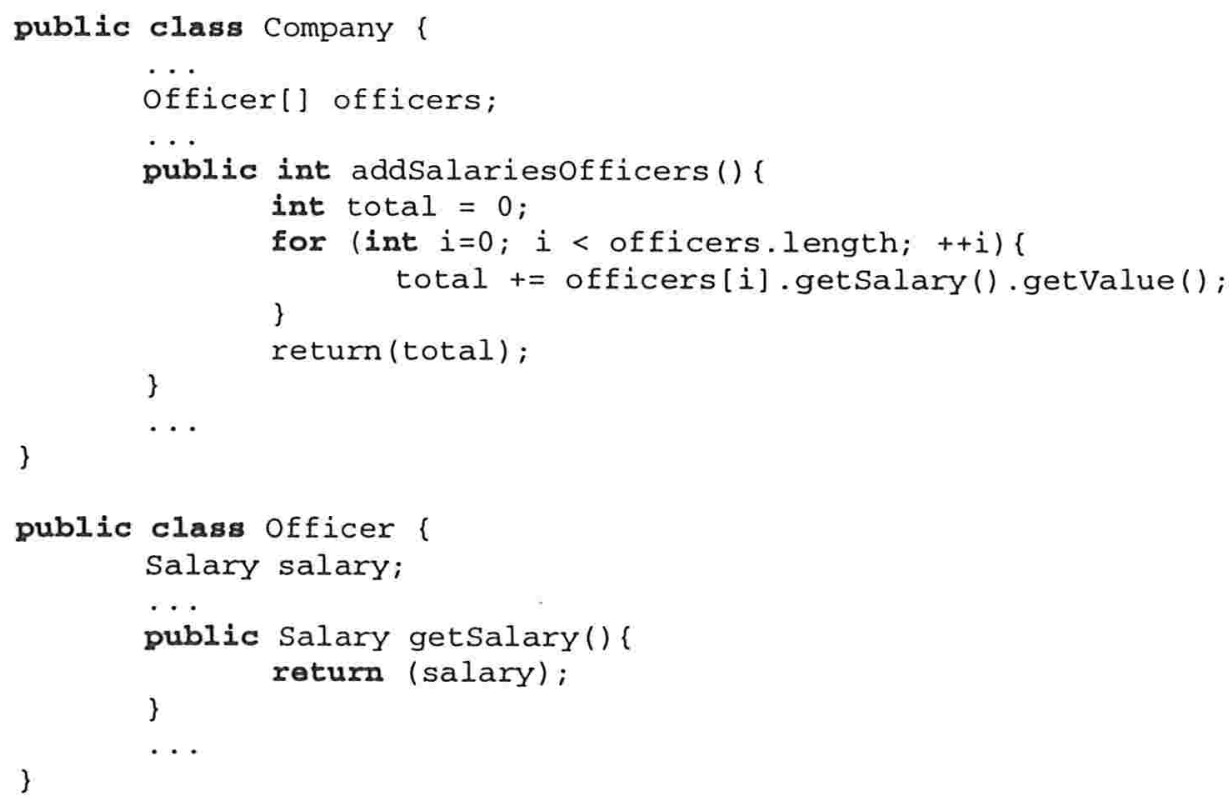




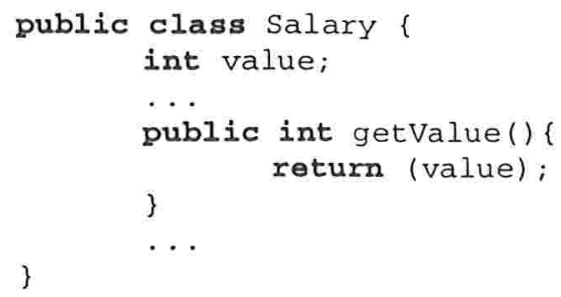

No exemplo acima, o método addSalariesofficers() da classe company viola a Lei de Demeter, pois ele invoca o método getvalue() de objetos salary que não fazem parte dele, mas são componentes dos seus diretores (objetos officer).

Sistemas desenvolvidos seguindo a Lei de Demeter ocasionam o surgimento de pequenos métodos cuja única função é repassar mensagens adiante ou transportar objetos necessários à computação de algum método. $\mathrm{O}$ grupo desenvolveu uma ferramenta associada à técnica que permite a geração automática destes pequenos métodos. Foi também criada uma nova abstração para especificação de métodos, denominado padrão de propagação, que oferece uma definição em alto nível de um caminho a ser percorrido em uma estrutura de classes para realização da tarefa sob responsabilidade do método.

\subsubsection{Demeter/Java}

O método/software Demeter procura tratar de problemas relacionados a evolução de software orientado a objetos, especificando separadamente a estrutura e o comportamento do sistema. A idéia principal do Demeter é definir o comportamento do sistema (implementação de métodos) sem o seu comprometimento para uma estrutura de classes específica; são feitas apenas algumas considerações a respeito da estrutura. Isto torna possível a adaptação do comportamento do sistema para o atendimento de novos requisitos que demandem manutenção na estrutura de classes atual do sistema. Nas subseções seguintes descrevemos a forma como são feitas as especificações da estrutura e comportamento de um sistema utilizando o método e ferramenta Demeter/Java [LO00] de programação adaptativa, além de tecermos considerações a respeito da geração do sistema e sua evolução estrutural. No estudo de casos de reengenharia do projeto de sistemas adaptáveis desta dissertação, a abordagem Demeter/Java ${ }^{4}$ de programação adaptativa foi utilizada.

\subsubsection{Especificação da Estrutura do Sistema}

A estrutura do sistema é especificada no método Demeter através do dicionário de classes, que representa as classes de interesse da aplicação bem como suas interligações (herança, agregação, associação). São portanto, uma representação análoga aos diagramas de classes de UML [BRJ99].

Em um dicionário de classes são definidas diversas classes do sistema, com a seguinte forma genérica:

\footnotetext{
${ }^{4}$ A versão 0.7 da ferramenta Demeter/Java foi usada nesta dissertação.
} 
<nome da classe> <símbolo de definição> <definição>.

onde,

nome da classe - especifica o nome que a classe receberá no sistema.

símbolo de definição-indica o tipo da classe.

definição - define os tipos de dados membros que pertencem a classe.

Existem três tipos de classes que podem ser definidas em um DC, sendo elas:

(a) Classes Concretas - são definidas como sendo "classes folhas" da hierarquia de herança das classes da aplicação. Uma classe concreta não pode ter subclasses. Elas são conhecidas na terminologia do método Demeter como classes de Construção. O símbolo de definição usado para definir classes Concretas é o "=".

(b) Classes Abstratas - são classes que não podem ser instanciadas, e que devem ter no mínimo uma subclasse. Na terminologia Demeter são conhecidas como classes de Alternação e seu símbolo de definição é o ":". Os tipos de dados membros definidos para uma classe Abstrata são herdados por suas subclasses.

(c) Classes Coleções - são classes cujas instâncias são coleções de objetos de alguma classe. São chamadas de classes de Repetição na terminologia Demeter. O símbolo de definição usado para definir classes Coleções é o " ".

A seguir apresentamos um dicionário de classes descrito detalhadamente em [LO00]. Utilizaremos este dicionário de classes para ilustrar ao longo desta seção os principais conceitos de Programação Adaptativa.

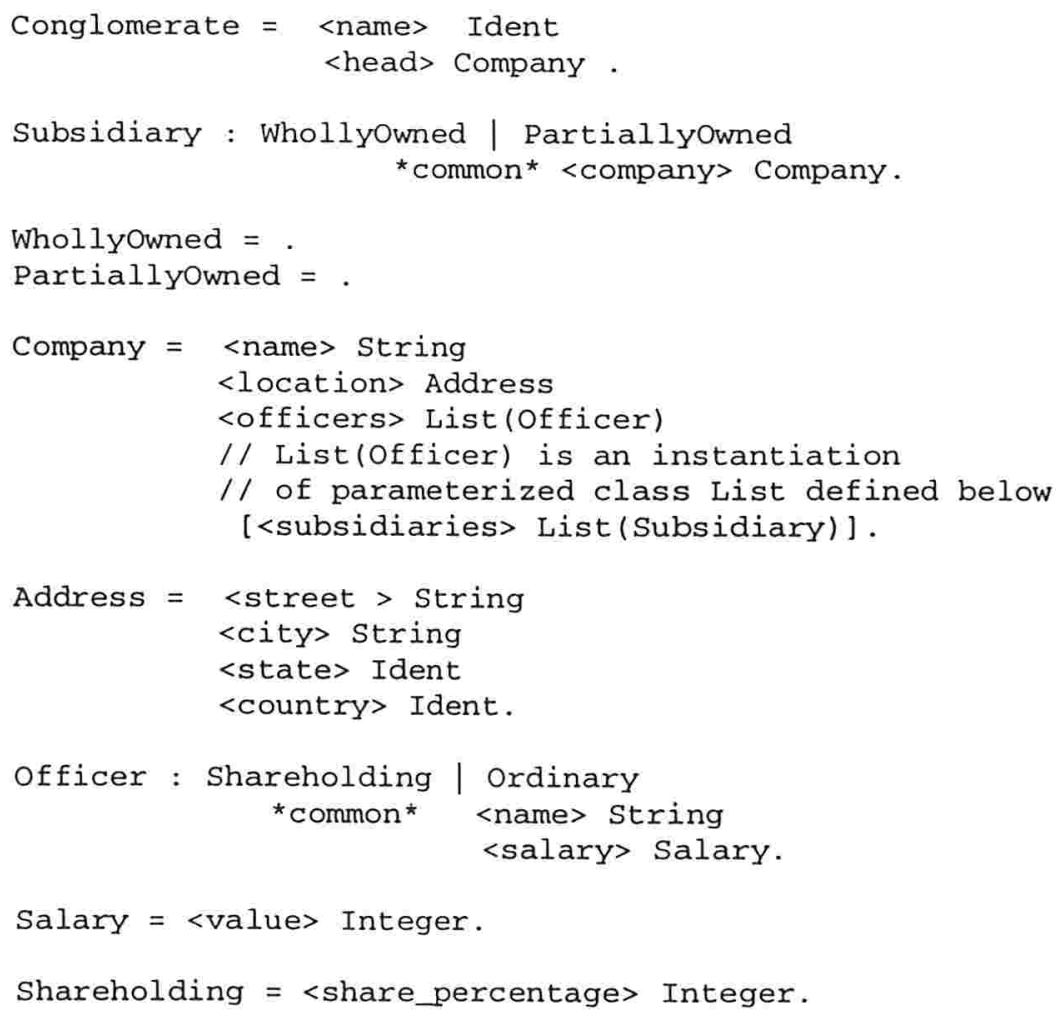




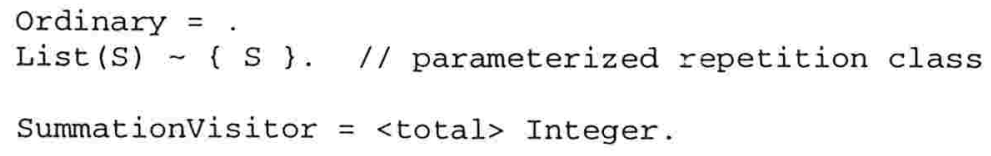

No exemplo estão definidas 9 classes concretas (Conglomerate, WhollyOwned, PartiallyOwned, Company, Address, Salary, ShareHolding, ordinary, Summationvisitor), duas classes abstratas (Subsidiary, officer) e uma classe coleção (List). A definição de cada classe é finalizada com o símbolo “.”.

Cada classe concreta possui a definição dos tipos de dados membros que cada uma delas contém. Por exemplo, a classe conglomerate contém um objeto (name) da classe Ident e outro objeto (head) da classe company.

As classes abstratas possuem uma definição diferente de classes concretas. Cada classe abstrata especifica seu conjunto de subclasses e pode também especificar um conjunto de tipos de dados membros que serão comuns para as suas subclasses. A classe abstrata officer possui as classes ShareHolding e Ordinary como suas subclasses, e define um objeto (name) da classe string e um objeto (salary) da classe salary como sendo tipos de dados membro comuns às suas subclasses. Observe que os tipos de dados membros comuns das classes abstratas são definidos após a palavra-chave common do Demeter.

A classe List é uma classe coleção que armazena objetos da classe S. A notação \{S\} indica que objetos da classe List poderão ser coleções vazias. A definição de uma classe de repetição List não vazia, seria: List S \{S\}. Além de ser uma classe de repetição, List é também uma classe parametrizada (sintaticamente especificada com "( $\mathrm{S})$ ", após o nome da classe), o que permite que ela seja instanciada com argumentos de classe. No exemplo acima existem duas parametrizações da classe List, como tipos de dados membros da classe company, sendo elas: List (officer) e List (Subsidiary).

A figura 3.5 apresenta um diagrama de classes UML equivalente ao dicionário de classes apresentado anteriormente ${ }^{5}$.

\footnotetext{
${ }^{5} \mathrm{O}$ grupo de pesquisa responsável pelo Demeter, desenvolveu também a ferramenta baseada em interface gráfica APStudio [LO00] que permite criar diagramas de classes UML, e gerar a partir destes, dicionários de classes equivalentes.
} 


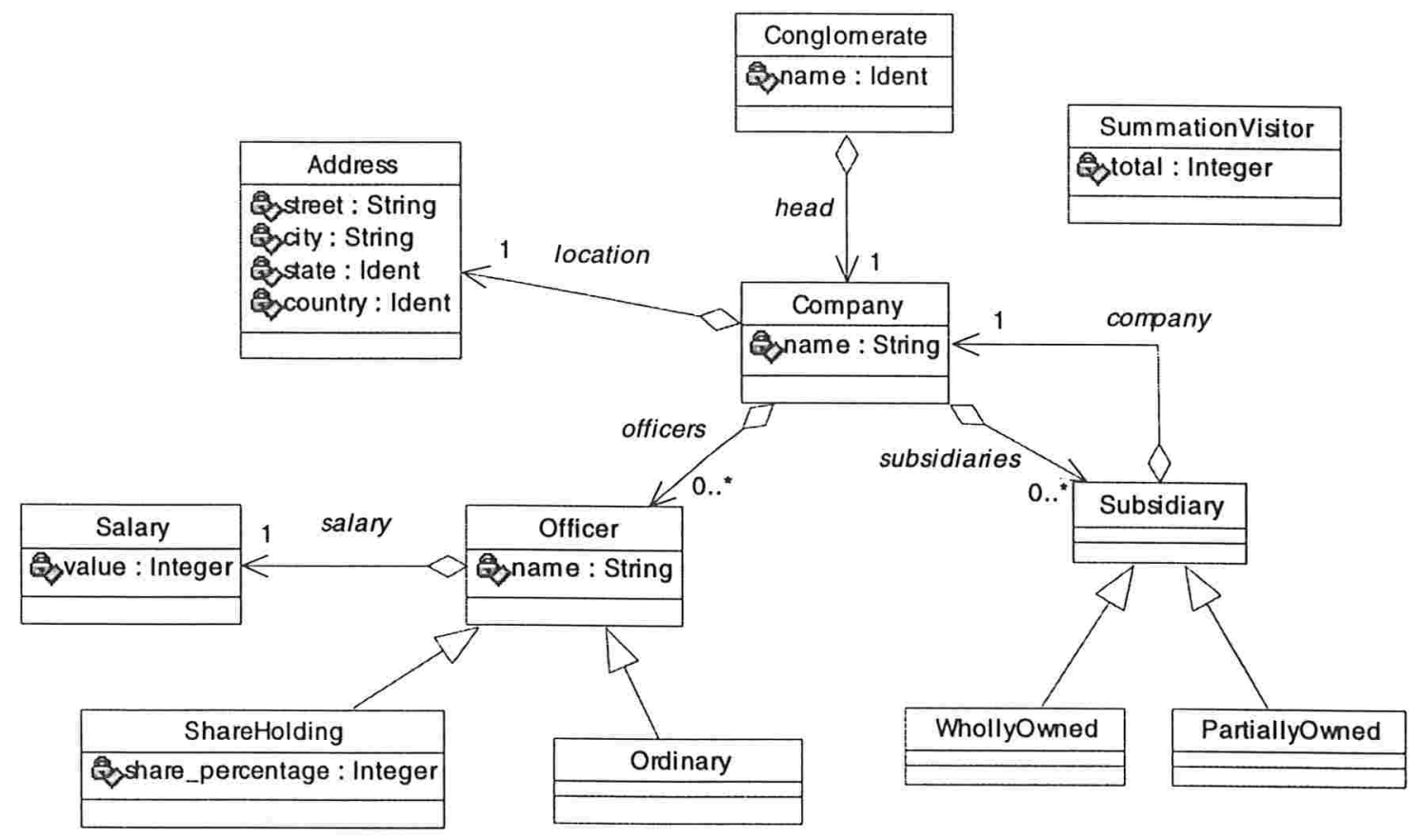

Figura 3.5: Diagrama de Classes do Conglomerado de Empresas

\subsubsection{Especificação do Comportamento do Sistema}

O comportamento do sistema é especificado no Demeter através de: métodos traversal; métodos e classes Visitor; e métodos adaptativos.

\section{Métodos Traversal}

Métodos Traversal determinam um caminho a ser percorrido na estrutura de classes do sistema para a realização de alguma tarefa, ou seja, representam um conjunto de objetos colaborando para o atendimento de alguma função de interesse do sistema. Eles consistem de: (1) um nome; (2) uma lista de classes Visitor como parâmetros; e (3) uma estratégia que determina/restringe os possíveis caminhos que o método traversal poderá seguir ao longo da estrutura de classes do sistema.

Abaixo temos a definição de um método traversal, definido para o dicionário de classes apresentado anteriormente.

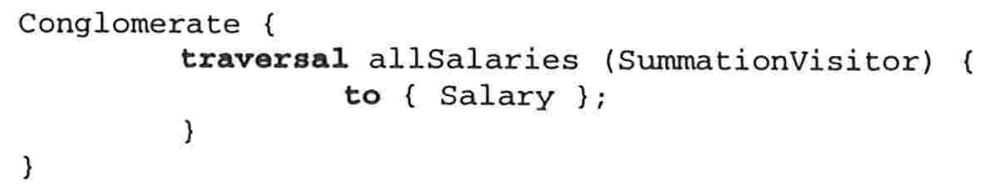

O método traversal definido acima possui nome allsalaries e recebe como parâmetro um objeto do tipo summationvisitor. O caminho que o método vai percorrer seguindo sua estratégia vai da classe onde ele é definido, no caso conglomerate, até a 
classe salary. Assim, no contexto do dicionário de classes apresentado anteriormente, o método allsalaries() atravessa todas as classes existentes entre Conglomerate e Salary considerando todos os caminhos possíveis entre a classe conglomerate (onde foi definido) e a classe salary. Durante a compilação dos arquivos que definem o comportamento e estrutura do sistema, será gerado um método com assinatura idêntica ao método traversal allsalaries() para cada uma das classes que estão ao longo do caminho definido por ele. Para a estrutura de classes especificada acima seria gerado um método allsalaries() para as classes conglomerate, Company, officer, Subsidiary e salary. Estes métodos são responsáveis pela implementação colaborativa de alguma operação (definida por classes Visitor) que se queira realizar com os salários dos diretores (officers) do conglomerado de empresas.

Existem formas de restringir ou forçar caminhos, dentro da estrutura de classes, a serem percorridos por um método traversal. Na seção 3.2.1.4 são apresentados outros exemplos de métodos traversal que utilizam cláusulas para restrição ou imposição de caminhos.

\section{Classes Visitor}

Classes Visitor possuem a mesma finalidade que o padrão de projeto Visitor [GHJV95], ou seja, definem comportamentos a serem executados quando percorrendo uma estrutura de objetos. No caso do Demeter, as classes Visitor definem o comportamento a ser executado pelos métodos traversal. Os métodos das classes Visitor são os responsáveis diretos pela implementação do comportamento do método traversal de cada classe que faz parte do caminho definido por ele. Existem três tipos de métodos Visitor, são eles:

(a) before - aqueles que são executados antes da continuação de execução do método traversal ao longo dos demais objetos que fazem parte do caminho definido pela sua estratégia;

(b) after - métodos executados depois da execução do método traversal;

(c) around - métodos que interrompem a continuação da execução do método traversal.

Classes Visitor podem ser definidas em um dicionário de classe com a palavrachave visitor. Poderíamos definir a classe summationvisitor do dicionário de classe apresentado anteriormente como sendo uma classe do tipo Visitor, assim:

visitor SummationVisitor $=$ <total> Integer .

Abaixo apresentamos a definição da classe summationvisitor com a definição de um método Visitor para a classe salary. 


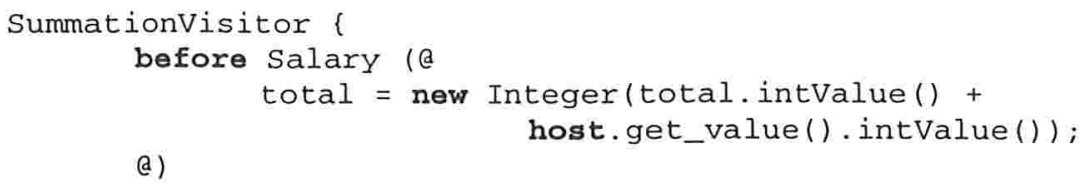

Um objeto da classe summationvisitor será passado como parâmetro na chamada do método traversal allsalaries(). Este método percorrerá um caminho ao longo da sua estratégia que atravessa objetos das classes Conglomerate, Company, officer, Subsidiary e salary. A classe summationvisitor oferece comportamento para apenas uma classe (Salary) dentro do caminho do método traversal allsalaries(). O objetivo de summationvisitor é acumular no seu atributo total do tipo Integer, a soma de todos os salários dos diretores (objetos do tipo officer) do conglomerado de empresas. O comportamento de métodos visitor (before, after ou around) são especificados entre delimitadores do escopo dos métodos (símbolos "( @" e “( )").

A palavra-chave host é usada para referenciar o objeto sendo percorrido por um método traversal. O método before salary da classe summationvisitor obtém o valor do objeto salary sendo percorrido, através do envio da mensagem host.get_value().

Assim, cada classe Visitor define métodos a serem chamados pelo método traversal para cada uma das classes contidas no caminho definido por este último. O tipo de método Visitor especifica se ele será chamado antes (before) ou depois (after) da continuação de execução do método traversal, ou se ele interromperá (around) a execução do método traversal.

\section{Métodos Adaptativos}

Em programação orientada a objetos adaptativa são definidos métodos adaptativos, os quais fazem uso do caminho especificado por métodos traversal para definir tarefas de interesse ao sistema. O método traversal associado a um determinado método adaptativo recebe objetos de classes Visitor como parâmetros, que definem seu comportamento. Métodos adaptativos no Demeter/Java tem a mesma finalidade que um padrão de propagação [Lie96]. Eles consistem de: (1) uma assinatura - que define o nome do método, seus parâmetros e valor de retorno; e (2) um método traversal - que define o caminho ao longo da estrutura de classes que o método adaptativo percorrerá.

Abaixo apresentamos um exemplo de método adaptativo para o contexto do conglomerado de empresas.

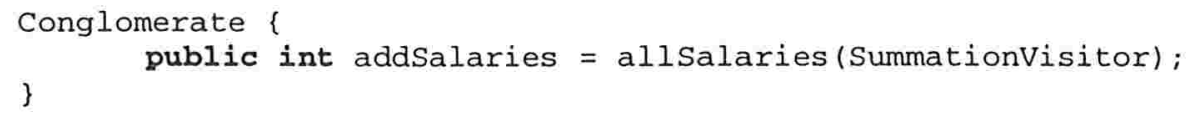


O objetivo do método adaptativo addSalaries() é somar o salário de todos os diretores (officers) da empresa, para isso ele utiliza a implementação do método traversal allsalaries() que percorre a lista de salários dos diretores da empresa.

\subsubsection{Geração do Sistema}

A ferramenta Demeter/Java compila os arquivos que definem a estrutura (dicionário de classes) e comportamento (métodos traversal, métodos adaptativos, classes Visitor) do sistema, e gera automaticamente um programa em código-fonte Java, contendo as classes e respectivos métodos necessários para realizar as tarefas de todos os métodos adaptativos.

Um método traversal é gerado em todas as classes que pertencem ao caminho que ele especifica. $\mathrm{O}$ comportamento de cada método traversal gerado pela ferramenta Demeter/Java é definido dinamicamente pelo objeto Visitor passado como parâmetro na sua chamada. Os métodos traversal são chamados durante a execução dos métodos adaptativos.

No desenvolvimento de sistemas orientado a objetos tradicionais, o programador usualmente deve se preocupar com a escrita de pequenos métodos ao longo da estrutura de classes do sistema; mudanças futuras nesta estrutura o forçam a analisar cada tarefa afetada e reescrever diversos métodos que no Demeter são gerados automaticamente. Na seção seguinte apresentamos exemplos de como os programas adaptativos podem facilmente se adaptar a evoluções na estrutura de classes do sistema.

\subsubsection{Evolução da Estrutura e Comportamento do Sistema}

O método/software Demeter permite em muitos casos que o comportamento especificado para o sistema se adapte automaticamente a eventuais evoluções na sua estrutura de classes. Esta adaptação é possível devido à especificação generalizada do comportamento do sistema através de métodos adaptativos.

Cada método adaptativo especificado no Demeter realiza alguma função de interesse do sistema seguindo um caminho, através do dicionário de classes, que é determinado pelo método traversal ao qual está associado. Toda vez que o dicionário de classes do sistema sofre algum refinamento (adição ou retirada de alguma classe ou de alguma relação entre classes), a tarefa do projetista é analisar se os caminhos determinados pelos métodos traversals podem ainda ser satisfeitos, e verificar se os métodos definidos para as classes Visitor de cada tarefa ainda estão de acordo com o novo dicionário de classes. Ambas as tarefas podem ser realizadas automaticamente pelo ferramenta Demeter/Java.

Nas seções anteriores $(3.2 .1 .1,3.2 .1 .2,3.2 .1 .3)$ apresentamos um dicionário de classe que representa a modelagem de um domínio para um conglomerado de empresas e especificamos o método adaptativo addsalaries(), que fazia o cálculo da soma total dos salários de todos os diretores (officers) da empresa-matriz (head), incluindo suas 
subsidiárias. Para exemplificar a forma como o Demeter lida com evoluções estruturais e de comportamento, vamos mostrar como ficaria a especificação de um novo método adaptativo addSalariesHeadCompany () que calcula a soma total dos salários apenas dos diretores da empresa-matriz (head). Em seguida, modificamos o dicionário de classes da aplicação para evidenciar se os métodos adaptativos se adaptam automaticamente à nova estrutura.

Para especificar nosso método adaptativo addSalariesHeadCompany() precisamos definir um novo método traversal allsalariesHeadcompany () que percorre todos os objetos da classe salary pertencentes aos empregados da principal empresa (head) do conglomerado. Nesta especificação não devem estar incluídos os salários dos empregados das empresas subsidiárias. Assim, o método traversal allSalariesHeadCompany () define sua estratégia utilizando a diretiva bypassing do Demeter, que ocasiona o desvio de determinados caminhos ao longo do dicionário de classes.

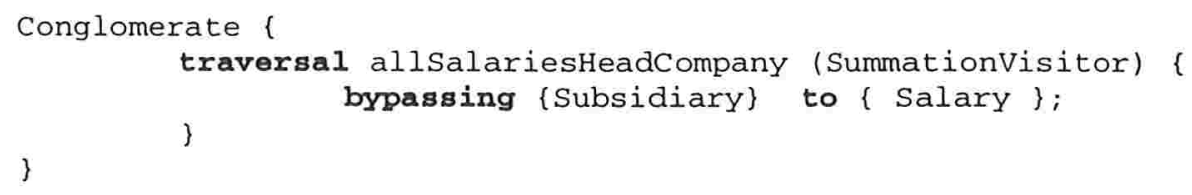

Observe que na especificação acima será passado como parâmetro para o método traversal allsalariesHeadcompany() um objeto da classe summationvisitor. Isto é possível porque a tarefa a ser realizada é essencialmente a mesma, ou seja, cálculo da soma de um conjunto de salários, e assim a única classe do caminho do método traversal a chamar um método Visitor continuará sendo salary.

Abaixo é apresentada a definição do método adaptativo addSalariesHeadCompany (), similar ao método addSalaries ().

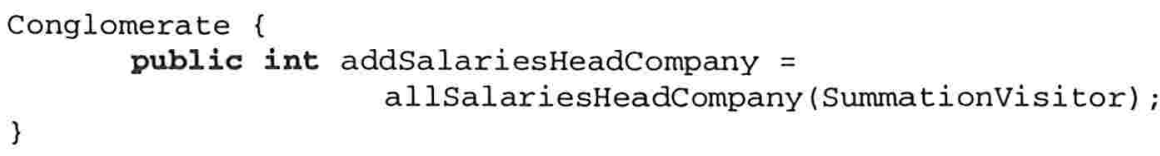

A recompilação dos arquivos do dicionário de classes juntamente com os arquivos que definem o comportamento do sistema (arquivos que contém os métodos adaptativos e traversal e as classes Visitor), gera automaticamente todos os métodos necessários entre as classes conglomerate e Salary, excluindo a classe subsidiary, alcançando assim o objetivo do método adaptativo addSalariesHeadCompany( ) .

Vamos então refinar o dicionário de classes apresentado na seção 3.2.1.1 com novas classes e novas relações entre as classes existentes, e mostrar como os métodos adaptativos addSalaries() e addSalariesHeadCompany() poderiam automaticamente se adaptar a estas mudanças. Para isso, vamos supor que todo conglomerado de empresas possui agora um conjunto de companhias-matriz (headers) e que cada companhia possui além de diretores (officers) também um conjunto de empregados (employees). Abaixo 
é apresentado o novo dicionário de classe, assim como o diagrama de classes equivalente em UML (figura 3.6).

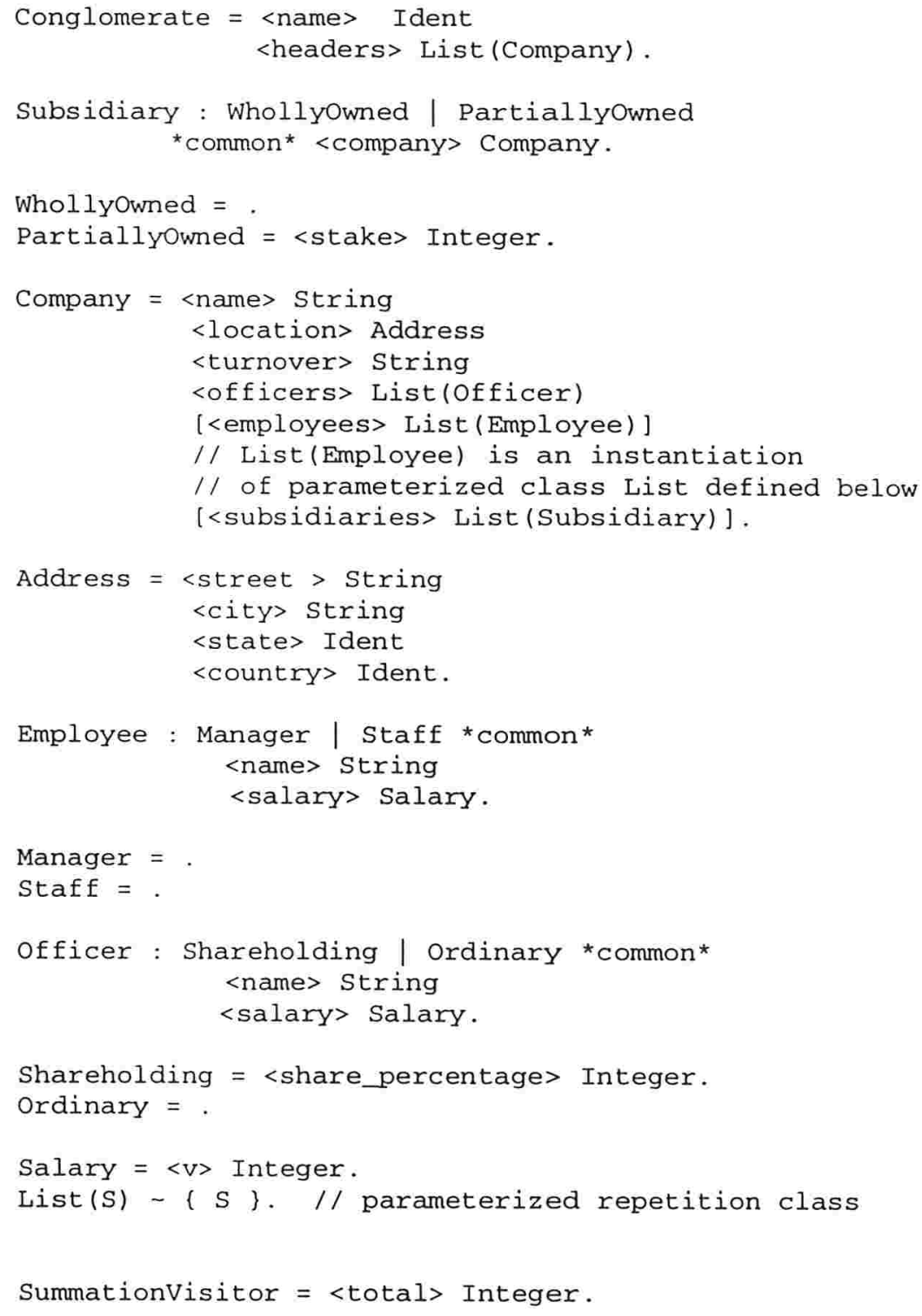




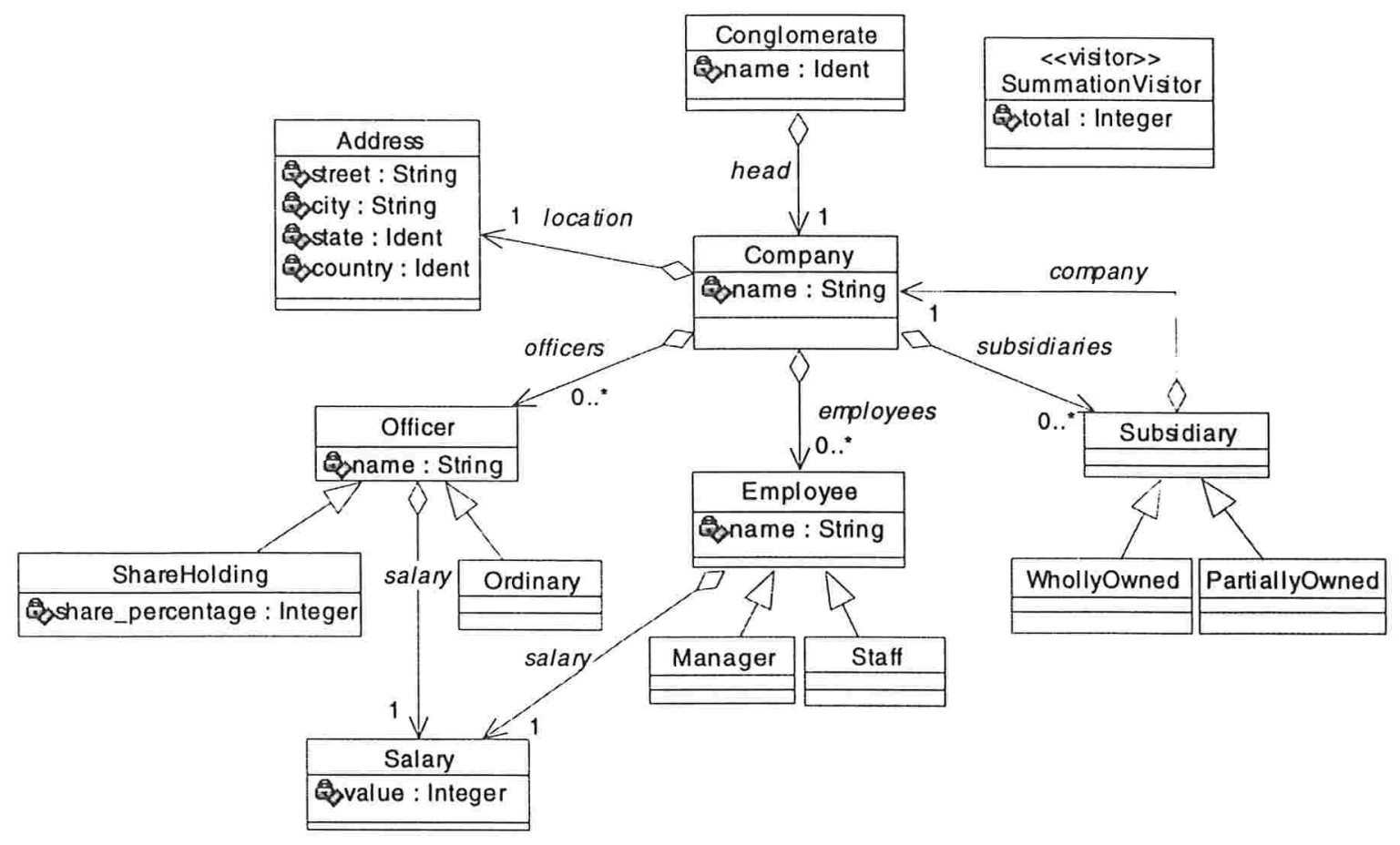

Figura 3.6: Novo Diagrama de Classes do Conglomerado de Empresas

Apesar das modificações feitas no dicionário de classes, os dois métodos adaptativos addSalaries () e addSalariesHeadCompany() não precisam ser novamente especificados, pois os caminhos dos métodos traversal aos quais eles estão associados continuam a ser satisfeitos. Entretanto, a semântica dos métodos é alterada. O método addSalaries() calcula agora a soma total dos salários dos diretores (officers) e empregados (employees) de todas as empresas do conglomerado, incluindo as subsidiárias. Já o método addSalariesHeadCompany () calcula a soma total dos salários de diretores (officers) e empregados (employees), mas apenas das empresas-matriz (headers).

Abaixo são definidos dois novos métodos adaptativos: addsalariesofficer() que calcula a soma total dos salários dos diretores (officers) do conglomerado; e addSalariesemployee() - que calcula a soma total dos salários dos empregados (employees) do conglomerado. A cláusula through especifica caminhos que métodos traversal necessariamente devem atravessar.

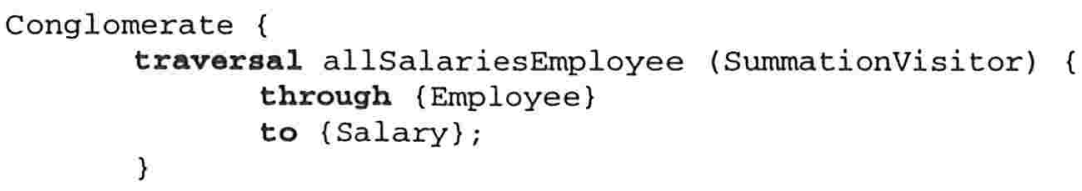




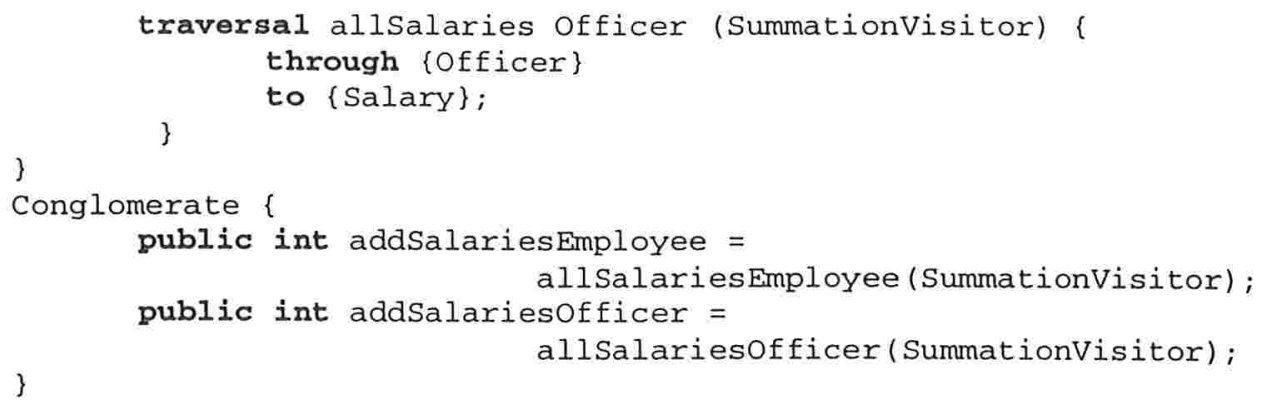

\subsubsection{Relações de Contexto}

Sistemas Orientados a Objetos construídos com linguagens de programação baseada em classes ( $\mathrm{C}++$, Java) têm seu comportamento definido estaticamente através da especificação de métodos para as classes do sistema. Os padrões de projeto, apresentados em [GHJV95], representam uma alternativa para o projeto de sistemas que necessitam ter algum aspecto de interesse do seu comportamento variando dinamicamente.

Os autores do método Demeter argumentam que a forma (relacionamentos de herança e agregação entre classes) como os padrões propostos em [GHJV95] dão suporte a aspectos de evolução dinâmica aumenta a complexidade do projeto, implementação e futura manutenção do sistema, porque ao trazem ao projeto orientado a objetos do sistemas diversas classes-extras com novos relacionamentos e colaborações. Eles propõem um novo tipo de relacionamento entre classes, denominado Relações de Contexto [Sei96, SPL98] visando resolver o problema de suporte a variações dinâmicas no comportamento de sistemas implementados com linguagens baseadas em classe.

Em Relações de Contexto é definido o conceito de classe Base, a qual possui associada uma ou mais classes de Contexto. Cada classe de contexto determina aspectos de variação dinâmica que a classe Base pode sofrer. Existem dois tipos gerais de variações dinâmicas que o mecanismo de relações de contexto suporta: variação dinâmica do comportamento de um objeto específico de uma classe e variação dinâmica de um grupo de objetos que colaboram na execução de uma tarefa específica, descritas a seguir.

\subsubsection{Modificação do Comportamento de um Objeto}

A alteração do comportamento de um objeto específico permite, em tempo de execução, modificar o comportamento de alguns de seus métodos. Para isso é necessário que esteja definido para a classe do objeto a ser modificado dinamicamente (classe Base) um conjunto de classes de Contexto que especificam as possíveis variações dinâmicas que a classe Base pode sofrer. A especificação das classes base e de contexto é feita através de uma sintaxe de extensão proposta pelos autores para o nível de implementação do sistema. Abaixo apresentamos o projeto original do padrão Strategy e logo em seguida seu projeto com o uso de Relações de Contexto. 
O padrão de projeto Strategy [GHJV95] permite definir e encapsular um conjunto de algoritmos permutáveis. Ele possibilita que o algoritmo varie de forma independente do cliente que o utiliza, através do fornecimento de diversas implementações definidas para uma única interface. O padrão de projeto Strategy possui três componentes: Strategy, ConcreteStrategy e Context. O componente Strategy é responsável pela definição de uma interface comum para as variantes do algoritmo. O ConcreteStrategy implementa o algoritmo através do uso da interface definida pelo Strategy. O Context utiliza a interface do Strategy para chamar o algoritmo definido pelo ConcreteStrategy.

A figura 3.7 mostra um exemplo de projeto com o Strategy descrito em [GHJV95]. Este exemplo mostra a definição de diferentes estratégias para um algoritmo de quebra de textos em linha. O método compose() representa este algoritmo. Cada classe deste exemplo é estereotipada com o nome do componente do padrão de projeto Strategy que ela representa.

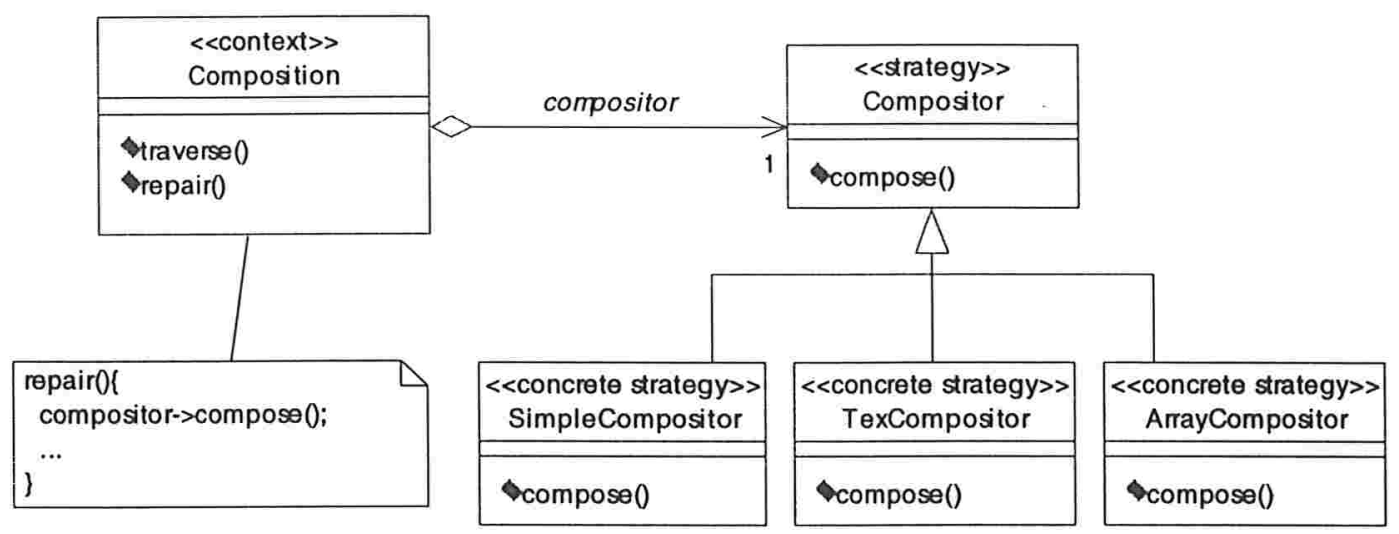

Figura 3.7: Padrão de Projeto Strategy

A figura 3.8 apresenta uma modelagem com Relações de Contexto para o exemplo do padrão de projeto Strategy da figura 3.7. São definidas para a classe base Composition três classes de contexto (simplecompositor, TexCompositor e ArrayCompositor) que especificam possíveis variações dinâmicas para o método compose() da classe base. O método compose() é utilizado para a definição de diferentes estratégias para a quebra de textos em linhas. Neste projeto com Relações de Contexto não é mais necessário a classe compositor (componente Strategy) para definir a interface comum para as variantes do algoritmo.

Em nossos diagramas de classes UML, classes base são representadas através do uso do estereótipo <<base>> e classes de contexto através do estereótipo <<context >>. Uma relação de contexto entre uma classe de contexto e uma classe base é representada por uma relação de dependência UML com o estereótipo <<context relation>>. 


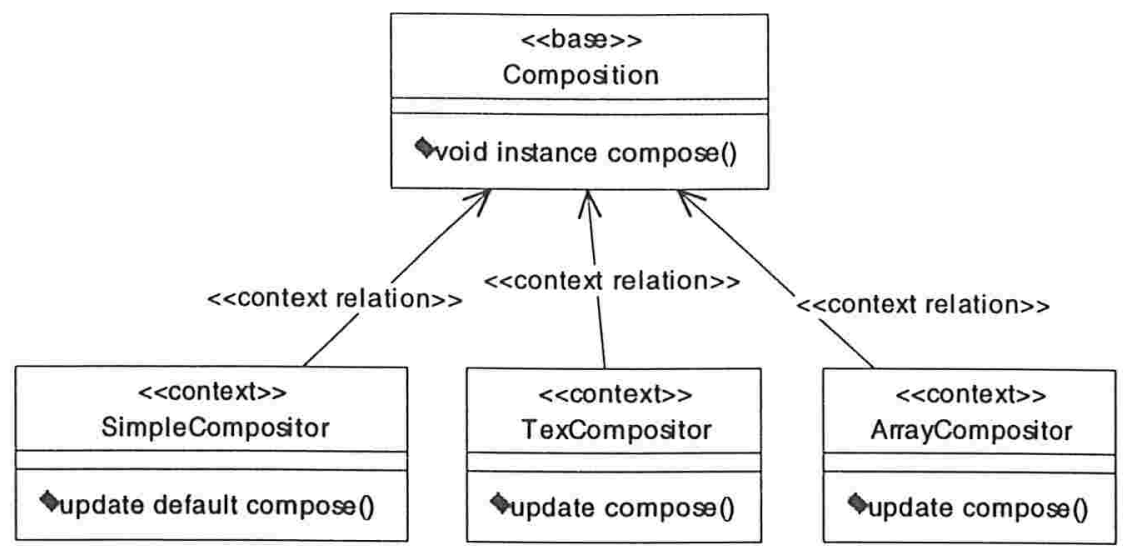

Figura 3.8: Padrão de Projeto Strategy modelado com Relações de Contexto

Para especificação de métodos que podem ter seu comportamento alterado dinamicamente, tal como o método compose () do exemplo acima, Seiter, Palsberg \& Lieberherr [SPL98] propõem a definição de métodos de instâncias. A palavra-chave instance é usada para a especificação de tais métodos.

Classes de contexto não herdam da classe base nem são consideradas subclasses desta. Uma classe de contexto define modificações dinâmicas sobre uma classe base, através da atualização de algum método de instância de um objeto da classe base em tempo de execução. Esta atualização de métodos de um objeto dinamicamente é realizada por meio da atualização da tabela de métodos virtuais, que realiza o mapeamento entre assinaturas de métodos e suas implementações, ou seja, a entrada do método sendo atualizado é modificada na tabela de métodos virtuais, de forma a apontar para a implementação definida por um objeto de uma classe de contexto.

Abaixo são apresentadas as definições das classes do exemplo do Strategy, de acordo com a sintaxe proposta [SPL98] para a linguagem Java.

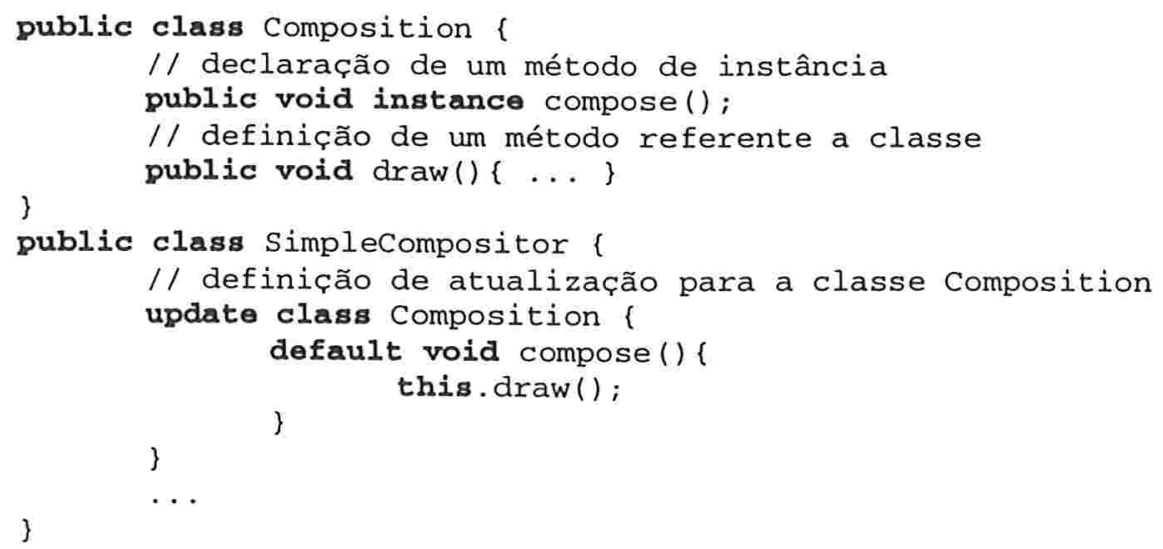




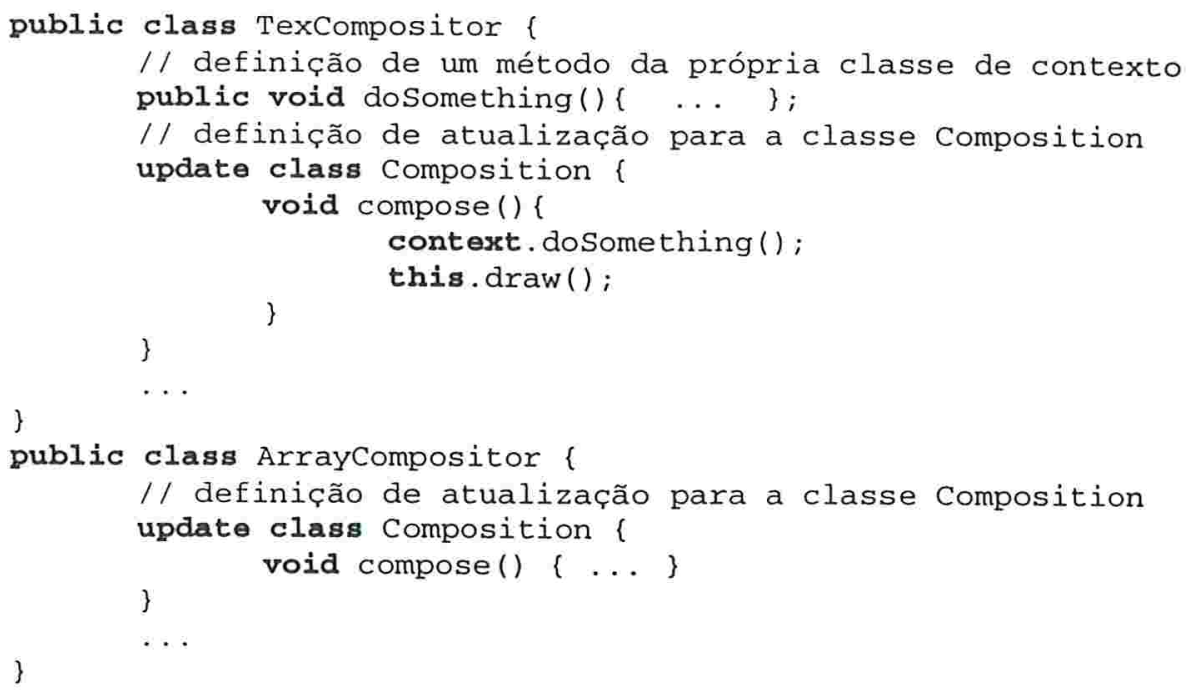

No exemplo acima são definidas as três classes de contexto Simplecompositor, TexCompositor e ArrayCompositor da classe base composition, e cada uma delas, além de especificar seus próprios métodos e atributos, define uma atualização dinâmica para o método compose() da classe composition, utilizando a palavra-chave update. Observe que o método compose() da classe composition é definido como um método de instância (instance), e sua implementação default é definida pela classe Simplecompositor.

Dentro da definição dos métodos de atualização dinâmica nas classes de contexto podem ser chamados métodos, tanto da classe de contexto (utilizando a palavra-chave context) quanto métodos da classe base (utilizando a palavra-chave this, já existente em Java). No exemplo acima, dentro da definição do método compose () da classe de contexto TexCompositor, há uma chamada para o método doSomething() desta própria classe, assim como uma chamada para o método draw() da classe base composition.

A seguir apresentamos um programa que instancia um objeto da classe Composition e altera dinamicamente a implementação default do seu método compose() (definida pela classe simplecompositor) para a implementação definida pela classe Texcompositor. Para associar dinamicamente um objeto de contexto a um objeto de uma classe base, os autores estendem a sintaxe da linguagem Java com o símbolo ": : :".

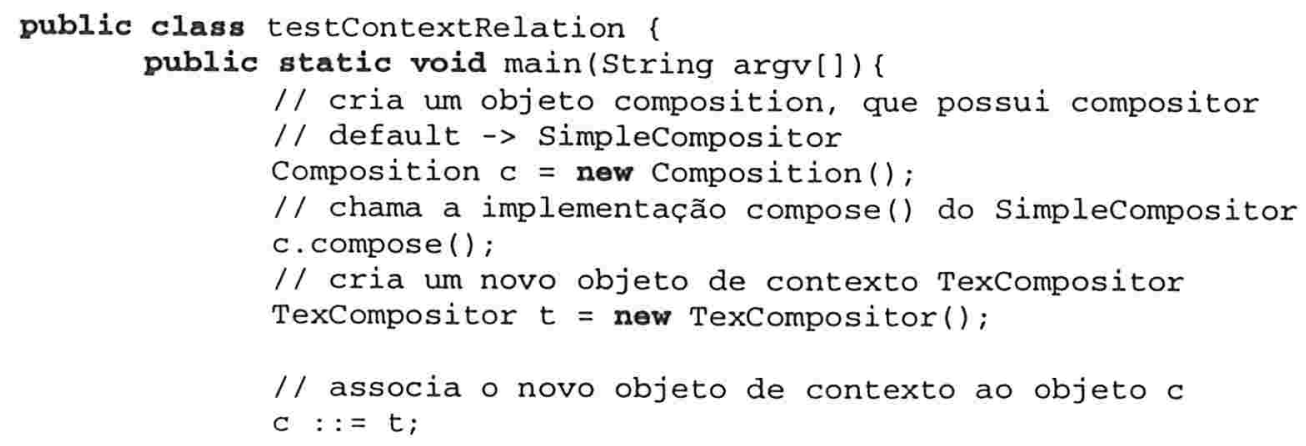




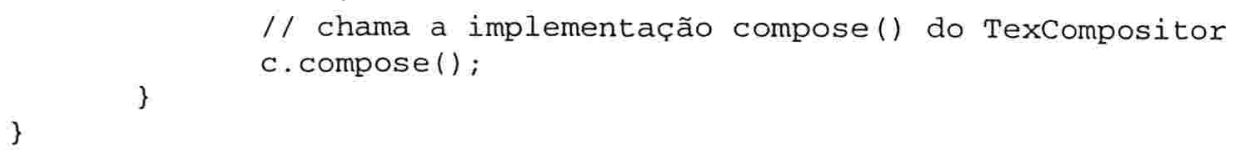

\subsubsection{Modificação do Comportamento de um Grupo de Objetos}

As relações de contexto do método Demeter permitem também a modificação dinâmica de um grupo de objetos que colaboram para a execução de uma determinada tarefa. Para exemplificarmos este tipo de modificação dinâmica apresentamos inicialmente uma modelagem com o padrão de projeto Visitor [GHJV95].

O padrão de projeto Visitor permite adicionar comportamento para uma estrutura de classes sem alterar as relações já existentes nesta. As figuras 3.9 e 3.10 mostram uma estrutura de classes para equipamentos simples e compostos de computadores, publicada em [SPL98], que possui associada uma hierarquia de classes Visitor (figura 3.10), responsável pela implementação de duas tarefas colaborativas: (1) Pricing - que calcula o custo total de cada equipamento, baseado no preço líquido (net) dos equipamentos simples e no preço com desconto (discount) dos equipamentos compostos; e (2) Inventory - que acumula uma lista de equipamentos existentes em um computador. Cada uma das tarefas é implementada através da definição de um método visit() para cada classe X não abstrata da estrutura de equipamentos e de um método atX() em cada classe Visitor.

A implementação de cada método visit() (figura 3.9) difere de acordo com o tipo de equipamento que a classe representa. Cada classe de equipamento simples $\mathrm{xxx}$ (Drive e FloppyDisk) possui um método visit() que simplesmente chama o método atxxx() do objeto Visitor que recebe como parâmetro. Cada classe de equipamento composto YYY (Chassis e Cabinet) possui um método visit(), que além de realizar uma chamada para o método atYYY() do objeto Visitor que recebe como parâmetro, ainda faz uma chamada para o método visit() de cada um dos equipamentos simples que ela mantém. Por exemplo, a classe Drive chama, na implementação do seu método visit(), apenas o método atDrive() do objeto Visitor que recebe como parâmetro. Já a classe cabinet, além de realizar uma chamada para o método atcabinet(), ainda realiza chamadas para o método visit () de cada um de seus componentes (parts).

Os autores de relações de contexto argumentam que o projeto de sistemas com o Visitor demonstra a dificuldade de suporte a comportamento dinâmico com linguagens baseadas em classes. Mostram ainda a possível existência de repetição de código dentro de classes Visitor na implementação de métodos at, para objetos com o mesmo significado semântico para a tarefa (como por exemplo, objetos de equipamentos simples do exemplo anterior). Outra dificuldade encontrada com o Visitor é a necessidade de adicionar um método atYYY () em cada classe Visitor toda vez que uma nova classe é incorporada à estrutura de classes do sistema. Alguns autores apresentam soluções para este problema [Vli95, Vli96] que em contrapartida inserem novas dificuldades no projeto. 


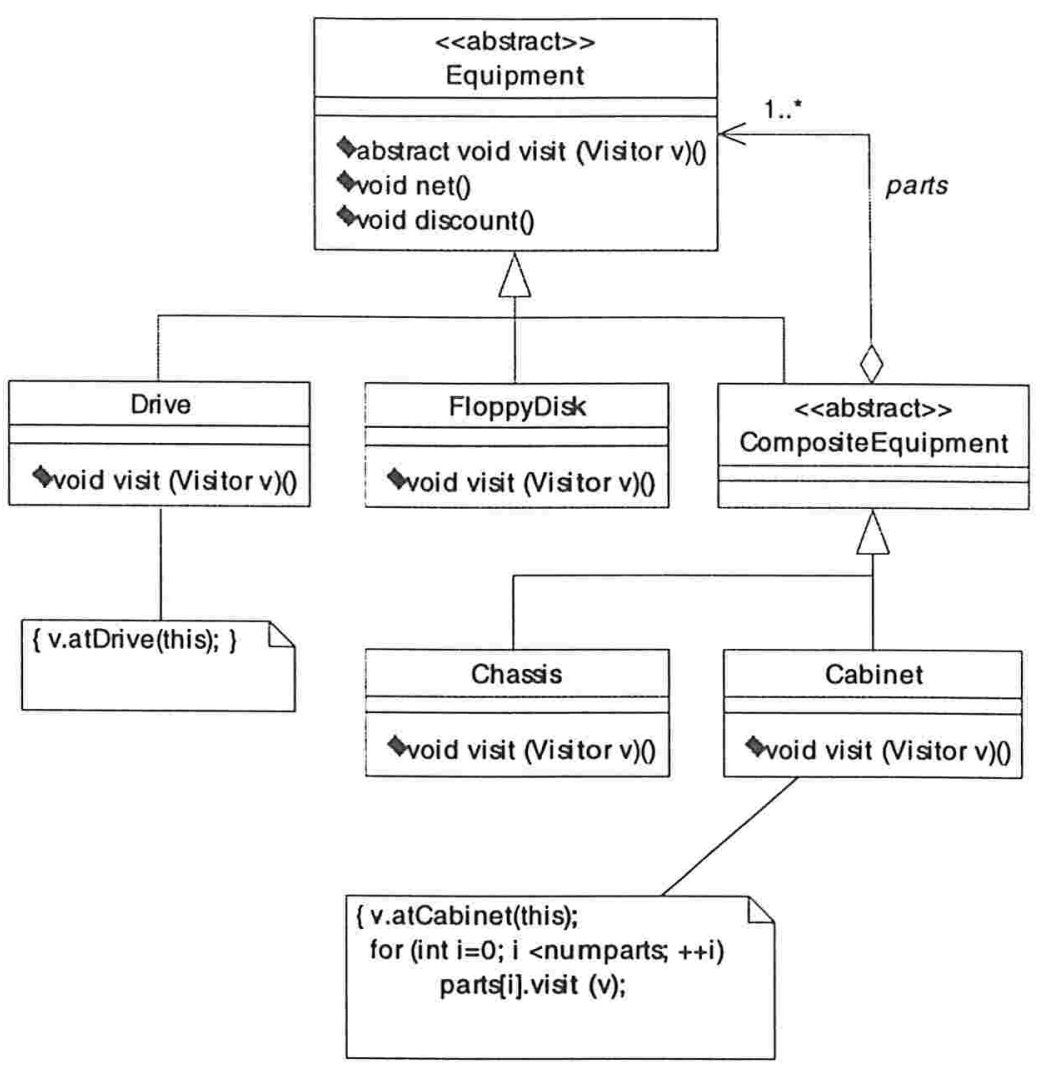

Figura 3.9: Diagrama de Classes UML para equipamentos de computadores

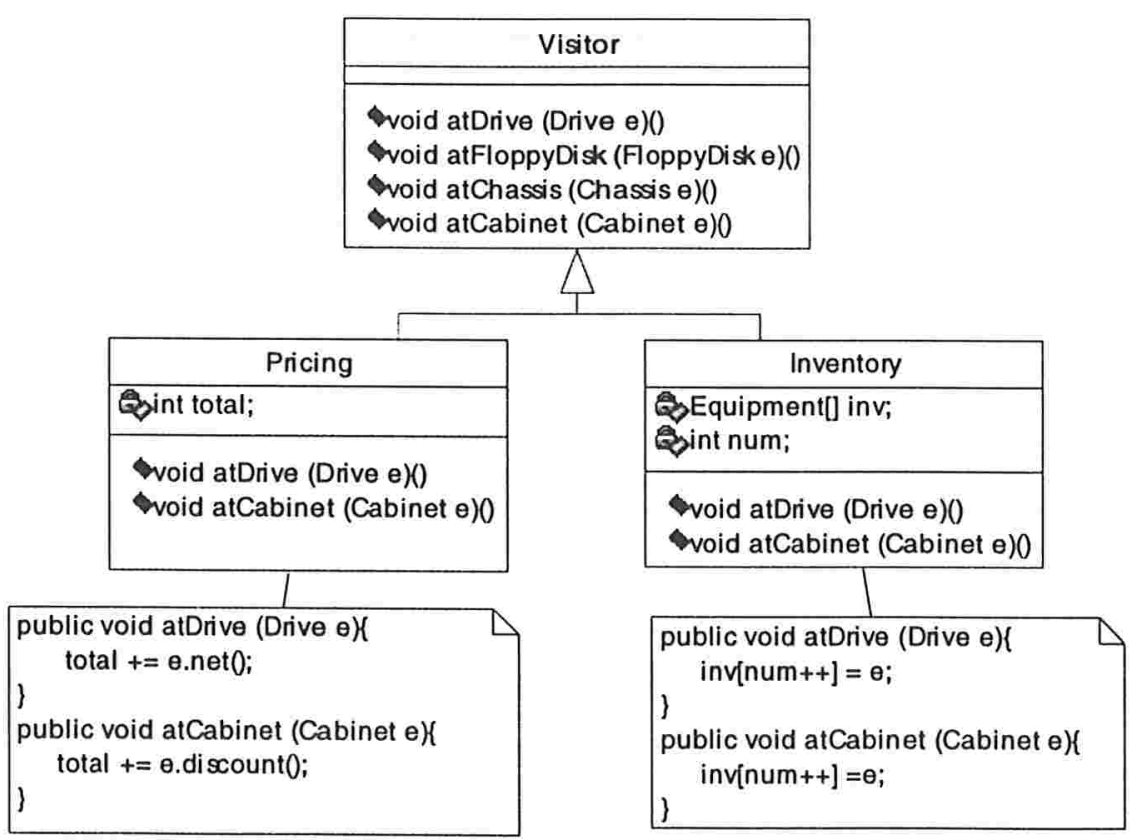

Figura 3.10: Diagrama de Classes da Hierarquia de Visitors 
O projeto do Visitor utilizando Relações de Contexto define atualizações para os métodos at () das classes centrais da estrutura, Equipment e compositeEquipment. Tal projeto evita o problema da definição de métodos atxxx () nas classes Visitor, para cada classe $\mathrm{xxx}$ da estrutura de classes. Novas classes de equipamentos podem ser assim incorporadas sem exigir alteração no código referente à realização das tarefas Pricing e Inventory. A estrutura de classes Visitor também não é mais necessária.

As figuras 3.11 e 3.12 apresentam diagramas de classes com o resultado das alterações realizadas sobre a estrutura de classes do sistema e a definição das classes Visitor de contexto Inventory e Pricing.

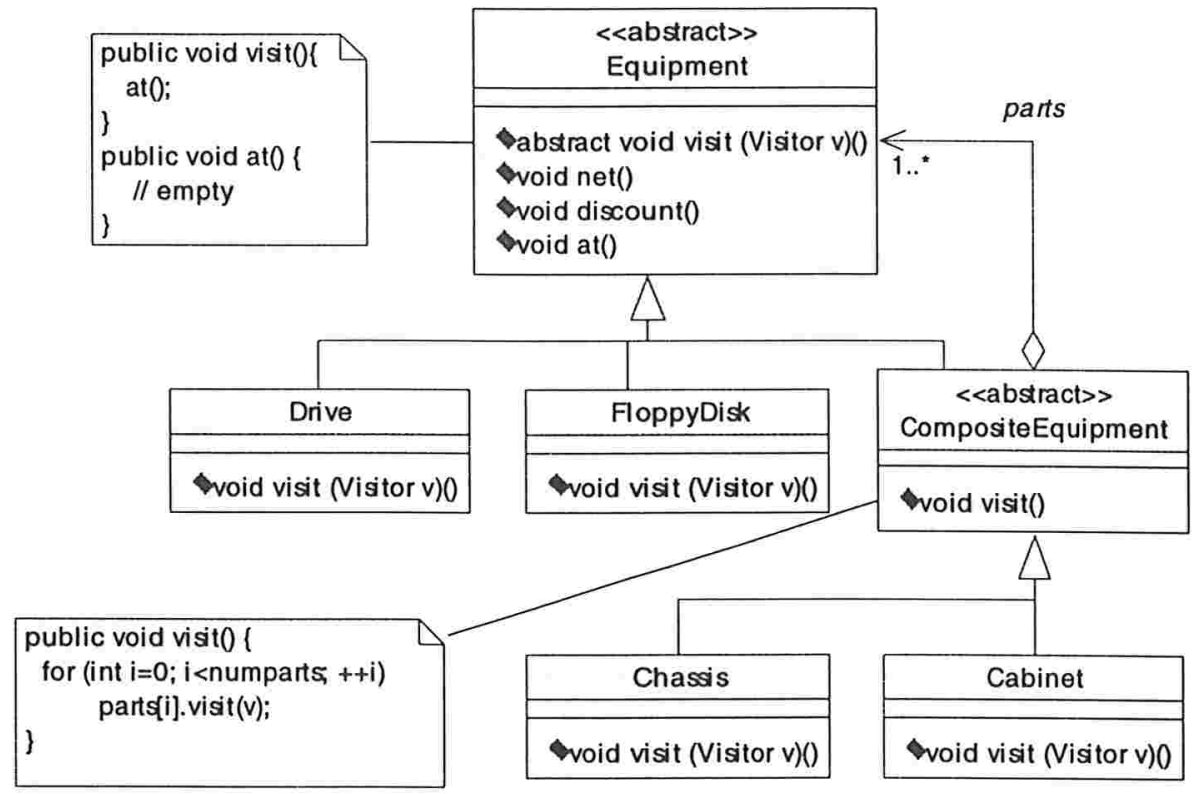

Figura 3.11: Diag. de Classes para equip. de computadores utilizando Relações de Contexto

A classe Inventory realiza dinamicamente atualizações no método at () da classe Equipment, já a classe Pricing realiza dinamicamente atualizações no método at () das classes Equipment e CompositeEquipment. As atualizações são feitas não mais em um método de instância, tal como no exemplo da modificação do comportamento de um objeto com o Strategy, mas sim em um método armazenado na própria classe, o que acaba afetando todas as instâncias das classes Equipment e CompositeEquipment, assim como instâncias de suas subclasses que fazem uso do mesmo método.

$\mathrm{Na}$ definição de métodos a serem modificados dinamicamente podem ser acessados métodos e atributos internos da classe de contexto, assim como também métodos da classe a ser modificada. A classe Pricing, por exemplo, na definição do método at () acessa tanto atributos próprios (context. total) quanto chama métodos da classe que ela modificará dinamicamente (this.net(), this.discount ()). 


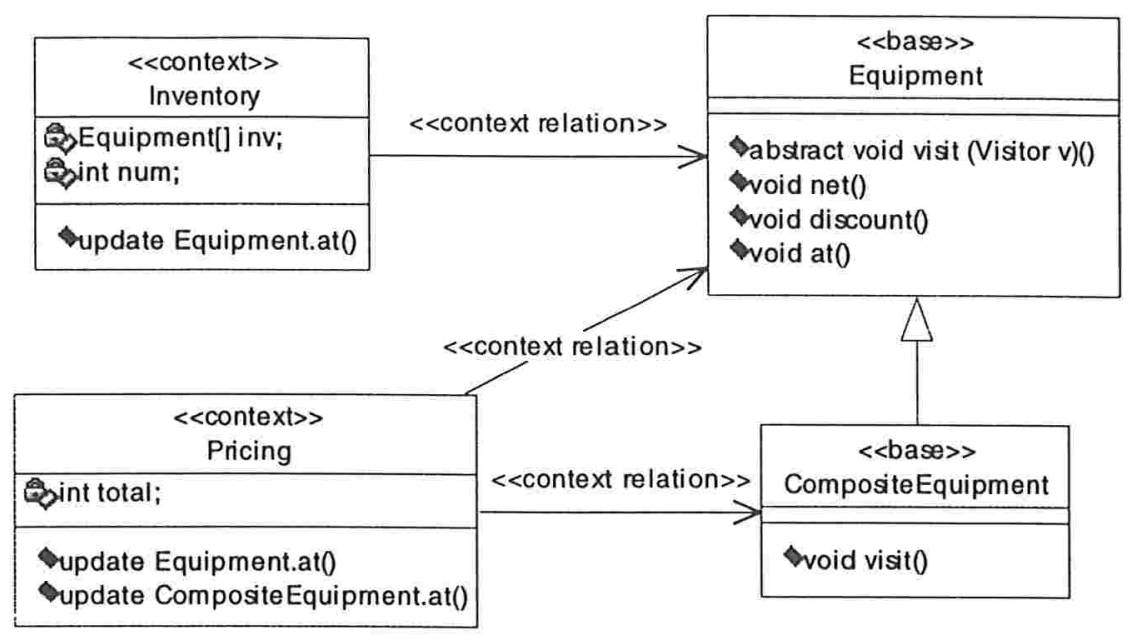

Figura 3.12: Classes Visitor utilizando Relações de Contexto

Para finalizar apresentamos um programa que utiliza as classes definidas acima.

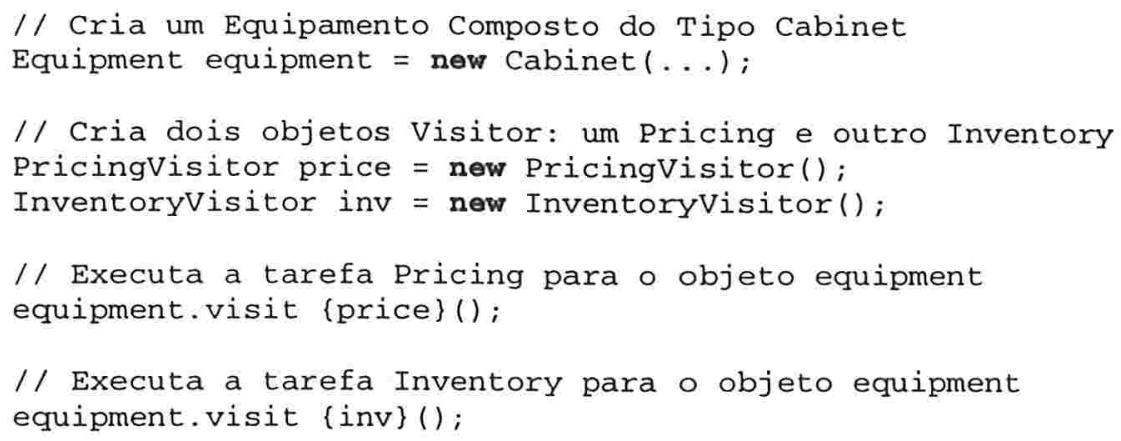

O efeito do programa acima é que para cada chamada do método visit() de um equipamento, é escolhido uma tarefa a ser executada dentro de um determinado contexto de atualização. As chamadas ao método visit() no programa ocasionam a atualização do método at (), modificando-o de acordo com a tarefa (contexto) que se quer realizar e a estratégia de atualização definida nos objetos price e inv. Para associar um objeto de contexto a uma chamada de um método, os autores estendem a sintaxe da linguagem Java. No exemplo acima, os comandos "equipment.visit(price)();" e "equipment.visit\{inv\} () ;" definem associações dos objetos de contexto price e inv a chamada do método visit() do objeto equipment.

\subsection{Resumo do Capítulo 3}

Neste capítulo foram descritas as abordagens AspectJ da técnica de programação orientada a aspectos e Demeter/Java da técnica de programação adaptativa com relações de contexto. Nos capítulos seguintes apresentamos o estudo de casos conduzido com o objetivo de avaliar o impacto destas abordagens no projeto de sistemas adaptáveis. 


\section{Estudo de Casos}

Os capítulos seguintes $(4,5$ e 6$)$ descrevem o estudo de casos de reengenharia do projeto de sistemas adaptáveis com as técnicas de programação orientada a aspectos e programação adaptativa com relações de contexto. O objetivo do estudo foi analisar o impacto destas técnicas no projeto de sistemas adaptáveis.

O estudo de casos consistiu dos seguintes passos:

(I) compreensão das características de cada sistema, através do estudo de artigos técnicos e sua documentação;

(II) entendimento do código-fonte de cada sistema com a possível identificação de entrelaçamentos entre seus interesses de projeto;

(III) engenharia reversa dos sistemas estudados com a geração de modelos UML para descrição da estrutura e comportamento de cada um deles;

(IV) reengenharia do projeto dos sistemas usando separadamente as técnicas de programação orientada a aspectos e programação adaptativa com relações de contexto;

(V) comparação do projeto original dos sistemas com os novos projetos gerados.

\section{Escolha dos Sistemas}

Antes de iniciar o estudo de casos foi necessário proceder a escolha de dois sistemas que apresentassem como uma das principais motivações de seu desenvolvimento o suporte a requisitos de adaptação estática e dinâmica. Além de ter que apresentar características relevantes de adaptação, outros critérios importantes para a seleção dos sistemas foram: a disponibilidade de código-fonte e documentação descrevendo o sistema e a linguagem de programação utilizada para o seu desenvolvimento. Os seguintes sistemas foram selecionados: JAWS - um servidor Web adaptativo e SPIN - um sistema operacional extensível.

Abaixo apresentamos uma tabela enumerando outros sistemas candidatos e o motivo pelo qual eles não foram incluídos em nosso estudo de casos.

\begin{tabular}{|l|l|}
\hline \multicolumn{1}{|c|}{ Sistema Avaliado } & \multicolumn{1}{c|}{ Motivo da Não Participação no Estudo } \\
\hline Choices [CRJ87] & Suporte apenas a adaptações estáticas \\
\hline Vino [EGS+94] & Boa parte do sistema desenvolvido em C \\
\hline Paramecium [vDHT95] & Aparentemente não concluído, código-fonte não disponível \\
\hline 2K [KCM+00] & Ainda em desenvolvimento \\
\hline Flux [FML+97] & $\begin{array}{l}\text { Por se tratar de uma biblioteca, concluímos que ele poderia } \\
\text { não fornecer situações concretas do projeto de sistemas } \\
\text { adaptáveis. }\end{array}$ \\
\hline Exokernel [EKO95] & Documentação disponível não-satisfatória \\
\hline
\end{tabular}


Nos capítulos seguintes (4 e 5) são apresentadas: as características, estrutura e comportamento dos sistemas estudados; as reengenharias do projeto dos sistemas usando as abstrações das técnicas investigadas; e análises comparativas do projeto original de cada sistema com os novos projetos gerados nas reengenharias. O capítulo 4 é dedicado ao JAWS e o capítulo 5 ao SPIN. O capítulo 6 traz as conclusões gerais do estudo de casos. 


\section{Reengenharia do Projeto do JAWS}

Este capítulo descreve o projeto original do servidor web adaptativo JAWS e as reengenharias do seu projeto usando as técnicas investigadas nesta dissertação. A seção 4.1 descreve as características, estrutura e comportamento do JAWS. A seção 4.2 apresenta a reengenharia do projeto do JAWS usando programação orientada a aspectos e a seção 4.3 apresenta a reengenharia do seu projeto usando programação adaptativa com relações de contexto. Cada uma das seções 4.2 e 4.3 descreve o método empregado e modelos resultantes do processo de reengenharia, assim como uma subseção de análise do novo projeto gerado em comparação com o projeto original do JAWS.

\subsection{JAWS - Servidor Web Adaptativo}

JAWS [HS99] é um framework orientado a objetos que permite a construção de servidores Web configuráveis. Diversas estratégias de configuração podem ser combinadas no JAWS, permitindo sua adaptação tanto estática quanto dinâmica a mudanças ocorrendo no seu ambiente de execução. O próprio JAWS é um servidor Web adaptativo e de alto desempenho que implementa o protocolo HTTP. Além disso, a estrutura definida pelo framework do JAWS possibilita que ele seja utilizado para a construção de outros tipos de servidores de comunicação.

O JAWS é formado por um conjunto de componentes, que foram estruturados utilizando o framework para software de comunicação ACE [SS94] e diversos padrões de projetos [Sch97a, GHJV95, BMR+96] catalogados pela comunidade. O JAWS foi implementado usando a linguagem de programação $\mathrm{C}++$.

São definidas no JAWS quatro estratégias que podem ser configuradas em tempo de compilação ou execução:

(1) Estratégia de Concorrência - determina uma política de concorrência para execução do protocolo definido para o JAWS. Em sua versão atual estão implementadas duas diferentes estratégias: (a) Thread-per-Request - manipula cada pedido de cliente em uma thread separada; e (b) Thread-Pool - durante inicialização do JAWS é ativado um conjunto pré-definido de threads, as quais obtêm pedidos de clientes de uma fila e os processam;

(2) Estratégia de I/O - determina uma política para entrega e recuperação de dados. Duas estratégias de I/O estão presentes na versão atual do JAWS: (a) I/O síncrona - neste modelo o kernel não retorna o thread de controle para o servidor antes que o pedido da operação de I/O tenha sido completado ou tenha falhado; e (b) I/O assíncrona - neste 
modelo o kernel executa cada pedido de operação de $\mathrm{I} / \mathrm{O}$ de forma assíncrona, enquanto o servidor processa outros pedidos;

(3) Estratégia de "Pipeline" de Protocolos - determina mecanismos para reconfiguração do protocolo HTTP definido pelo JAWS. Um protocolo é definido no JAWS como um conjunto de tarefas organizadas em seqüência, seguindo o padrão Pipes and Filters [BMR+96]. Este protocolo pode ser modificado estática ou dinamicamente (através da adição, remoção ou substituição de tarefas);

(4) Estratégia de Cache de Arquivos - determina uma política para armazenamento de arquivos em cache, com o intuito de melhorar o desempenho do servidor Web, através da diminuição de acessos ao servidor remoto. Tal estratégia encontra-se ainda em desenvolvimento, e portanto, não foi abordada neste nosso estudo.

Nas subseções seguintes, são apresentados: diagramas UML [BRJ99] que descrevem a estrutura e comportamento do JAWS, e entrelaçamentos de código de diferentes interesses identificados no código do JAWS.

\subsubsection{Estrutura do JAWS}

Nesta seção descrevemos a estrutura e comportamento dos principais componentes do JAWS. Foram encontradas bastantes diferenças entre os modelos UML do JAWS descritos em [HS99], e os modelos gerados durante o estudo e leitura de seu código atual. Para facilitar o entendimento das classes presentes no JAWS, elas foram organizadas neste documento sob a forma de componentes de acordo com a funcionalidade oferecida.

As principais classes presentes no framework do JAWS são as seguintes:

(a) JAWS_Server - responsável por agregar a política de funcionamento do servidor, pela configuração inicial das estratégias do JAWS e pela ativação de algumas destas estratégias;

(b) JAWS_Default_Dispatch_Policy - define a política do servidor e mantém as estratégias do JAWS;

(c) JAWS_Concurrency_Base - define a estratégia de concorrência. Esta classe implementa mecanismos para executar de forma concorrente o protocolo do JAWS. Suas subclasses implementam estratégias de concorrência concretas;

(d) JAWS_IO - implementa a estratégia de I/O. Suas subclasses implementam estratégias de I/O concretas;

(e) JAWS_IO_Acceptor - define a estratégia de estabelecimento de conexões com clientes;

(f) JAWS_Pipeline_Handler - define uma interface básica para as tarefas do protocolo HTTP do JAWS. Subclasses implementam cada uma da tarefas do protocolo;

(g) JAWS_Data_Block - define a unidade de comunicação entre as tarefas do protocolo do JAWS.

Nas subseções seguintes são descritas de forma mais detalhada cada uma destas classes do framework do JAWS. 


\subsubsection{Classe JAWS_Server}

A classe JAWS_Server é um dos elementos principais do JAWS; é ela quem possibilita criar e configurar suas diferentes estratégias. Tais estratégias são escolhidas a partir da consulta de atributos específicos (port, concurrency, dispatch) da classe JAWS_Server.

A classe JAWS_Server agrega a política do servidor (instância da classe JAWS_Default_Dispatch_Policy), a qual mantém referência para suas diferentes estratégias. Seus dois principais métodos são:

- init() - se responsabiliza pela criação e inicialização das estratégias mantidas por sua política (JAWS_Default_Dispatch_Policy), de acordo com os valores estabelecidos para seus parâmetros; inicia a "escuta" de pedidos de clientes através da invocação do método open () da estratégia de aceitação de sua política; e inicia os threads de sua estratégia de concorrência;

- open() - configura o protocolo do JAWS; cria e configura um objeto JAWS_Data_Block (abordado adiante); e ativa as threads da estratégia de concorrência repassando para esta o objeto JAWS_Data_Block criado.

\subsubsection{Classe JAWS_Default_Dispatch_Policy}

A classe JAWS_Default_Dispatch_Policy representa a política do servidor e agrega suas diferentes estratégias. Ela oferece métodos para a configuração de cada uma de suas estratégias. Na figura 4.1 é apresentado um diagrama de classes que inclui as classes JAWS_Server, JAWS_Dispatch_Policy e também as classes que representam as estratégias do JAWS. 


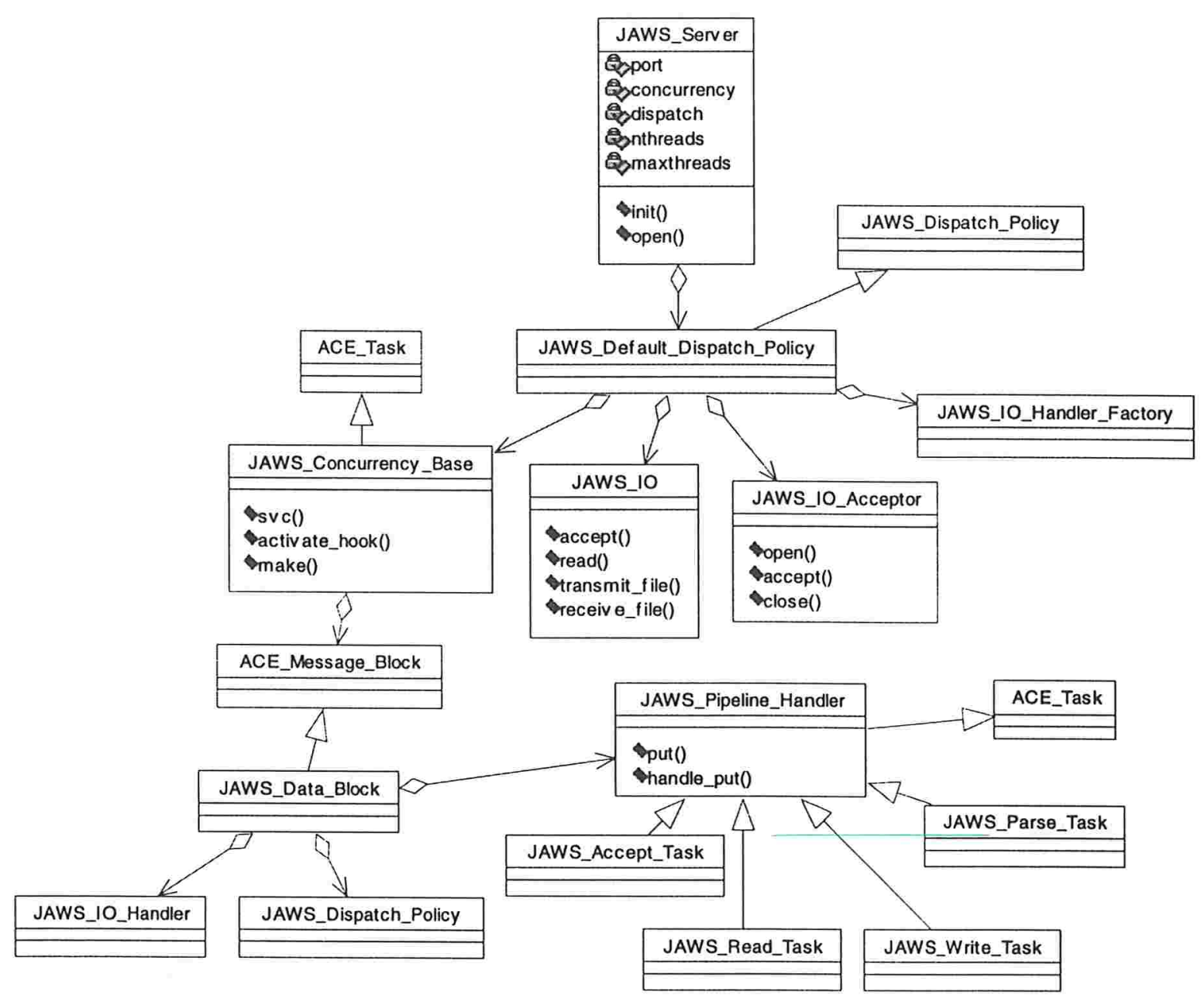

Figura 4.1: Diagrama de Classes parcial do JAWS

\subsubsection{Componentes da Estratégia de Concorrên cia}

A estratégia de concorrência do JAWS está representada em seu projeto pela classe JAWS_Concurrency_Base e suas subclasses JAWS_Thread_Per_Task e JAWS_Thread_Pool_Task. A figura 4.2 apresenta um diagrama contendo tais classes.

\section{Classe JAWS_Concurrency_Base}

A classe JAWS_Concurrency_Base oferece uma implementação básica para a definição de uma estratégia de concorrência. Ela herda da classe ACE_Task do framework $\mathrm{ACE}$, o que permite que ela defina um comportamento (método svc) que será executado em uma thread de controle separada, seguindo o padrão ActiveObject [LS95].

Os métodos principais definidos na classe JAWS_Concurrency_Base são:

- singleton_mb() - espera pelo armanezamento de uma JAWS_Data_Block na fila de mensagens da JAWS_Concurrency_Base; 
- put () - método que armazena a JAWS_Data_Block passada como parâmetro na fila de mensagens;

- svc() - determina o serviço a ser executado pelas threads da estratégia de concorrência. Sua função é simplesmente recuperar a JAWS_Data_Block, através do método singleton_mb(), e em seguida chamar o método svc_loop ();

- svc_loop() - chama, em um loop infinito, o método svc_hook() da própria classe JAWS_Concurrency_Base, passando sempre como argumento um novo objeto JAWS_Data_Block com os parâmetros padrões para sua inicialização (a tarefa inicial do protocolo definido para o JAWS, a JAWS_Policy configurada para o servidor e um JAWS_IO_Handler nulo);

- svc_hook() - executa sequencialmente as tarefas do protocolo do JAWS;

\section{Classe JAWS_Thread_Pool_Task}

Implementa uma estratégia concreta de concorrência que permite inicializar um conjunto de threads responsáveis pela execução de pedidos solicitados por clientes do JAWS. A classe JAWS_Thread_Pool_Task herda da classe JAWS_Concurrency_Base e fornece uma implementação para o seguinte método:

- make() - cria e ativa o pool de threads desta estratégia.

\section{Classe JAWS_Thread_Per_Task}

Implementa uma estratégia concreta de concorrência que permite inicializar um thread para cada pedido solicitado por clientes do JAWS. A classe JAWS_Thread_Per_Task herda da classe JAWS_Concurrency_Base e fornece uma implementação para os seguintes métodos:

- make() - apenas inicializa os parâmetros passado como argumentos (flags e maxthreads);

- put() - armazena a JAWS_Data_Block passada como parâmetro na fila de mensagens, e em seguida chama o método activate_hook();

- svc_loop() - reimplementa o método svc_loop() da classe JAWS_Concurrency_Base, para que ele simplesmente faça uma única chamada para o método svc_hook ();

- activate_hook() - cria e ativa uma thread para execução de um novo pedido solicitado por um cliente. 


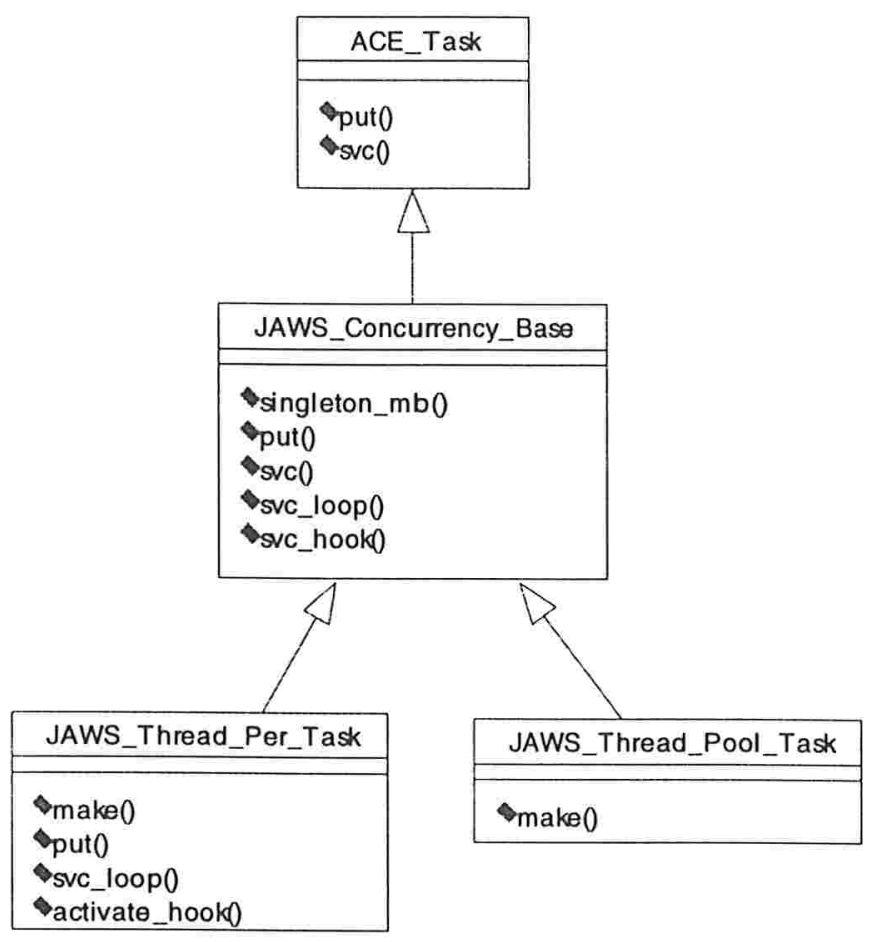

Figura 4.2: Diagrama de classes da Estratégia de Concorrência do JAWS

\subsubsection{Componentes da Estratégia de Aceitação de Conexões}

A estratégia de aceitação de conexões do servidor Web JAWS é implementada por uma hierarquia de classes contendo a classe JAWS_IO_Acceptor e suas subclasses JAWS_IO_Synch_Acceptor e JAWS_IO_Asynch_Acceptor. Diagrama de classes da estratégia de aceitação de conexões é apresentado na figura 4.3.

\section{Classe JAWS_IO_Acceptor}

A classe JAWS_IO_Acceptor é responsável por encapsular classes que seguem o padrão Acceptor [Sch97b] e já estão definidas dentro do framework ACE [SS94]. Ela determina uma interface básica que deve ser implementada pelas suas subclasses. Os seguintes métodos fazem parte desta interface:

- open() - inicia um socket em modo passivo;

- accept () - estabelece uma conexão com um cliente;

- close () - finaliza o acceptor;

- get_handle() - permite obter o handle responsável por "escutar" as conexões de rede. 


\section{Classe JAWS_IO_Synch_Acceptor}

A classe JAWS_IO_Synch_Acceptor é uma subclasse de JAWS_IO_Acceptor que utiliza o modelo do padrão de projeto Adapter [GHJV95] para encapsular um objeto do tipo LOCK_SOCK_Acceptor. É responsável por implementar a interface definida pela sua superclasse, definindo um Acceptor que aceita conexões de forma síncrona.

\section{Classe JAWS_IO_Asynch_Acceptor}

A classe JAWS_IO_Asynch_Acceptor é uma subclasse de JAWS_IO_Acceptor que também segue o padrão de projeto Adapter [GHJV95] para encapsular um objeto do tipo ACE_Asynch_Acceptor. Ela define um Acceptor para o JAWS que aceita conexões de forma assíncrona.

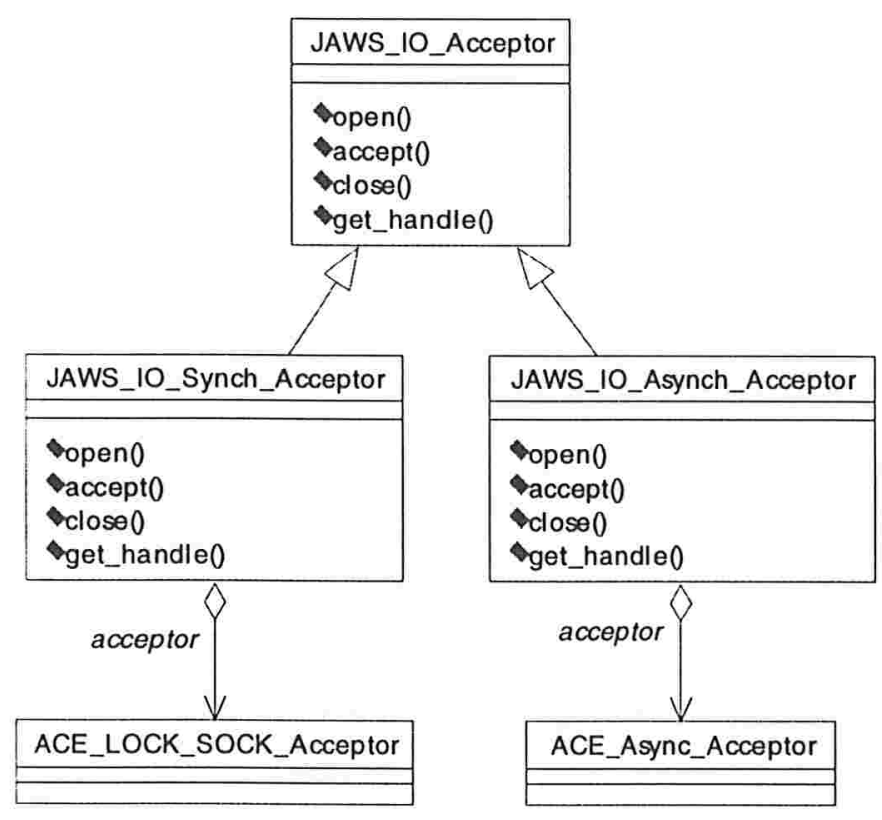

Figura 4.3: Diagrama de classes da Estratégia de Aceitação de Conexões do JAWS

\subsubsection{Componentes do Protocolo}

O protocolo HTTP do JAWS é implementado por um conjunto de tarefas, especializações da classe ACE_Task, organizadas seqüencialmente. A classe ACE_Task faz parte do framework ACE [SS94] e define uma interface a ser implementada por classes-tarefas. Estas classes-tarefas são organizadas em streams para processamento específico de um serviço. Os métodos abstratos put () e svc() da classe ACE_Task são definidos por suas subclasses para especificação do seu serviço de forma síncrona (na mesma thread de controle do objeto que fez a sua chamada) ou assíncrona (em uma thread de controle separada), respectivamente. Cada uma das tarefas do protocolo do JAWS (subclasses de JAWS_Pipeline_Handler) utiliza a interface do método put() para implementar seu serviço. A estratégia de concorrência apresentada anteriormente e implementada pela classe JAWS_Concurrency_Base (também subclasse de ACE_Task), 
utiliza a implementação do método svc() para executar de forma concorrente o protocolo do JAWS.

\section{Classe JAWS_Pipeline_Handler}

A classe JAWS_Pipeline_Handler herda da classe ACE_Task. Ela define uma interface padrão para ser implementada por cada uma das tarefas do protocolo do JAWS, contendo os seguintes métodos/atributos:

- put() - método herdado da classe ACE_Task e que é reimplementado para fornecer as diretivas para o processamento da tarefa (salva atributos passados como argumentos, chama o método handle_put () e configura a próxima tarefa a ser processada);

- handle_put() - implementação especializada do serviço de cada tarefa, é invocado pelo método put ();

- policy - mantém referência para a política (objeto JAWS_Dispatch_Policy) definida para o JAWS.

\section{Subclasses de JAWS_Pipeline_Handler}

As subclasses de JAWS_Pipeline_Handler definem uma implementação para o método handle_put () de acordo com a tarefa do protocolo a que se propõem realizar. $\mathrm{O}$ processamento do método handle_put() de cada uma das subclasses de JAWS_Pipeline_Handler envolve: (1) a recuperação da política definida para o servidor a partir do JAWS_Data_Block passado como parâmetro para tal método; (2) o processamento da tarefa em si que, em geral, envolve a invocação de algum dos métodos implementados pela classe JAWS_IO; e (3) a configuração do resultado do processamento (variável result) do método handle_put (). do JAWS:

A seguir descrevemos as quatros tarefas definidas para o protocolo da versão atual

- JAWS_Pipeline_Accept_Task - define a tarefa responsável por aceitar conexões de pedidos de clientes. Envia a mensagem accept () para o objeto JAWS_IO da política do servidor;

- JAWS_Pipeline_HTTP_Read_Task - responsável pela leitura do pedido inicial do cliente. Envia a mensagem read () para o objeto JAWS_IO da política do servidor;

- JAWS_Pipeline_HTTP_Parse_Task - realiza o parsing do pedido do cliente;

- JAWS_Pipeline_HTTP_Write_Task - envia a resposta do pedido do cliente, que pode ser o arquivo solicitado (método transmit_file() da estratégia de I/O) ou uma mensagem de erro no processamento do pedido (método send_error_message () da estratégia de I/O). As informações necessárias para o envio da resposta do pedido ao cliente estão contidas em atributos do objeto HTTP_Request.

A figura 4.4 apresenta o diagrama de classes da estratégia do protocolo do JAWS. 


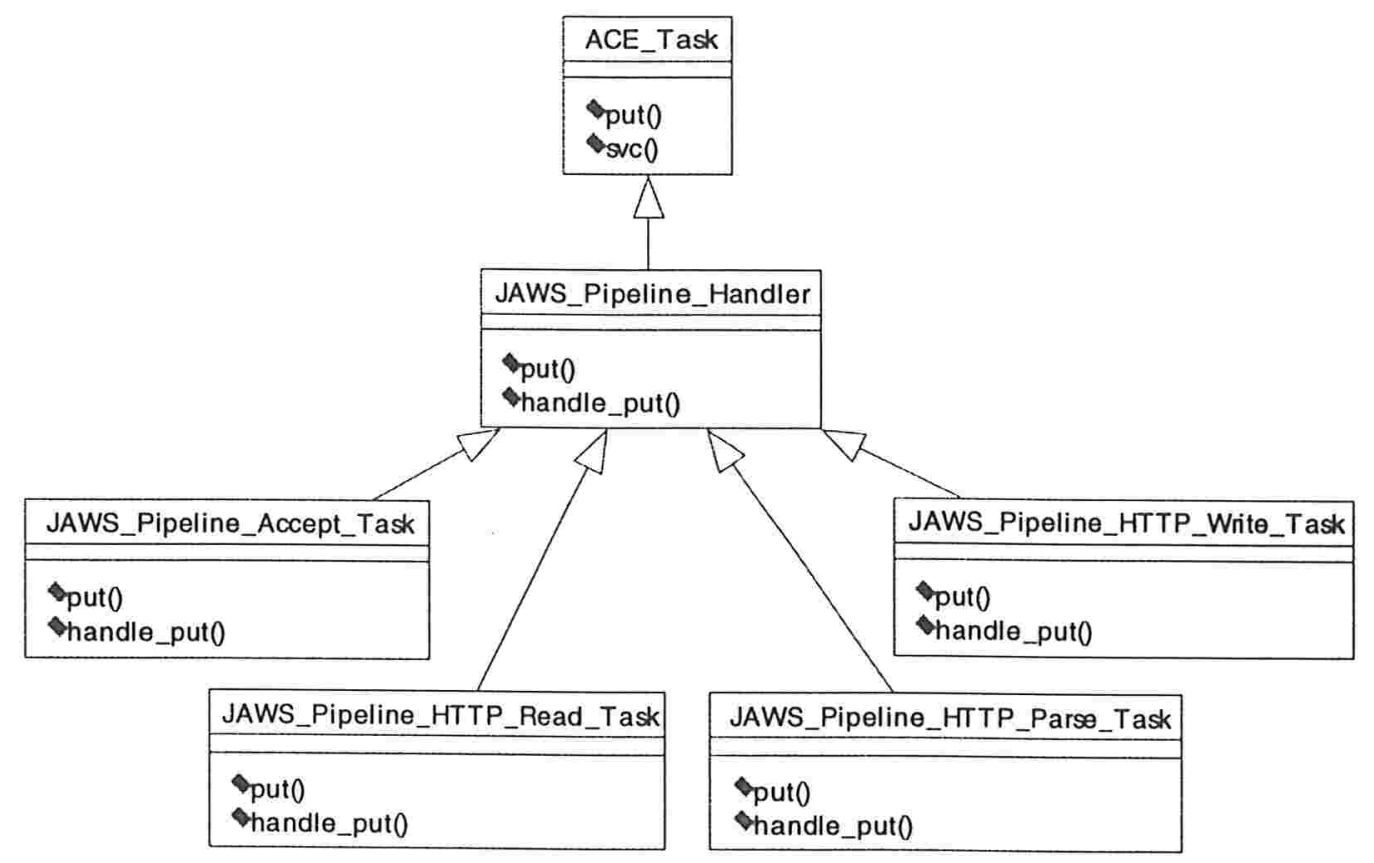

Figura 4.4: Diagrama de classes da Estratégia do Protocolo do JAWS

\subsubsection{Componentes da Estratégia de I/O}

A estratégia de I/O do JAWS é responsável pelo recebimento de pedidos e envio de respostas aos clientes. Ela é implementada pela classe JAWS_IO e suas subclasses JAWS_Synch_IO e JAWS_Asynch_IO. As classes da estratégia de I/O do JAWS são apresentadas no diagrama da figura 4.5 .

\section{Classe JAWS_IO}

A classe JAWS_IO define uma interface abstrata que deve ser implementada por suas subclasses para oferecer a funcionalidade necessária para recebimento de pedidos de clientes e envio de suas respectivas respostas.

A interface definida pela classe JAWS_Io possui os seguintes métodos:

- accept () - método responsável por aceitar uma conexão passiva, através do envio da mensagem accept() para a estratégia de aceitação da política do servidor;

- read() - método responsável pela leitura dos dados contidos na JAWS_Data_Block;

- transmit_file() - método responsável por transmitir a resposta (contendo o header, o arquivo e o trailer da mensagem) do pedido do cliente;

- receive_file() - método responsável por ler dados do handle do seu JAWS_IO_Handler e armazená-lo em um determinado arquivo; 
- send_confirmation_message() - método responsável pelo envio de uma mensagem de confirmação para o handle do seu JAWS_IO_Handler;

- send_error_message() - método responsável pelo envio de uma mensagem de erro para o handle do seu JAWS_IO_Handler.

Classe JAWS_Synch_IO

Uma das subclasses da classe JAWS_Io é a classe JAWS_Synch_IO. Ela define uma classe de $\mathrm{I} / \mathrm{O}$ com processamento síncrono que utiliza um objeto da classe ACE_SOCK_Stream do framework ACE para envio e recebimento de dados.

\section{Classe JAWS_Asynch_IO}

A classe JAWS_Asynch_Io implementa a interface definida pela sua super-classe JAWS_IO definindo uma classe de I/O com processamento assíncrono. Para atingir tal finalidade ela utiliza um objeto da classe ACE_Asynch_Read_Stream.

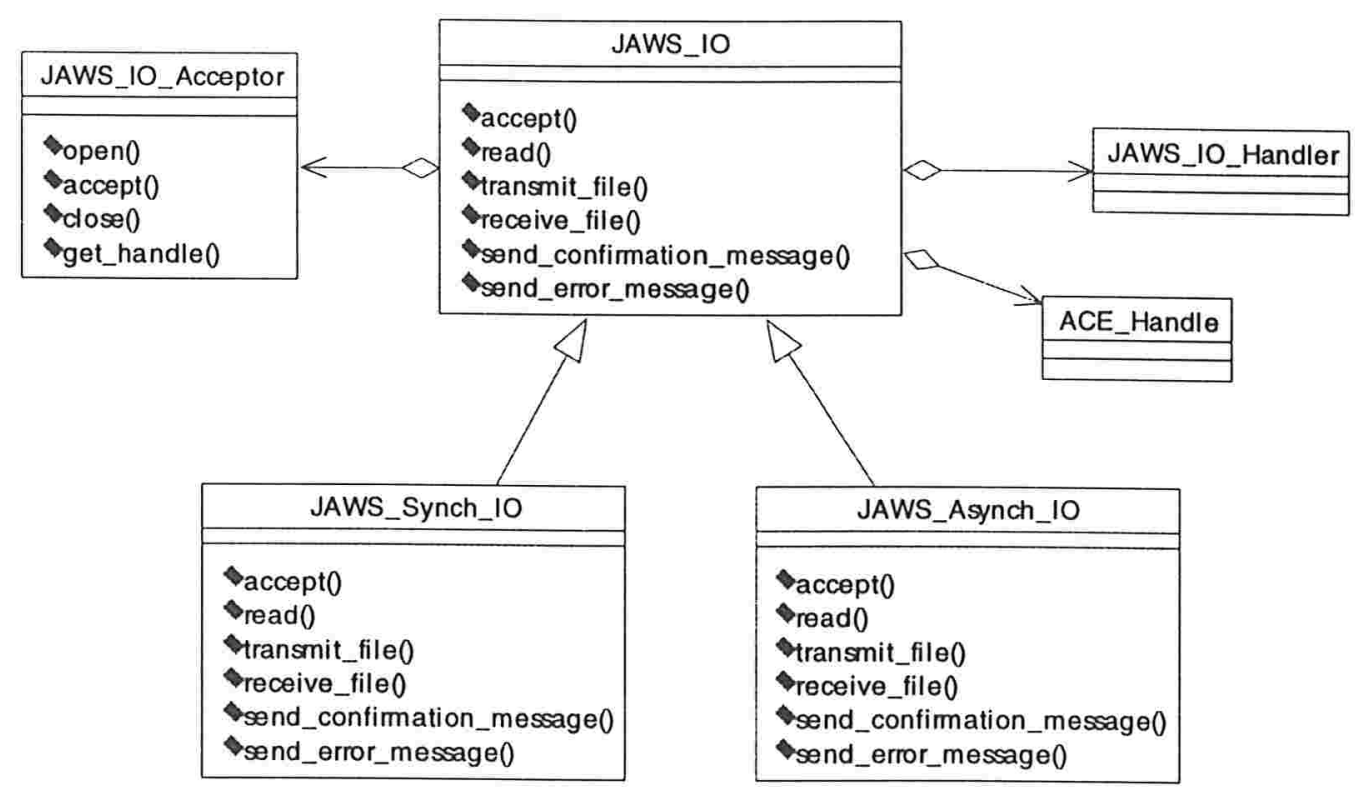

Figura 4.5: Diagrama de classes da Estratégia de I/O do JAWS

\section{Classe JAWS_IO_Handler}

A principal função das classes JAWS_IO_Handler e JAWS_Asynch_IO_Handler é definir um conjunto de métodos que especificam operações a serem executadas, após a realização de alguma atividade de forma correta ou com a ocorrência de algum erro, por um objeto do tipo JAWS_IO (ex: accept_complete, accept_error). Para cada pedido HTTP recebido pelo servidor é criado um novo objeto do tipo JAWS_IO_Handler ou JAWS_Asynch_IO_Handler, que será usado pelas tarefas do protocolo durante o processamento do pedido. 


\subsubsection{Classe JAwS_Data_Block}

A classe JAWS_Data_Block define uma unidade de comunicação entre as tarefas do protocolo do JAWS. Cada tarefa recebe um objeto JAWS_Data_Block durante a chamada do seu método put(). A classe JAWS_Data_Block herda da classe ACE_Message_Block, o que permite receber blocos de mensagens usando os recursos do framework ACE. Ela mantém ainda referências para a política do servidor (objeto JAWS_Dispatch_Policy), para um objeto JAWS_IO_Handler criado para manipulação de um pedido HTTP e para um objeto JAWS_Pipeline_Handler (a próxima tarefa a ser executada).

\subsubsection{Comportamento do JAWS}

\subsubsection{Inicialização do Servidor}

Os métodos init () e open() da classe JAWS_Server são usados para inicializar o servidor. Nas figuras 4.6 e 4.7 são apresentados diagramas de seqüência UML dos métodos init() e open(), respectivamente.

O método init() se responsabiliza pela configuração das estratégias de concorrência, I/O e aceitação de conexões, e também pela ativação das estratégias de concorrência (através da invocação do método make() de uma instância do tipo JAWS_Concurrency_Base) e de aceitação de conexões (através da invocação do método open() de uma instância do tipo JAWS_IO_Acceptor). As estratégias do JAWS são configuradas e ativadas pelo método init () com base em atributos de instância da classe JAWS_Server, inicializados pelo seu método parse_args ().

O método open () da classe JAWS_Server se responsabiliza pela configuração do protocolo do servidor e pela criação e inicialização de um objeto JAWS_Data_Block. Outra atribuição do método open() é o repasse deste objeto JAWS_Data_Block para a estratégia de concorrência através da invocação do seu método put(). Este objeto JAWS_Data_Block será utilizado pelos threads da estratégia de concorrência responsáveis pelo processamento dos pedidos de clientes. 


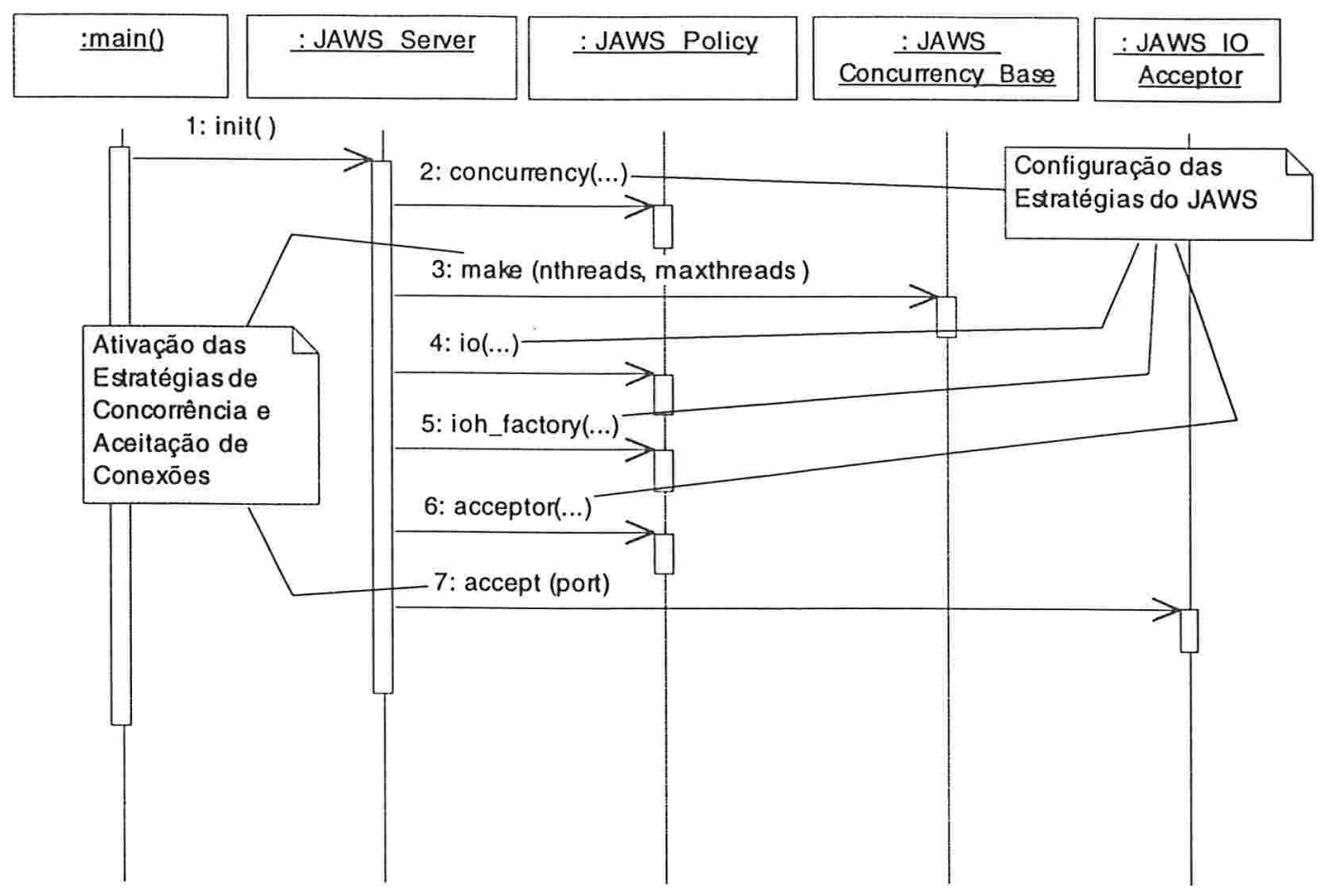

Figura 4.6: Diagrama de Seqüência do método init () da classe JAws_Server

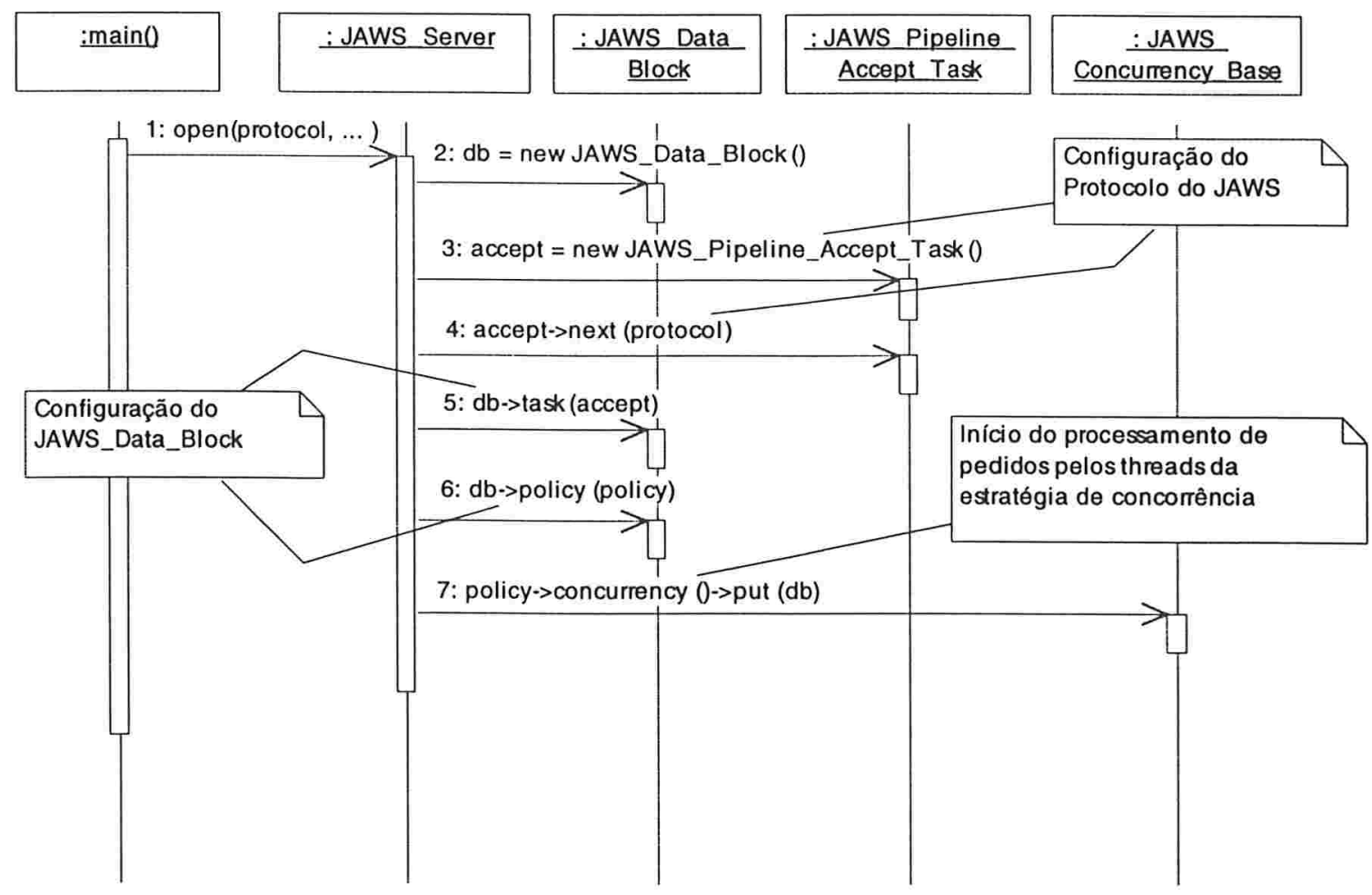

Figura 4.7: Diagrama de Seqüência do método open( ) da classe JAws_Server 


\subsubsection{Estratégia de Concorrência}

O método svc () da classe JAWS_Concurrency_Base define o comportamento de execução dos threads de processamento de pedidos de cliente da estratégia de concorrência. Cada thread executa em sua própria linha de controle o método svc (). A função deste método é recuperar, através do método singleton_mb(), o objeto JAWS_Data_Block passado para a estratégia de concorrência pelo método put(), e repassar uma cópia de tal objeto para o método svc_loop() da própria classe JAWS_Concurrency_Base.

O método svc_loop () da classe JAWS_Concurrency_Base chama repetidamente o método svc_hook() desta mesma classe. O método svc_loop() é herdado pela classe JAWS_Thread_Pool_Task (subclasse de JAWS_Concurrency_Base) e reimplementado pela classe JAWS_Thread_Per_Task (também subclasse de JAWS_Concurrency_Base) para chamar uma única vez o método svc_hook().

Finalmente, o método svc_hook() da classe JAWS_Concurrency_Base implementa o serviço propriamente dito do servidor Web JAWS. Ele executa uma a uma as tarefas definidas para o seu protocolo (subclasses de JAWS_Pipeline_Handler) através da invocação de seus métodos put ().

Nas figuras 4.8, 4.9 e 4.10 são apresentados diagramas de seqüência dos métodos svc (), svc_loop () e svc_hook () da classe JAWS_Concurrency_Base.

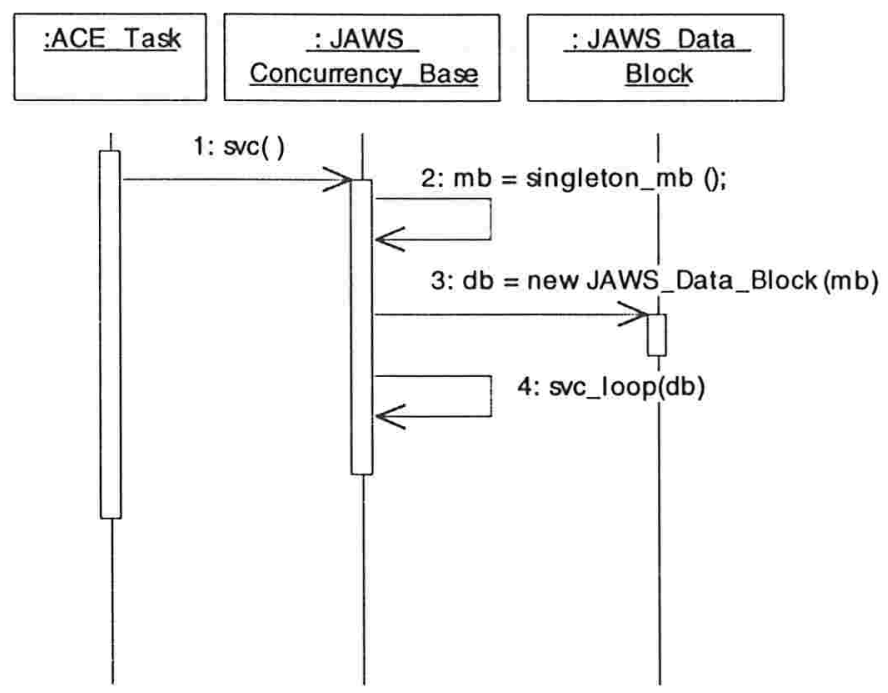

Figura 4.8: Diagrama de Seqüência do método svc () da classe JAwS_Concurrency_Base 


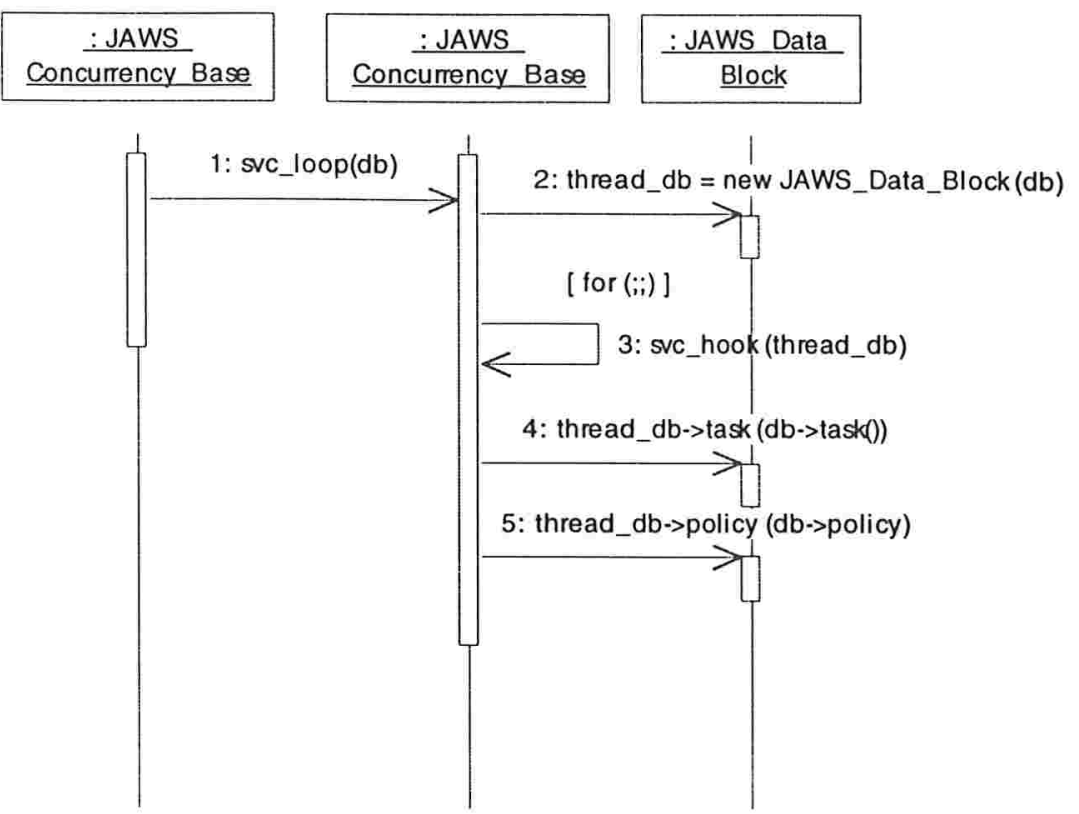

Figura 4.9: Diagrama de Sequiência do método svc_loop() da classe JAWS_Concurrency_Base

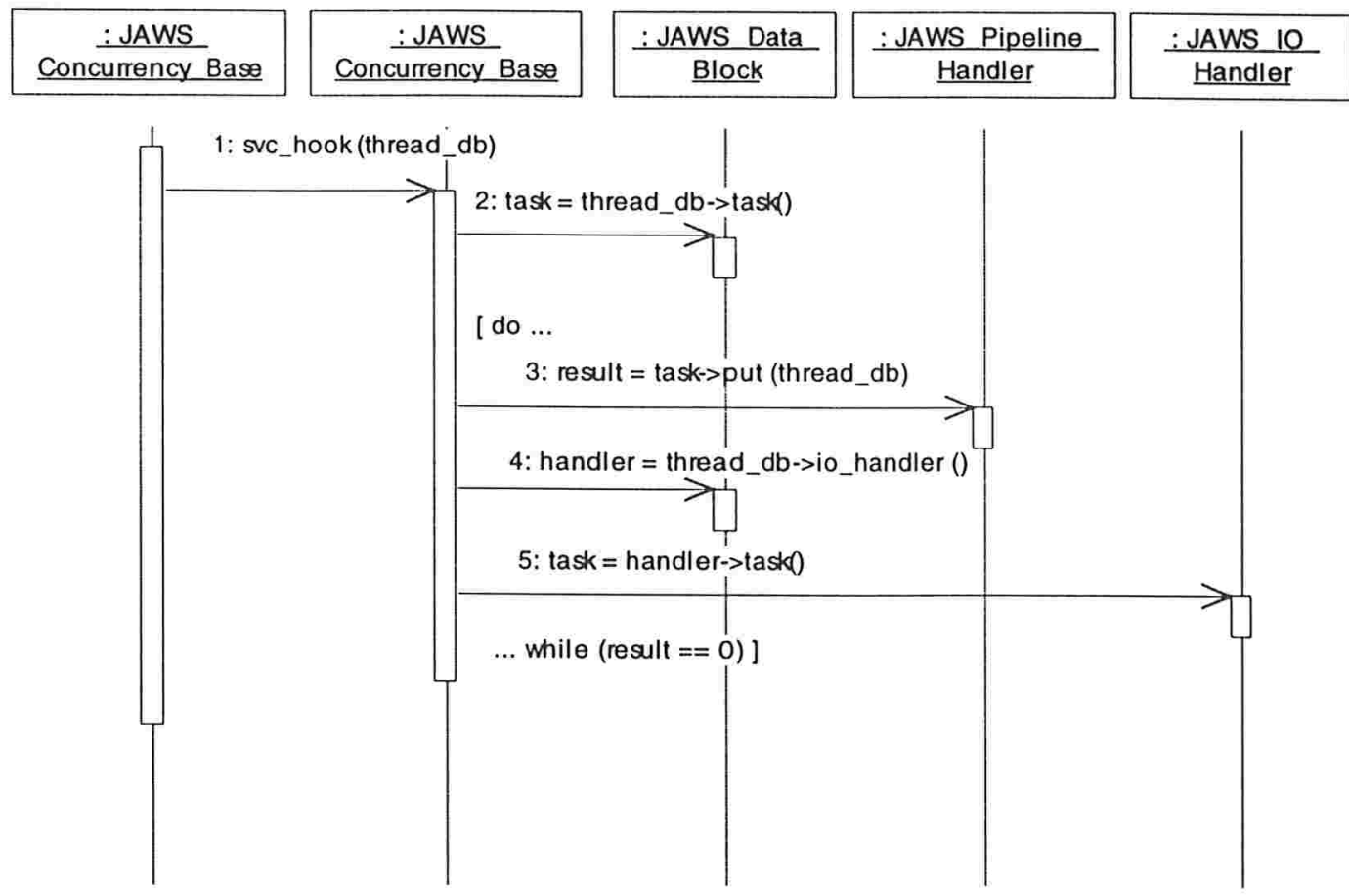

Figura 4.10: Diagrama de Seqüência do método svc_hook() da classe JAWS_Concurrency_Base 


\subsubsection{Protocolo do JAWS}

O protocolo do JAWS é implementado por subclasses da classe JAWS_Pipeline_Handler que definem uma implementação para o método handle_put() herdado. Na seção 4.1.1.5 foi descrito o comportamento de execução do método handle_put(), o qual envolve: (1) a recuperação da política definida para o servidor a partir do JAWS_Data_Block passado como parâmetro para tal método; (2) o processamento da tarefa em si que, em geral, envolve a invocação de algum dos métodos implementados pela classe JAWS_Io; e (3) a configuração do resultado do processamento (variável result) do método handle_put ().

Nos diagramas de seqüência das figuras 4.11 e 4.12 são apresentados os comportamentos dos métodos put () e handle_put () de uma das tarefas do protocolo do JAWS, a classe JAWS_Pipeline_Accept_Task. Esta classe é a única que reimplementa o método put () da sua super-classe JAWS_Pipeline_Handler. O método put () definido pela classe JAWS_Pipeline_Accept_Task, além de invocar o seu próprio método handle_put (), cria inicialmente um objeto do tipo JAWS_IO_Handler que será usado no processamento do pedido do cliente. As demais subclasses de JAWS_Pipeline_Handler utilizam a sua implementação do método put () que simplesmente chama os respectivos métodos handle_put () que elas definem.

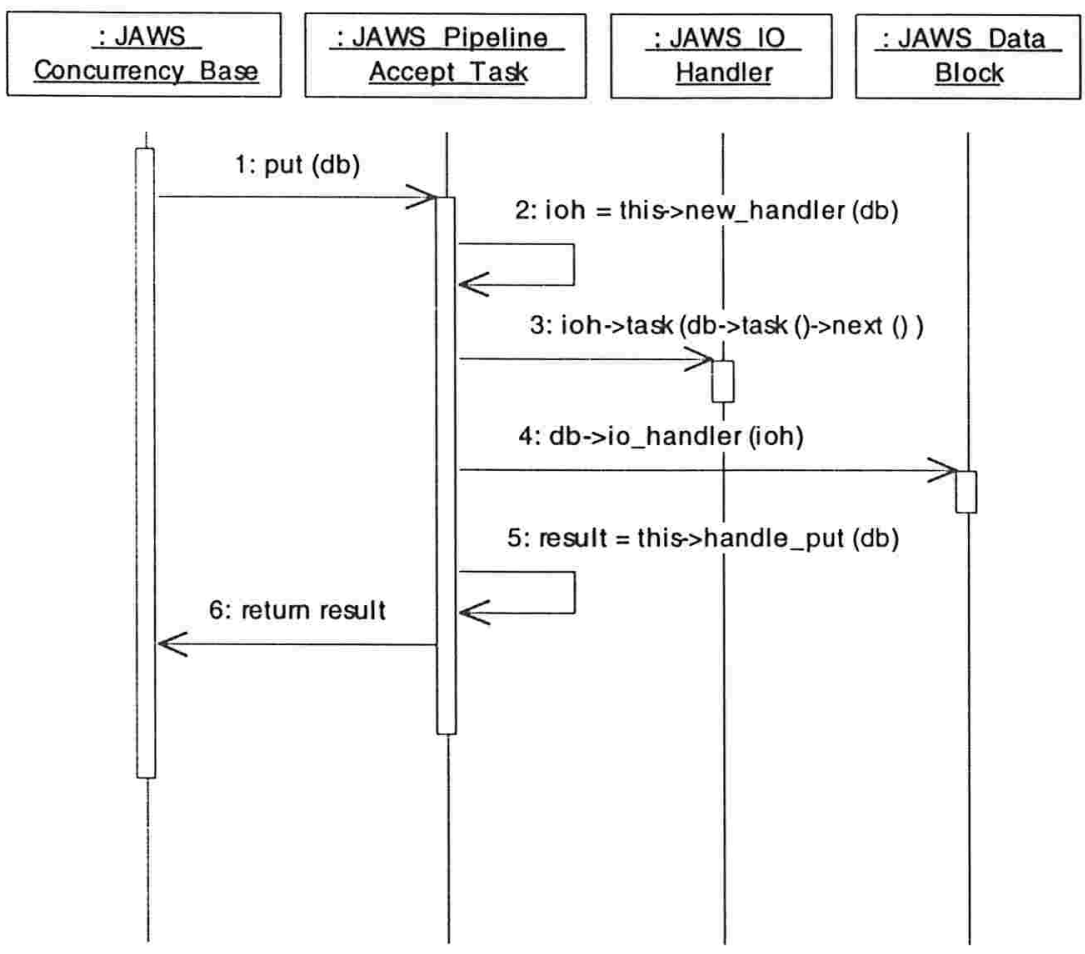

Figura 4.11: Diagrama de Sequiência do método put () da classe JAWS_Pipeline_Acccept_Task 


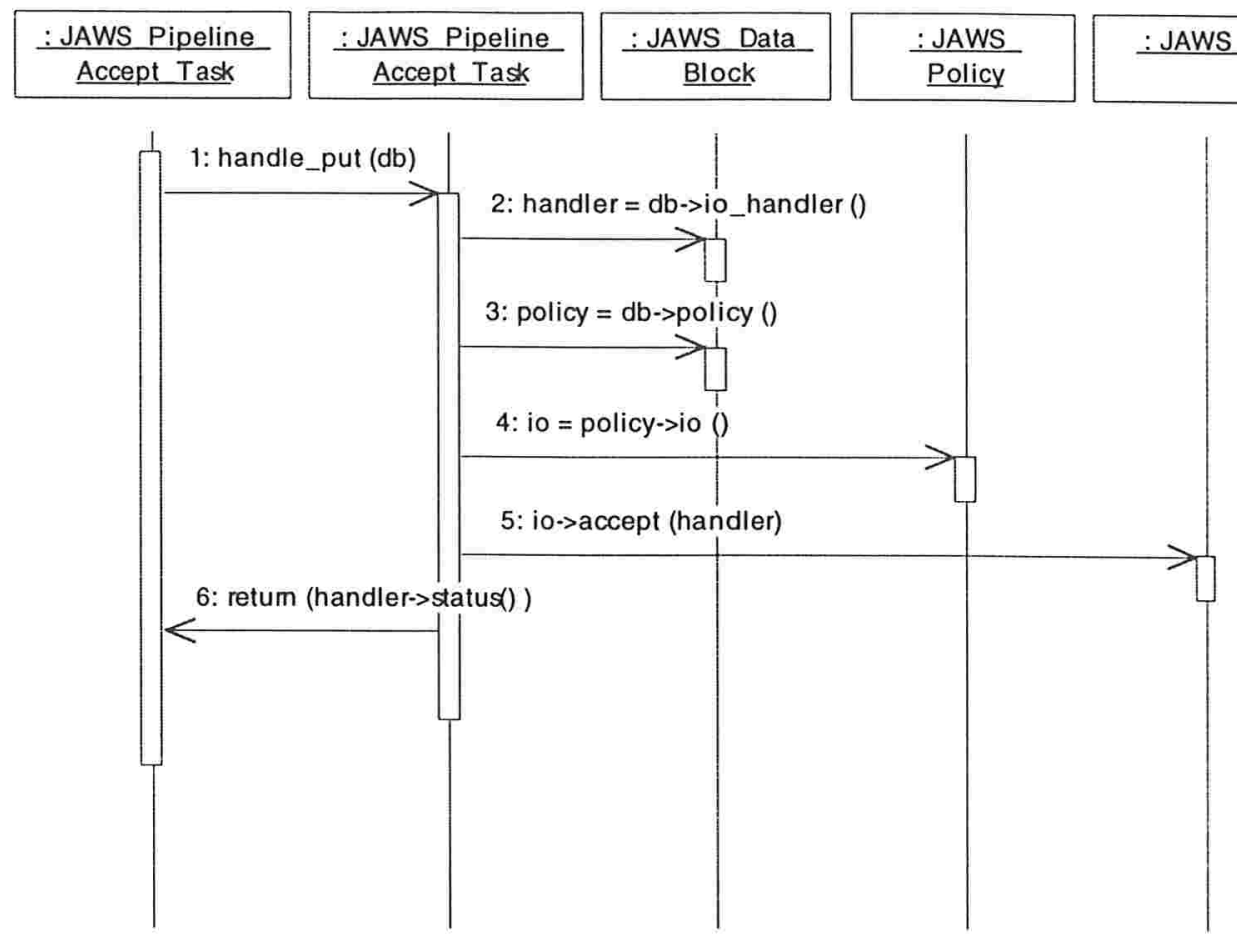

Figura 4.12: Diagrama de Seqüência do método handle_put () da classe JAWS_Pipeline_Acccept_Task.

\subsubsection{Entrelaçamento de Interesses}

A análise da estrutura e comportamento do projeto do JAWS demonstrou o entrelaçamento de código relacionado aos seguintes interesses:

- configuração e ativação das estratégias - as diferentes estratégias presentes no JAWS são configuradas e ativadas inicialmente nos métodos init () e open() da classe JAWS_Server. Embora o código relacionado a tal interesse esteja bem localizado dentro destes métodos, há um claro entrelaçamento do código de configuração e ativação das diferentes estratégias. Tal entrelaçamento pode dificultar o entendimento e posteriores adaptações no comportamento de tal método a medida que novas estratégias são criadas ou estratégias existentes são modificadas ou removidas do sistema. Além disso, a reconfiguração dinâmica e ativação de uma determinada estratégia poderia ser feita em diferentes pontos ao longo do código do JAWS, o que torna o código relacionado ao atendimento de tal interesse distribuído por entre diversos métodos de classes do sistema, possivelmente aumentando o entrelaçamento de código com outros interesses;

- definição do protocolo e processamento concorrente - estes interesses são ambos atendidos pela classe JAWS_Concurrency_Base. Isto dificulta o entendimento da "porção" do projeto do sistema relacionado a cada um dos interesses, assim como impede a possível reutilização do protocolo com um mecanismo de suporte a processamento concorrente diferente do fornecido pelo framework ACE, que é o utilizado pelo JAWS; 
- tratamento de $\mathrm{I} / \mathrm{O}$ assíncrono - o tratamento deste interesse no JAWS envolve não apenas a configuração de uma estratégia de I/O assíncrona (classe JAWS_Asynch_Io), mas também a invocação do método wait_for_completion() de um objeto do tipo JAWS_Waiter, cuja responsabilidade é lidar com eventos de $\mathrm{V} / \mathrm{O}$ assíncronos que estão sendo tratados em um dado instante. Como a invocação deste método no JAWS é feita dentro do método svc_hook() da instância que define a sua estratégia de concorrência, isto acaba trazendo entrelaçamento de código relacionado aos interesses de tratamento de I/O assíncrono, processamento concorrente e de definição do protocolo do JAWS. Outros aspectos de configuração do objeto JAWS_Waiter estão também emaranhados ao longo do código de diversos métodos da classe JAWS_Concurrency_Base e suas subclasses;

- ativação de threads e manipulação de I/O - a classe JAWS_Thread_Per_Task define a estratégia de concorrência do JAWS que cria uma nova thread para cada pedido HTTP a ser manipulado pelo servidor. Cada nova thread é criada através da invocação do método activate_hook () da classe JAWS_Thread_Per_Task. Durante análise do código do JAWS foi observado que o método activate_hook() é chamado dentro do método accept_complete() da classe JAWS_IO_Handler. Isto demonstra entrelaçamento de código relacionado aos interesses de ativação de threads da estratégia de concorrência Thread-per-Request e manipulação de $\mathrm{I} / \mathrm{O}$;

- desativação da estratégia de aceitação de conexões e finalização dos threads da estratégia de concorrência - o JAWS cria uma instância da classe JAWS_Reaper, cuja função é esperar o término da execução de todas as threads da estratégia de concorrência para executar operações de finalização do servidor. A única operação de finalização definida pela classe JAWS_Reaper, no seu método svc (), é a desativação da estratégia de aceitação definida para o JAWS através de uma chamada ao método close() de um objeto do tipo JAWS_IO_Acceptor.

A identificação destes entrelaçamentos de código relacionados a diferentes interesses do projeto do JAWS foi de fundamental importância para o processo de reconstrução do seu projeto utilizando a técnica de programação orientada a aspectos, nos indicando partes específicas de classes do sistema que poderiam ser projetadas utilizando a abstração de aspectos. Na figura 4.13 são explicitados os pontos de entrelaçamento na estrutura de classes do JAWS. 


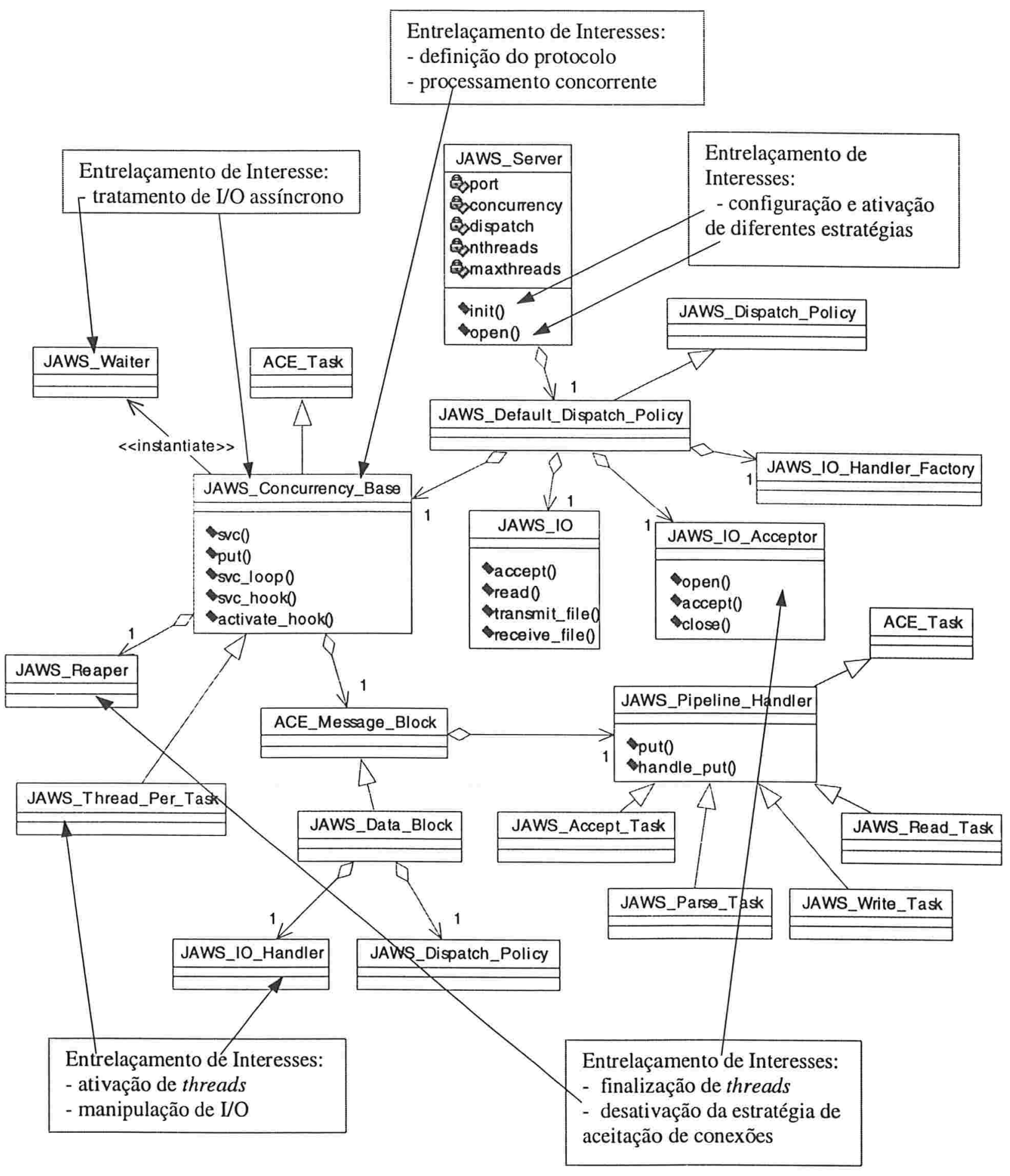

Figura 4.13: Diag. de Classes parcial do JAWS indicando entrelaçamentos de interesses 


\subsection{Reengenharia do Projeto do JAWS com Programação Orientada a Aspectos}

Nas subseções seguintes descrevemos o método empregado e modelos resultantes da reconstrução do JAWS utilizando a abordagem de AspectJ da técnica de programação orientada a aspectos.

O JAWS foi implementado utilizando a linguagem $\mathrm{C}++$ e AspectJ é utilizada para construir programas orientados a aspectos em Java. O uso destas duas diferentes tecnologias não trouxe problemas para o nosso estudo porque estavámos interessados em investigar apenas questões relacionadas ao projeto do JAWS, e Java e C++ são linguagens orientadas a objetos muito similares neste aspecto. Assim, o código-fonte parcial dos componentes funcionais e aspectos do JAWS apresentado nas subseções seguintes são representados em Java e AspectJ, respectivamente.

\subsubsection{Componentes Básicos do JAWS}

Na fase inicial de modelagem do JAWS com programação orientada a aspectos, nos detivemos em determinar a funcionalidade básica que um servidor de comunicação, tal como o JAWS, deve implementar. Este tipo de raciocínio foi útil para tentarmos separar os componentes funcionais básicos de um servidor de comunicação dos aspectos que os afetam.

Identificamos as seguintes atividades funcionais básicas por parte de um servidor de comunicação: (1) atividade de espera por conexões de clientes em uma porta específica da rede; (2) atividade de recepção de pedidos de clientes e encaminhamento dos mesmos para processamento; (3) atividade de processamento do pedido do cliente, que pode eventualmente ser customizada de acordo com as características do pedido; e (4) atividade de retorno de um arquivo ou erro para o cliente do pedido processado.

Cada uma destas atividades funcionais básicas possui no JAWS um componente/classe responsável por seu processamento. Os componentes funcionais do JAWS que definem estas atividades funcionais são as tarefas do seu protocolo (subclasses de JAWS_Pipeline_Handler, descritas na subseção 4.1.1.5) em colaboração com a estratégia de I/O definida para o JAWS (apresentada na subseção 4.1.1.6). Decidimos manter tais componentes no novo projeto do JAWS com programação orientada a aspectos. Houve, entretanto, a necessidade de criação de um componente que agregasse tais componentes e realizasse o gerenciamento da execução destas atividades funcionais. Foi então criada a classe JAWS_Requestmanager, cuja função principal é definir o serviço a ser oferecido pelo JAWS, integrando os componentes responsáveis pelo processamento do seu protocolo. No projeto original do JAWS, a função desempenhada pelo JAWS_RequestManager, é atendida pelo método JAWS_ConcurrencyBase : : svc_hook () . A figura 4.14 apresenta um diagrama de classes com o JAWS_Requestmanager e os componentes funcionais que ele agrega. 


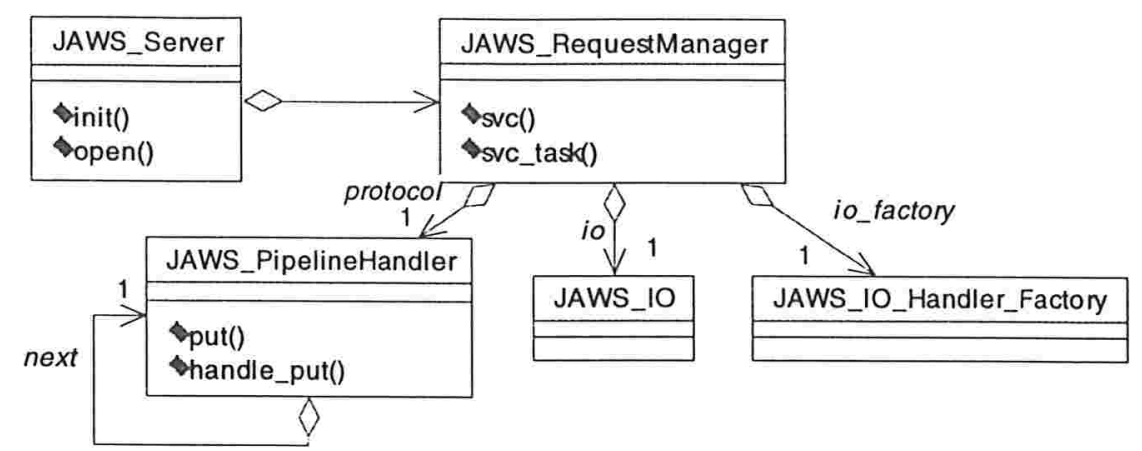

Figura 4.14: Diagrama de Classe do JAWS_RequestManager

Abaixo apresentamos código fonte parcial das classes JAWS_Server e JAWS_RequestManager.

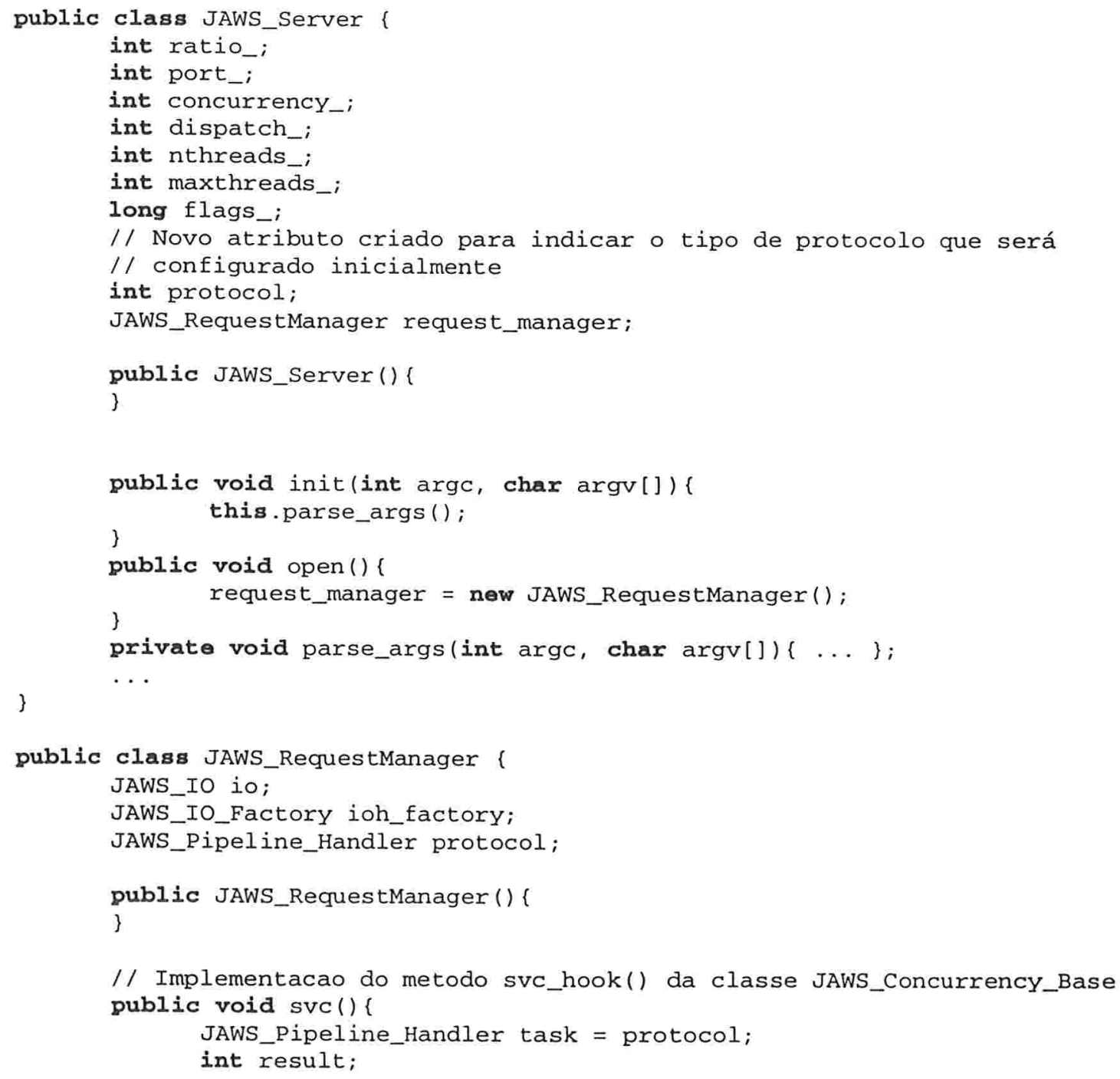




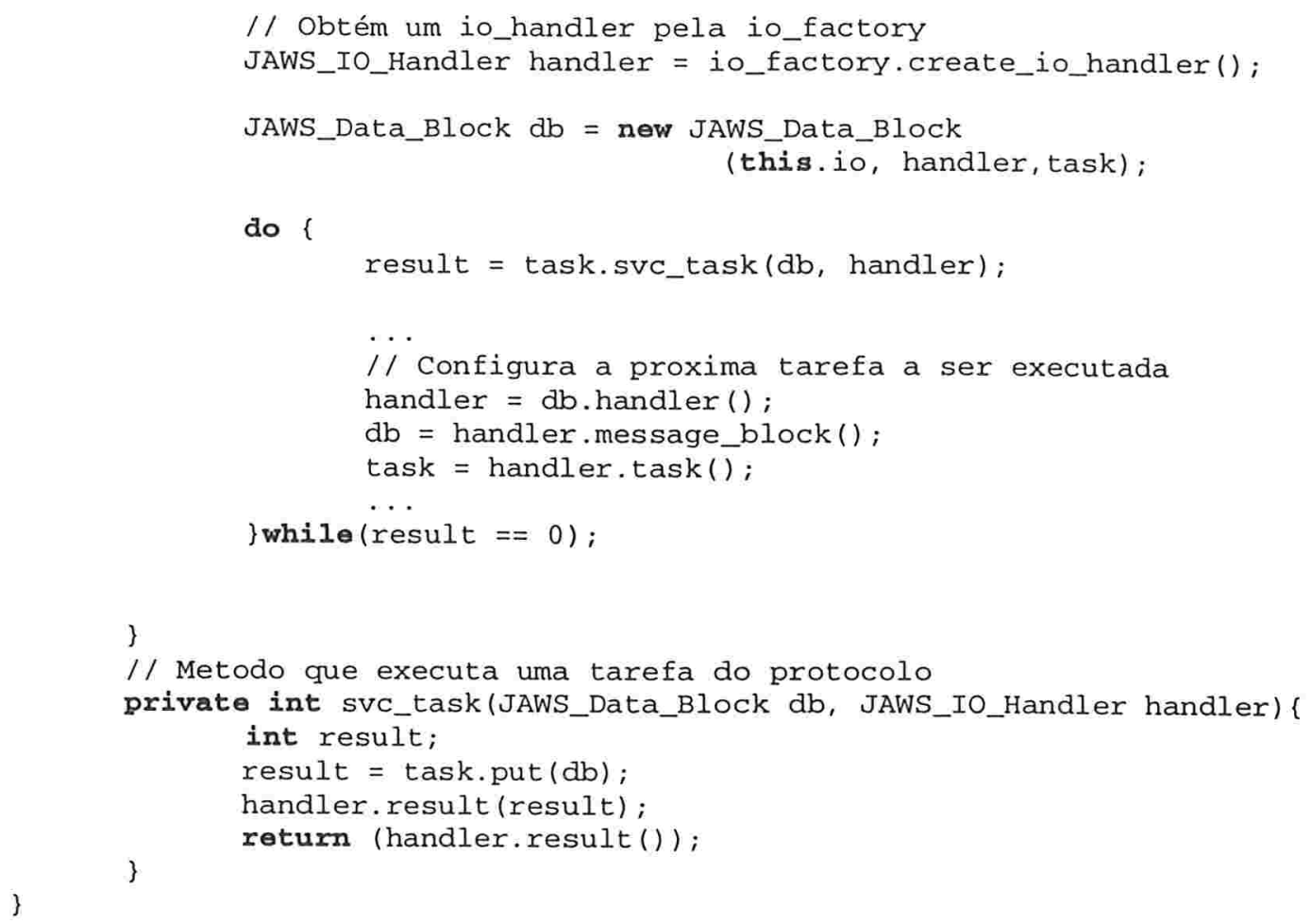

\subsubsection{Aspectos no JAWS}

O passo seguinte da reconstrução do JAWS com programação orientada a aspectos foi identificar possíveis aspectos que poderiam afetar o componente JAWS_Requestmanager e os demais componentes funcionais que ele agrega, apresentados na subseção anterior. O entendimento da estrutura e comportamento do JAWS, e a compreensão de aspectos capturados em outros sistemas [KM99, LL99, LK97, Lop97, KL99] foi bastante útil para concluir este passo.

Os seguintes aspectos foram identificados:

(a) estratégia de concorrência - os pedidos de clientes poderiam ser processados de forma concorrente por diferentes threads ou processos, objetivando melhorar o desempenho e tempo de resposta do próprio servidor;

(b) estratégia de aceitação de conexões - responsável por definir um componente Acceptor [Sch97b] para receber pedidos de clientes em uma determinada porta da rede;

(c) configuração da estratégia de I/O - para manipulação de dados que chegam ao servidor ou que são enviados por ele é importante definir uma configuração para a estratégia de tratamento de $\mathrm{I} / \mathrm{O}$;

(d) configuração do protocolo - para determinados tipos de pedidos para um servidor de comunicação há a necessidade de se construir protocolos customizados;

(e) monitoramento do ambiente de execução e carga do sistema - é fundamental definir elementos no JAWS que sejam responsáveis pela supervisão do seu ambiente de execução e carga, a fim de que esta atividade permita a adaptação dinâmica de suas diferentes estratégias; 
(f) tratamento de falhas e exceções poderia ser endereçado separadamente por aspectos para facilitar a manutenção de tais códigos e permitir que sejam reutilizados na construção de novos servidores de comunicação;

(g) comunicação remota com outros servidores (de banco de dados ou de arquivos) - um aspecto poderia se responsabilizar por garantir a transparência nesta comunicação;

(h) serviço de logging - servidores Web, em geral, realizam o registro de suas atividades para fins de administração do sistema;

(i) rastreamento da execução do servidor pode ser útil para fins de depuração e administração do sistema, podendo ser utilizado em conjunto com o serviço de logging.

Embora todos os aspectos acima sejam relevantes, focamos na modelagem dos aspectos de (a) a (d), que já estavam expressos no projeto do JAWS, e também no aspecto (e), que tem uma relação direta com seus objetivos de adaptação dinâmica. Os aspectos de (f) a (i) não foram modelados no projeto do JAWS com programação orientada a aspectos e vêm sendo abordados em outros trabalhos [KM99, LL99, LK97, Lop97, KL99]. Nas subseções seguintes apresentamos a modelagem dos aspectos de (a) a (e).

\subsubsection{Estratégia de Concorrência}

A estratégia de concorrência do JAWS é implementada pela classe JAWS_Concurrency_Base e suas subclasses JAWS_Thread_Pool_Task e JAWS_Thread_Per_Task. Estas classes definem não apenas uma estratégia para gerência (criação, destruição e monitoramento) de threads, mas também se encarregam de definir o serviço a ser fornecido pelo JAWS, ou seja, de executar seqüencialmente as tarefas de seu protocolo.

No projeto da estratégia de concorrência com programação orientada a spectos, optamos por separá-la em um aspecto que afetasse diretamente o componente JAWS_RequestManager. Desta forma podemos garantir a separação de interesses, deixando a responsabilidade de implementação do serviço do JAWS sob encargo do JAWS_Requestmanager. A figura 4.15 apresenta um diagrama de classes e aspectos do novo projeto com programação orientada a aspectos da estratégia de concorrência. São indicados os aspectos e/ou classes responsáveis por determinados interesses.

O aspecto Concurrencypolicy define qual (ou quais) componente/classe será afetado pela estratégia de concorrência, qual estratégia será instanciada e quando ela será ativada. No caso específico do JAWS, este aspecto afetará o componente JAWS_Requestmanager, inicializando e ativando em seu construtor a estratégia de concorrência escolhida. Uma outra responsabilidade do aspecto concurrencyPolicy é instanciar o aspecto waiterstrategy e associá-lo dinamicamente ao JAWS_Requestmanager. $\mathrm{O}$ aspecto Waiterstrategy implementa $\mathrm{o}$ interesse de tratamento de $\mathrm{I} / \mathrm{O}$ assíncrono do JAWS, sendo instanciado pelo ConcurrencyPolicy apenas se a estratégia de I/O escolhida tenha sido a assíncrona. 


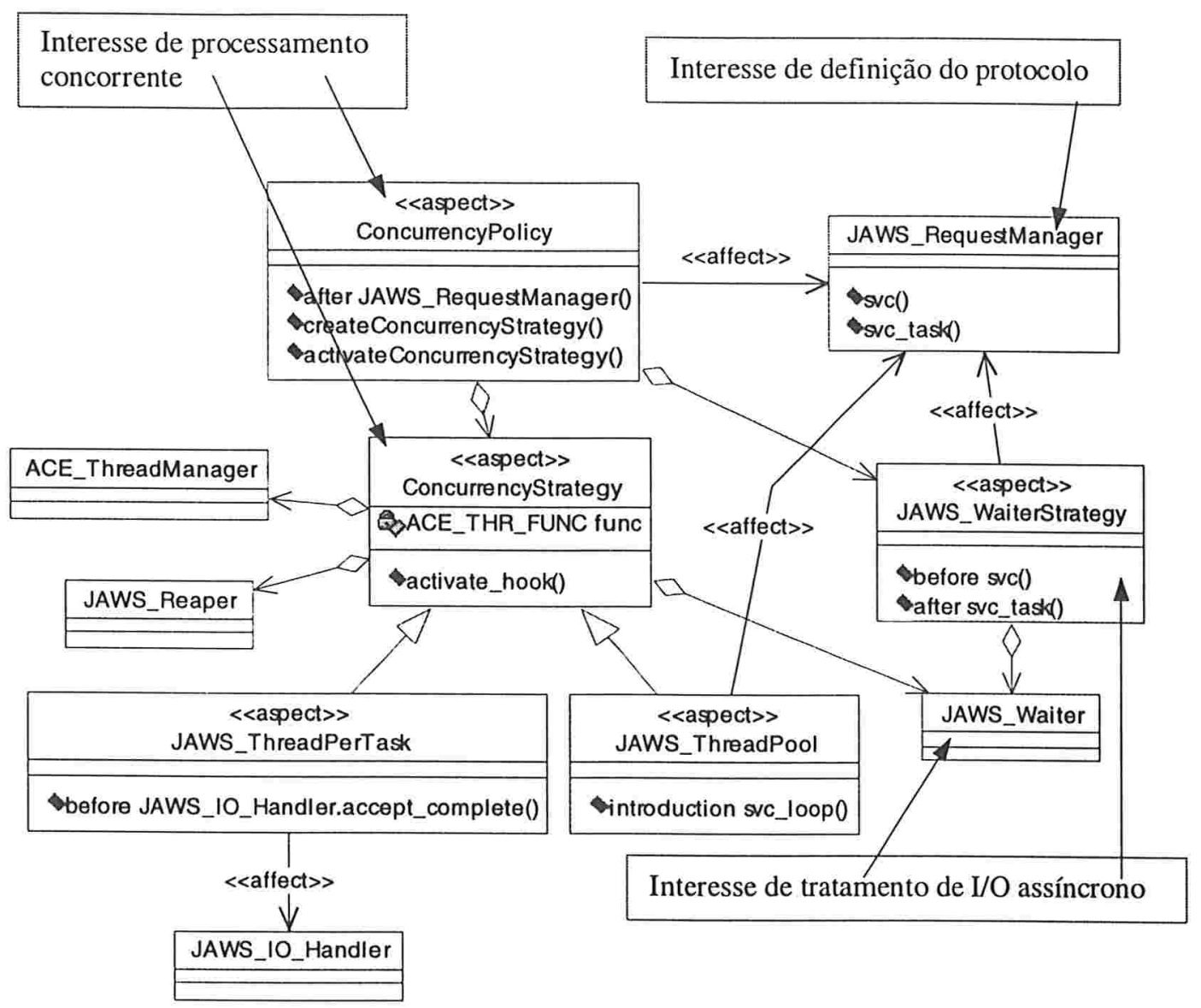

Figura 4.15: Diagrama de Classes e Aspectos da Estratégia de Concorrência

A estratégia de concorrência propriamente dita é implementada pelo aspecto Concurrencystrategy, cuja finalidade é definir uma interface padrão para uma estratégia concreta e manter atributos comuns para alguma estratégia de concorrência. No caso específico do JAWS, este aspecto agrega: (1) um objeto do tipo ACE_ThreadManager - responsável por fornecer os mecanismos para execução concorrente do protocolo HTTP do JAWS e gerenciamento de threads; (2) um objeto do tipo JAWS_Reaper - responsável por realizar operações após a finalização de todas as threads; e (3) um objeto do tipo JAWS_Waiter - responsável pelo tratamento de eventos assíncronos. Além disso, ele ainda declara o atributo func que representa o método que será executado concorrentemente pelas threads, e define a assinatura do método de ativação da estratégia de concorrência (activate_hook). Os sub-aspectos de Concurrencystrategy são responsáveis pela implementação da interface definida pelo seu super-aspecto e podem definir inclusões ou extensões de métodos em algumas classes. $O$ subaspecto JAWS_ThreadPerTask insere no final do método accept_complete() da classe JAWS_IO_Handler uma chamada para o método activate_hook(), para possibilitar a ativação de uma nova thread responsável pela manipulação de um novo pedido que chega ao servidor. Já o subaspecto 
JAWS_ThreadPool introduz o método svc_loop() no JAWS_RequestManager. Este método svc_loop() tem como função executar repetidamente o método svc() do JAWS_RequestManager, e é definido pelo subaspecto JAWS_ThreadPool como o método que será executado pelas threads criadas por ele.

A seguir apresentamos código-fonte do aspectos presentes na figura 4.15.

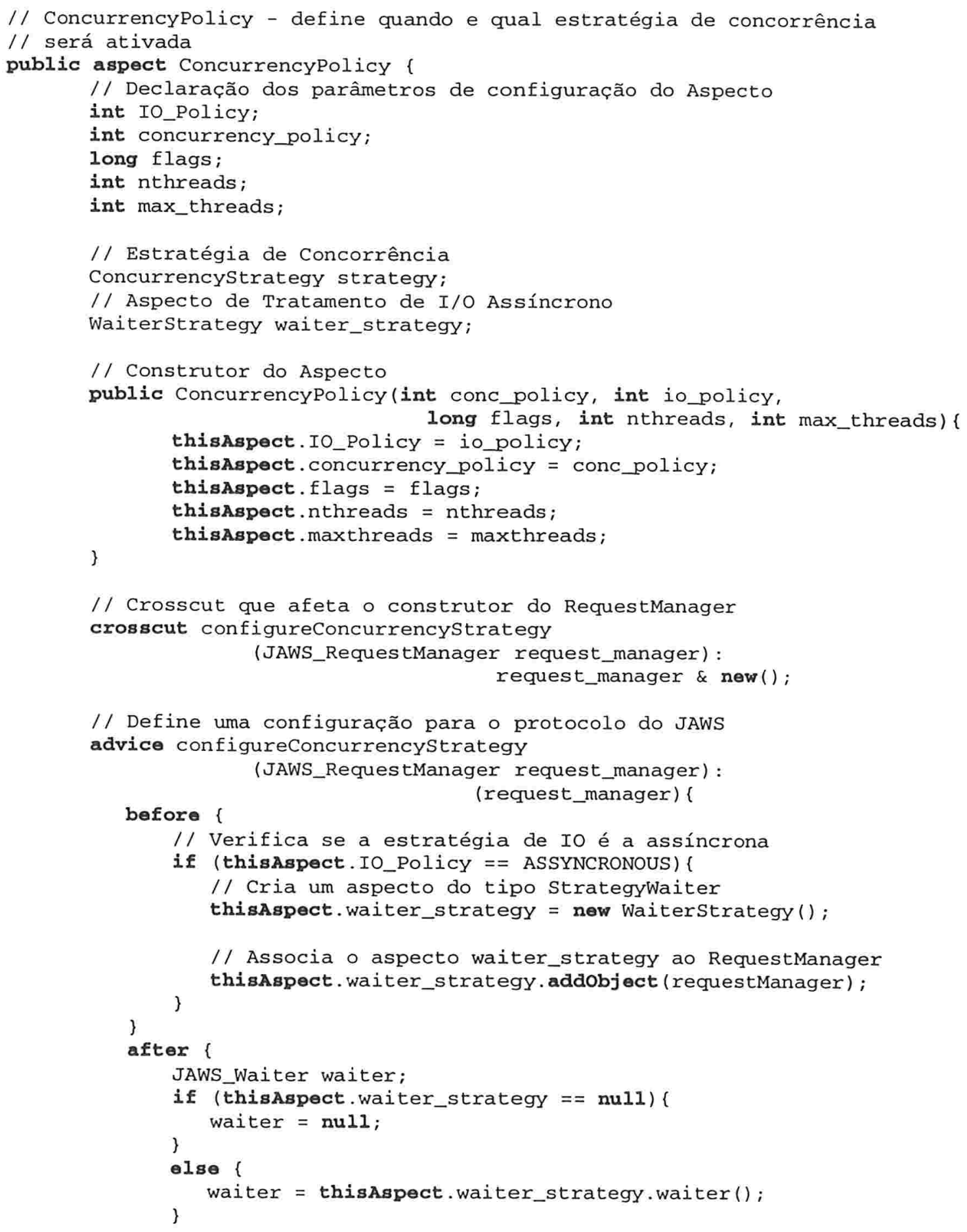




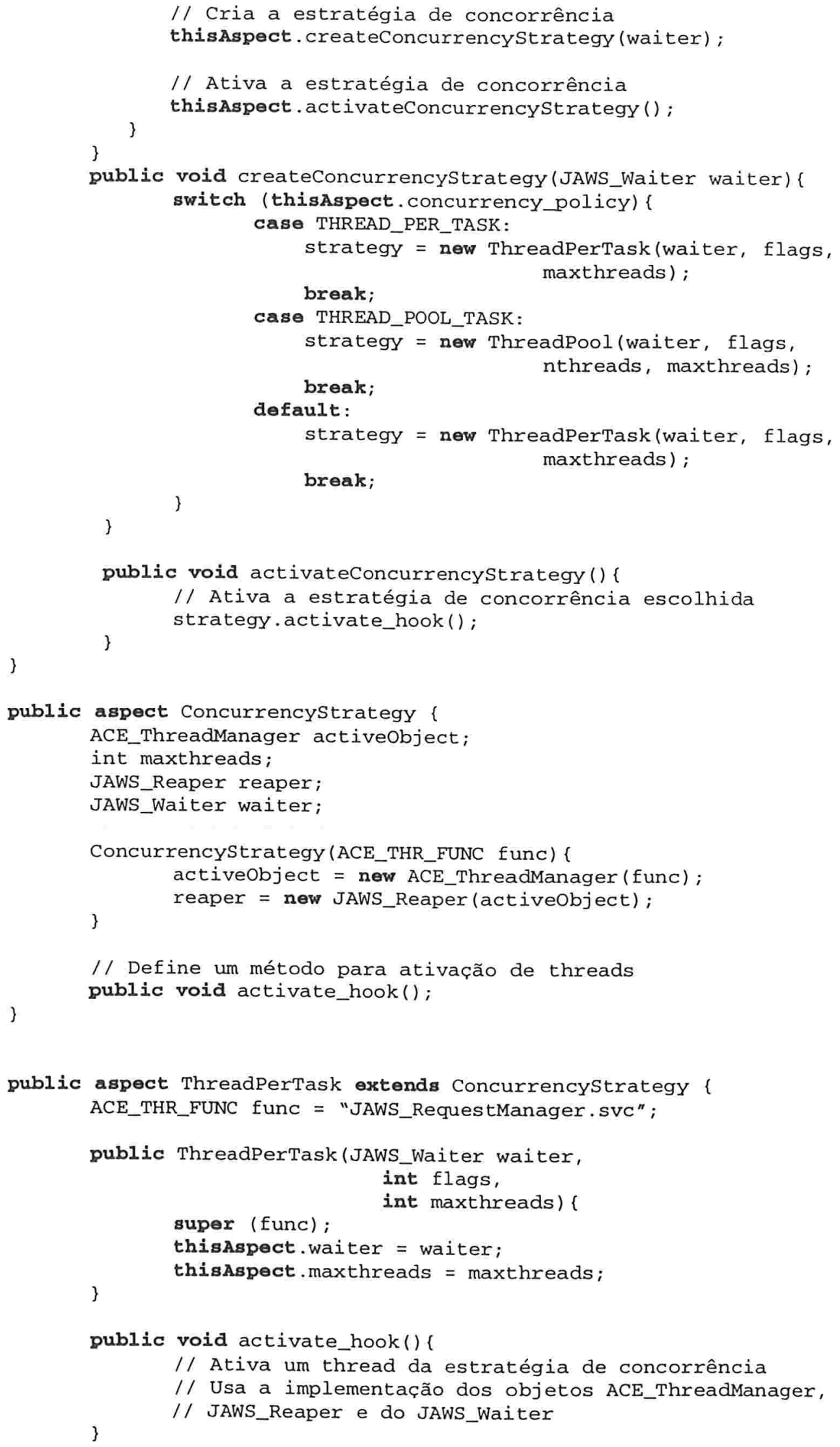




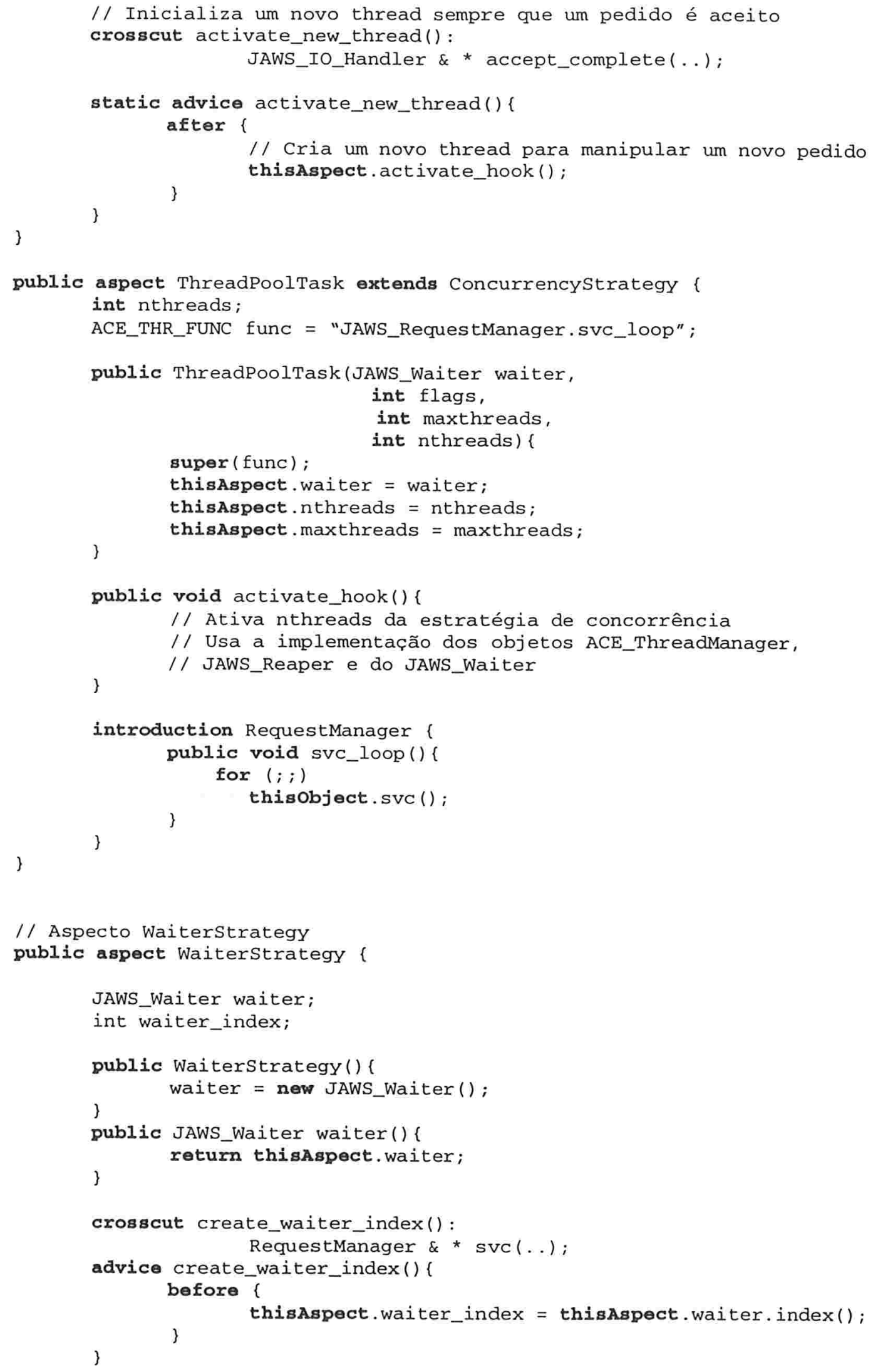




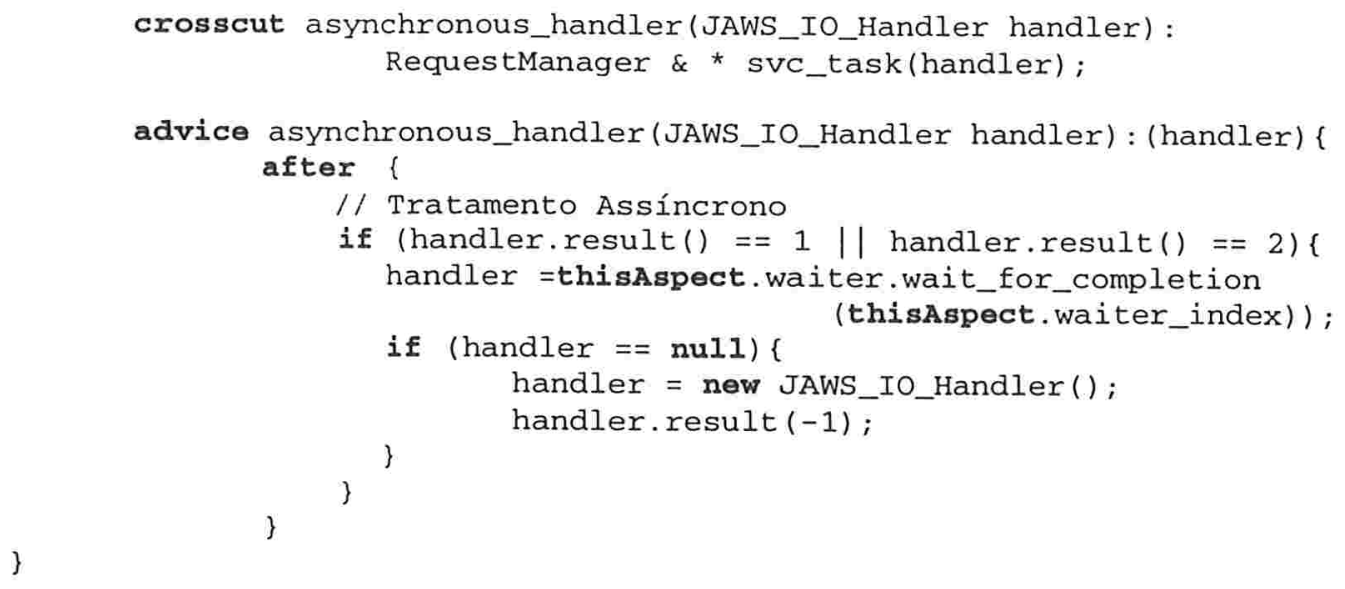

\subsubsection{Estratégias de Aceitação de Conexões e de I/O}

A estratégia de aceitação de conexões de um servidor de comunicação define que tipo de componente será utilizado para estabelecer conexões com seus clientes e quando este componente será criado, ativado e encerrado. No JAWS, este componente é implementado pela classe JAWS_IO_Acceptor e suas subclassses que encapsulam objetos Acceptors [Sch97b] do framework ACE.

A estratégia de I/O define uma política para tratamento dos dados que chegam e que são enviados por um servidor de comunicação. Ela é implementada no JAWS pela classe JAWS_IO - que define uma interface abstrata a ser implementada por estratégias concretas de I/O - e por suas subclasses JAWS_Synch_IO e JAWS_Asynch_IO - que representam as estratégias concretas de I/O síncrona e assíncrona, respectivamente.

No novo projeto do JAWS com programação orientada a aspectos, decidimos integrar as configurações das estratégias de aceitação de conexões e I/O dentro de um único aspecto, denominado IO_Acceptor_Policy_Configuration. Tal decisão foi tomada devido a constatação da forte ligação entre as estratégias, evidente no código do método init () da classe JAWS_Server. Neste método, observa-se que o tipo de Acceptor e componente de I/O configurados para o JAWS dependem ambos do valor da variável de instância dispatch da classe JAWS_Server. Em um novo projeto estas estratégias poderiam, entretanto, ser configuradas separadamente em aspectos distintos. Na figura 4.16 é apresentado o diagrama de aspectos e classes relacionado ao interesse de configuração destas estratégias.

O aspecto IO_Acceptor_Policy_Configuration possui, para as estratégias de aceitação de conexões e I/O, basicamente a mesma função que o concurrencyPolicy possui para a estratégia de concorrência, ou seja, ele define: (1) qual componente funcional será afetado pela estratégia de aceitação e de que forma; (2) que tipo de Acceptor será instanciado e quando ele será ativado; e (3) uma configuração inicial para a estratégia de I/O e para a classe JAWS_IO_Handler_Factory responsável por criar objetos JAWS_IO_Handler. O aspecto IO_Acceptor_Policy_Configuration definido 
acima afeta a implementação do método construtor do JAWS_RequestManager criando e ativando a estratégia de aceitação de conexões e definindo uma configuração para a estratégia de I/O do JAWS no final (after) deste construtor. Uma outra função do IO_Acceptor_Policy_Configuration é definir, através de uma construção static advice, uma chamada para o método close () da estratégia de aceitação de conexões no final do método svc () da classe JAWS_Reaper.

A estratégia de aceitação de conexões é representada pelo aspecto Acceptorstrategy, que define uma interface padrão para estratégias concretas de aceitação e mantém um atributo do tipo ACE_Acceptor. O aspecto AcceptorStrategy define ainda uma construção introduction que insere um aspecto do tipo AcceptorStrategy na classe JAWS_IO e o método set_acceptor() para atualização deste objeto. A inserção deste aspecto do tipo Acceptorstrategy na estratégia de I/O do JAWS permite que ela mantenha uma referência para a estratégia de aceitação de conexões.

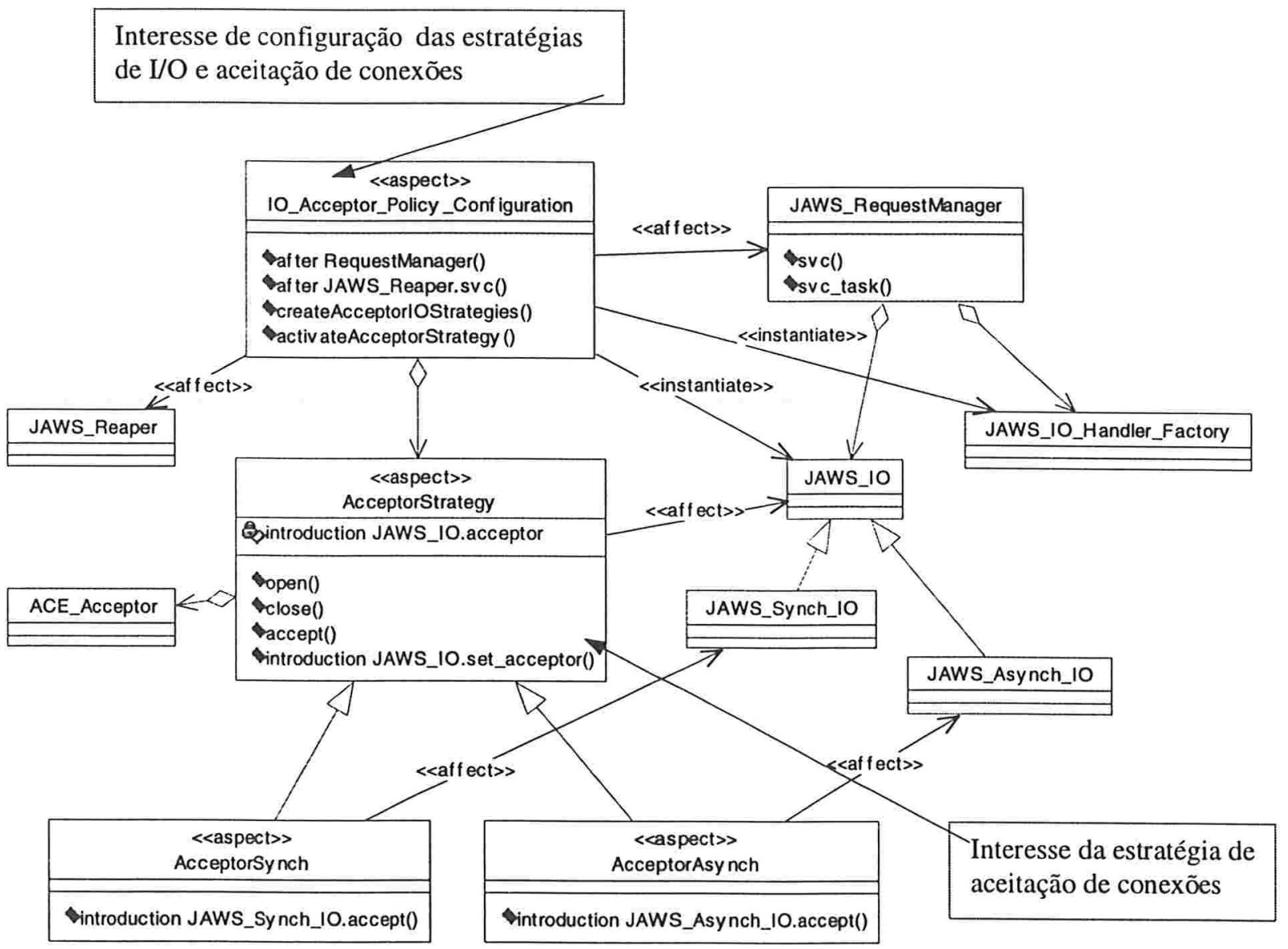

Figura 4.16: Diagrama de Classes e Aspectos da Estratégia de Aceitação de Conexões e I/O

Os subaspectos de Acceptorstrategy definem estratégias concretas de aceitação de conexões. As funções destes sub-aspectos são definir o tipo de objeto Acceptor do 
framework ACE que será utilizado; os atributos adicionais necessários para determinadas estratégias de aceitação; e inserções de métodos accept () (cláusulas introduction) que estendem subclasses de JAWS_Io com métodos para a aceitação de conexões baseado na estratégia escolhida.

Abaixo apresentamos código-fonte do aspectos da figura 4.16.

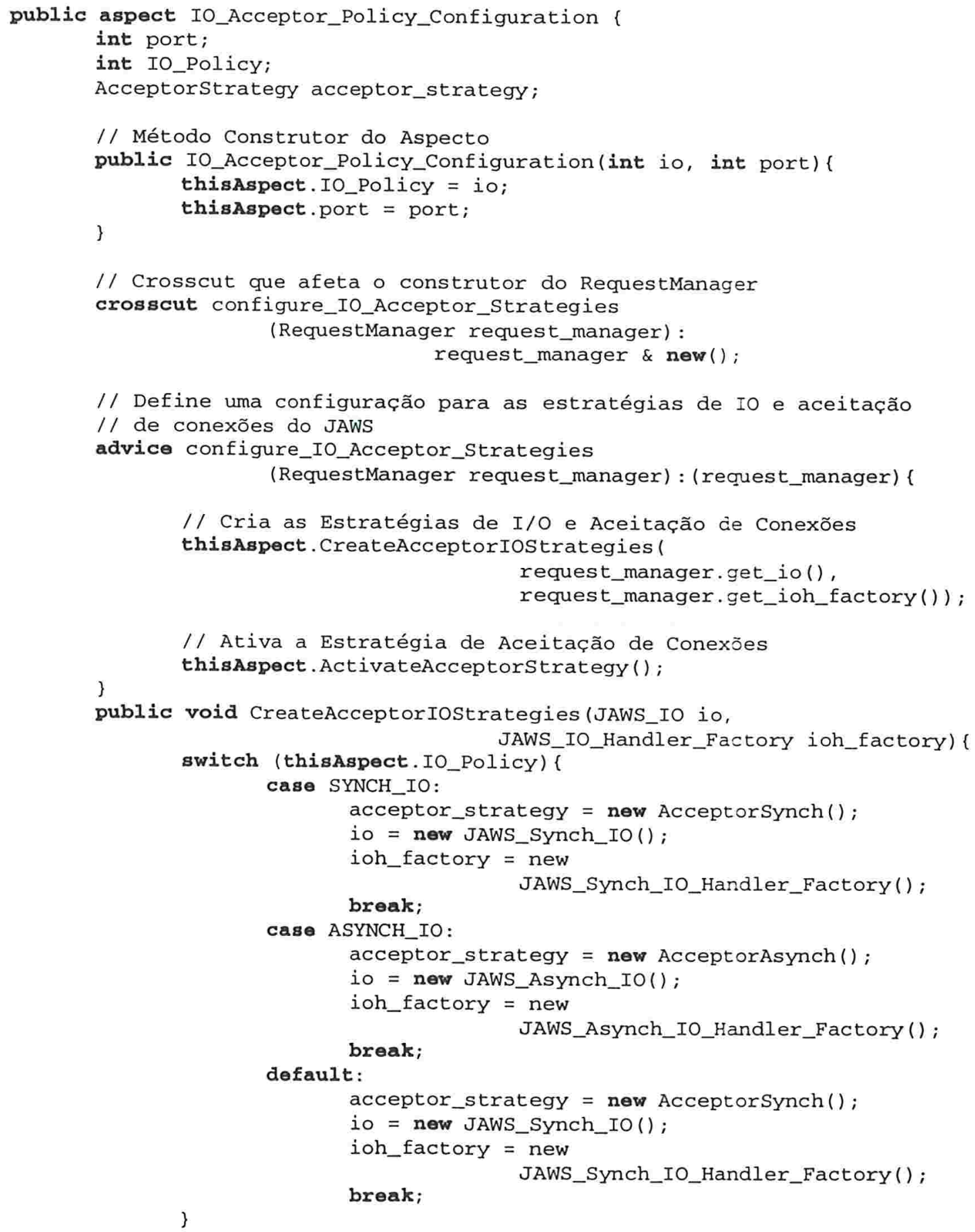




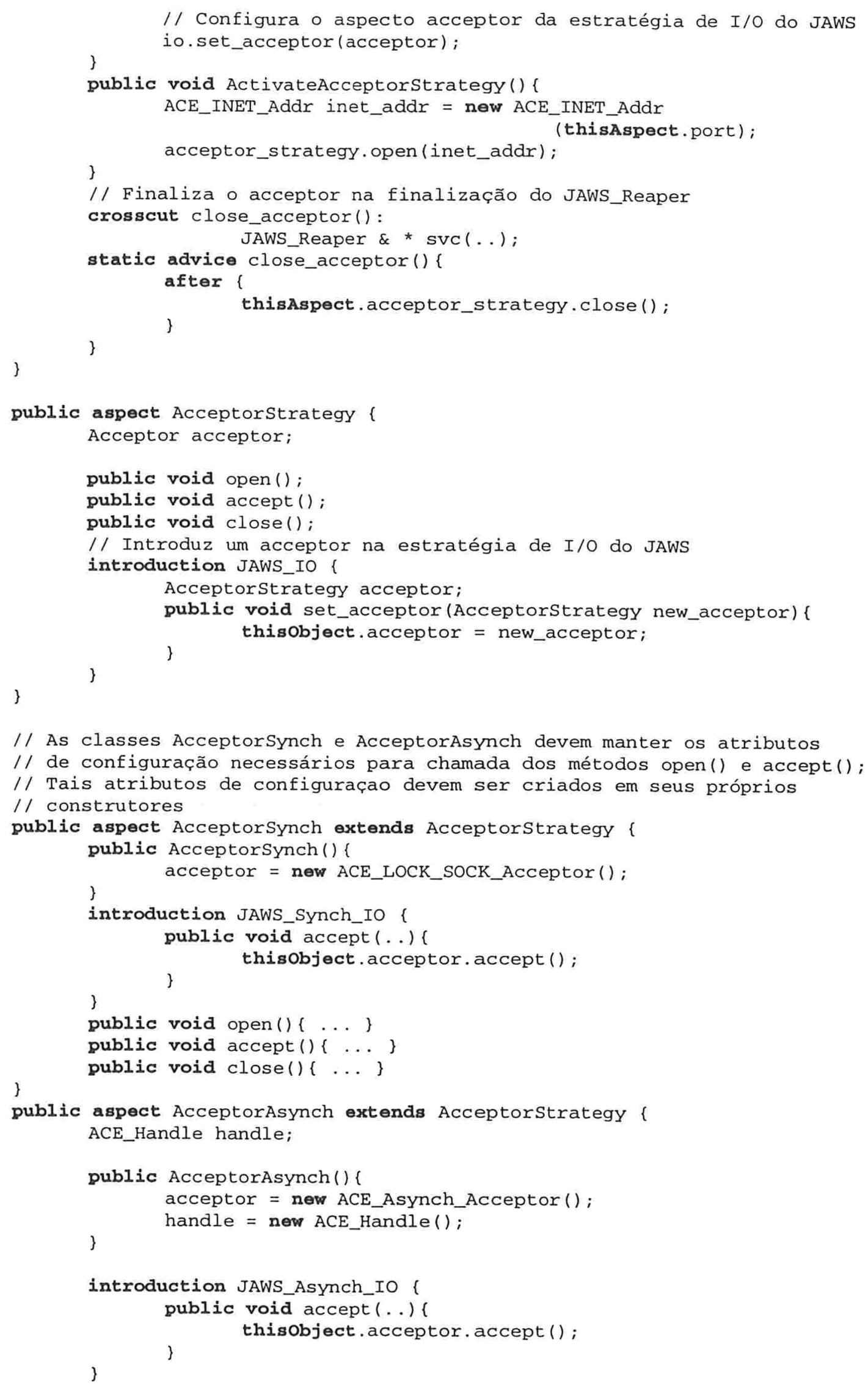




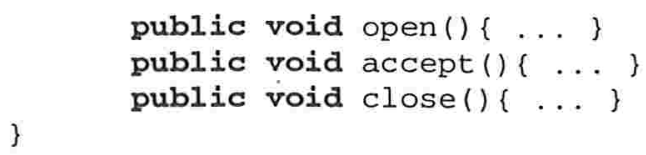

\subsubsection{Configuração e Extensão do Protocolo}

Um protocolo é visto como um conjunto de tarefas organizadas seqüencialmente, onde o resultado do processamento de uma delas serve como entrada para o processamento da subseqüente. O padrão Pipes and Filters [BMR+96] explicita bem este tipo de comportamento.

Para o protocolo do JAWS foram identificadas e descritas, na subseção 4.1.1.5, quatro tarefas básicas para a sua composição. Embora este conjunto de tarefas possa ser suficiente para processar a maioria dos pedidos HTTP de clientes Web, podem existir situações [HS99] onde a customização dinâmica do protocolo (através da inclusão, remoção, substituição e extensão de tarefas) torna-se necessária. Assim, no projeto do protocolo HTTP de um servidor Web, tal como o JAWS, é fundamental oferecer mecanismos que facilitem a sua configuração estática e dinâmica.

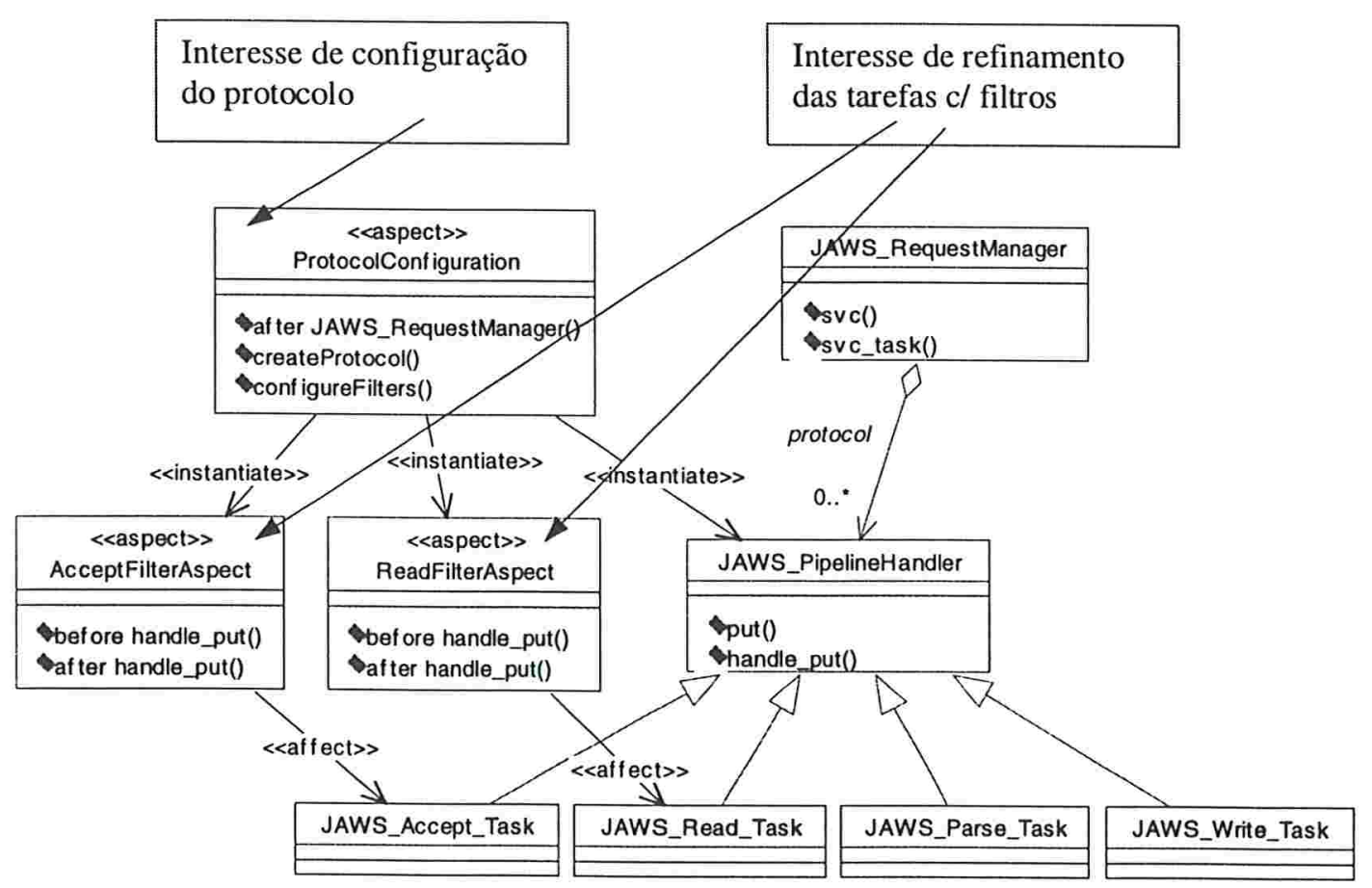

Figura 4.17: Diagrama de Classes e Aspectos da Configuração do Protocolo

Projetamos o protocolo do JAWS com programação orientada a aspectos considerando dois tipos de componentes na sua estrutura, sendo eles: (1) tarefas - que definem as atividades funcionais do protocolo e que já estavam definidas no projeto original do JAWS como subclasses de JAWS_Pipeline_Handler; e (2) filtros - que 
definem extensões para as tarefas e que são definidos no novo projeto como aspectos que podem ser anexados dinamicamente às tarefas do protocolo.

Foi então criado o aspecto Protocolconfiguration, responsável pelas configurações: estática - que consiste na inicialização e composição das tarefas e filtros - e dinâmica - que consiste na definição de métodos e cláusulas advice, responsáveis pela inclusão, remoção, substituição e refinamento de tarefas e filtros. Na figura 4.17 apresentamos o diagrama de classes e aspectos relacionado ao interesse de configuração estática e dinâmica do protocolo HTTP do JAWS.

Abaixo apresentamos código-fonte do aspectos da figura 4.17.

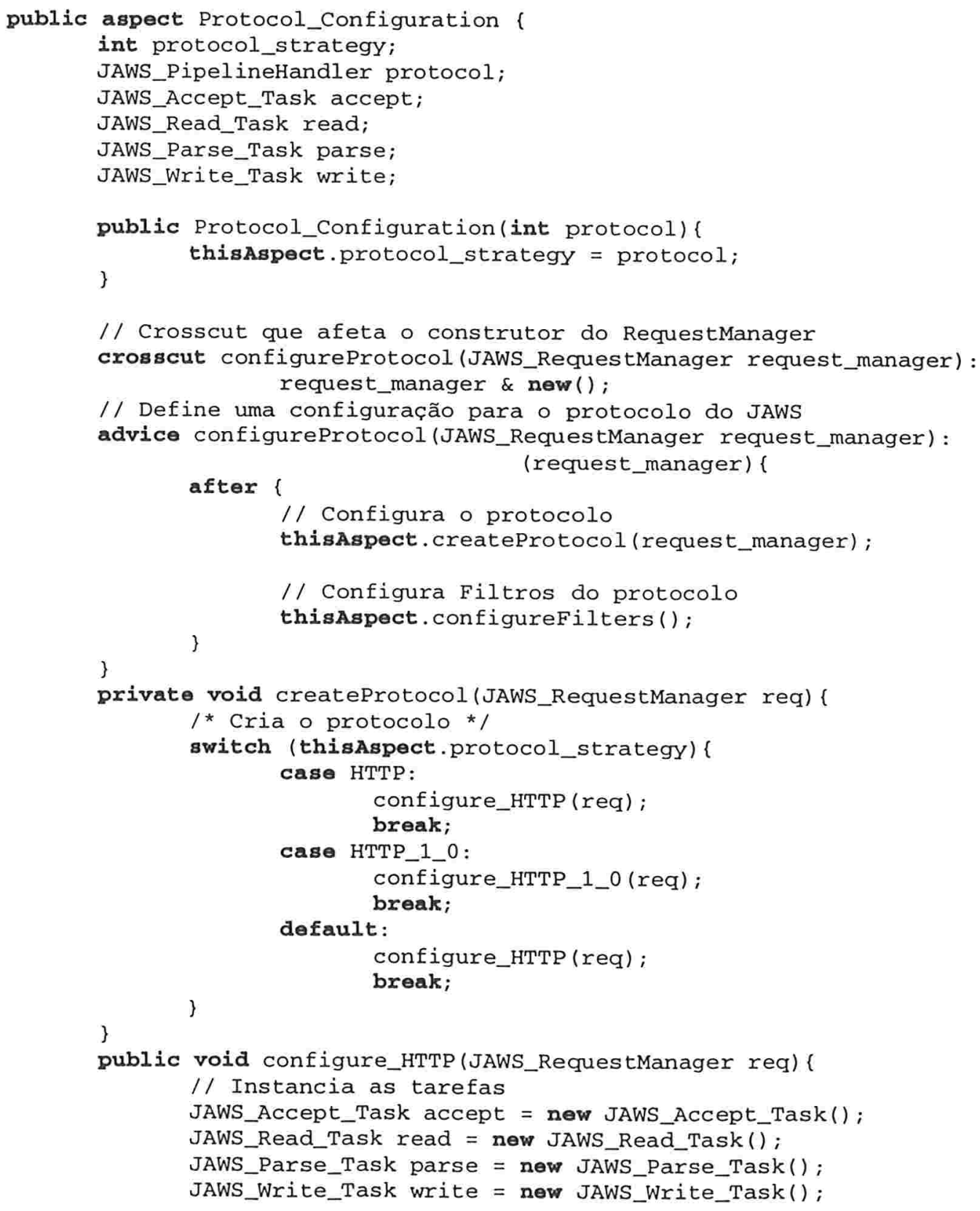




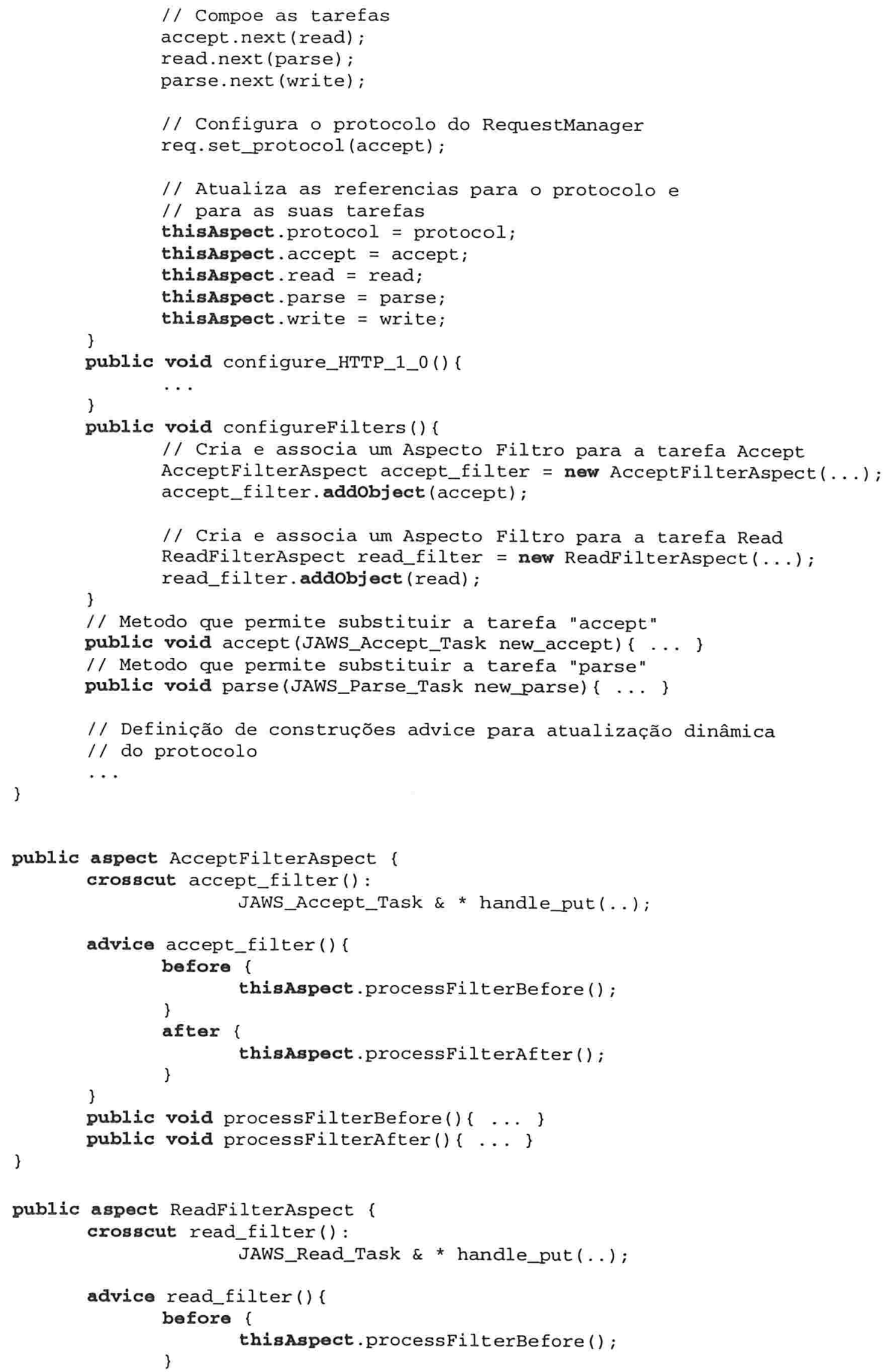




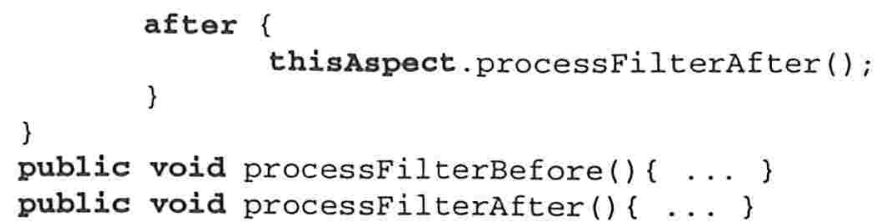

\subsubsection{Monitoramento e Reconfiguração do Siste ma}

O JAWS é um servidor Web para alto desempenho que permite adaptação de suas estratégias em relação a fatores estáticos (ambiente de hardware, plataforma de sistema operacional) e fatores dinâmicos (carga na máquina em que o servidor executa, número de pedidos simultâneos ao servidor, carga de trabalho do servidor, uso de memória dinâmica). Seu projeto atual suporta a configuração estática e dinâmica de suas estratégias de $\mathrm{I} / \mathrm{O}$, concorrência e aceitação de conexões, e de seu protocolo. Entretanto, não existem ainda em seu projeto componentes relacionados ao monitoramento do estado do seu ambiente de execução e carga no sistema, de forma a permitir que as adaptações de suas estratégias possam ser feitas dinamicamente de acordo com variações neste estado.

Na reconstrução do JAWS com programação orientada a aspectos, criamos o aspecto Monitoring, que afeta o componente JAWS_Io e trata do interesse de monitoramento do ambiente de execução e carga no sistema. Diagrama contendo tal aspecto é apresentado na figura 4.18.

Para realizar o monitoramento, o aspecto Monitoring mantém:

- o estado do ambiente de execução no qual o JAWS opera - com informações sobre a quantidade de processadores presentes, a presença ou não de suporte a threads $\mathrm{e}$ I/O assíncrono no sistema operacional. Tais informações devem ser configuradas na inicialização do servidor, de forma automática (através da leitura de variáveis/parâmetros do sistema operacional) ou manual (por um administrador do sistema), e são úteis para determinar as possíveis estratégias que o JAWS poderá instanciar, assim como para definir sua configuração inicial;

- o estado da carga no servidor - com informações sobre o número de conexões estabelecidas com clientes, a quantidade de pedidos atendidos em um determinado intervalo de tempo, e throughput (bytes transmitidos por segundo). Estas informações são atualizadas em pontos específicos do código do JAWS, os quais são definidos por cláusulas advice do aspecto Monitoring. A partir dos valores que estas informações da carga no servidor assumem elas podem ocasionar a reconfiguração dinâmica de alguma(s) das estratégias.

Os estados do ambiente de execução e da carga no servidor mantidos pelo aspecto Monitoring são repassados para o aspecto Configurator durante a inicialização e execução do JAWS. O aspecto Configurator é responsável pela definição de uma política para configurações estáticas e dinâmicas nas estratégias do JAWS, baseado nas variações dos estados mantidos pelo aspecto Monitoring. Para exercer sua função, o 
aspecto

ProtocolConfiguration, e os associa dinamicamente aos respectivos componentes funcionais que eles afetam, durante a inicialização do sistema. Baseado nas informações do estado da carga no servidor, o Configurator pode direcionar a reconfiguração dinâmica de uma ou mais estratégias do JAWS.

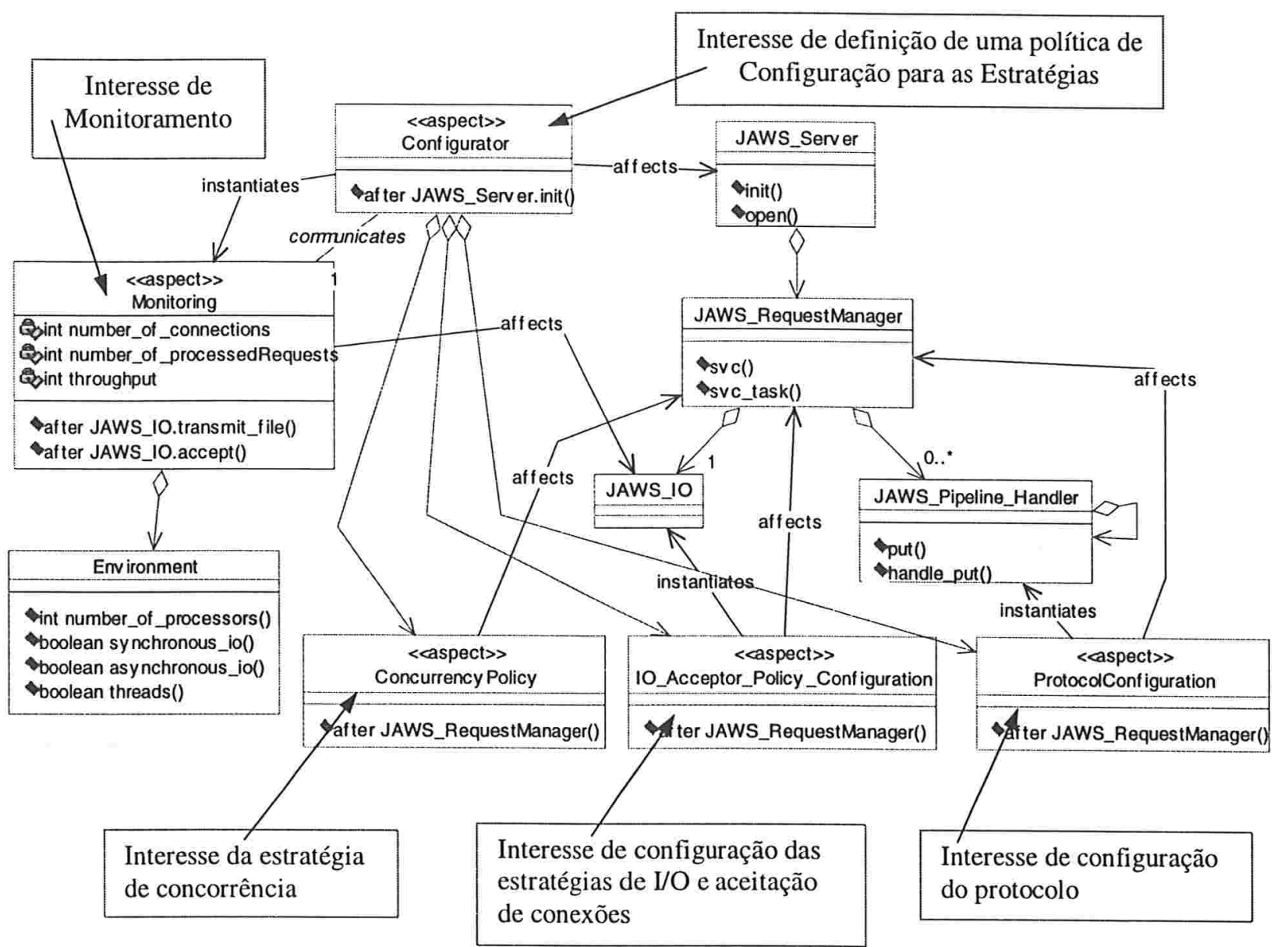

Figura 4.18: Diag. de classes/aspectos dos Interesses de Monitoramento e Configuração do Sistema

Abaixo apresentamos código-fonte dos aspectos Monitoring e Configurator. É também apresentado código-fonte do aspecto Createconfigurator que define uma construção advice estática que afeta a classe JAWS_Server e associa instâncias desta classe a um aspecto configurator.

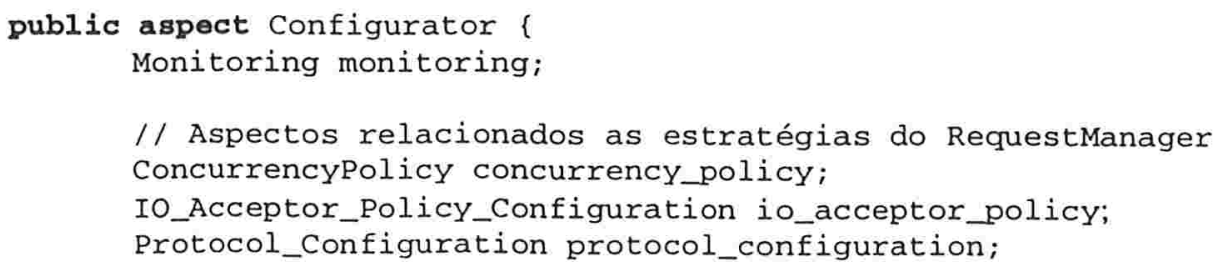




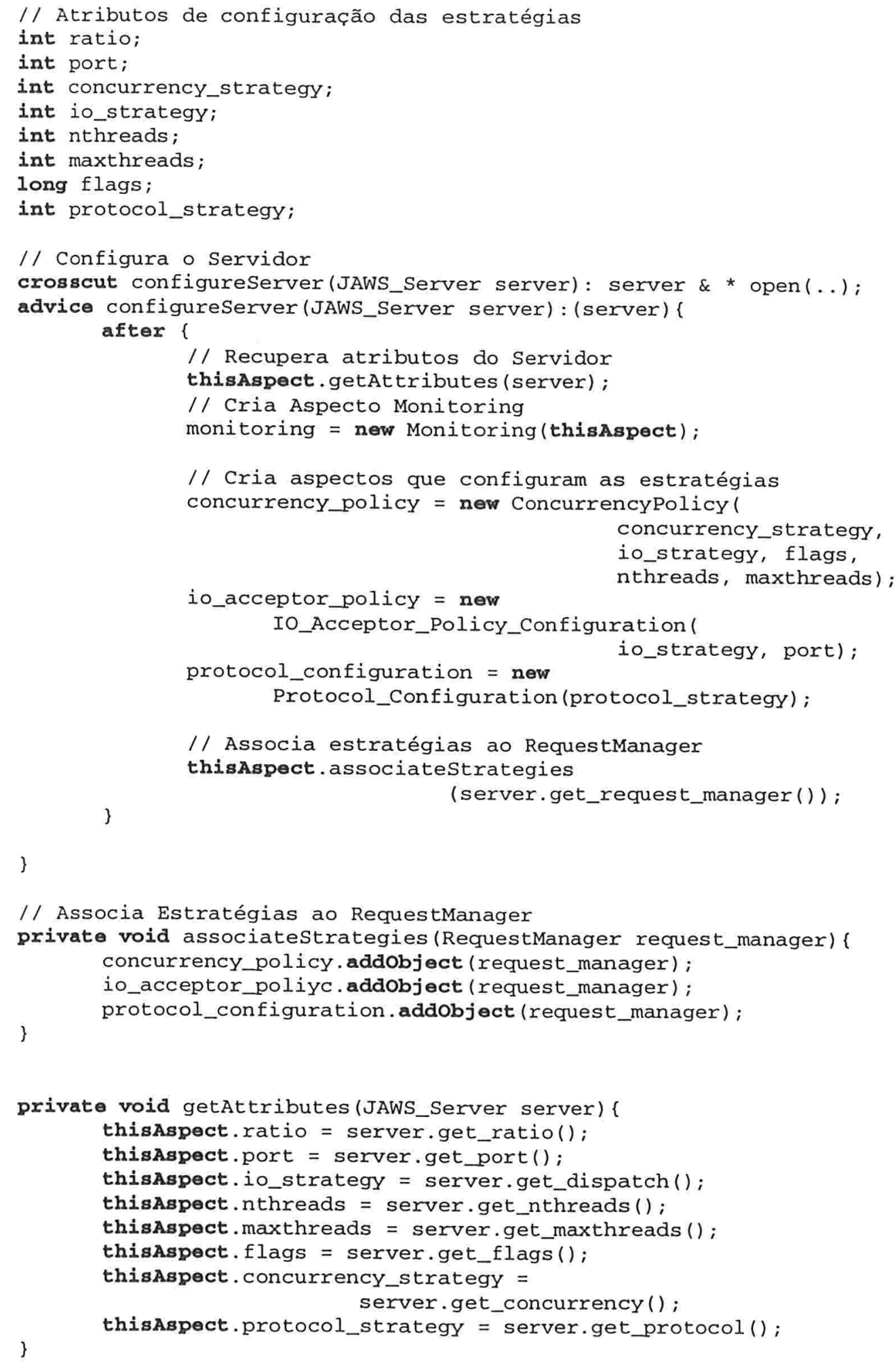


public aspect Monitoring \{

// Referência para o aspecto Configurator do Sistema

Configurator configurator;

// Estado do Ambiente de Execucao do JAWS

Environment environment;

// Estado da carga no sistema

int number_of_connections $=0$;

int number_of_requests $=0$;

int throughput;

// Construtor do aspecto de Monitoramento

public Monitoring(Configurator config) \{

// Recupera o estado do ambiente de execução do JAWS

thisAspect.environment = new Environment ();

// Mantém uma referência para o Configurator do Sistema

thisAspect. configurator = config;

// Determina configurações iniciais possíveis para o

// servidor, de acordo com o ambiente thisAspect. initialConfiguration():

public void initialconfiguration() (

// Se nao tem suporte a threads

if (thisAspect.environment.threads ()$==$ false) \{

thisAspect. configurator. concurrency_strategy (SINGLE_THREADED) ;

// Se nao tem suporte a IO Assíncrono

if (thisAspect.environment.asynchronous_io() $==$ false) \{ thisAspect.configurator. io_strategY(SYNCRONOUS_IO); \}

// Incrementa o número de conexões

crosscut num_of_connections() :

(JAWS_Asynch_IO | JAWS_Synch_IO) \& * accept $(.$.$) ;$

advice num_of_connections () \{

after \{

thisAspect.number_of_connections++;

if (number_of_connections >= MAX_CONNECTIONS) \{

thisAspect .exceed_connections () ;

\}

public void exceed_connections () \{

\} // Avisa o Configurator

/1

$1 /$

// Incrementa o throughput

crosscut transmit_asynch_io(JAWS_Asynch_IO asynch_io):

asynch_io \& * transmit_file $(\ldots)$;

advice transmit_asynch_io(JAWS_Asynch_IO asynch_io): (asynch_io) ( after \{ 


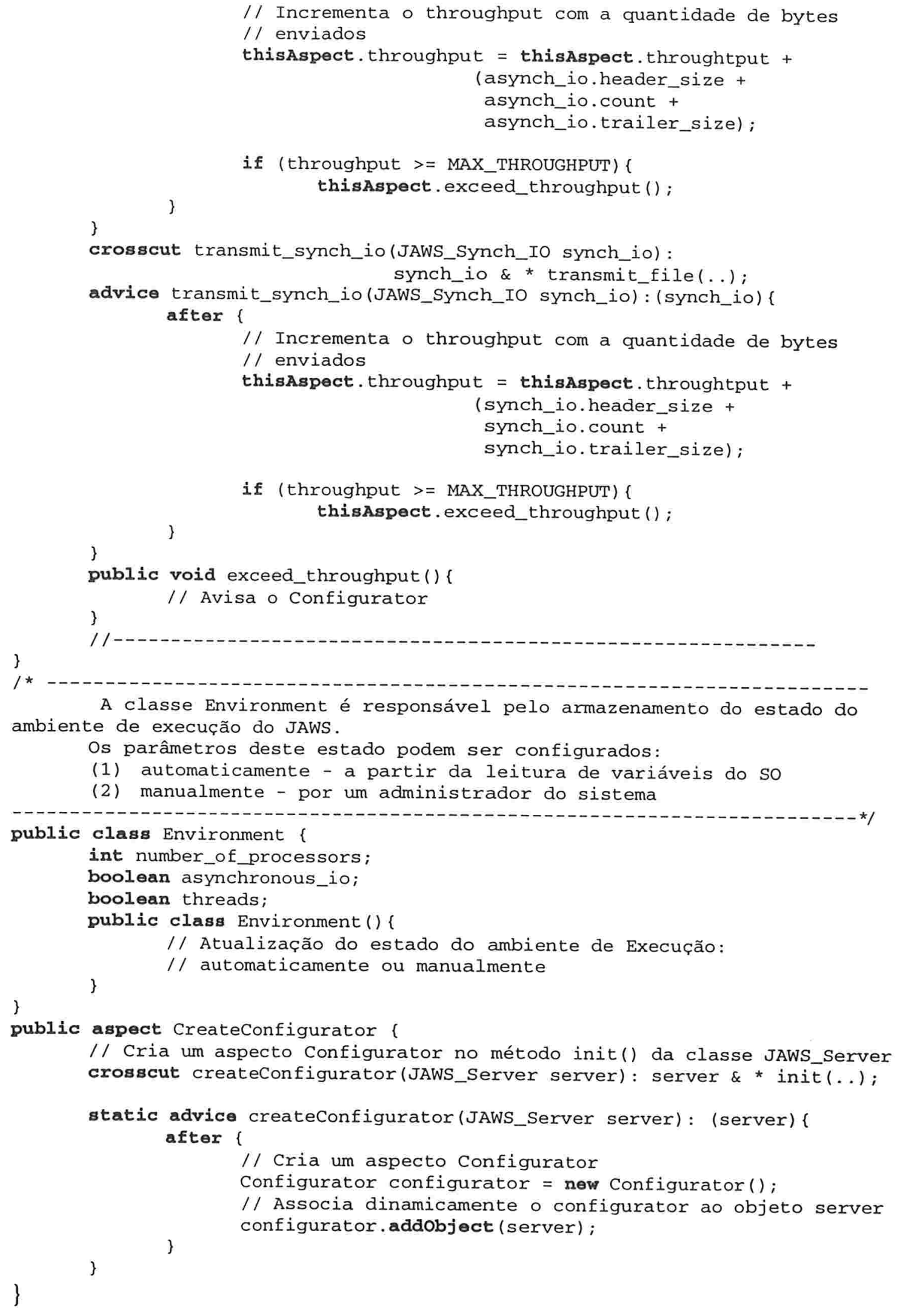

A classe Environment é responsável pelo armazenamento do estado do ambiente de execução do JAWS.

Os parâmetros deste estado podem ser configurados:

(1) automaticamente - a partir da leitura de variáveis do so

(2) manualmente - por um administrador do sistema

public class Environment

int number_of_processors;

boolean asynchronous_io;

boolean threads;

public class Environment () \{

// Atualização do estado do ambiente de Execução:

\}

// automaticamente ou manualmente

\}

public aspect CreateConfigurator \&

// Cria um aspecto Configurator no método init() da classe JAWS_Server crosscut createConfigurator(JAWS_Server server): server \& * init (..);

static advice createConfigurator(JAWS_Server server): (server) \{ after \{

// Cria um aspecto Configurator

Configurator configurator = new Configurator () ;

// Associa dinamicamente o configurator ao objeto server

\} configurator.addobject (server);

\} 


\subsubsection{Análise do Projeto do JAWS com Programação Orientada a Aspectos}

Uma análise da nova estrutura do projeto do JAWS com programação orientada a aspectos nos revela diversas vantagens obtidas em relação ao seu projeto original, entre elas:

- separação de interesses: um dos principais objetivos da técnica de programação orientada a aspectos é tentar expressar sintaticamente e de forma separada os diversos interesses que estão envolvidos no projeto de um sistema [KLM+97]. No novo projeto do JAWS com programação orientada a aspectos, alcançamos este objetivo de separação de interesses conseguindo expressar, em hierarquias separadas de aspectos e classes, as estratégias de concorrência e aceitação de conexões, as configurações das estratégias de concorrência, I/O, aceitação de conexões e do protocolo, e também o interesse de monitoramento do ambiente de execução e carga no sistema. Os entrelaçamentos de código de diversos interesses descritos na subseção 4.1 .3 foram evitados, com cada um deles sendo expresso por uma hierarquia coesa e distinta de aspectos/classes, o que conseqüentemente leva a um melhor entendimento de como tais interesses são alcançados, e contribui portanto, para facilidade de manutenção no código do JAWS;

- reutilização: a especificação separada de cada um dos interesses do JAWS permite também reutilizá-los em novos contextos ou em novos servidores de comunicação. Esta reutilização implica apenas na redefinição de algumas cláusulas presentes em aspectos da hierarquia de cada interesse que explicitam os pontos específicos do código do JAWS que cada aspecto afetará. Na estratégia de concorrência, por exemplo, o aspecto concurrencyPolicy define a configuração inicial e ativação da estratégia no construtor do JAWS_RequestManager. A reutilização da estratégia de concorrência em um novo contexto implicaria na redefinição desta cláusula, com a especificação do método de uma dada classe, onde a estratégia seria então configurada e possivelmente ativada. A estrutura como um todo da hierarquia do projeto de cada um dos interesses poderia assim ser reutilizada em novos contextos;

- evolução estática: com o novo projeto do JAWS é possível desconectar as hierarquias de aspectos/classes que afetam o JAWS_RequestManager de forma estática ou dinâmica. Assim, permite-se a fácil adaptação deste componente para novas hierarquias de aspectos/classes, que enderecem cada um de seus interesses de configuração de estratégias e monitoramento. Esta facilidade de "desplugar" os aspectos acaba trazendo benefícios para a evolução estática do sistema, permitindo reconstruir completamente cada uma das hierarquias de interesses que afetam o comportamento de seus componentes funcionais;

- configurações estáticas e dinâmicas: as hierarquias de classes/aspectos elaboradas para o novo projeto do JAWS permitem expressar as configurações estáticas e dinâmicas de suas estratégias. Os aspectos Concurrency_Policy, IO_Acceptor_Policy_Configuration e Protocol_Configuration definem as configurações iniciais para as estratégias adaptativas do JAWS. Estes mesmos aspectos poderiam definir "pontos" específicos do código do JAWS, através da especificação de cláusulas advice, onde as estratégias poderiam ser reconfiguradas dinamicamente a partir da ocorrência de algum evento ou mudança no estado do sistema. Uma outra alternativa de projeto seria os aspectos que definem as configurações das estratégias do 
JAWS implementarem métodos para a troca de estratégias; neste caso, o aspecto Configurator (que já agrega tais aspectos) se responsabiliza pela invocação destes métodos, de acordo com mudanças nos estados mantidos pelo aspecto Monitoring.

- entendimento progressivo: a especificação separada dos diferentes interesses de projeto do JAWS permite entender a sua estrutura e comportamento de forma progressiva. Este entendimento pode ser iniciado pela compreensão do modelo de componentes funcionais definido para o sistema e, em seguida, estudando separadamente cada uma das hierarquias de aspectos que afetam o modelo de componentes funcionais e endereçam os interesses não-funcionais do sistema.

\subsection{Reengenharia do Projeto do JAWS com Programação Adaptativa e Relações de Contexto}

Para o projeto do JAWS com programação adaptativa e relações de contexto, buscamos: (1) identificar comportamentos colaborativos entre classes que pudessem ser modelados com a utilização das abstrações presentes na técnica de programação adaptativa (isto é, métodos adaptativos, métodos traversals e classes visitors, descritos na subseção 3.2.1.2); e (2) utilizamos relações de contexto para projetar aspectos de variação dinâmica presentes nas estratégias do JAWS.

Nas subseções seguintes são apresentadas as modelagens realizadas sobre o JAWS com programação adaptativa e relações de contexto.

\subsubsection{Projeto do JAWS com Programação Adaptativa}

Nesta subseção apresentamos os comportamentos do JAWS que foram projetados usando programação adaptativa. Os comportamentos do JAWS especificados com as abstrações desta técnica foram: a configuração e ativação das suas estratégias; e a definição do seu protocolo. $O$ projeto destes comportamentos com programação adaptativa permitiu especificar separadamente: um método traversal - que define as classes que colaboram para a sua execução; e uma classe visitor - que define o comportamento a ser executado durante o percurso do método traversal. Foram definidos métodos adaptativos que utilizam a implementação dos métodos traversal e classes visitor. Esta especificação separada traz facilidades para o entendimento e posterior manutenção dos elementos envolvidos na definição de cada comportamento.

\subsubsection{Projeto do Servidor com Programação Ad aptativa}

A classe JAWS_Server define dois métodos públicos principais: init () e open(). Conforme descrito na subseção 4.1.1.1, estes métodos endereçam o interesse de configuração e ativação das estratégias do servidor.

O método init() se responsabiliza pela configuração das diversas estratégias da política do JAWS (classe JAWS_Default_Dispatch_Policy) com exceção da estratégia do protocolo, e pela ativação das estratégias de concorrência e aceitação de conexões. Ele 
utiliza os diversos atributos configurados para o servidor para escolher entre as estratégias possíveis. Estes atributos da classe JAWS_Server são obtidos através da execução do seu método parse_args () no início do método init ().

O método open() se responsabiliza pela configuração do protocolo do JAWS e pela criação e inicialização de um objeto JAWS_Data_Block. É ainda função do método open ( ) repassar este objeto JAWS_Data_Block para a estratégia de concorrência quando então ele será utilizado pelas threads de processamento dos pedidos de clientes.

Estes dois comportamentos da classe JAWS_Server foram reprojetados usando programação adaptativa. Para cada um deles foi criado um método adaptativo, um método traversal e uma classe visitor. A figura 4.19 mostra o diagrama de classes que representa o projeto da política e estratégias do JAWS com programação adaptativa. Os métodos init() e open() do projeto do JAWS com programação adaptativa são representados neste diagrama. 


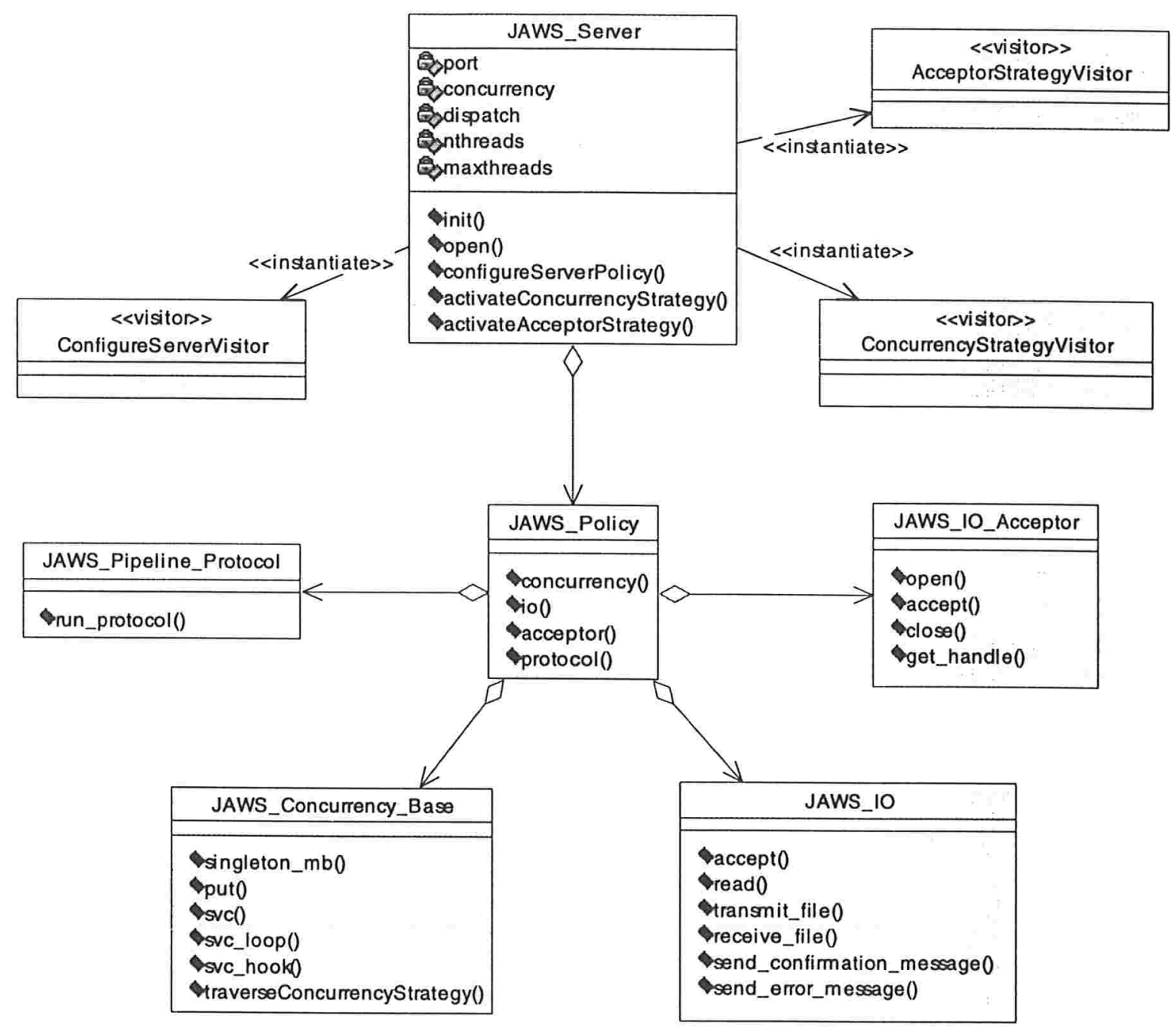

Figura 4.19: Diagrama de classes do projeto do JAWS com programação adaptativa

O método init() do projeto do JAWS com programação adaptativa, após invocar 0 método parse_args(), chama o método adaptativo configureserverPolicy (), cuja função é percorrer a política do servidor e definir uma configuração para as estratégias do JAWS, inclusive a estratégia do protocolo. Para realizar esta tarefa o método configureserverPolicy() usa as implementações do método traversal traverseserverPolicy() e da classe visitor Configureservervisitor. A política do servidor (representada no novo projeto pela classe JAWS_Policy) agrega no projeto do JAWS com programação adaptativa todas as estratégias do JAWS, inclusive a do seu protocolo. No projeto original do JAWS não existe nenhuma classe representando diretamente o seu protocolo, no projeto do JAWS com programação adaptativa criamos a classe JAWS_Pipeline_Protocol com esta finalidade. 
O método open() possui como função no projeto do JAWS com programação adaptativa a ativação das estratégias de concorrência e aceitação de conexões. Para cumprir seu papel ele invoca os métodos adaptativos activateconcurrencystrategy () e activateAcceptorstrategy().

O método traversal traverseconcurrencystrategy() e a classe visitor ConcurrencystrategyVisitor são usados para a definição do método activateconcurrencystrategy(). A classe concurrencystrategyVisitor define o comportamento de ativação da estratégia de concorrência, durante o percurso do método traversal traverseConcurrencystrategy(). Entre as responsabilidades da classe ConcurrencystrategyVisitor estão: (1) chamar o método make() da estratégia de concorrência (instância da classe JAWS_Concurrency_Base); e (2) criar e configurar um objeto do tipo JAWS_Data_Block e, em seguida, o repassar para o objeto que define a estratégia de concorrência, invocando o seu método put ().

O método adaptativo activateAcceptorStrategy() utiliza na sua implementação o método traversal traverseAcceptorStrategy() e a classe visitor AcceptorstrategyVisitor. O método traverseAcceptorStrategy () é utilizado para definição de um caminho de percurso que sai da classe JAWS_Server e vai até a classe JAWS_IO_Acceptor (estratégia de aceitação de conexões). A classe visitor Acceptorstrategyvisitor define o comportamento de ativação da estratégia de aceitação de conexões no percurso do método traversal traverseAcceptorStrategy ( ). A ativação da estratégia de aceitação de conexões é feita através da invocação do método open ( ) da classe JAWS_IO_Acceptor.

A seguir apresentamos código-fonte dos comportamentos da classe JAWS_Server projetados com programação adaptativa.

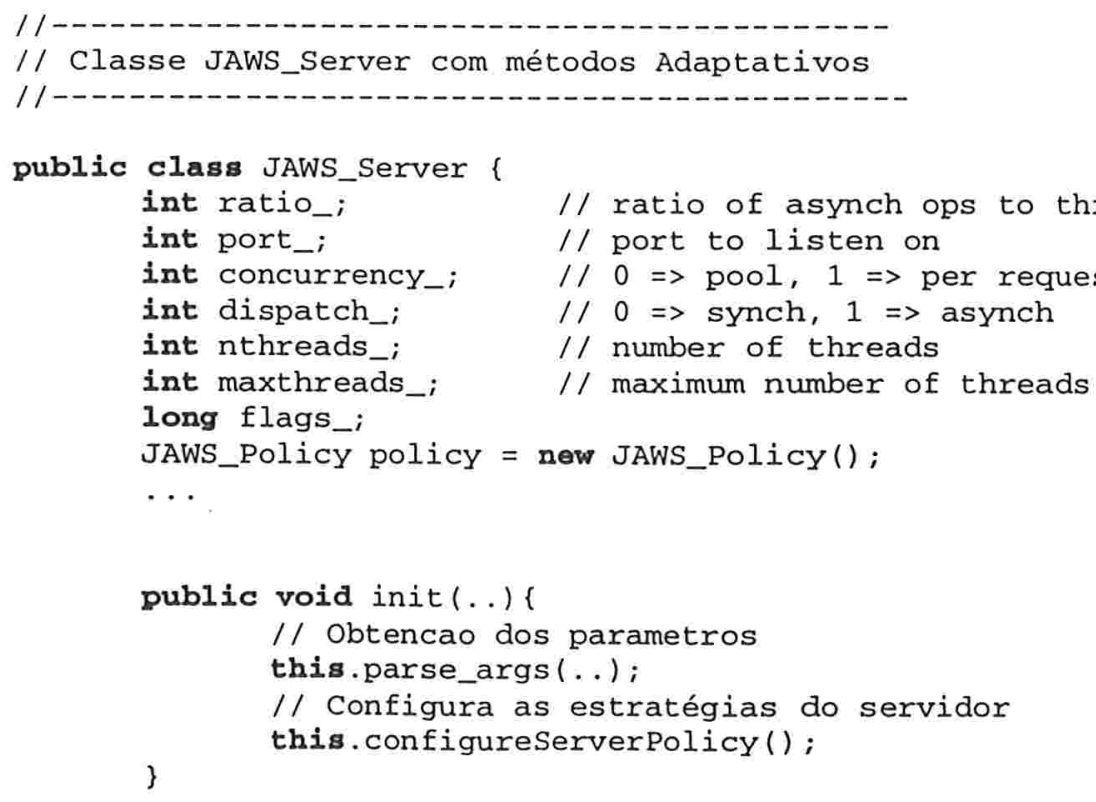


public void open (..) \{

// Ativa a estratégia de Concorrência

this.activateConcurrencystrategy ();

// Ativa a estratégia de Aceitação de Conexões

\} this.activateAcceptorstrategy();

// Especificacao de um método traversal que percorre

// a sua Política

traversal traverseServerPolicy(ConfigureServerVisitor) \{

\} ; to \{JAWS_Policy\}

// Especificacao de um método adaptativo de configuração das

$1 /$ estratégias

void configureServerPolicy ()$=$

traverseServerPolicy (ConfigureServerVisitor);

// Especificacao de um método traversal que vai até a estratégia

// de concorrência pela política do servidor

traversal traverseConcurrencystrategy

(Concurrencystrategyvisitor) (

\} via \{JAWS_Policy\} to \{JAWS_Concurrency_Base\}

// Especificacao do método adaptativo de ativação da estratégia

// de concorrência

void activateConcurrencystrategy ()$=$

traverseConcurrencystrategy (ConcurrencystrategyVisitor);

// Especificacao de um método traversal que vai até a estratégia

// de aceitação de conexões pela política do servidor

traversal traverseAcceptorstrategy

(AcceptorstrategyVisitor) \{

\} via \{JAWS_Policy\} to \{JAWS_IO_Acceptor\}

// Especificacao do método adaptativo de ativação da estratégia // de aceitação de conexões

void activateAcceptorStrategy ()$=$

traverseAcceptorStrategy (AcceptorStrategyVisitor);

\}

public class JAWS_Policy \{

JAWS_Concurrency_Base concurrency;

JAWS_IO io;

JAWS_IO_Acceptor acceptor;

JAWS_Pipeline_Protocol protocol.

$\cdots$

\}

// Este Visitor define a configuracao básica de um servidor baseada nos // parâmetros de JAWS_Server

public class ConfigureServerVisitor \{

int ratio;

int concurrency;

int port:

int dispatch_;

int protocol;

before JAWS_Server (e

this.ratio $=$ host $\cdot$ ratio;

this.port $=$ host . port;

this. dispatch = host $\cdot$ dispatch; 


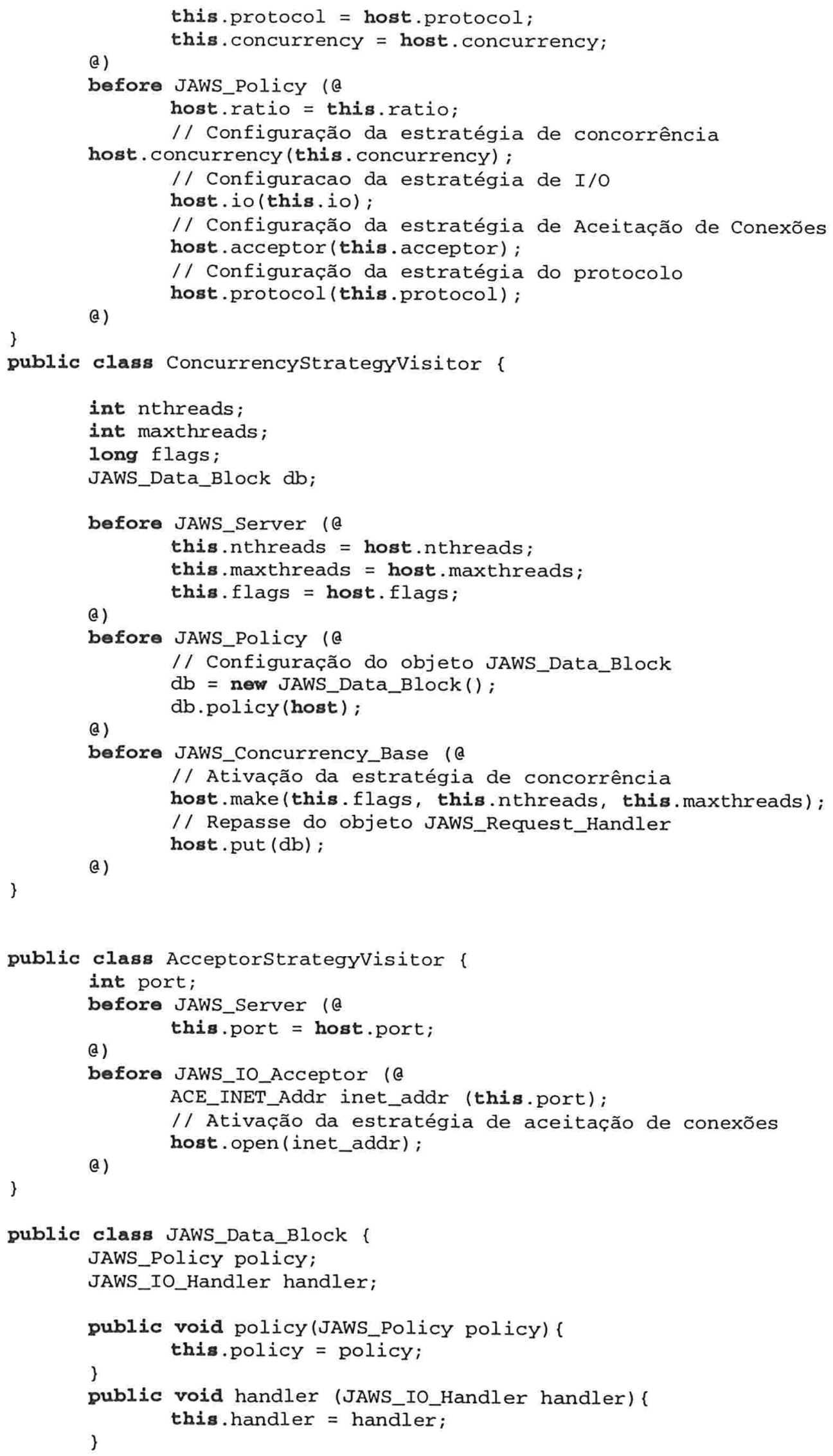




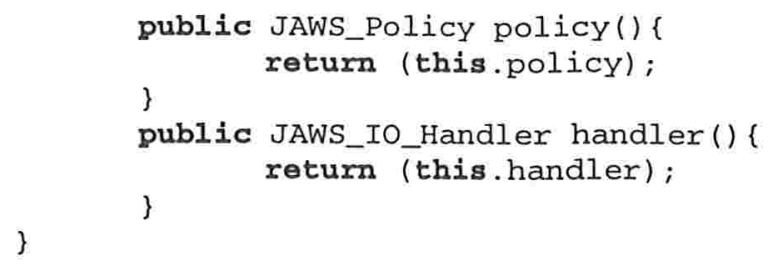

\subsubsection{Projeto do Protocolo do JAWS com Programação Adaptativa}

No projeto original do JAWS, a classe JAWS_Concurrency_Base define o protocolo HTTP implementado para o JAWS, através do método svc_hook() (descrito na subseção 4.1.1.3). A função deste método é executar sequiencialmente as tarefas do protocolo, com o objetivo de realizar o processamento de cada pedido de cliente endereçado ao servidor. Cada thread iniciada pela estratégia de concorrência executará o método svc_hook() em sua própria linha de execução. A implementação do método svc_hook() envolve percorrer um conjunto de tarefas a partir da classe JAWS_Concurrency_Base. Este conjunto de tarefas (subclasses de JAWS_Pipeline_Handler) formam na verdade o protocolo do JAWS, que não possui em seu projeto original nenhuma classe o representando diretamente.

Na seção anterior foi criada a classe JAWS_Pipeline_Protocol para representar o protocolo do JAWS. Esta classe define o método run_protocol() que é responsável pela execução das tarefas do protocolo. O método svc_hook() da classe JAWS_Concurrency_Base delega no projeto do JAWS com programação adaptativa seus pedidos para o método run_protocol ( ).

O método run_protocol () foi especificado como um método adaptativo que percorre as diversas tarefas do protocolo e dispara a execução das mesmas. Para desempenhar sua função, este método usa as implementações: (a) do método traversal traverseProtocolTasks () - que percorre todas as tarefas do protocolo; e (b) da classe visitor Protocolservicevisitor - que especifica a execução das tarefas, através da invocação de seus respectivos métodos put(). A figura 4.20 apresenta diagrama de classes dos elementos envolvidos no projeto do protocolo do JAWS com programação adaptativa. Código fonte das classes JAWS_Pipeline_Protocol e JAWS_Pipeline_Handler é apresentado logo a seguir. 


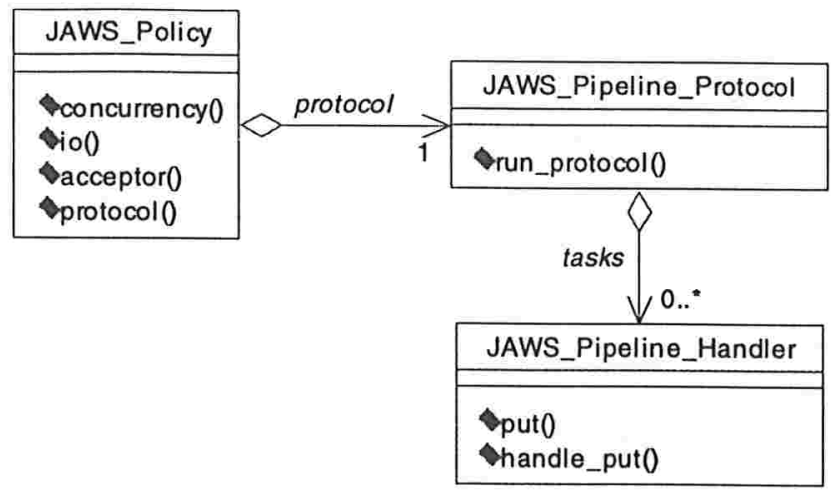

Figura 4.20: Diagrama de classes do projeto do protocolo do JAWS com programação adaptativa

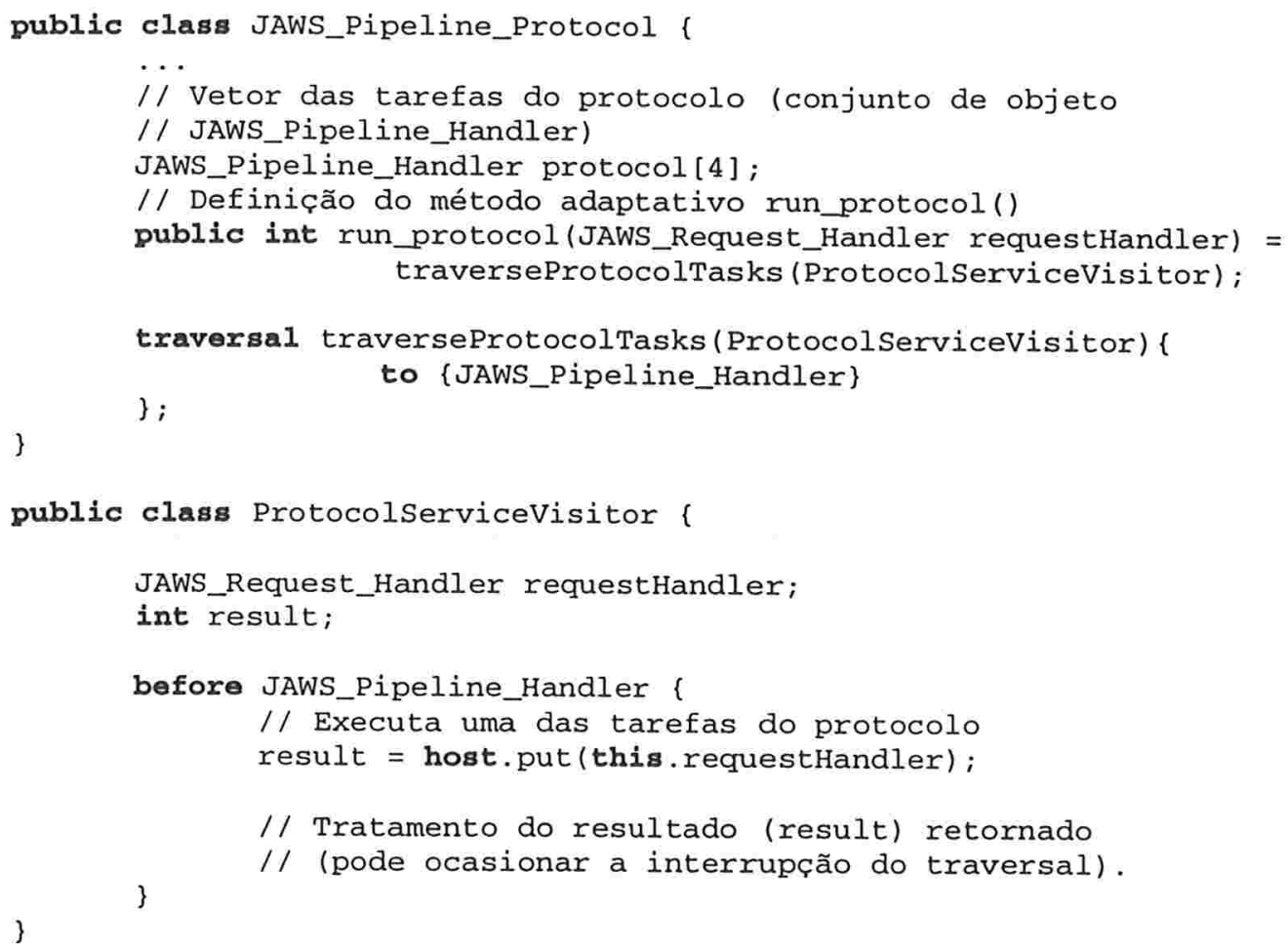

Um exemplo de manutenção que poderia ser feita no protocolo do JAWS seria o de possibilitar que outros protocolos pudessem ser concatenados com ele, ou seja, de permitir que a classe JAWS_Pipeline_Protocol agregasse atributos de seu mesmo tipo, e esses protocolos agregados fossem executados em sequiência com as tarefas já definidas. A figura 4.21 demonstra esta modificação na estrutura de classes do protocolo do JAWS.

Esta mudança na estrutura de classes do protocolo do JAWS não implicaria em nenhuma modificação na especificação do método adaptativo run_protocol () definido acima, pois o modelo de programação adaptativa prevê tais tipos de adaptações na 
estrutura de classes e gera, durante a compilação do sistema, código para percorrer as tarefas desta nova relação.

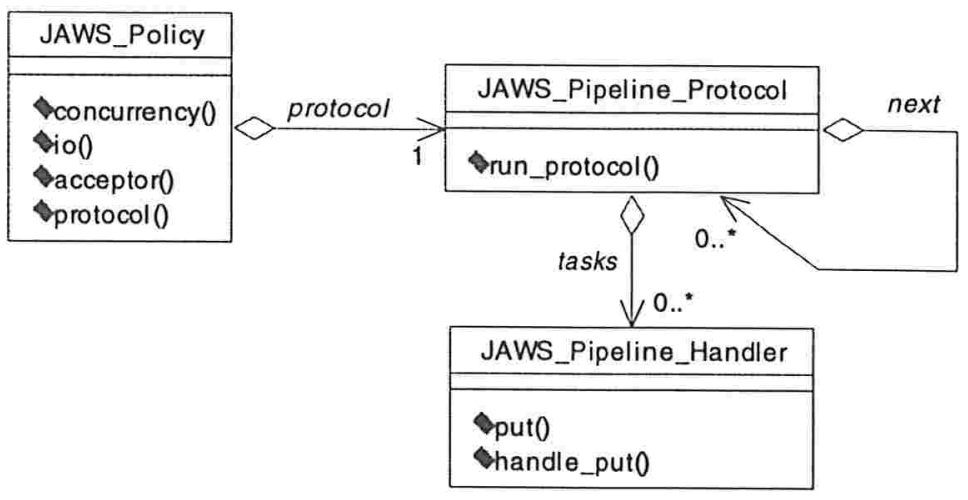

Figura 4.21: Manutenção no Protocolo do JAWS com programação adaptativa

\subsubsection{Projeto das Estratégias do JAWS com Relações de Contexto}

Cada uma das estratégias presentes no JAWS é implementada através de uma hierarquia de classes que contém: (a) uma super-classe que define a interface básica que as estratégias concretas devem ter e mantém implementações comuns às mesmas; e (b) um conjunto de subclasses desta super-classe, que implementam sua interface e definem assim estratégias concretas.

Cada uma das subclasses que representam as estratégias concretas pode ser vista como uma variação dinâmica para as estratégias do JAWS. Nas subseções seguintes descrevemos o projeto das estratégias e suas variações dinâmicas com relações de contexto.

\subsubsection{Projeto da Estratégia de Concorrência}

A estratégia de concorrência do JAWS é implementada pela classe JAWS_Concurrency_Base e suas duas subclasses JAWS_Thread_Per_Task e JAWS_Thread_Pool_Task que representam as variações dinâmicas de tal estratégia.

Reconstruímos as classes JAWS_Thread_Per_Task e JAWS_Thread_Pool como classes de contexto de JAWS_Concurrency_Base. Cada uma delas representa uma variação dinâmica para a estratégia de concorrência alterando métodos específicos. A figura 4.22 mostra um diagrama de classes representando o novo projeto da estratégia de concorrência com relações de contexto. Código relativo às implementações das classes presentes neste modelo é também apresentado logo a seguir. 


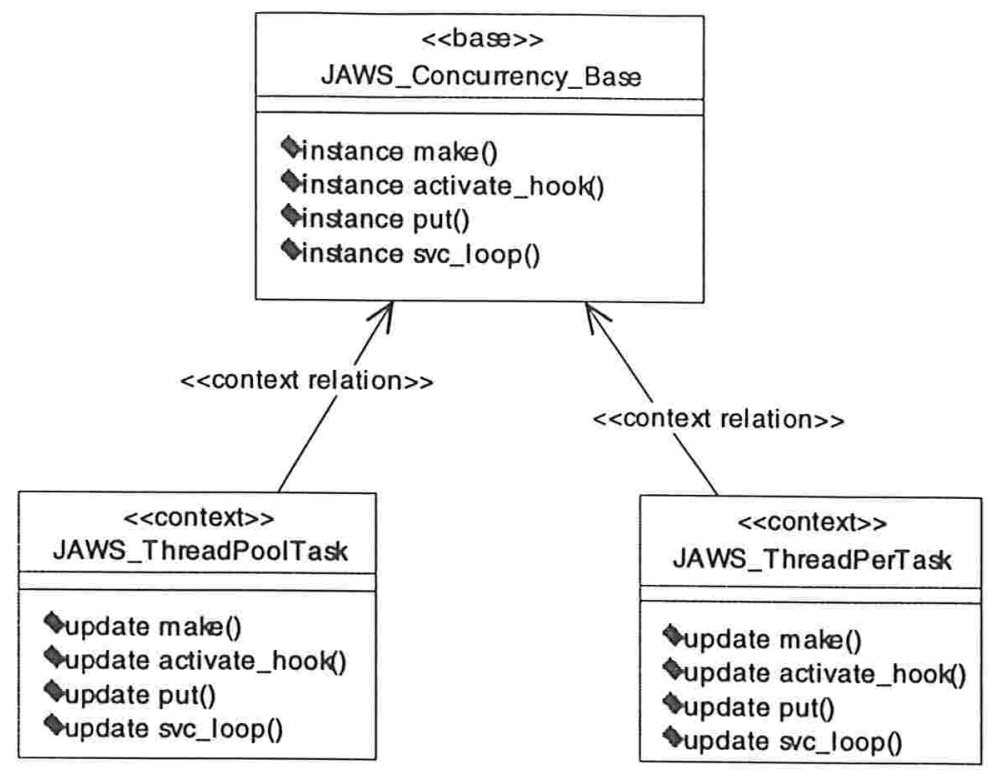

Figura 4.22: Estratégia de Concorrência com Relações de Contexto

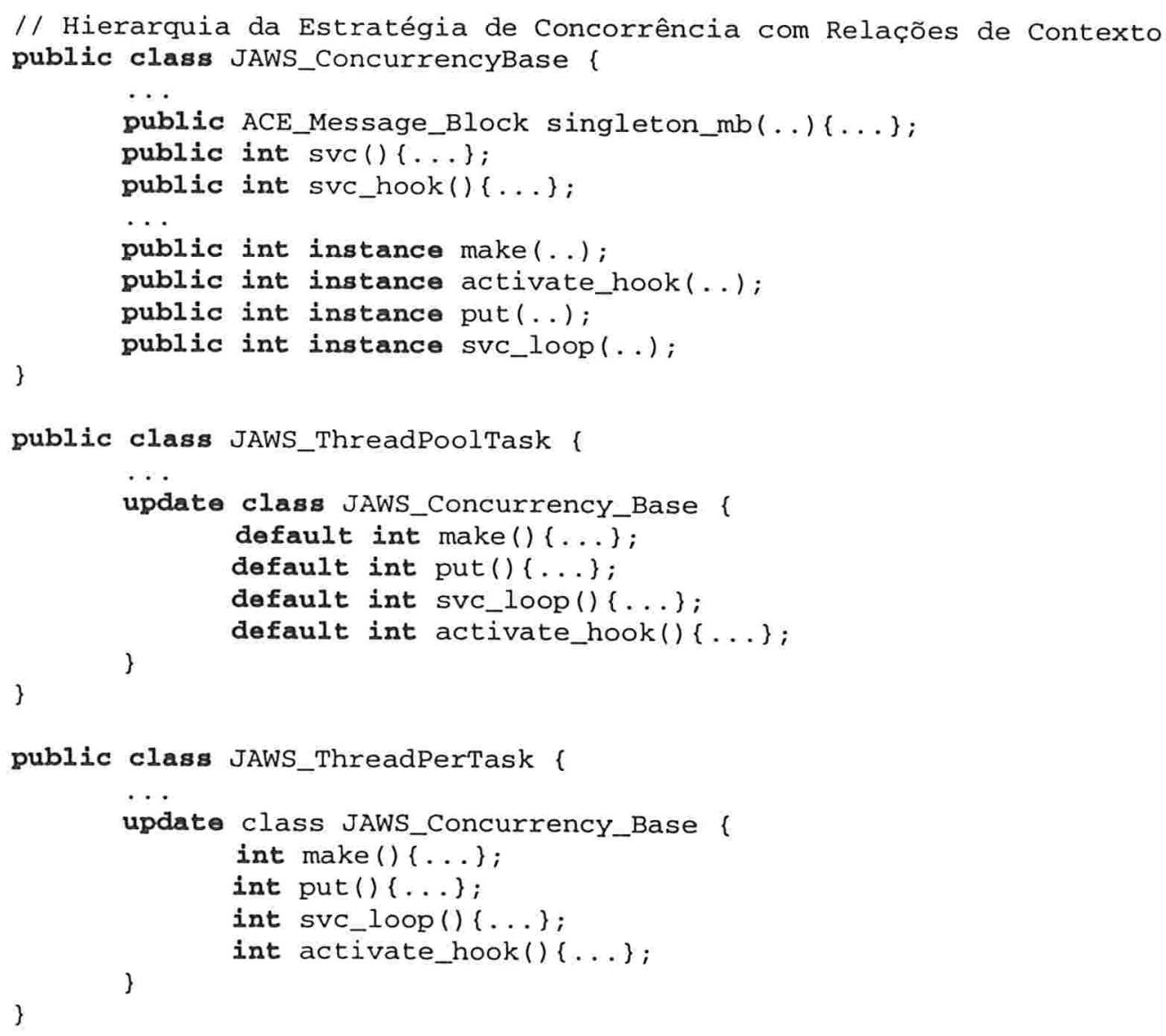




\subsubsection{Projeto da Estratégia de $1 / O$}

A estratégia de I/O do JAWS é implementada pela classe JAwS_IO e suas duas subclasses JAWS_Synch_IO e JAWS_Asynch_IO.

De forma idêntica ao projeto da estratégia de concorrência, podemos definir as classes JAWS_Synch_IO e JAWS_Asynch_IO como classes de contexto da classe JAWS_IO. Assim, objetos destas classes de contexto podem ser dinamicamente associados a estratégia de I/O (objeto da classe JAWS_IO) modificando seu comportamento. Diagrama de classes representando o novo projeto da estratégia de I/O é apresentado na figura 4.23. Código-fonte das classes presentes neste modelo estão também dispostos adiante.

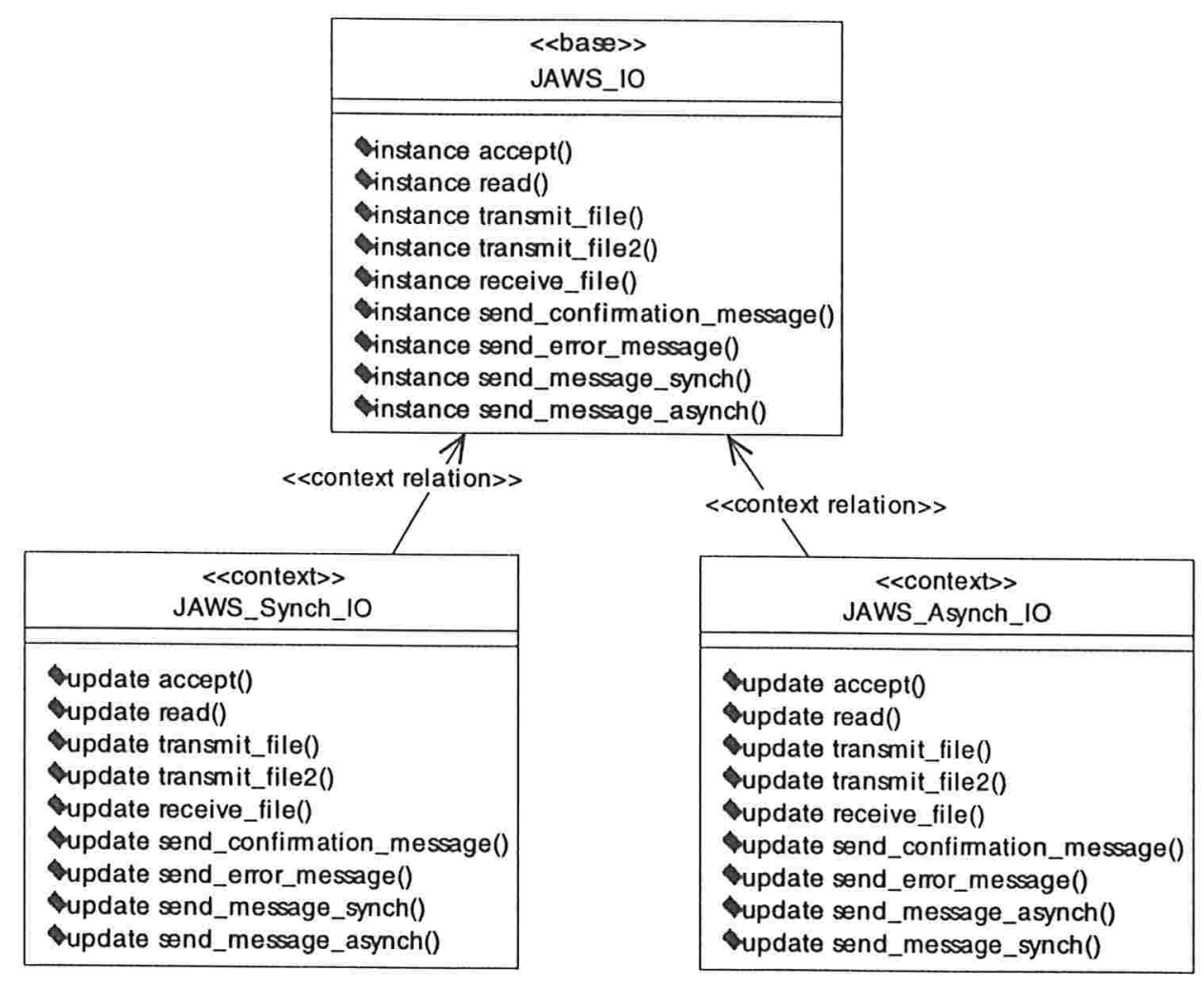

Figura 4.23: Estratégia de I/O com Relações de Contexto

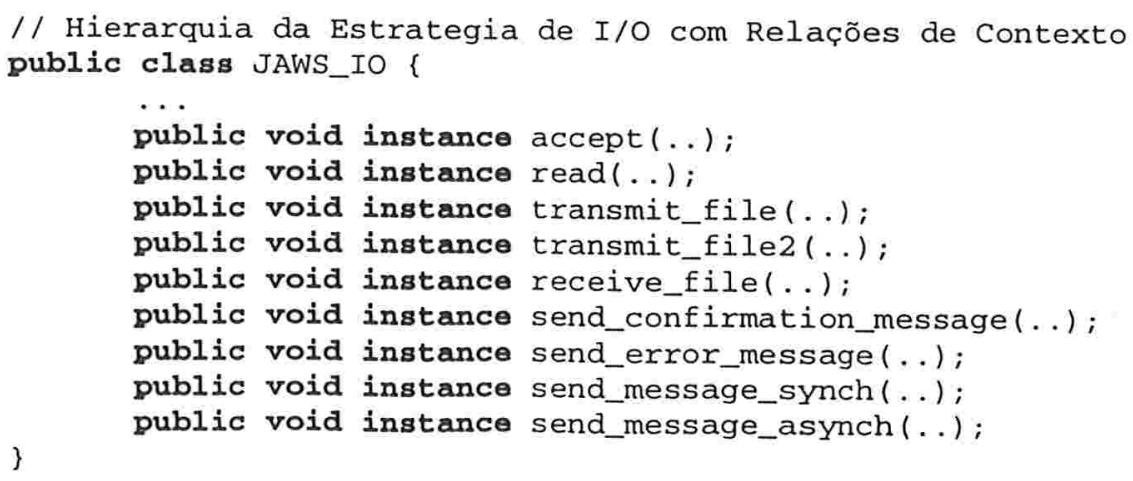




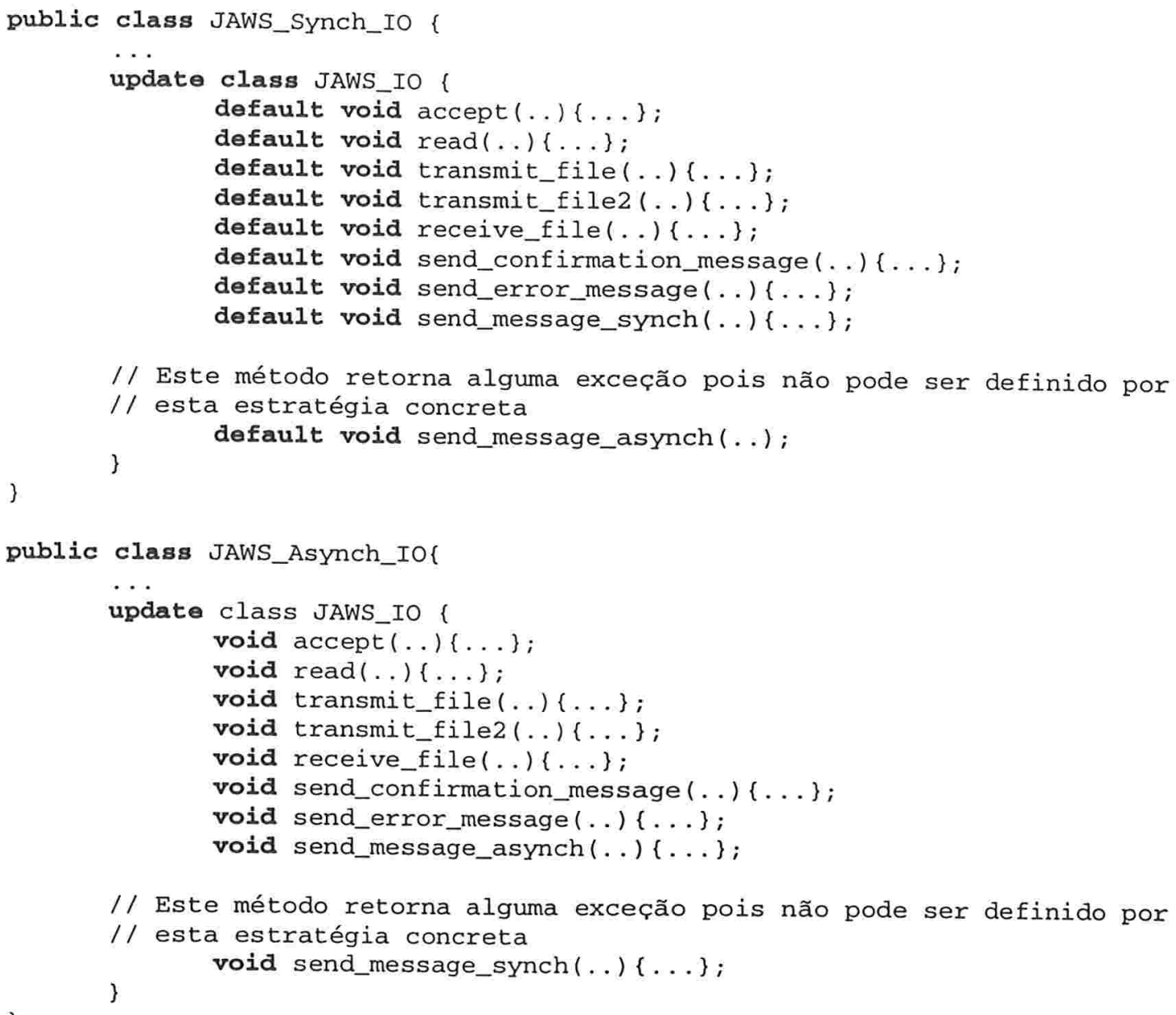

\subsubsection{Projeto da Estratégia de Aceitação de Conexões}

A estratégia de aceitação de conexões do JAWS é implementada pela classe JAWS_IO_Acceptor e suas duas subclasses JAWS_IO_Synch_Acceptor e JAWS_IO_Asynch_Acceptor.

No novo projeto da estratégia de aceitação de conexões com Relações de Contexto, as classes JAWS_IO_Synch_Acceptor e JAWS_IO_Asynch_Acceptor foram modeladas como classes de contexto da classe JAWS_IO_Acceptor. Na figura 4.24 é apresentado um diagrama contendo tais classes. As implementações parciais das classes presentes neste modelo são também apresentadas. 


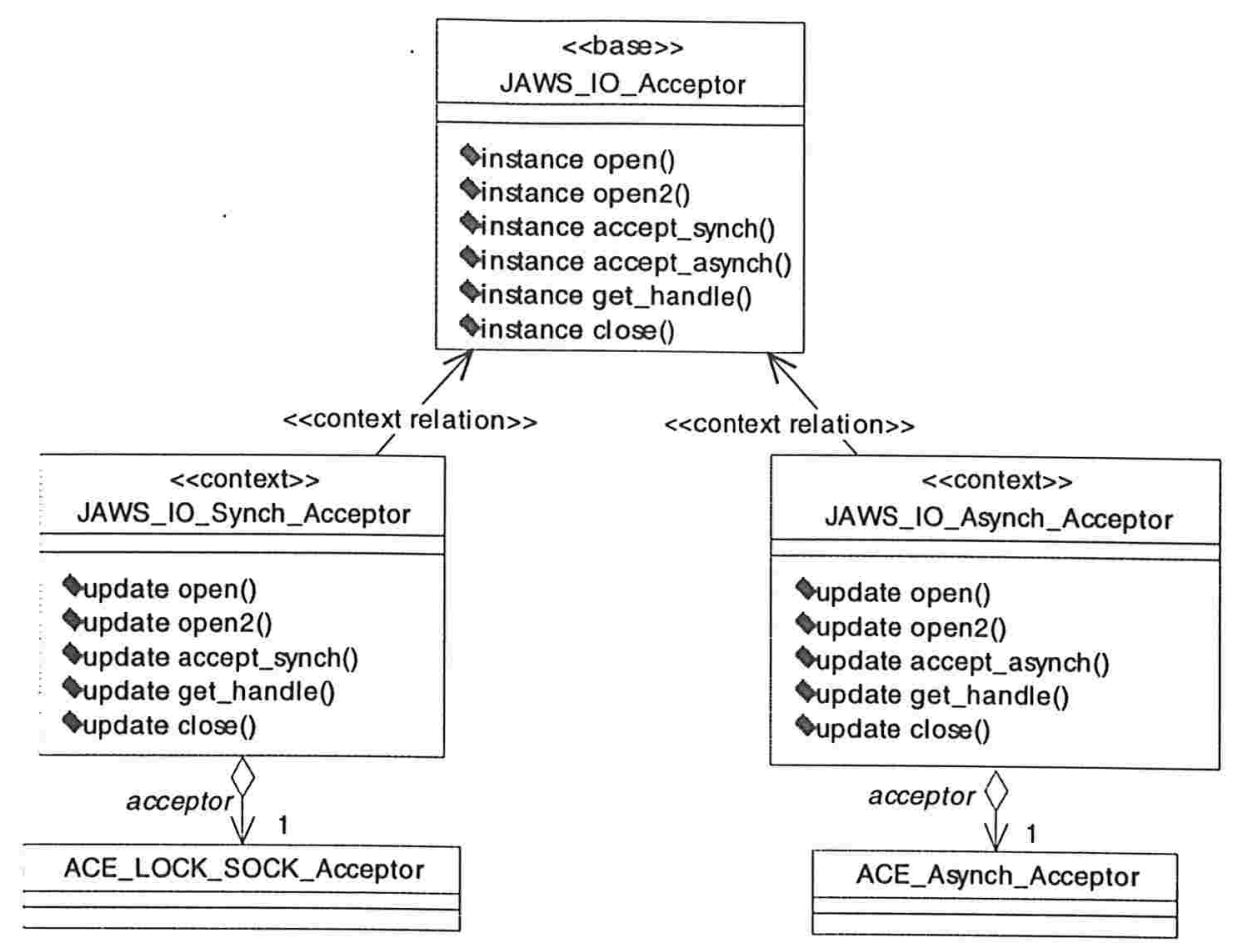

Figura 4.24: Estratégia de Aceitação de Conexões com Relações de Contexto

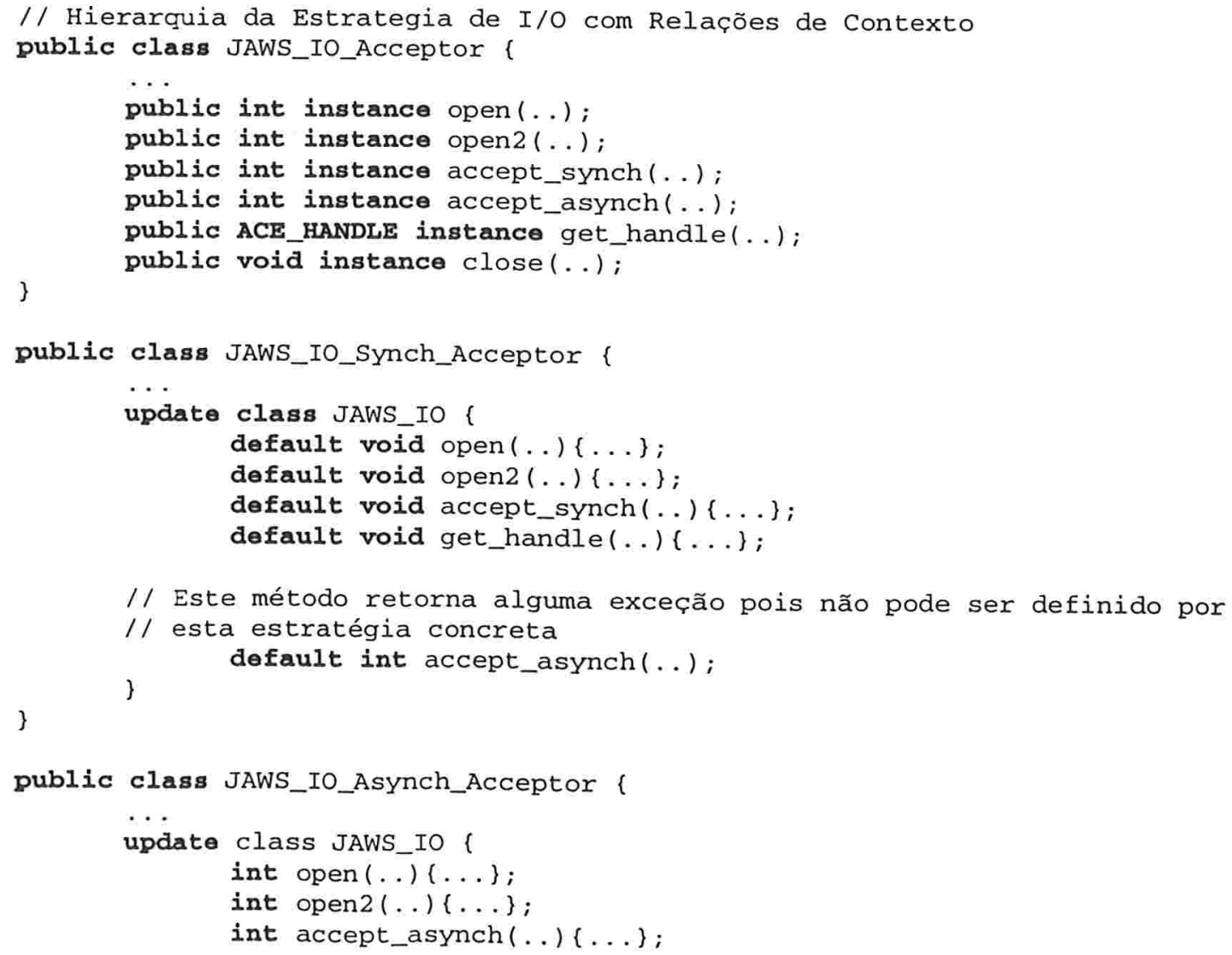




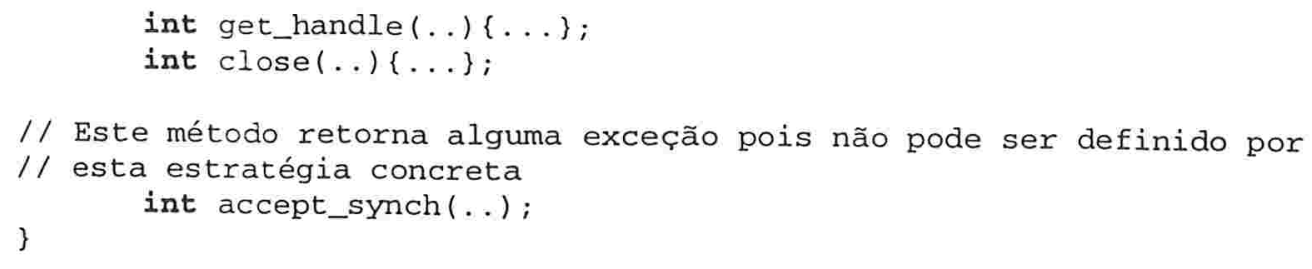

\subsubsection{Projeto da Estratégia de Configuração do Protocolo}

No projeto do protocolo HTTP do JAWS com Relações de Contexto foram considerados dois aspectos: (1) a extensão das tarefas que formam o protocolo; e (2) a própria configuração do protocolo.

\section{Extensão de Tarefas}

Para estender as tarefas que formam o protocolo definimos classes de contexto que representam variações dinâmicas para cada uma delas. Tais classes de contexto podem definir uma modificação completa no comportamento de tal tarefa através da atualização do método de instância handle_put(), ou modificações apenas parciais através da atualização de funcionalidades específicas de cada tarefa, separadas em métodos de instância.

$\mathrm{Na}$ figura 4.25 apresentamos a definição de uma classe de contexto Accept_Filter que estende a classe-tarefa JAWS_Pipeline_Accept_Task, através da atualização dos métodos before_handle_put() e after_handle_put (). Tais métodos representam comportamentos a serem executados no início e fim do método handle_put (), respectivamente. Novas classes de contexto poderiam ser definidas de forma a estender o método handle_put () da classe JAWS_Pipeline_Accept_Task, de forma diferente da extensão definida por Accept_Filter.

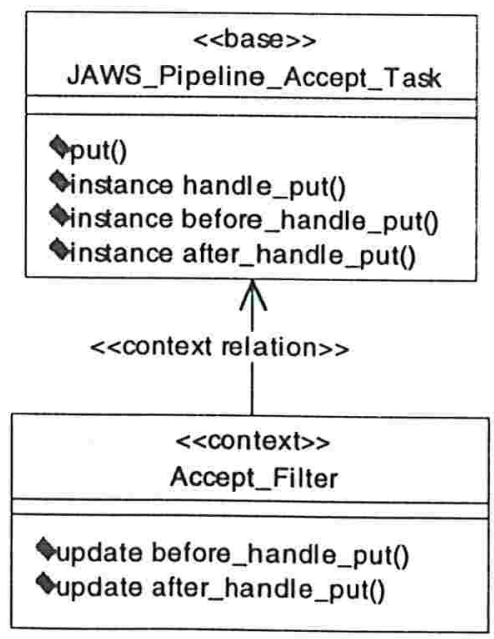

Figura 4.25: Extensão de Tarefas do Protocolo com Relações de Contexto 


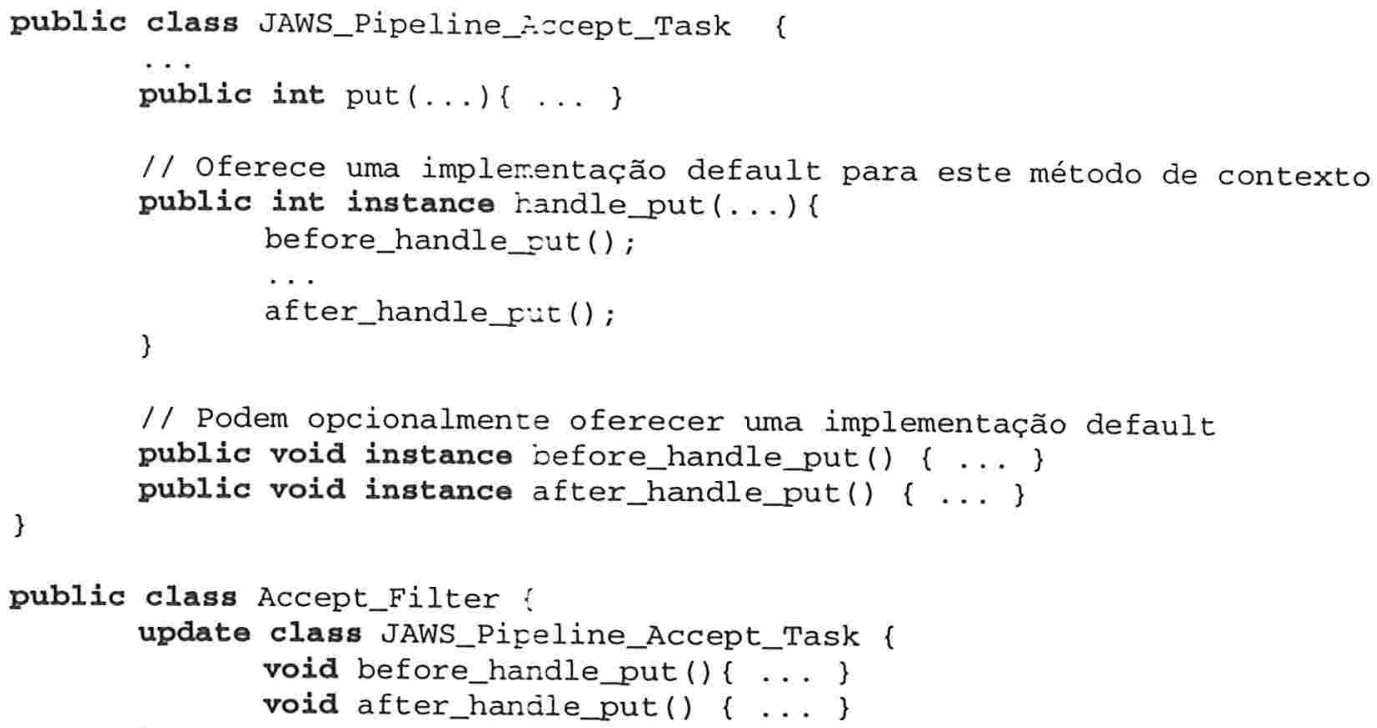

Cada classe que representa uma tarefa do protocolo do JAWS pode definir dentro do método handle_put() seus próprios pontos específicos de extensão, através da chamada a métodos de instância que serão posteriormente implementados por classes de contexto e anexados em tempo de execução as tarefas.

\section{Configuração do Protocolo}

A configuração do protocolo HTTP do JAWS envolve a instanciação das tarefas que dele farão parte e o alinhamento em seqüência das mesmas. A configuração do protocolo do JAWS é realizada em seu projeto original dentro do método open () da classe JAWS_Server.

No projeto do JAWS com Relações de Contexto a configuração do protocolo do JAWS é realizada através da definição de uma classe de contexto da agora classe-base JAWS_Pipeline_Protocol. Esta classe de contexto realiza a configuração do protocolo em seu método construtor e oferece uma implementação para o método de instância configure_protocol() da classe base JAWS_Pipeline_Protocol. O método configure_protocol() será chamado pelo método protocol() da classe JAWS_Policy, durante a configuração das estratégias do JAWS (chamada ao método adaptativo configureServerPolicy () da classe JAWS_Server).

Abaixo apresentamos um exemplo de configuração possível para o protocolo do JAWS. A classe de contexto BasicProtocol define em seu construtor as tarefas que farão parte do protocolo e oferece uma implementação para o método configure_protocol(). Diagrama das classes envolvidas nesta configuração é apresentado na figura 4.26 . 

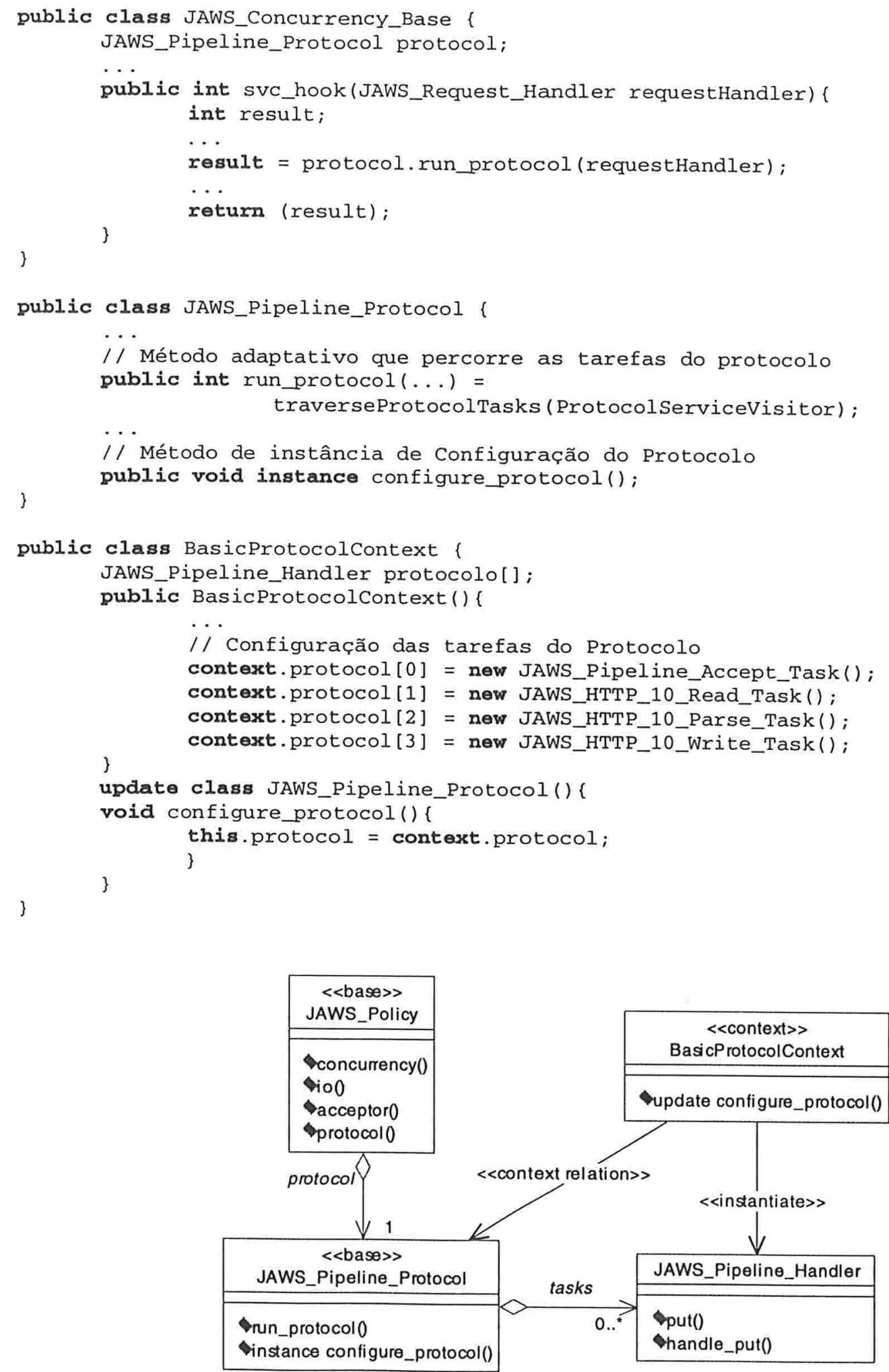

Figura 4.26: Configuração do Protocolo com Relações de Contexto 
A definição de novas configurações para o protocolo é feita através da criação de novas classes de contexto que seguem o mesmo padrão da classe BasicProtocol, ou seja, definem uma configuração para as tarefas do protocolo em seu método construtor e uma implementação para o método de instância configure_protocol() da classe JAWS_Pipeline_Protocol.

\subsubsection{Projeto da Configuração das Estratégias}

No projeto original do JAWS a configuração inicial de suas estratégias é realizada nos métodos init () e open() da classe JAWS_server. Por ser um sistema adaptativo, o JAWS pode, durante sua execução, demandar a substituição de alguma(s) destas estratégias, com o intuito de melhorar o seu desempenho no atendimento a clientes. A classe JAWS_Default_Policy oferece os métodos para substituição das estratégias do JAWS. Esta classe foi reprojetada para adequar-se ao novo projeto das estratégias do JAWS com relações de contexto.

Abaixo apresentamos código do novo projeto da classe JAWS_Default_Policy com relações de contexto. Este código apresenta os métodos para configuração das estratégias de concorrência, I/O e do protocolo. Tais métodos são chamados durante a invocação do método adaptativo configureserverPolicy() da classe JAWS_Server, apresentados na subseção 4.3.1.1.

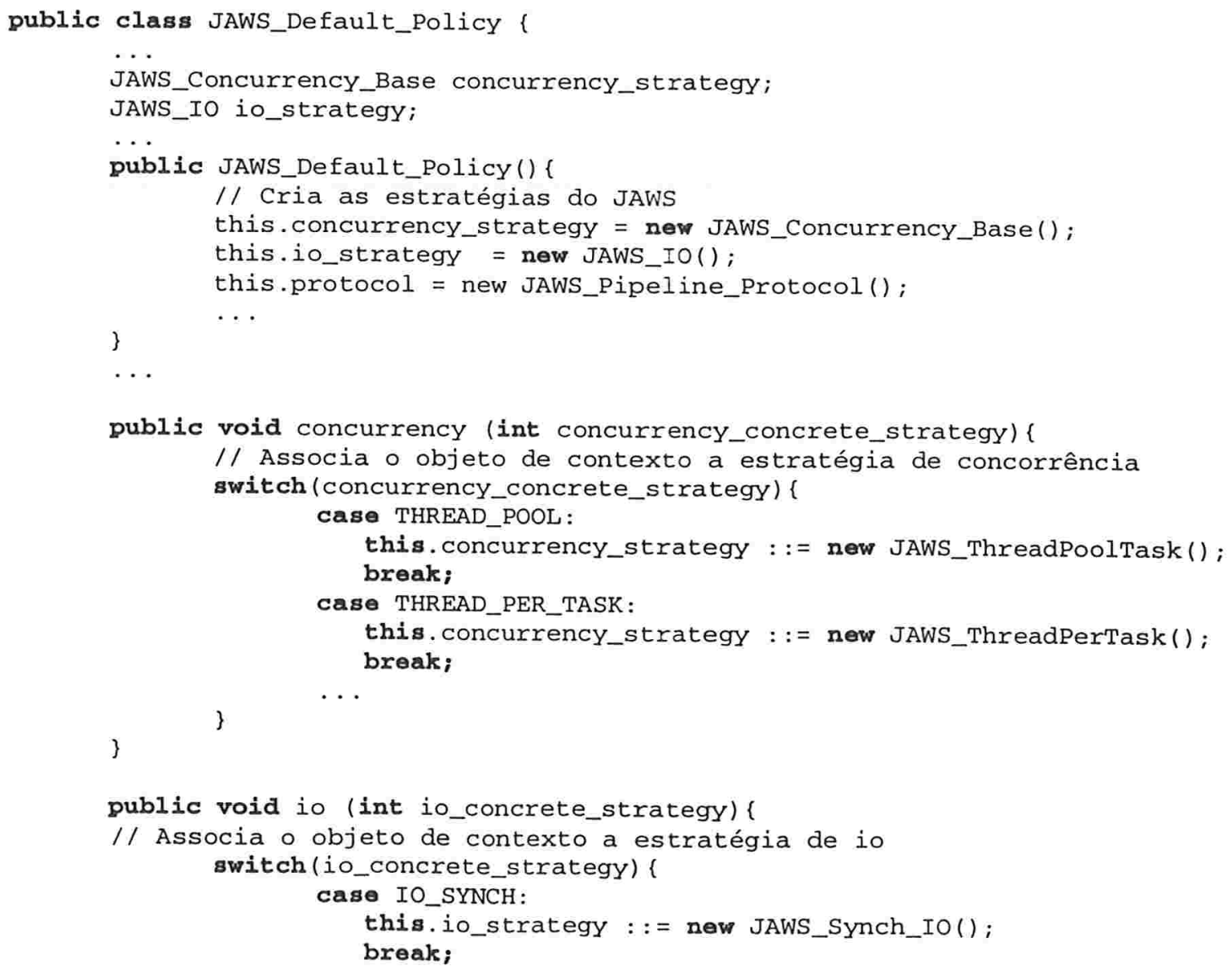




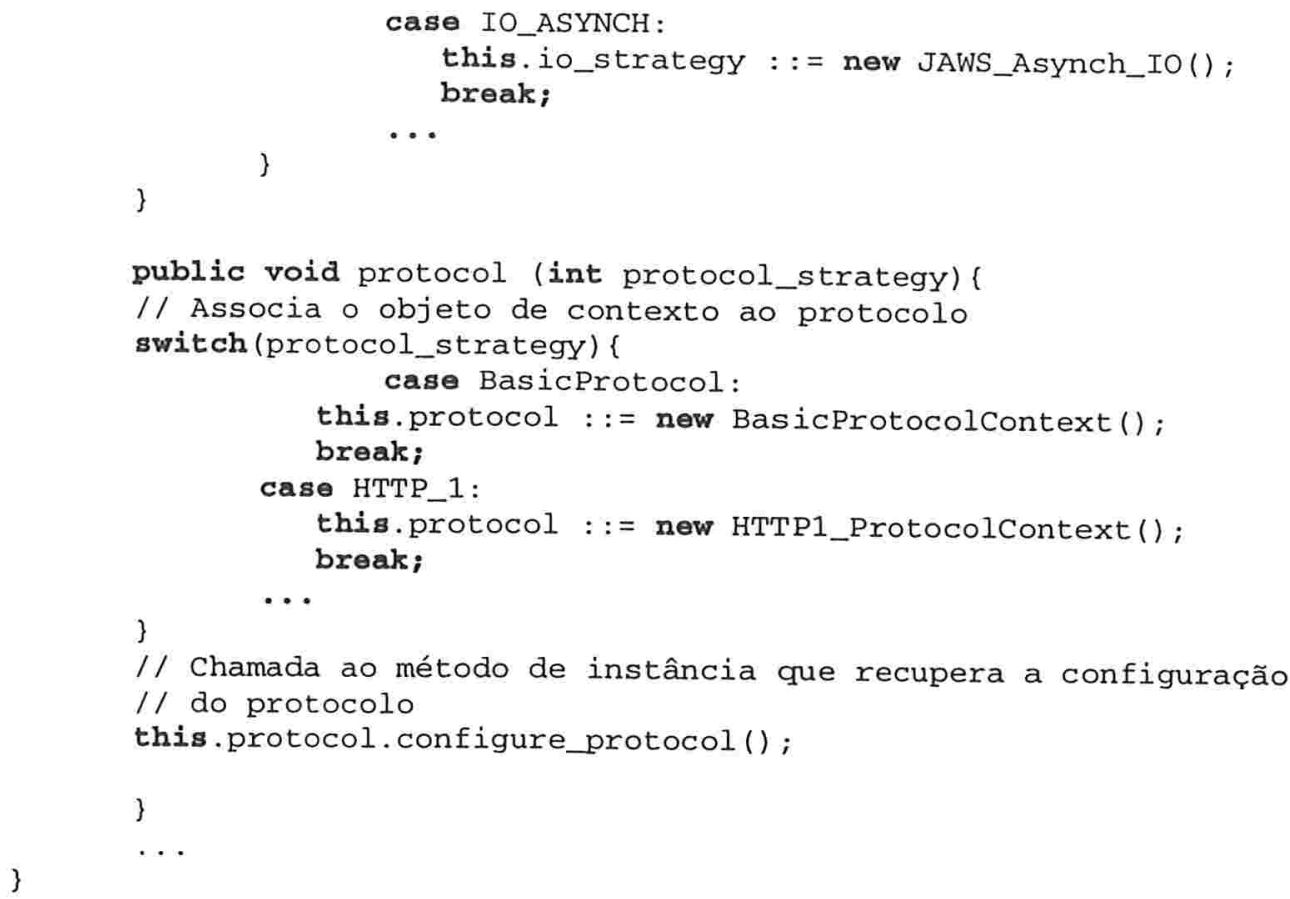

\subsubsection{Análise do Projeto do JAWS com Programação Adaptativa e Relações de Contexto}

A técnica de programação adaptativa oferece benefícios para a evolução de sistemas orientados a objetos quando estes possuem diversas funcionalidades cuja implementação torna necessário percorrer um conjunto de classes da sua estrutura. Programação adaptativa permite especificar separadamente: (a) as classes da estrutura do sistema que são necessárias para implementar determinada funcionalidade; e (b) o comportamento a ser executado quando percorrendo estas classes. Esta especificação traz alguns benefícios como: (a) reutilização do método traversal que determina as classes da estrutura do sistema que colaboram para implementação de suas funcionalidades; e (b) a possilidade de adaptação automática dos comportamentos do sistema especificados anteriormente a uma possível modificação em sua estrutura (inserção/remoção de classes, relações). No projeto do JAWS com programação adaptativa os seguintes comportamentos colaborativos foram modelados utilizando abstrações desta técnica:

- configuração das estratégias do JAWS;

- ativação dos threads da estratégia de concorrência e ativação da estratégia de aceitação de conexões;

- definição do protocolo HTTP do JAWS.

As estratégias adaptativas do JAWS foram modeladas usando relações de contexto. Todas elas são implementadas no projeto original através de hierarquias de classes, onde as estratégias concretas são subclasses de uma classe que representa os elementos comuns de cada estratégia. Estas subclasses expressam as variações dinâmicas que cada estratégia pode ter e são representadas no novo projeto como classes de contexto. Estas classes de contexto se responsabilizam pela extensão de métodos 
específicos das classes base que representam as estratégias. Algumas vantagens identificadas neste novo projeto das estratégias do JAWS com relações de contexto foram:

- definição de um estado comum: no projeto original do JAWS quando uma estratégia é substituída por outra, pode ser necessário transferir algum estado mantido pela antiga estratégia para a nova. O projeto com relações de contexto eliminou este problema representando cada estratégia como uma única classe-base. Tal classe-base mantém o estado da estratégia que ela representa. Uma vez instanciado um objeto de tal classe (uma estratégia do JAWS) este nunca mais será trocado por outro, apenas objetos de contexto serão associados a ele de forma a customizá-lo dinamicamente. Por se tratar de um sistema concorrente, o JAWS pode, entretanto, permitir em um dado instante (no momento que as estratégias estão sendo trocadas) que duas variações de uma mesma estratégia possam coexistir, uma para atender os pedidos cujo processamento já havia sido iniciado e outra para atender aos pedidos que foram solicitados a partir daquele instante. Neste caso, seria necessário a criação de uma nova estratégia (objeto da classebase) customizado com uma de suas variações dinâmicas (objeto de contexto) e poderia ser necessário a transferência de algum estado da antiga estratégia para a nova. Assim, a vantagem de definição de um estado comum só é válida para os casos em que duas variações dinâmicas relacionadas não necessitem coexistir;

- separação do interesse de variação dinâmica: as classes de contexto de cada estratégia representam explicitamente os métodos de cada uma delas que podem variar dinamicamente. Isto permite um melhor entendimento do comportamento de cada estratégia que poderá ser modificado durante a execução do sistema;

- evolução do comportamento dinâmico: além de permitir a separação do interesse de variação dinâmica, as classes de contexto podem ser facilmente desacopladas da classe-base, a qual estão associadas. Este acoplamento fraco facilita a evolução do sistema permitindo substituir as classes de contexto que determinam as variações dinâmicas do sistema por outras novas;

- configuração: cada classe de contexto pode além de definir as variações dinâmicas de cada estratégia, pode também manter estado e comportamento necessários a determinada estratégia concreta. $O$ estado de cada objeto de contexto pode ser configurado no seu próprio método construtor. Assim, cada classe de contexto pode definir uma nova configuração para um determinado interesse/comportamento do sistema, podendo inclusive ser dinamicamente associada ou desassociada do sistema.

\subsection{Comparação do Estudo de Reengenharias do JAWS}

O estudo de aplicação das técnicas de programação orientada a aspectos e programação adaptativa com relações de contexto nas reengenharias do projeto do JAWS demonstrou que a técnica de programação orientada a aspectos permite expressar de forma mais clara os interesses de adaptação presentes no JAWS do que a técnica de programação adaptativa com relações de contexto e traz vários benefícios significativos para o projeto destes interesses usando a abstração de aspectos, tais como, a separação dos interesses de adaptação dos interesses funcionais do sistema e facilidades na 
reutilização, evolução estática, configuração dinâmica e entendimento progressivo do sistema. A técnica de programação adaptativa se apresenta como uma solução viável e útil para o projeto de sistemas em que são identificadas muitas interações entre os objetos da sua estrutura. Já o mecanismo de relações de contexto demonstrou ser útil para o projeto de interesses de variação dinâmica de métodos de classes.

Na seção 6.3 do capítulo 6 de conclusões gerais do estudo de casos são apresentadas propostas para a integração das técnicas de programação orientada a aspectos e programação adaptativa com relações de contexto. Estas propostas visam possibilitar a utilização conjunta das técnicas com cada uma delas endereçando o projeto de diferentes interesses do sistema. 


\section{Reengenharia do Projeto do Dispatcher/SPIN}

Este capítulo descreve o projeto original do sistema operacional extensível SPIN e as reengenharias do seu projeto usando as técnicas investigadas nesta dissertação. A seção 5.1 descreve as características, estrutura e comportamento do SPIN, mais particularmente do subsistema Dispatcher, responsável pela implementação do seu modelo de eventos. A seção 5.2 apresenta a reengenharia do projeto do Dispatcher/SPIN usando programação orientada a aspectos e a seção 5.3 apresenta a reengenharia do seu projeto usando programação adaptativa com relações de contexto. Cada uma das seções 5.2 e 5.3 descreve o método empregado e modelos resultantes do processo de reengenharia, assim como uma subseção de análise do novo projeto gerado em comparação com o projeto original do Dispatcher/SPIN.

\subsection{SPIN - Sistema Operacional Extensível}

O SPIN [BSP+95, PB96] é um sistema operacional extensível que pode ser dinamicamente customizado para atender os requisitos de funcionalidade e desempenho de suas aplicações. A principal motivação para o desenvolvimento do SPIN é baseada no fato de que os sistemas operacionais não podem atender a demanda de diversos tipos de aplicações oferecendo uma única implementação para seus serviços. Embora alguns sistemas operacionais atuais possam ser especializados para atender as necessidades de suas aplicações, isto é feito a custa de grande esforço por parte dos programadores.

O SPIN permite que aplicações estendam as interfaces e implementações do sistema operacional de forma a atender suas necessidades, através da instalação de extensões junto ao kernel. O kernel do SPIN define apenas alguns serviços de baixo nível, como por exemplo, acesso a dispositivos, ligação dinâmica e gerência de recursos de memória e processamento. Serviços como memória virtual e threads no nível do usuário são oferecidos por extensões instaladas junto ao kernel. Ambos, kernel e extensões do SPIN, são implementados usando a linguagem Modula-3 [Nel91].

A arquitetura do SPIN define uma infraestrutura que permite combinar código do sistema operacional e das extensões de aplicações de forma segura. Ela determina os modelos de:

- proteção - responsável pela definição de mecanismos de controle de acesso das extensões para os recursos do sistema;

- extensão - responsável pela definição dos mecanismos que permitem que as extensões modifiquem os serviços do SPIN ou a forma como eles são oferecidos; 
O modelo de extensão do SPIN representa a forma como tal sistema permite ser adaptado. Assim, dentro de nosso estudo foram investigados apenas os componentes presentes neste modelo. Na seção seguinte é descrito mais detalhadamente o modelo de extensão do SPIN.

\subsubsection{Modelo de Extensão do SPIN}

O modelo de extensão do sistema operacional SPIN é baseado em eventos [PB96]. Um evento para o SPIN é qualquer procedimento Modula-3. Uma chamada ao procedimento indica a ocorrência do evento definido por ele. Extensões interessadas em modificar a funcionalidade do sistema indicam o interesse em eventos específicos exportados pelos módulos internos do kernel, e a partir da ocorrência destes ocasionam a execução de suas operações.

O mecanismo de extensão do SPIN é implementado por um módulo Modula-3, denominado Dispatcher. Uma das funções do Dispatcher é permitir o registro de handlers em eventos do SPIN. Handlers representam as operações de extensões que modificam a funcionalidade do SPIN. Os handlers são executados a partir da ocorrência dos eventos nos quais eles estão registrados, e podem ser instalados ou removidos dinamicamente em/de um determinado evento. Cada evento pode ter um, nenhum ou vários handlers registrados. Cada handler pode se registrar junto a um ou mais eventos também.

Cada handler pode ter associado um guard que determina uma condição para a sua execução na ocorrência do evento ao qual ele está instalado. Os guards representam operações cujo resultado é um objeto do tipo boolean, podendo assumir os valores: true neste caso o handler pode ser executado; ou false - neste caso o handler não será executado. O SPIN define ainda o conceito de imposed guards que são guards que podem ser associados e removidos dinamicamente de handlers. Cada handler permite a instalação de vários imposed guards.

Como cada evento no SPIN é definido como um procedimento Modula-3, o seu handler original será sempre o procedimento que o define. O handler original de um dado evento é sempre executado na sua ocorrência, a menos que seja desinstalado.

Nos casos em que todos os guards dos handlers de um evento são avaliados para false, pode-se definir um handler default para ser executado.

Para eventos que retornam algum resultado é necessário a definição de um mecanismo que permita a manipulação de diversos resultados quando existirem vários handlers instalados junto a um mesmo evento. Result Handlers são utilizados com tal finalidade.

Cada um dos elementos (handlers, guards, imposed guards e handlers result/default) quando instalados junto a um evento, permitem ter associado estruturas de 
dados que mantém informações de interesse ao elemento. Estas estruturas são chamadas closures e deve ser instaladas junto com o elemento a que estão associadas. O Dispatcher se responsabiliza por passar o closure como argumento durante a chamada de execução do elemento.

A figura 5.1 apresenta os elementos que fazem parte do modelo de eventos do SPIN dentro do contexto de ocorrência de um evento específico (uma chamada ao procedimento que representa tal evento). Neste evento existe, além do handler original, dois handlers adicionais instalados sobre o mesmo. Um destes handlers possui apenas um guard associado, e o outro possui um guard e um imposed guard. Foram também instalados para este evento um handler result e um default.

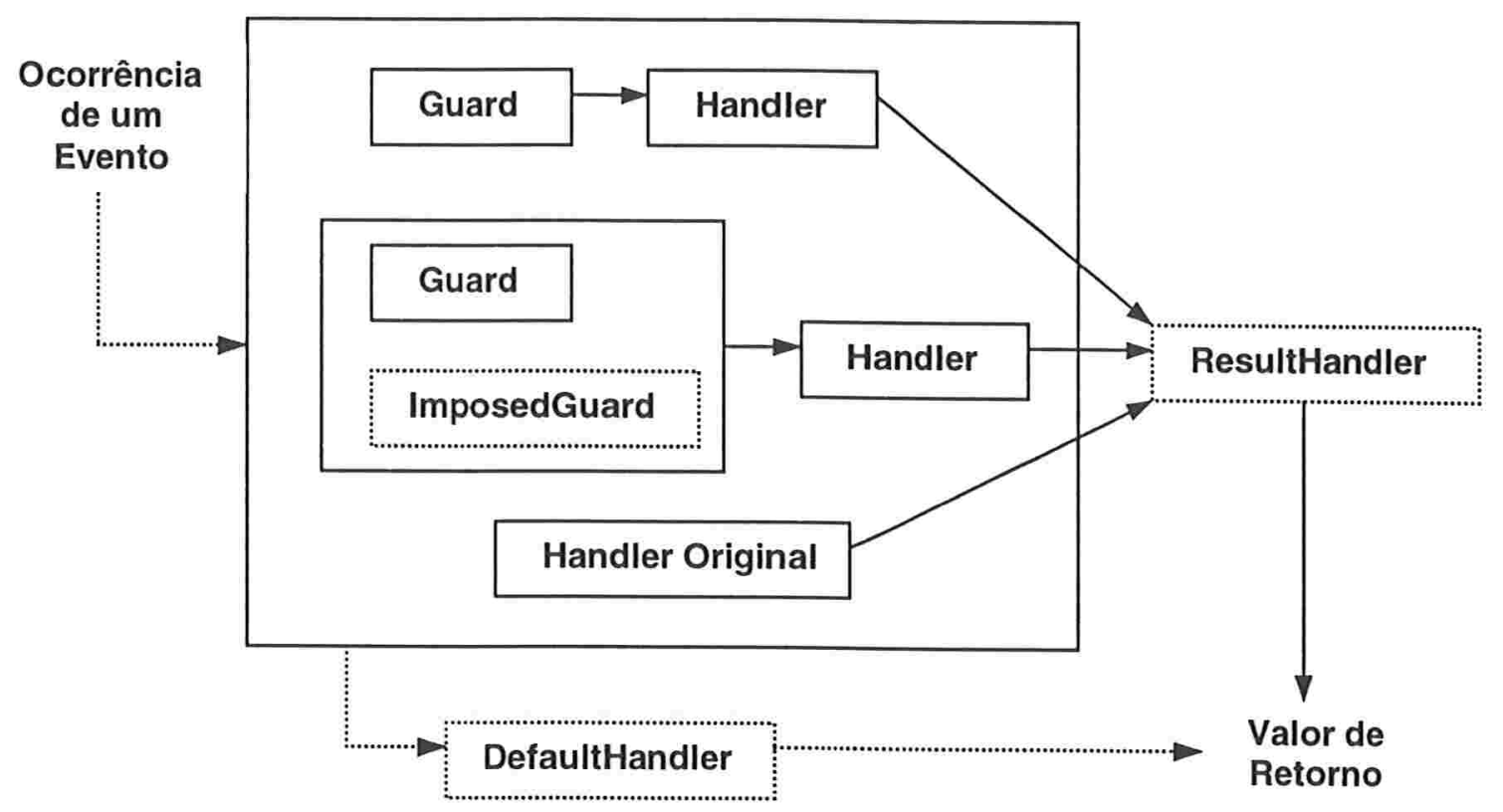

Figura 5.1: Modelo de Eventos do SPIN

\subsubsection{Módulo Dispatcher}

O módulo Dispatcher do SPIN é responsável: (a) pela instalação de handlers, guards, imposed guards, e handlers default e result, em eventos do kernel do sistema; e (b) pelo despacho de eventos, que envolve a execução dos elementos instalados junto aos mesmos. Para implementar tal funcionalidade, ele mantém internamente: (1) uma tabela dos eventos que tiveram novos handlers registrados; e (2) um conjunto de estruturas contendo informações sobre os elementos instalados junto a eventos; estas estruturas são consultadas durante o despacho de eventos ocorrendo no sistema.

O Dispatcher foi implementado usando abstrações de Módula-3, sendo definido como um módulo nesta linguagem. Ele exporta interfaces contendo conjuntos de procedimentos necessários à implementação da sua funcionalidade. A estrutura e interfaces do Dispatcher são apresentadas nas subseções seguintes. 


\subsubsection{Estrutura do Dispatcher}

Apesar de Modula-3 oferecer suporte para programação orientada a objetos, o Dispatcher utiliza na sua implementação os recursos oferecidos nesta linguagem para programação modular. As técnicas investigadas nesta dissertação estendem o modelo convencional de orientação a objetos. Para permitir a aplicação dos conceitos presentes nas técnicas, foi necessário mapear os módulos da estrutura do Dispatcher para classes de linguagens orientada a objetos. Esta nova estrutura é apresentada na figura 5.2 como um diagrama de classes UML.

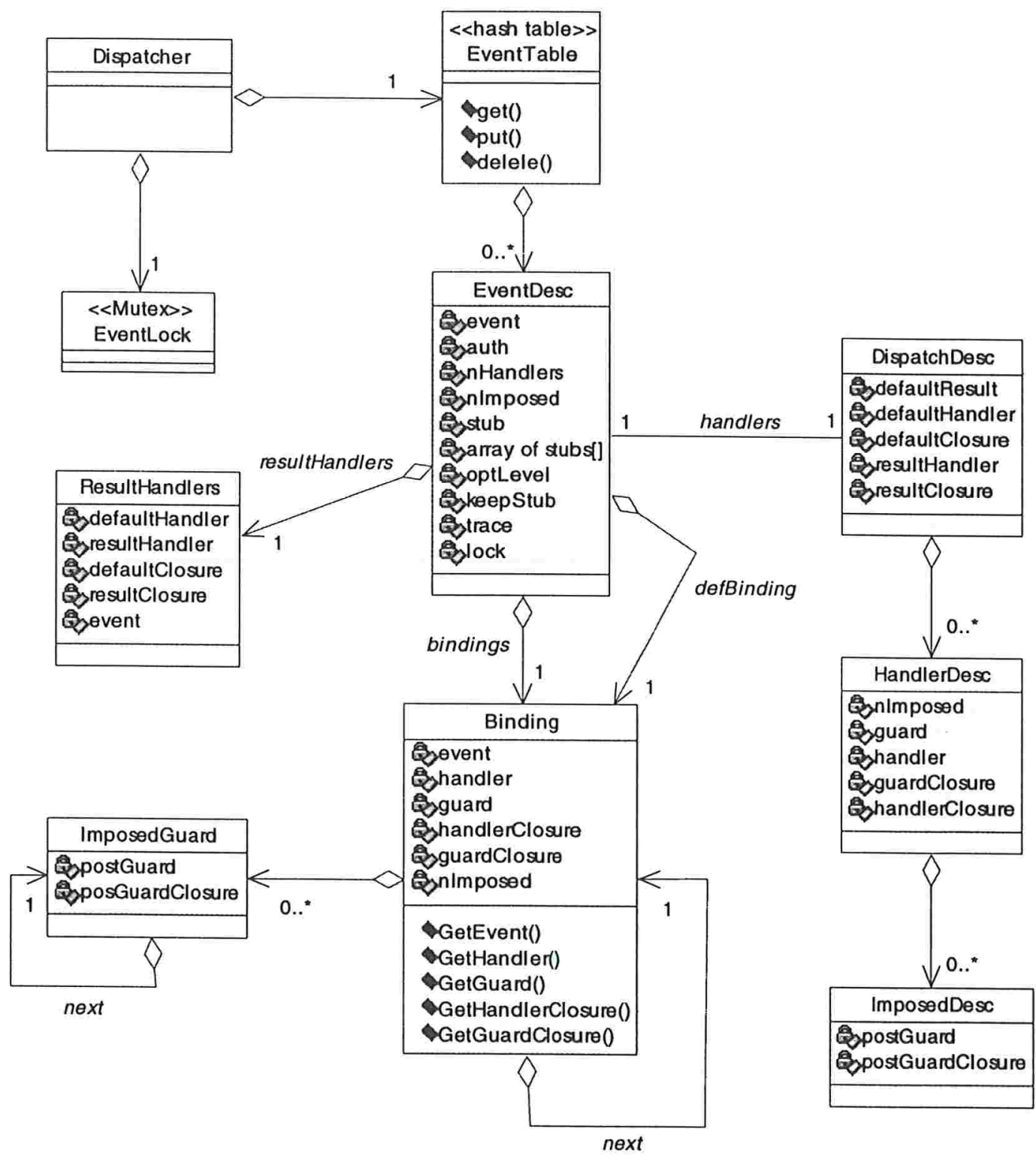

Figura 5.2: Diagrama de classes da Estrutura Original do Dispatcher 
O Dispatcher mantém internamente a EventTable (figura 4.15), um hash que associa eventos a seus respectivos descritores EventDesc. A tabela EventTable mantém referências para descritores de eventos (EventDesc). Um EventDesc mantém as informações de interesse de cada evento, sendo elas: (a) informações sobre o próprio procedimento que representa o evento; (b) informações sobre os elementos (handlers, guards, imposed guards e handlers default/result) registrados junto ao evento; e (c) informações sobre os stubs (descritos mais detalhadamente na subseção 5.2.2.7) gerados para o evento.

Dentro do conjunto de informações mantidas pelo EventDesc sobre os elementos registrados junto ao evento há uma referência para um DispatchDesc. Um DispatchDesc é responsável por manter o estado do evento que é necessário para o seu despacho. Assim, ele mantém referências para os handlers default e result (e respectivos closures) do evento e para um conjunto de HandlerDesc - que por sua vez mantém o estado de cada handler instalado no evento. Cada HandlerDesc armazena entre suas informações referências para ImposedDesc, que representam o estado de cada imposed guard instalado dinamicamente em um handler.

Cada EventDesc mantém ainda referências para objetos do tipo Binding e para um objeto do tipo ResultHandlers. Objetos Binding são responsáveis por associar handlers e guards a eventos do sistema; eles são criados sempre que um novo handler é instalado junto a um evento e mantém informações relacionadas a tal handler, tais como, referências para os procedimentos que representam o evento, o próprio handler, seu guard e imposed guards. Objetos ResultHandlers armazenam informações sobre handler result e default e seus respectivos closures.

\subsubsection{Interface do Dispatcher}

Nesta subseção são apresentadas as interfaces que o Dispatcher exporta para permitir a instalação de extensões junto ao sistema e para realizar o despacho de eventos que ocorrem no kernel.

a) Interface para instalação e remoção de handlers

Esta interface contém quatro procedimentos:

(1) Create () - procedimento utilizado para criar um binding não ativo. O binding é o elemento responsável por associar handlers e guards a eventos do sistema. Este binding criado é passado como parâmetro para instalação do handler, através de uma chamada ao procedimento Install ();

(2) Install ( ) - procedimento utilizado para instalação e ativação de um binding;

(3) Uninstall () - procedimento utilizado para desinstalação de um binding; 
(4) InstallHandler () - este procedimento realiza em um único passo a criação e instalação de um binding, sendo uma composição dos procedimentos Create() e Install().

Abaixo apresentamos as assinaturas dos procedimentos desta interface.

PROCEDURE Create (event: PROCANY; guard: PROCANY; handler: PROCANY;

guardClosure: REFANY := NIL;

handlerClosure: REFANY := NIL;

options: Options := Defaultoptions;

key : Auth.Key := NIL ): Binding RAISES \{ Error \};

PROCEDURE Install (binding: Binding) RAISES ( Error \};

PROCEDURE Uninstall (binding: Binding) RAISES \{ Error \};

PROCEDURE InstallHandler (event: PROCANY; guard: PROCANY;

handler: PROCANY; guardClosure: REFANY := NIL;

handlerClosure: REFANY := NIL; options:

Options := Defaultoptions; key: Auth. Key := NIL

): Binding RAISES \{ Error \};

b) Interface para manipulação de um conjunto de handlers.

Esta interface define os seguintes procedimentos:

(1) SwapHandlers () - este procedimento recebe como parâmetro duas listas de bindings, as quais podem estar associadas ao mesmo evento ou eventos distintos. Ele permite a instalação da primeira lista de binding e desinstalação da segunda dentro de uma única operação atômica;

(2) GetHandlers () - permite a recuperação da lista de bindings instalados em um evento específico;

(3) IsInstalled ( ) - verifica se um dado binding está ativo ou não;

(4) GetoriginalHandler ( ) - retorna o handler original de um evento.

Abaixo apresentamos as assinaturas dos procedimentos desta interface.

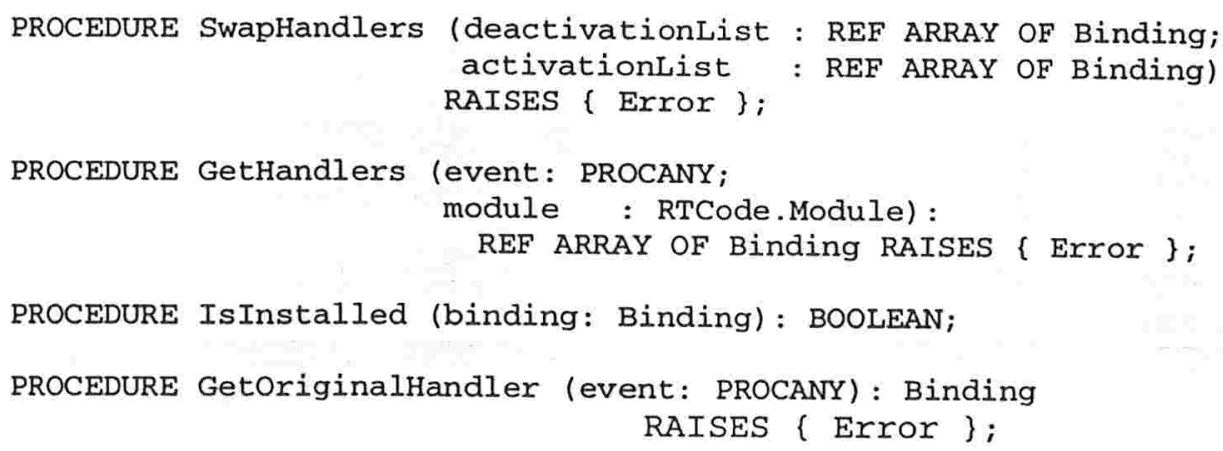

c) Interface para instalação de handlers default e result

Esta interface contém os seguintes métodos: 
(1) InstallResultHandler() - permite a instalação de um handler para manipulação dos resultados dos diversos handlers instalados em um dado evento;

(2) InstallDefaultHandler() - permite a instalação de um handler em um evento, que será executado no caso em que nenhum handler instalado para este mesmo evento seja invocado.

As assinaturas dos procedimentos desta interface são apresentadas abaixo.

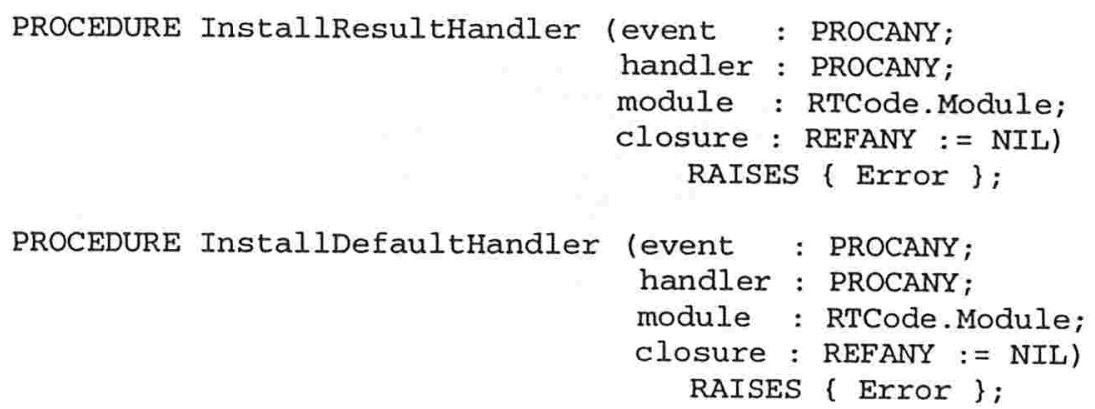

d) Interface para definição de execução assíncrona

Esta interface possui dois procedimentos:

(1) SetAsynchronousEvent () - este procedimento permite configurar a execução de um dado evento para o modo assíncrono. Isto significa que toda vez que ocorrer aquele evento no sistema, será criada uma nova thread para a execução dos seus handlers;

(2) SetAsynchronousHandler () - este procedimento permite configurar um dado handler para ser executado de forma assíncrona. Isto ocasiona a criação de uma thread para execução do handler sempre que ele é chamado.

Abaixo apresentamos a assinatura dos procedimentos desta interface.

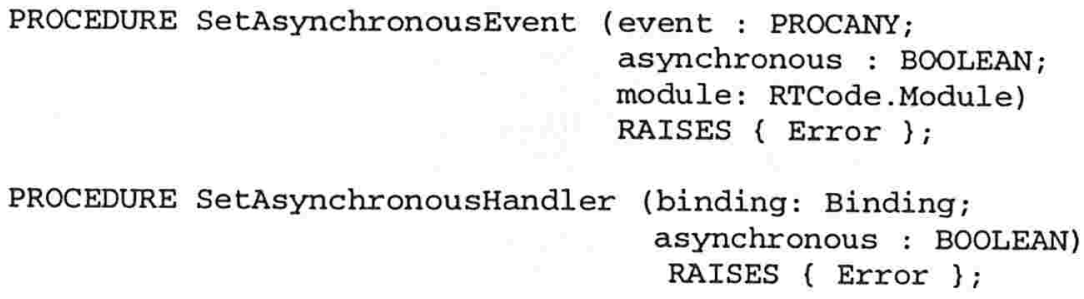

e) Interface para Autorização

Durante a instalação de handlers em um evento, estes passam por um serviço de autorização, que pode aceitar ou rejeitar tal pedido. O Dispatcher oferece uma interface que permite a instalação de serviços de autorização (authorizer) para um evento 
específico ou uma interface inteira. Os procedimentos da interface de autorização requerem, para permitir a instalação do authorizer, como um de seus parâmetros a identidade do módulo responsável pela implementação do evento ou da interface em que será instalado o serviço de autorização. Os seguintes procedimentos definem tal funcionalidade:

(1) InstallAuthorizerForInterface () - permite a instalação de um novo serviço de autorização para todos os procedimentos que fazem parte da interface passada como parâmetro;

(2) InstallAuthorizerForEvent () - possibilita a instalação de um novo serviço de autorização em um evento específico.

Abaixo apresentamos a assinatura de tais procedimentos.

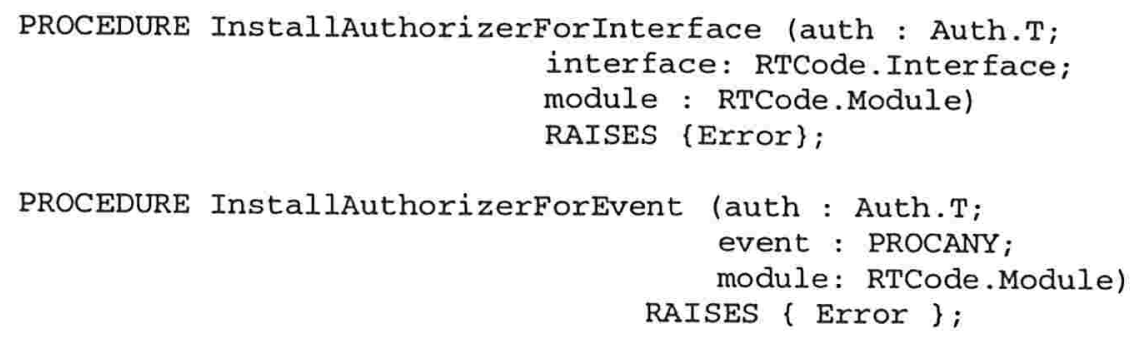

f) Interface para instalação e remoção de imposed guards

Esta interface oferece os seguintes procedimentos:

(1) ImposeGuard () - este procedimento permite a adição de um imposed guard para o conjunto já instalado em um dado evento;

(2) UnimposeGuard() - permite a remoção de um imposed guard do conjunto instalado para um determinado evento.

As assinaturas de tais procedimentos são apresentadas abaixo.

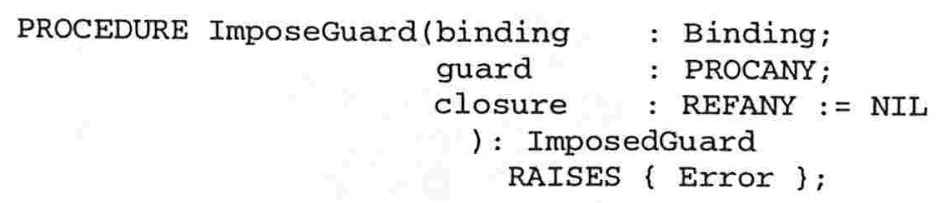

g) Interface para despacho de eventos

Esta interface oferece um único procedimento: 
(1) DebugDispatch() - este procedimento realiza o despacho de um evento que ocorreu no sistema. Ele percorre as informações para despacho de eventos (DispatchDesc, HandlerDesc e ImposedDesc) mantidas pelo descritor do evento em questão (EventDesc). O despacho envolve a execução dos handlers instalados em um evento a partir da avaliação de seus respectivos guards e imposed guards. Handlers result e default podem também ser acionados cada qual em sua situação específica.

PROCEDURE DebugDispatch(desc: AliasDesc.T;

VAR args: DebugDispatchArgs): INTEGER

RAISES \{ Error \};

\subsection{Reengenharia do Projeto do Dispatcher com Programação Orientada a Aspectos}

Nesta seção apresentamos o método empregado e modelos resultantes do projeto do Dispatcher usando a abordagem AspectJ da técnica de programação orientada a aspectos. Durante análise do código-fonte do Dispatcher foram encontrados diversos entrelaçamentos relacionados a diferentes interesses de projeto. Estes entrelaçamentos são apresentados ao longo das subseções que descrevem o projeto de cada um dos aspectos do Dispatcher.

A implementação original do Dispatcher foi realizada usando a linguagem Modula-3. O código do Dispatcher projetado com programação orientada a aspectos é representado na linguagem orientada a objetos Java. O objetivo foi facilitar a criação do código dos aspectos que são especificados usando AspectJ, uma extensão orientada a aspectos para Java. Note entretanto, que a partir dos modelos gerados para o projeto do Dispatcher com programação orientada a aspectos estes poderiam ser mapeados para uma outra linguagem orientada a objetos.

\subsubsection{Componentes do Dispatcher}

Durante a etapa inicial de projeto do Dispatcher com a técnica de programação orientada a aspectos foram apenas consideradas as funções e componentes que tal módulo deveria ter para atender a funcionalidade básica de um sistema baseado em eventos. $\mathrm{O}$ conhecimento das características, estrutura, comportamento e interface do Dispatcher foi útil para tentarmos separar sua funcionalidade básica dos interesses adicionais que ele deveria também manter.

Um sistema baseado em eventos deve conter dois elementos essenciais: (1) eventos - que representam mensagens anunciando a mudança do estado do sistema ou solicitando diretamente um de seus serviços; e (2) handlers - que implementam operações a serem executadas na ocorrência dos eventos aos quais eles estão registrados. Estes elementos são representados no projeto original do Dispatcher através de um conjunto de estruturas (ver subseção 5.1.1.2). O projeto do Dispatcher com programação 
orientada a aspectos manteve inicialmente apenas as estruturas de seu projeto original relacionadas diretamente aos eventos e handlers. Estas estruturas foram reprojetadas e os elementos evento e handler foram representados como classes independentes.

Outra decisão de projeto, durante esta etapa, foi procurar manter a interface fornecida pelo módulo Dispatcher. Assim, os elementos guards foram incorporados ao modelo de componentes funcionais, após constatação da sua presença na interface de instalação e remoção de handlers. Também a abstração Binding (elemento responsável por associar handlers e guards a eventos do sistema) foi incorporada ao modelo de componentes funcionais devido a sua presença em diversos métodos da interface do Dispatcher. O elemento Binding no projeto com programação orientada a aspectos não mais agrega elementos imposed guards.

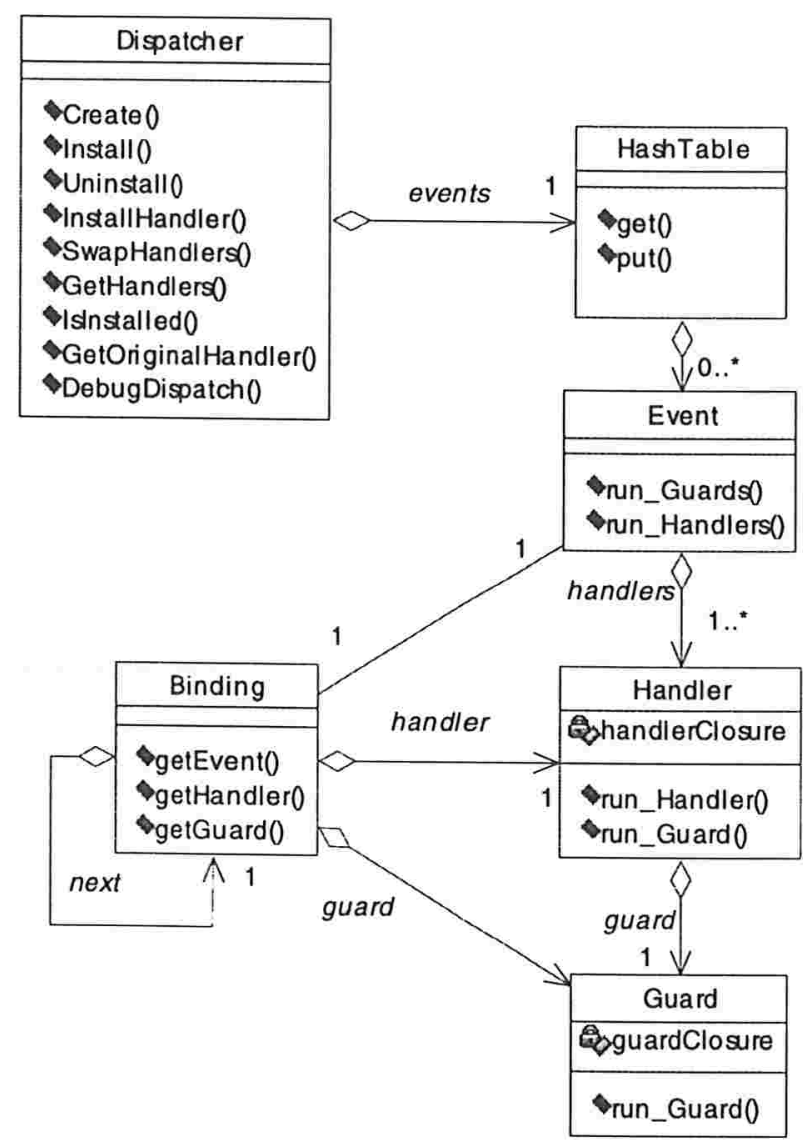

Figura 5.3: Diagrama de Classes do Projeto do Dispatcher com POA

Diagrama de classes para o projeto dos componentes funcionais do Dispatcher com programação orientada a aspectos (POA) é apresentado na figura 5.3. Como pode ser observado nesta figura, as únicas interfaces oferecidas pelo Dispatcher nesta sua estrutura inicial são: a interface para instalação e remoção de handlers, a interface para manipulação de um conjunto de handlers e a interface para despacho de eventos. Logo a seguir são também apresentados um diagrama de sequência do método 
DebugDispatch() (figura 5.4) e o código das classes do modelo de componentes funcionais projetados para o Dispatcher (este código é útil para entender o projeto de aspectos que afetam estes componentes funcionais).

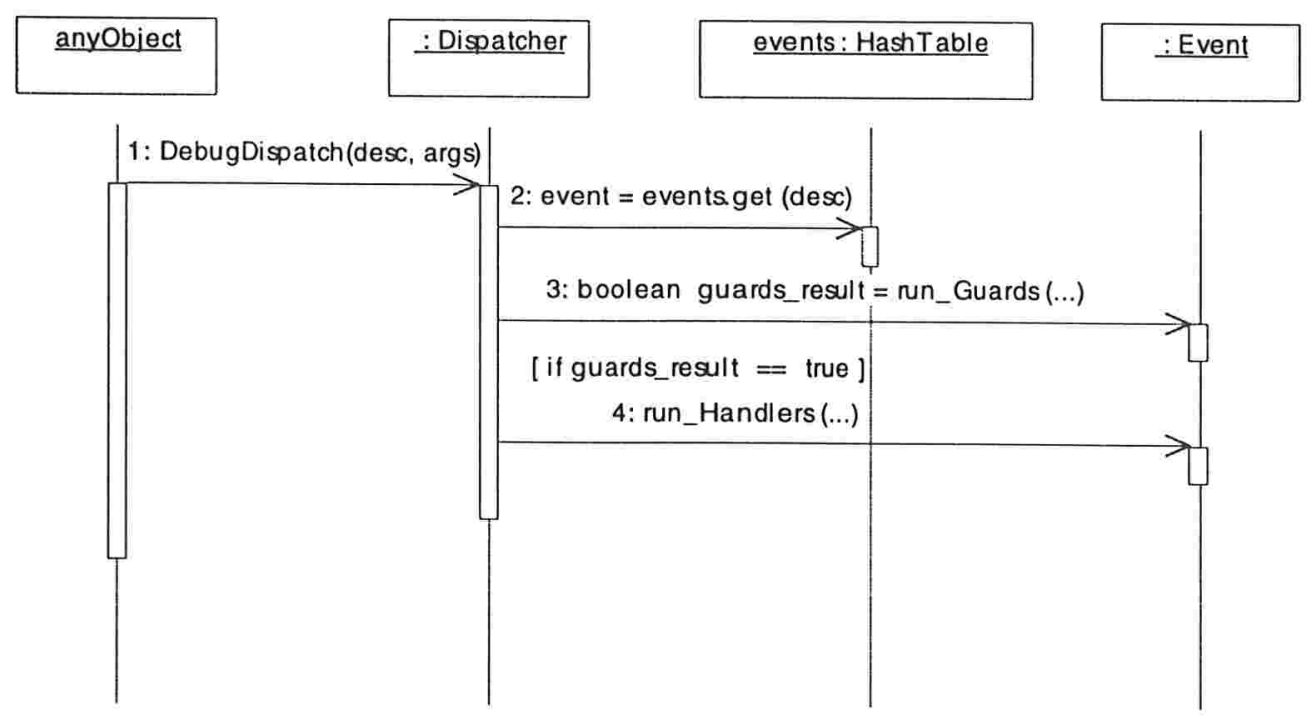

Figura 5.4: Diagrama de Sequiência do método DebugDispatch() da classe Dispatcher

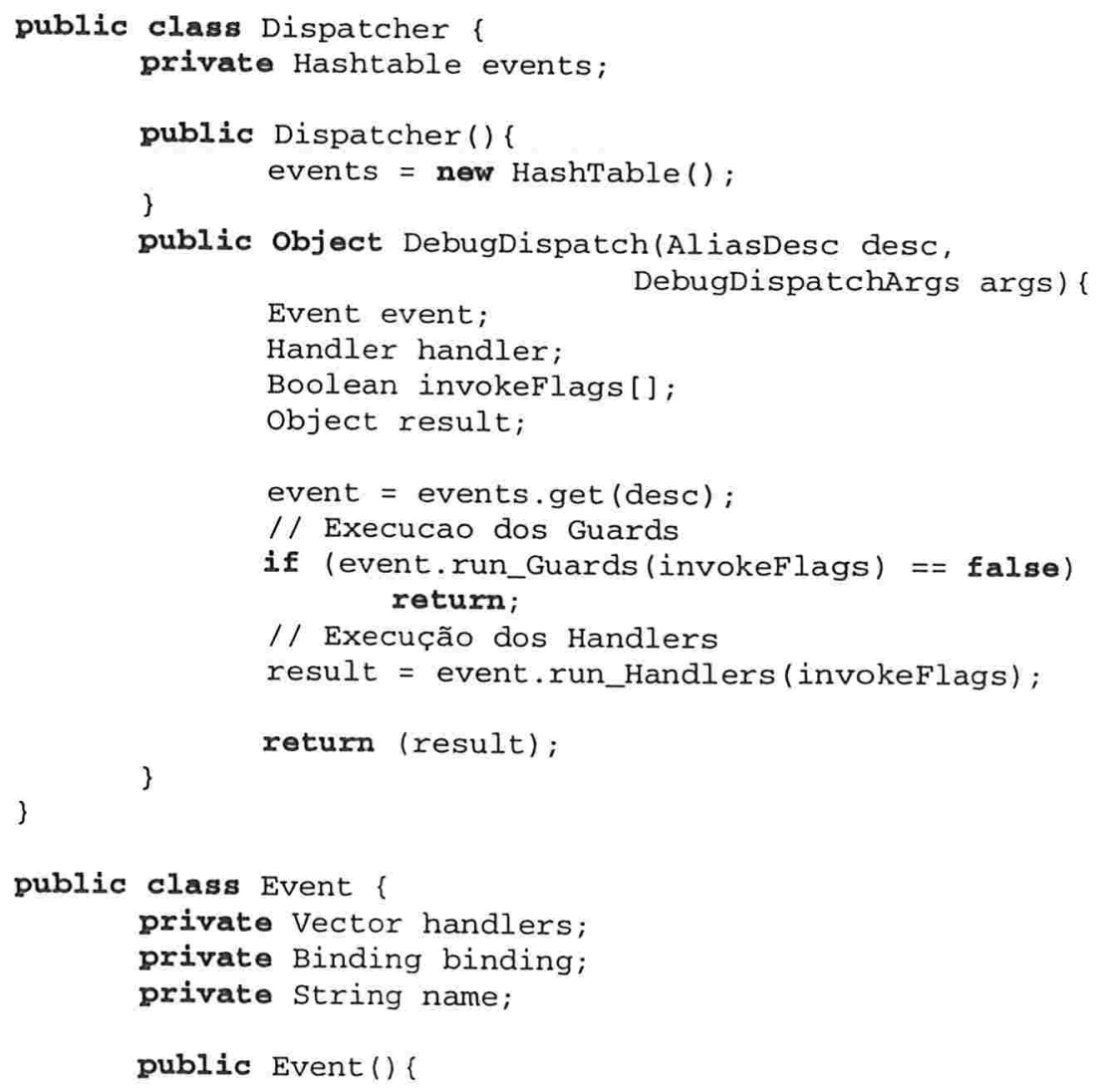


public boolean run_Guards (boolean invokeFlags []) \{

// Handler a ser recuperado Handler handler;

// Variavel booleana que indica algum handler sera invocado boolean invoked = false;

// Avaliacao dos Guardas

for (int $i=0 ; i<$ handlers.size(); ++i) \{

// Obtem proximo Handler handler = handlers.elementAt $(i)$ :

// Executa o Guard de cada um dos Handlers deste evento invokeFlags $[i]=$ handler.run_Guard () ;

if (invokeFlags $[i]==$ true) invoked = true;

\}

return true;

public object run_Handlers (boolean invokeFlags[]) \{

// Objeto de retorno

object result;

// Handler a ser recuperado

Handler handler;

// Avaliacao dos Handlers

for (int $i=0 ; i<$ handlers.size (); ++i) \{

// Obtem proximo Handler

handler $=$ handlers.elementAt $(i)$;

if (invokeFlags [i] $==$ trua)

// Executa um dos Handlers associado a este evento

\} result $=$ handler.run_Handler () ;

\}

return (result);

)

public class Handler \{

private Guard guard = null;

private Closure handlerclosure;

public Handler () \{\}

public object run_Handler () \{

object returnvalue;

// Execução do Handler

ReturnValue $=$ this . execute () .

\}

return returnValue;

public boolean run_Guard() \{

\}

\}

public class Guard \{

private Closure guardClosure;

public Guard ()$\{\ldots\}$

public boolean run_Guard()\{... $\}$ 


\subsubsection{Aspectos do Dispatcher}

O passo seguinte do projeto do Dispatcher com programação orientada a aspectos, após a identificação dos seus componentes funcionais básicos e a definição de uma estrutura para englobar tais elementos, foi iniciar a identificação dos aspectos que afetariam tais componentes. O entendimento da estrutura e comportamento original do Dispatcher, a compreensão dos interesses de projeto deste módulo e a detecção de entrelaçamentos e difusão de muitos destes interesses no código de diversos procedimentos de sua estrutura, ofereceram um conjunto de informações que permitiu a identificação dos diferentes aspectos envolvidos no projeto do Dispatcher. Estes aspectos são os seguintes:

(a) handler default - cada evento poderia permitir a instalação de um handler default que será executado nos casos em que nenhum de seus handlers seja chamado. Este handler poderia ser instalado dinamicamente;

(b) imposed guard - cada handler poderia dinamicamente ser afetado por guards que determinariam condições para a sua execução em situações específicas;

(c) result handler - eventos que retornam algum resultado e que possuem diversos handlers instalados, poderiam permitir a instalação dinâmica de um result handler, responsável pela manipulação dos diversos resultados de seus handlers e pela geração de um resultado único;

(d) serviço de autorização - cada evento poderia definir que tipos de handlers podem ser instalados junto ao mesmo ou condições para a instalação de um handler em um evento. Um serviço de autorização implementaria tal funcionalidade;

(e) execução assíncrona - o despacho de determinados eventos poderia ocorrer de forma assíncrona ao thread de controle responsável pelo "lançamento" do evento;

(f) sincronização de objetos - deve ser garantido o acesso mutuamente exclusivo a objetos que podem ser acessados de forma concorrente por diferentes threads e necessitam ter seu acesso sincronizado durante o despacho de eventos e a instalação de handlers e guards;

(g) checagem de tipos - para instalação segura de handlers e guards em um evento é fundamental a definição de mecanismos para checagem dos tipos de seus argumentos e valores de retorno.

(h) rastreamento da execução do Dispatcher - pode ser útil para atender as necessidades de depuração e administração do sistema;

(i) tratamento de exceções - o tratamento de exceções pode ser modelado separadamente em aspectos, evitando o entrelaçamento deste interesse com o código de diversas operações funcionais do sistema;

(j) geração de stubs - o projeto original do Dispatcher define funções para a geração de código em tempo de execução, que oferece versões otimizadas da rotina de despacho de eventos.

Nas subseções seguintes apresentamos a modelagem dos aspectos descritos acima, com exceção do aspecto de execução assíncrona cuja interface não foi implementada no projeto original do Dispatcher. Os aspectos (h), (i) e (j) foram 
parcialmente projetados, através da apresentação de alternativas de projeto que ilustram como eles poderiam ser tratados no projeto do SPIN com programação orientada a aspectos. Outros trabalhos [KL99, LL99] vem abordando de forma mais detalhada o projeto dos aspectos (h) e (i).

\subsubsection{Instalação de Imposed Guards e Handlers Default/Result}

No projeto original do Dispatcher, os elementos imposed guards e handlers default e result foram implementados de forma bastante acoplada aos componentes evento e handler, sendo mantidos dentro das estruturas internas que este módulo agrega. No projeto do Dispatcher com programação orientada a aspectos, estes elementos foram separados do modelo de componentes funcionais apresentado na subseção 5.2.1. As principais motivações para esta separação está na simplificação do modelo de componentes do Dispatcher e na possibilidade de um melhor entendimento do projeto destes elementos, que estão relacionados com a modificação dinâmica da semântica de despacho de eventos.

Assim, estes três elementos (imposed guards, e handlers default e result) foram representados no projeto do Dispatcher com programação orientada a aspectos utilizando a abstração de aspectos, tal como definido em AspectJ. Cada um deles afeta um ponto específico dos componentes Event e Handler, através da especificação de uma construção advice dinâmica. Isto permite que eles sejam dinamicamente acoplados ou desacoplados de tais componentes. Na figura 5.5 apresentamos um diagrama de aspectos e classes contemplando o novo projeto de tais elementos.

Nesta figura observamos que os aspectos DefaultHandler, ImposedGuard e ResultHandler definem: (I) os pontos específicos dos componentes Event e Handler que terão sua implementação afetada; e (II) um método abstrato que será implementado por subaspectos e que define funcionalidade a ser executada nos pontos indicados pelos aspectos.

O aspecto DynamicManager é responsável pela: (I) introdução da interface de instalação dos aspectos DefaultHandler, ImposedGuard e ResultHandler no Dispatcher; e (II) pela associação destes aspectos aos componentes funcionais que eles afetam.

Código-fonte dos aspectos descritos acima são também apresentados a seguir. 


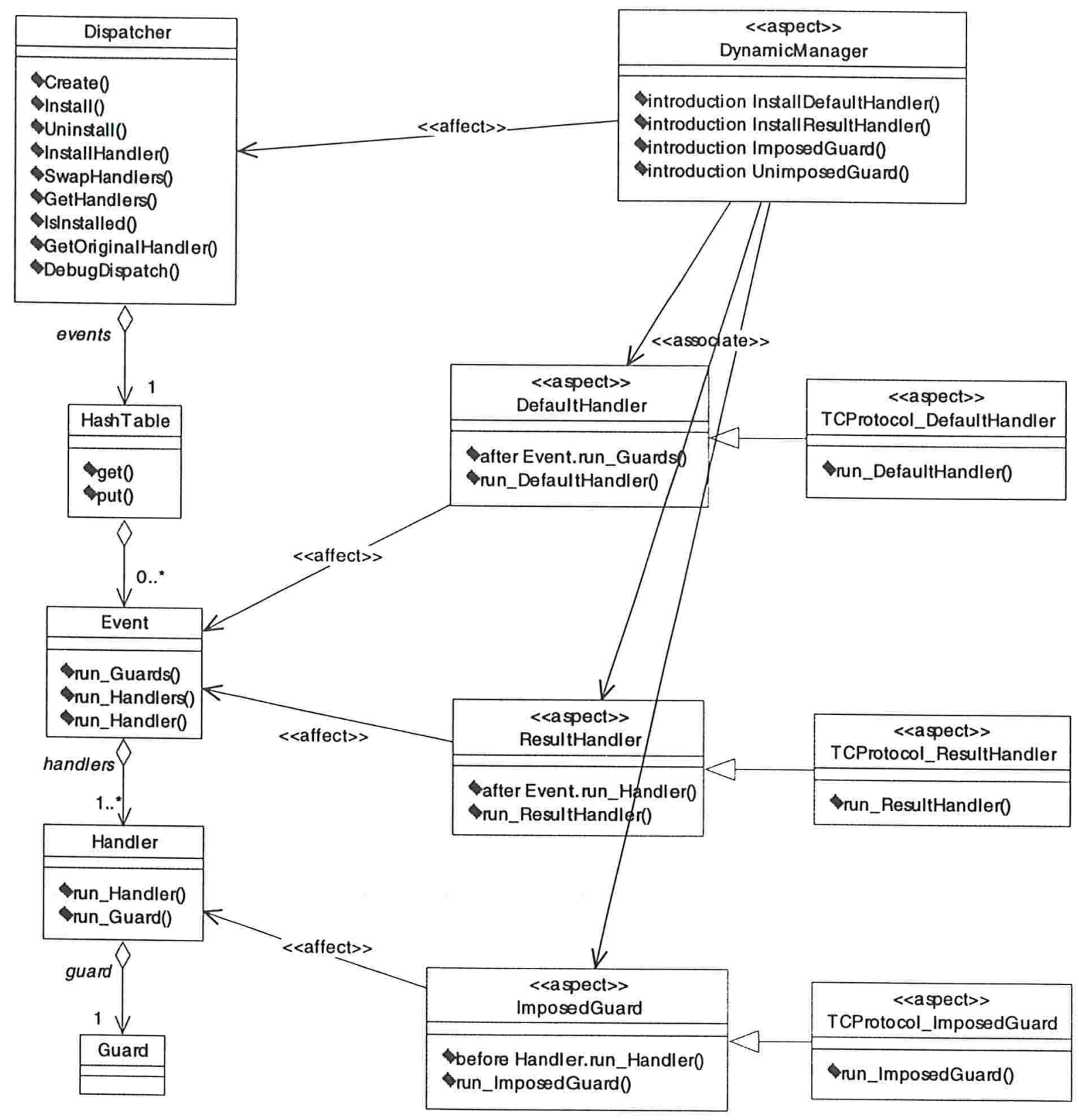

Figura 5.5: Diagrama de Aspectos e Classes dos Elementos Dinâmicos 


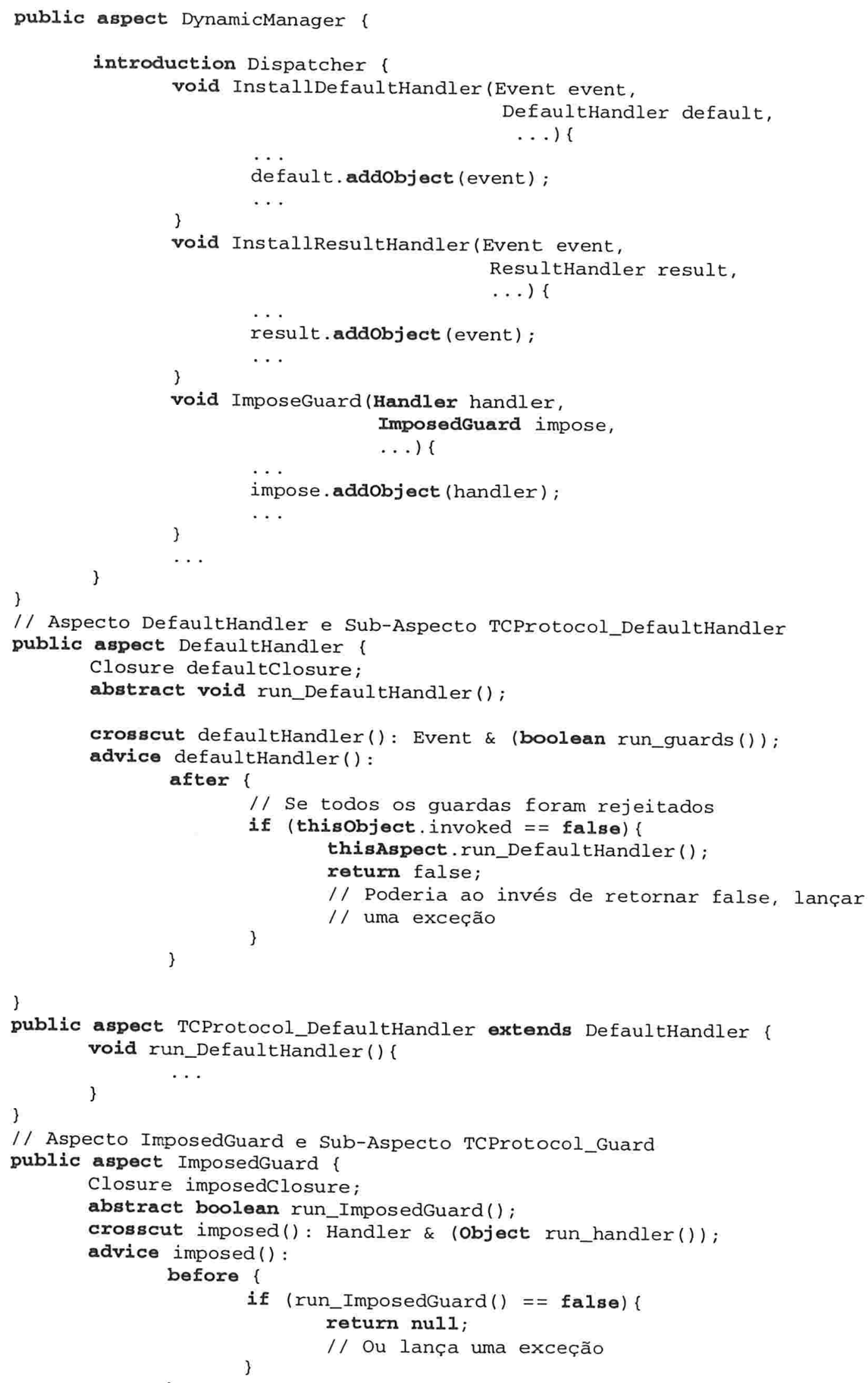




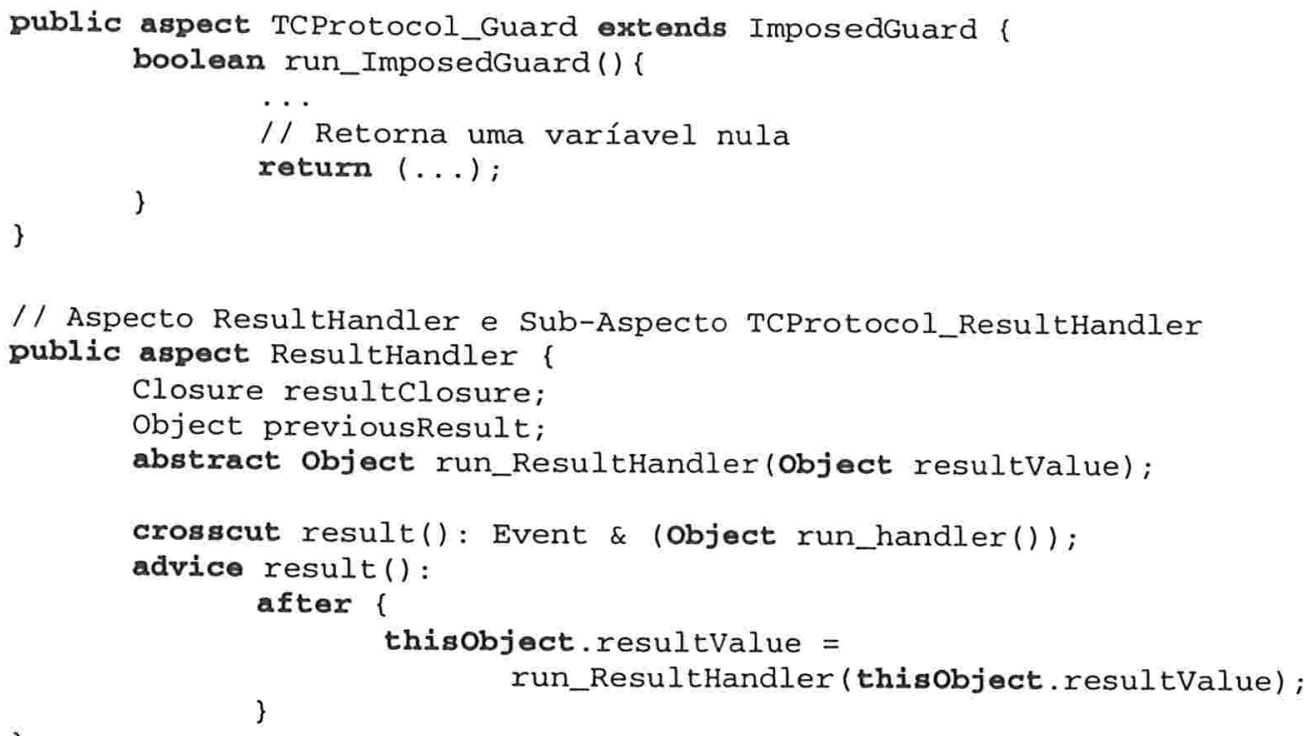

public aspect TCProtocol_ResultHandler extends ResultHandler \{

// Construtor deste Aspecto

public TCPProtocol_ResultHandler () \{

// Inicialização de previousResult

\} previousResult $=\ldots$;

Object run_ResultHandler (Object resultValue) \{ // Processa previousResult e resultValue ..

// Salva valor do ResulHandler thisAspect.previouResult $=\ldots$. // Retorna algum Object 
O projeto do elemento Resulthandler com programação orientada a aspectos tornou necessário a quebra do método run_Handlers() da classe Event, em dois métodos: (1) um que implementa um comando de iteração (for) para percorrer todos os objetos Handler do evento; e (2) outro que faz uma chamada ao método run_Handler () de cada objeto Handler do evento. Este segundo método será afetado pelo aspecto ResultHandler que manipula todos os valores de retorno das chamadas aos métodos run_Handler () dos objetos Handler do evento.

Apesar de termos apresentado o projeto dos elementos imposed guards, e handlers default/result como aspectos, acreditamos que projetá-los como classes seria uma alternativa válida já que eles estão diretamente ligados aos elementos funcionais básicos do Dispatcher. O projeto destes elementos com programação orientada a aspectos poderia ser motivado pela inserção destes elementos em um modelo de eventos tal como Dispatcher, que inicialmente não contemplasse os mesmos.

\subsubsection{Serviço de Autorização}

O serviço de autorização do projeto original do Dispatcher é implementado pelos procedimentos da sua interface InstallAuthorizerForInterface() e InstallAuthorizerForEvent(). Estes procedimentos recebem um parâmetro do tipo Auth que define um procedimento de autorização. Um procedimento de autorização é sempre executado durante a instalação de handlers nos eventos aos quais ele está associado. O retorno de um procedimento de autorização é um valor do tipo BOOLEAN, e indica a permissão ou impedimento da instalação de handlers no evento protegido. $\mathrm{O}$ EventDesc de cada evento é o responsável por manter uma referência para o seu procedimento de autorização dentro do projeto original do Dispatcher.

O procedimento privado do Dispatcher Realcreate() é chamado durante a tentativa de criação de um binding (associação de um handler com um evento) pelo procedimento create() da sua interface pública. Uma das atribuições do procedimento RealCreate() é chamar o procedimento privado Authcheck(). Este procedimento Authcheck() se responsabiliza pela execução do procedimento de autorização do evento em questão, podendo lançar uma exceção nos casos em que o valor de retorno do procedimento de autorização é false.

No projeto do Dispatcher com programação orientada a aspectos, o seu serviço de autorização foi reconstruído separadamente do seu modelo de componentes funcionais utilizando a abstração de aspecto. Tal aspecto, denominado Authorizer, é responsável: (I) pela introdução da interface de autorização no Dispatcher; (II) pela definição de uma construção advice estática que afeta o método Realcreate () do Dispatcher e especifica uma chamada ao método Authcheck () que é também introduzido no Dispatcher pelo próprio aspecto Authorizer; e (III) pela introdução de um objeto de autorização no componente funcional Event. Na figura 5.6, apresentamos um diagrama de aspectos e classes que representa a estrutura do novo projeto do serviço de autorização. O 
procedimento InstallAuthorizerForInterface(), apesar de estar presente na interface do Dispatcher, não possui uma implementação dentro deste módulo, assim ele não foi modelado no aspecto Authorizer. Código-fonte do aspecto Authorizer é também apresentado a seguir.

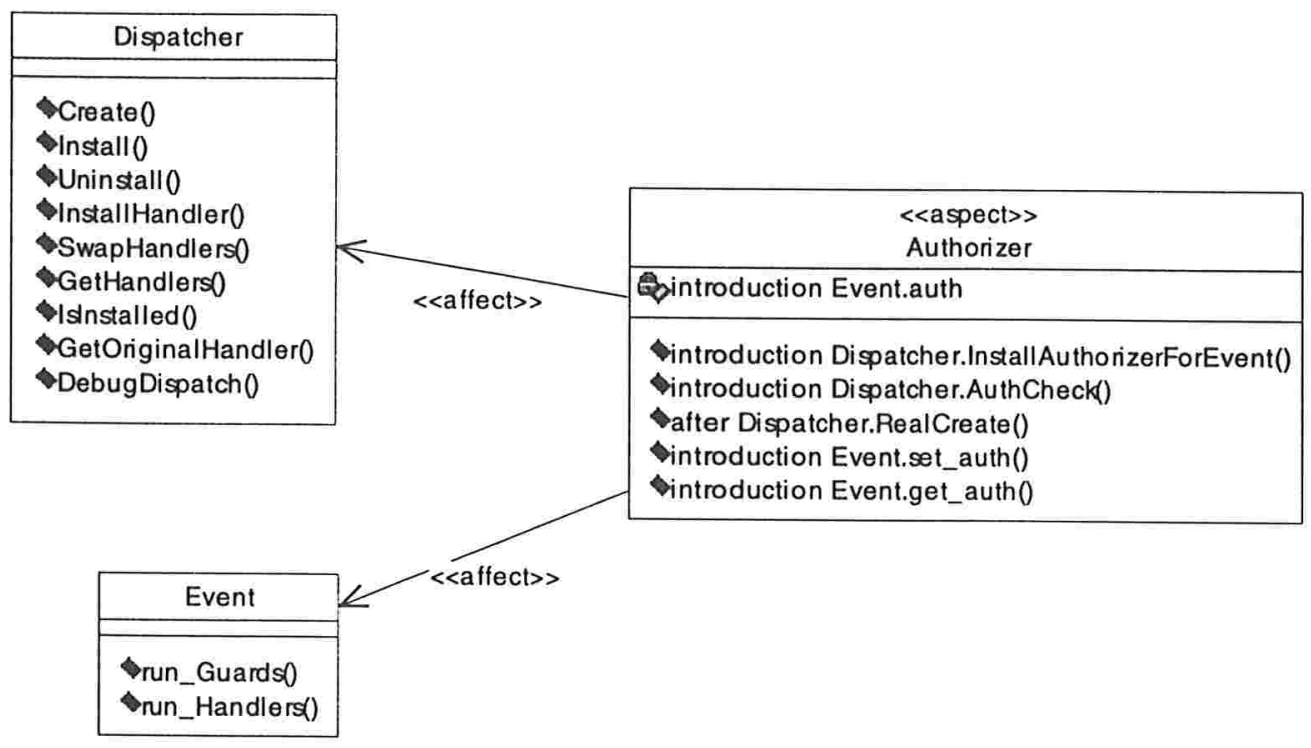

Figura 5.6: Diagrama de Aspectos e Classes do Serviço de Autorização

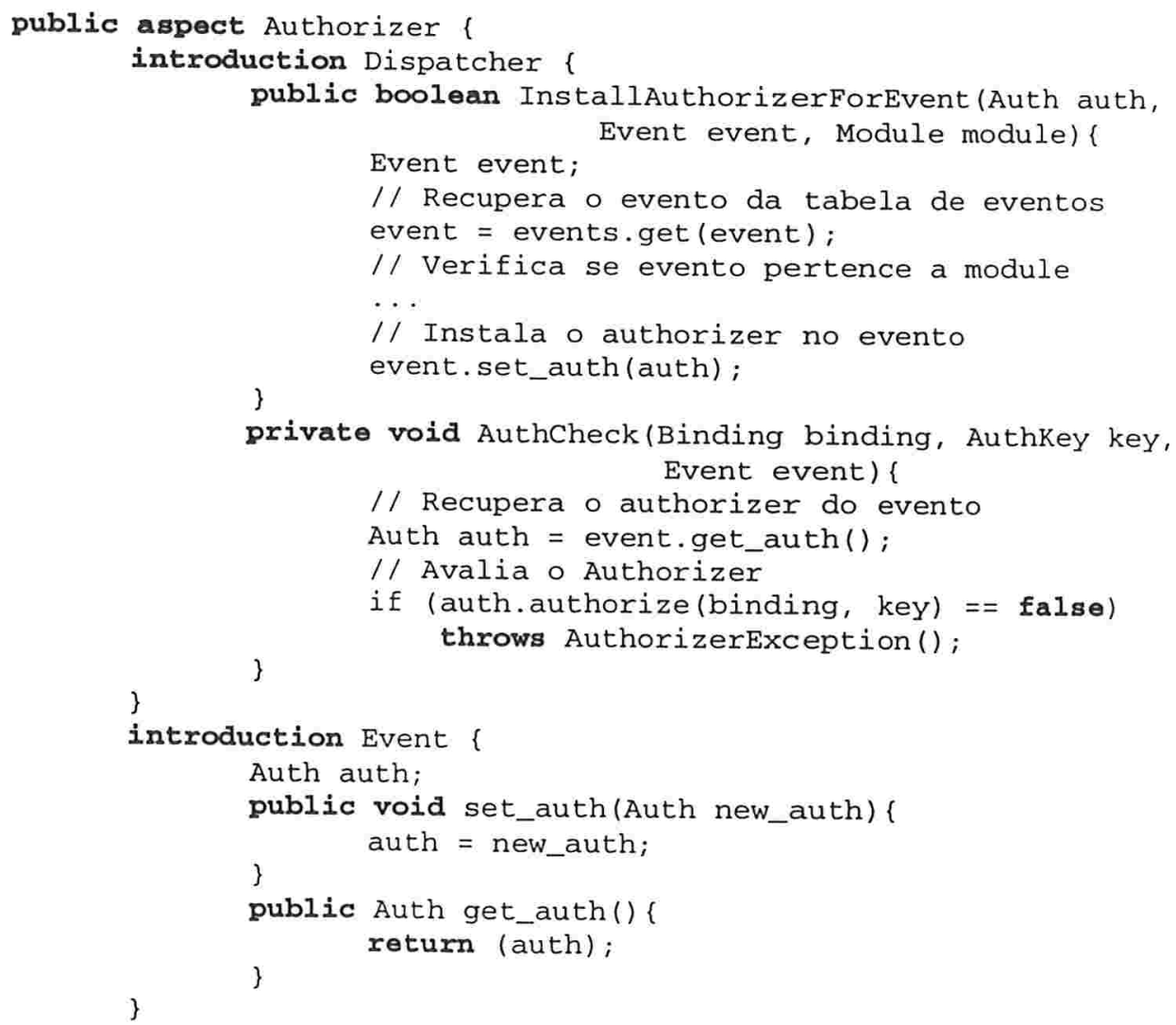




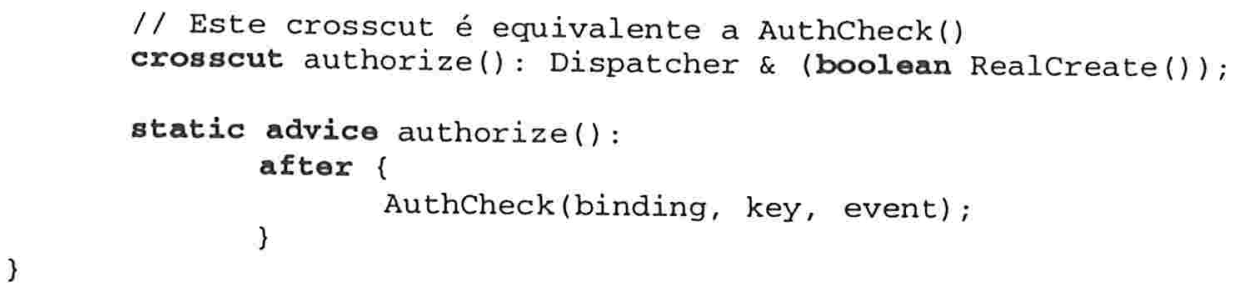

\subsubsection{Sincronização de Objetos}

O Dispatcher permite que suas operações sejam executadas concorrentemente por diferentes threads do sistema. Para garantir consistência no despacho de eventos é fundamental a definição de uma política de controle de concorrência no acesso as estruturas dos componentes funcionais mantidos pelo Dispatcher.

Durante análise do código dos procedimentos do projeto original do Dispatcher, foram identificadas diversas sincronizações de exclusão mútua (locks) no acesso às estruturas responsáveis por manter as informações de componentes eventos (objetos EventDesc). A captura destes mecanismos de sincronização demonstrou 0 entrelaçamento do interesse de sincronização com outros interesses funcionais do sistema. Os seguintes procedimentos do Dispatcher obtém acesso exclusivo ao componente evento durante sua execução: Install(), Uninstall(), InstallHandler(), AtomicSwap(), KeepStub(), SetoptLevel(), SetSave(), InstallAuthorizerForEvent(), AuthCheck(), UninstallGuard(), ImposeGuard().

O Dispatcher cria também durante sua inicialização um objeto MUTEX que permite definir um esquema de sincronização para um conjunto de procedimentos auto e mutualmente exclusivos. Os seguintes procedimentos fazem parte deste esquema: RealGetEventDesc(), GetProcDesc(), RecordStubs(), SetDefaultoptLevel(), TraceAll ().

No projeto com programação orientada a aspectos do interesse de sincronização de objetos do Dispatcher, foi utilizada a biblioteca de aspectos coolib disponível junto com AspectJ. Esta biblioteca oferece construções de programação de alto nível que permitem a coordenação de acessos concorrentes a objetos específicos. Ela define o aspecto Coordinator que oferece métodos para a definição de: (1) um conjunto de métodos de classes do sistema que serão de acesso exclusivo, ou seja, poderão ser executados apenas em uma thread por vez; (2) um conjunto de métodos de classes que serão de acesso mutuamente exclusivo, ou seja, os métodos deste conjunto não poderão ser executados simultaneamente por diferentes threads; e (3) um conjunto de guardas de 
O aspecto EventobjectSynchronization define o crosscut lock_methods (), o qual especifica os métodos do Dispatcher em que objetos Event terão seu acesso sincronizado. Este crosscut possui duas ações associadas: (1) uma construção advice before que define uma pré-condição para execução dos métodos afetados, através de um guarda de entrada (guardedEntry); e (2) uma construção advice finally que define uma pós-condição para os métodos afetados, através de um guarda de saída (guardedExit).

O método guardedEntry do aspecto coordinator define um guarda para forçar uma coordenação na execução concorrente de determinados métodos. Ele recebe três parâmetros: (1) o método a ter sua execução coordenada; (2) uma pré-condição Condition - para execução do método; e (3) uma operação de coordenação CoordinationAction - a ser executada assim que a pré-condição for satisfeita e o método iniciar sua execução. Já o método guardedExit() do aspecto coordinator permite definir um guarda que irá realizar atualizações no estado de coordenação de acesso a algum objeto.

O aspecto EventobjectSynchronization herda do aspecto Coordinator e define que os métodos afetados por sua cláusula crosscut lock_methods() serão sincronizados por um guarda de entrada e um guarda de saída. O guarda de entrada permite a execução dos métodos apenas se nenhuma outra thread estiver acessando o mesmo objeto Event que eles desejam acessar. O controle das threads que estão acessando algum objeto Event é feito através de uma tabela de hash, responsável pela associação de eventos a variáveis booleanas que indicam a ocorrência de acesso a cada evento por alguma thread num dado instante. O guarda de saída define uma operação de coordenação (CoordinationAction) na tabela de hash de controle de acesso, indicando que uma nova thread pode acessar um evento que acabou de ser manipulado. 


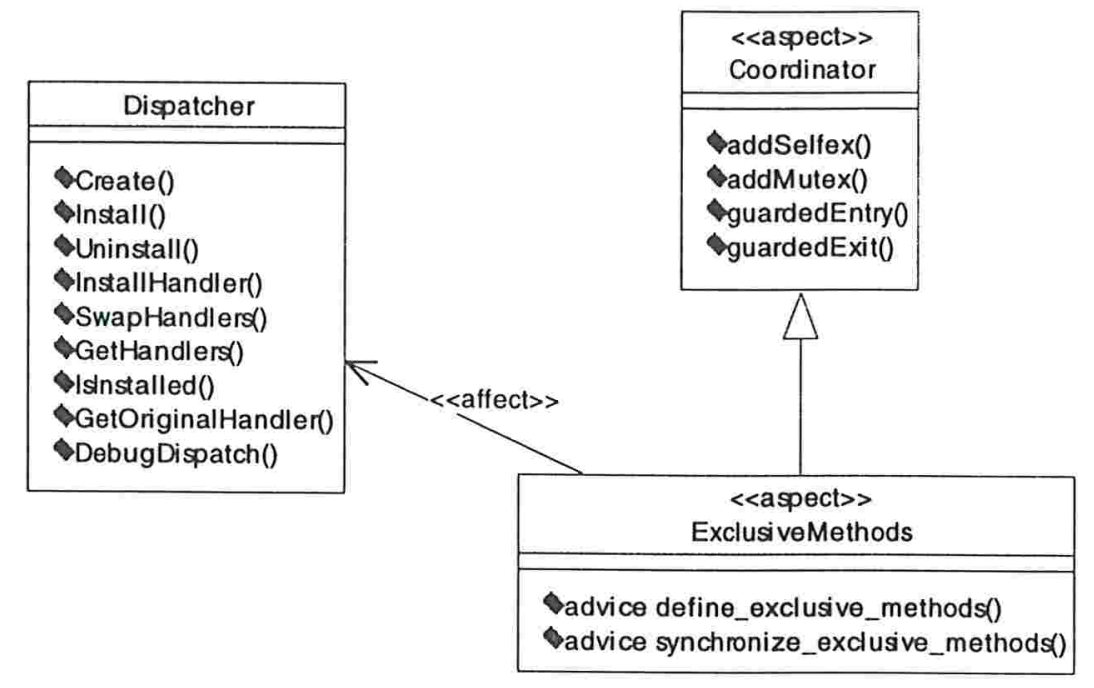

Figura 5.8: Aspecto ExclusiveMethods

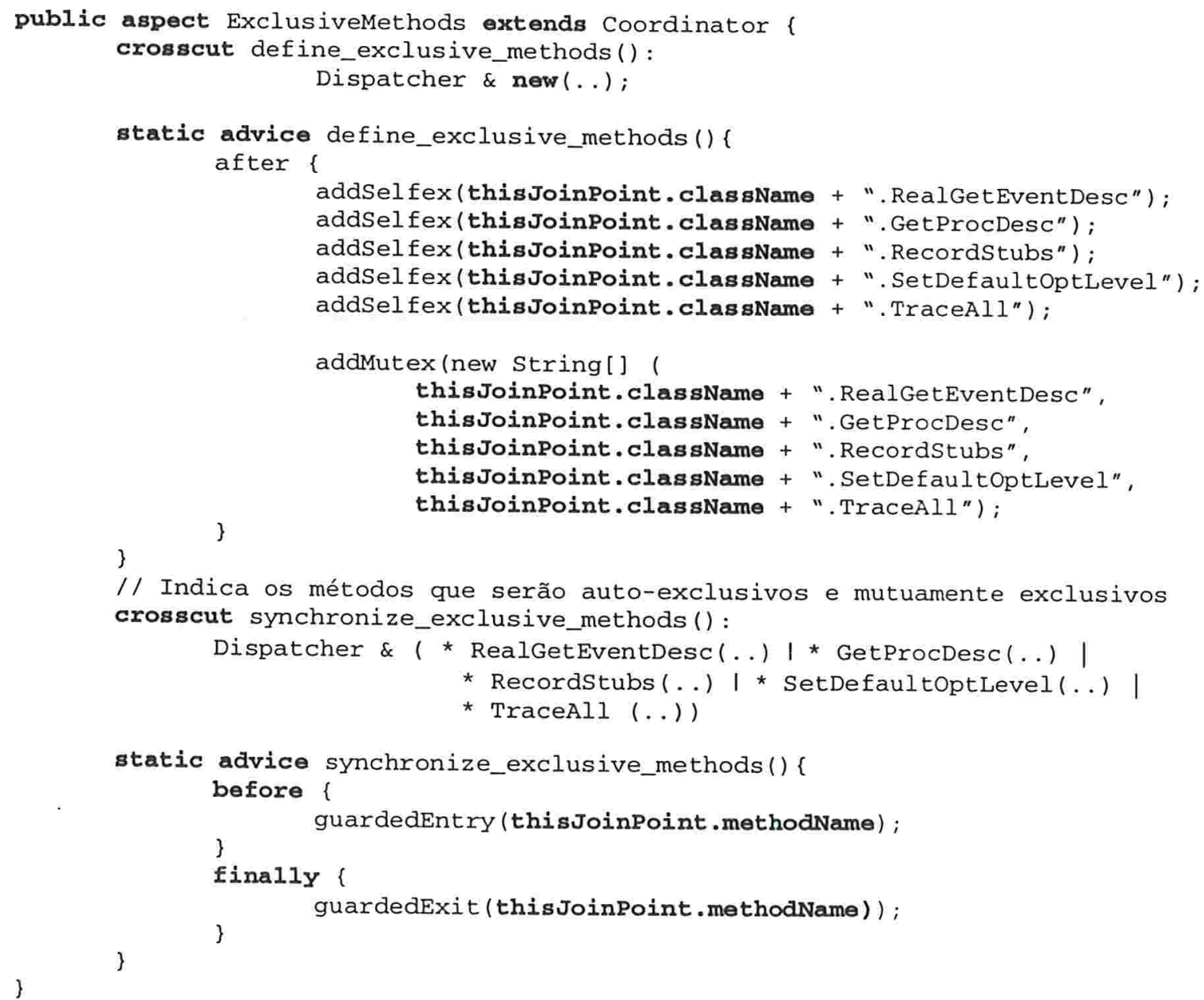


$\mathrm{O}$ aspecto Exclusivemethods também herda do aspecto coordinator e define dois crosscuts: (1) define_exclusive_methods() - que especifica no construtor do Dispatcher os métodos que serão de acesso exclusivo; e (2) synchronize_exclusive_methods () - que especifica as operações para sincronização dos métodos de acesso exclusivo.

Para especificar os métodos que serão de acesso exclusivo o aspecto Exclusivemethods utiliza o comportamento herdado do aspecto coordinator para: (a) o registro de métodos auto-exclusivos (addsel fex) e mútuo-exclusivos (addMutex); e (b) definir a sincronização desses métodos através de chamadas (guardedEntry e guardedExit) aos guardas de entrada e saída do coordinator que automaticamente definirá um esquema para acesso exclusivo a tais métodos.

\subsubsection{Verificação de Tipos}

O Dispatcher se responsabiliza, durante a instalação, pela verificação dos tipos de handlers e guards garantindo dessa forma segurança de tipos durante o despacho de eventos. Nesta checagem de tipos são verificados, por exemplo, se os tipos de argumentos e valor de retorno de um handler são idênticos aos do evento para o qual ele será instalado. Para a instalação de um guard é necessário que este tenha os mesmos argumentos do evento em que ele está sendo instalado e que possua valor de retorno do tipo boolean.

Foram identificados dentro do código de procedimentos de instalação de handlers e guards do Dispatcher, diversas chamadas a operações que estão relacionadas ao interesse de checagem de tipos. Como exemplo, apresentamos a seguir o código do procedimento RealCreate() utilizado para a criação de Bindings entre eventos e handlers, antes da sua instalação. Podem ser observados o entrelaçamento de três interesses neste procedimento: checagem de tipos, criação do Binding e autorização.

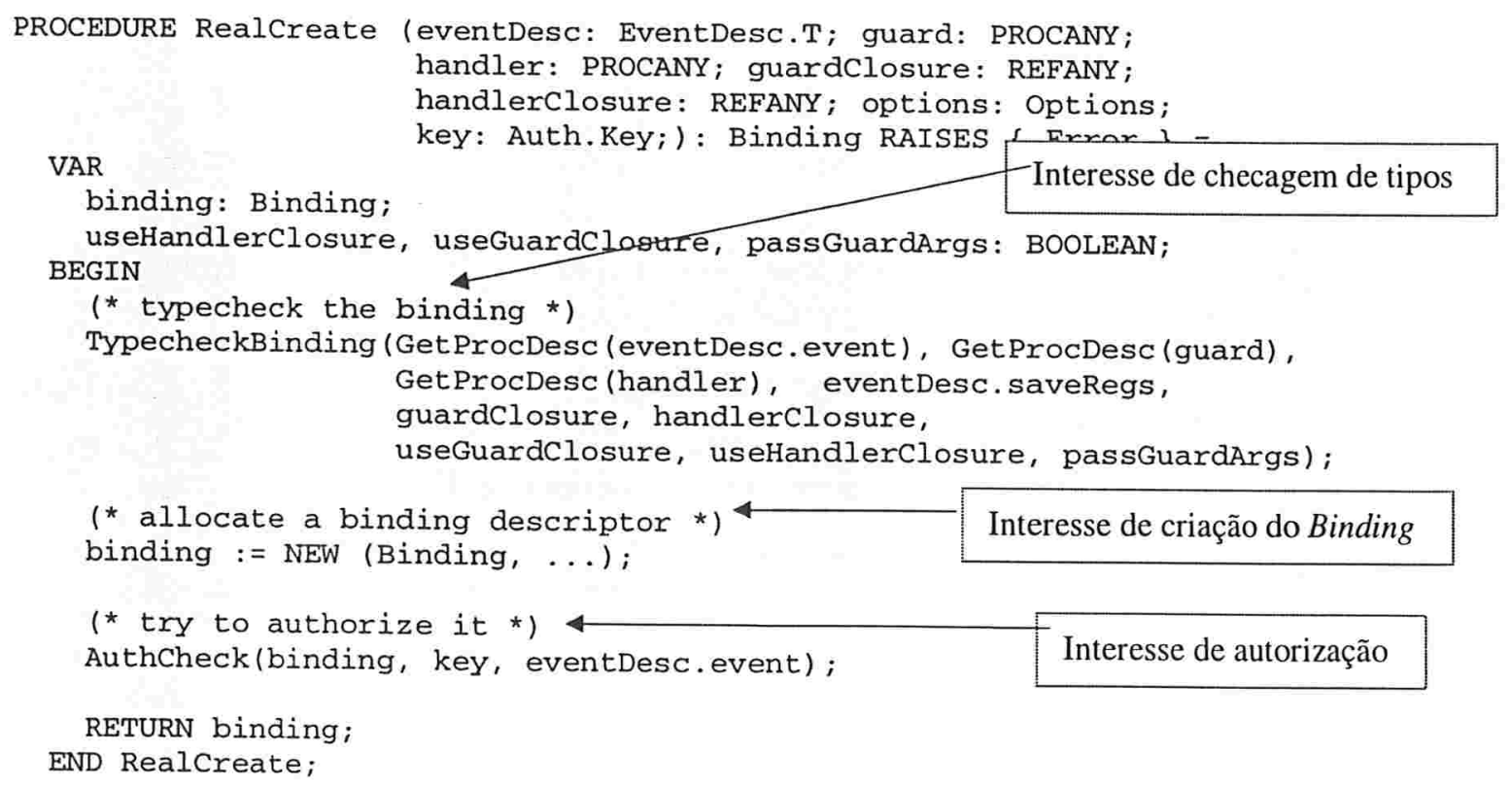


No projeto do Dispatcher com programação orientada a aspectos, o interesse de checagem de tipos foi separado em um aspecto que define como tal interesse é alcançado no sistema. A figura 5.9 apresenta o diagrama de aspectos e classes deste interesse.

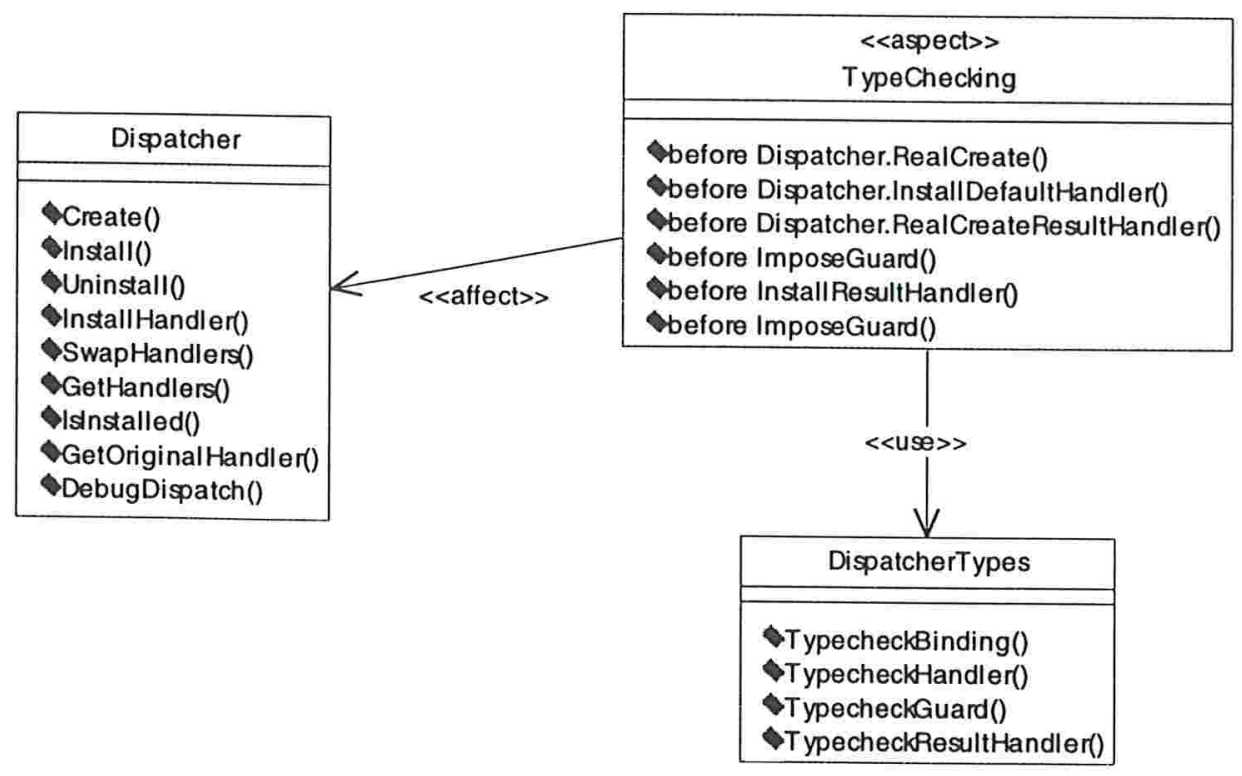

Figura 5.9: Aspecto Typechecking

public aspect Typechecking \{

private DispatcherTypes dispatcher_types;

$1 /$ Tratamento do TypecheckBinding

crosscut typecheckingBinding:

Dispatcher \& (* RealCreate (..));

static advice typecheckingBinding (..) \{

before \{

DispatcherTypes. TypecheckBinding(

GetProcDesc (thisobject . event),

GetProcDesc (thisobject.guard),

GetProcDesc (thisobject. handler),

thisobject.eventDesc.saveRegs,

thisobject.guardclosure,

thisobject.handlerclosure,

thisobject.useGuardclosure,

thisobject. useHandlerclosure,

thisObject . passGuardArgs);

\}

\}

// Tratamento do TypecheckHandler

crosscut typecheckHandler:

$\begin{aligned} \text { Dispatcher \& ( } & \text { InstallDefaultHandler }(. .) \mid \\ & * \text { RealCreateResultHandler (..) } \\ & * \text { ImposeGuard (..) ); }\end{aligned}$ 


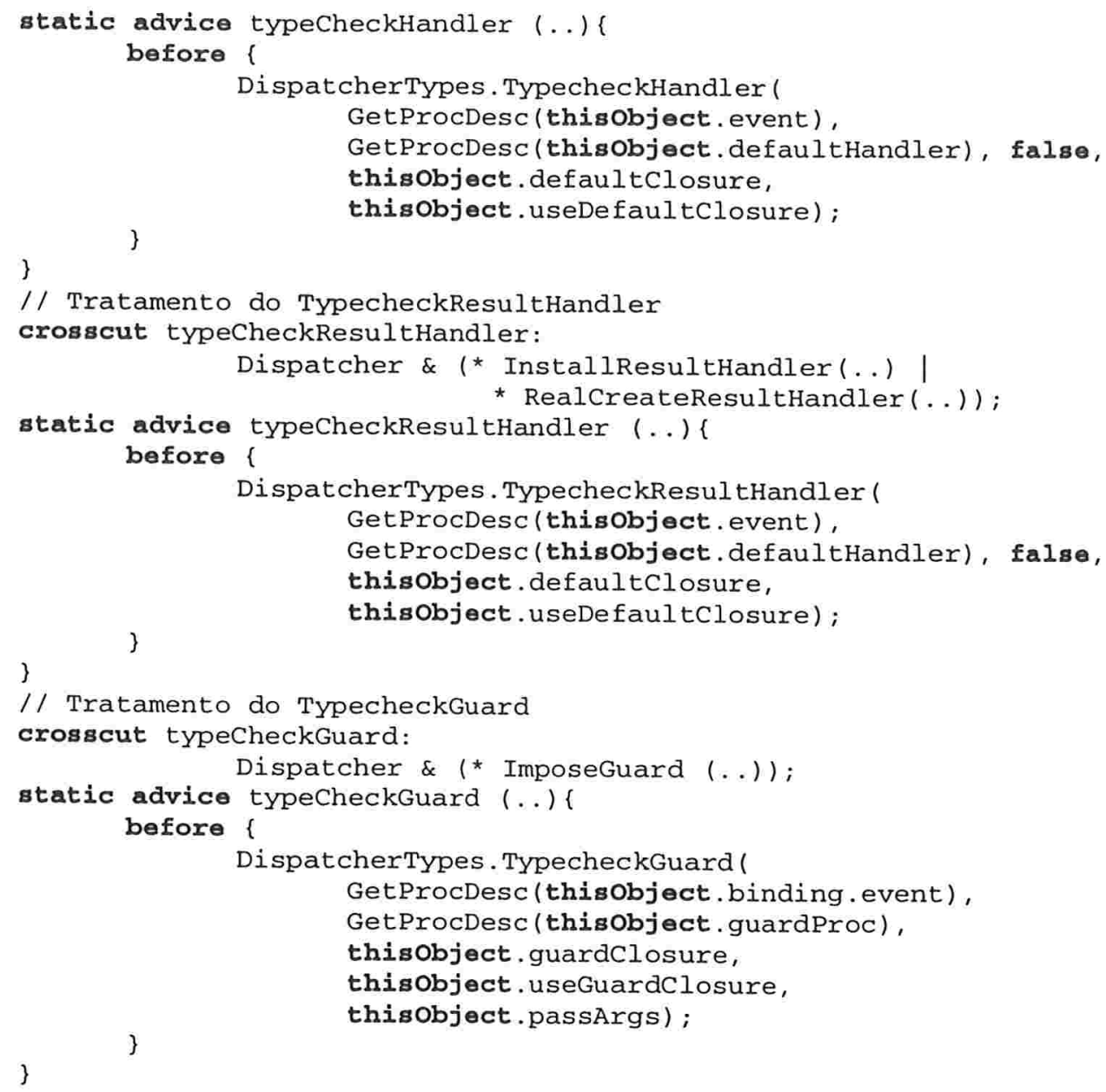

No aspecto Typechecking estão definidos quatro crosscuts que definem o tratamento do interesse de checagem de tipos de bindings, handlers, guards, imposed guards e handlers result e default. Cada um deles especifica: (1) o conjunto de métodos de instalação que durante o início de sua execução terão os tipos dos elementos verificados; e (2) uma construção advice before que define uma chamada a um método específico da classe DispatcherTypes para checagem dos tipos sendo instalados.

O método RealCreate () do Dispatcher apresentado anteriormente, por exemplo, terá seu interesse de checagem de tipos tratado pelo crosscut typecheckingBinding. Este crosscut insere uma chamada no início de sua execução ao método TypecheckBinding da classe DispatcherTypes.

\subsubsection{Tratamento de Exceções}

Durante o estudo e análise do código do projeto original do Dispatcher foram detectados, em diversas partes de seus procedimentos, código relacionado ao interesse de tratamento de exceções. Este código se apresenta basicamente sob duas formas: (1) 
definição de pré e pós-condições; e (2) lançamento de alguma exceção. A maioria dos procedimentos que realizam algum tratamento de exceção fazem um teste de pré ou póscondição e, em seguida, caso o teste não seja satisfeito, lançam a exceção diretamente associada àquele teste. Em muitos procedimentos, ao invés de ser lançada uma exceção há simplesmente o retorno para o método chamado. Abaixo apresentamos o exemplo do procedimento GetEventDesc ( ).

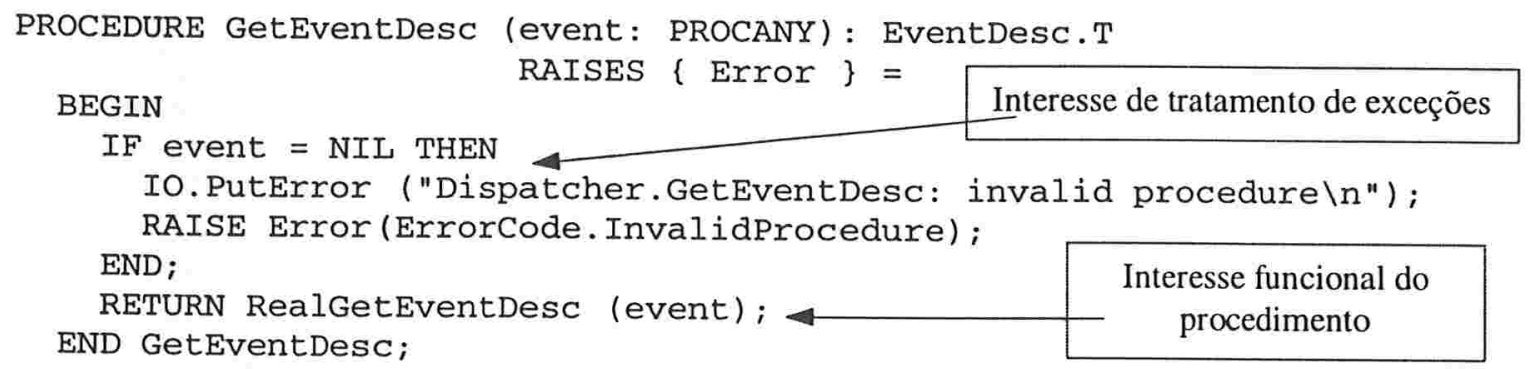

$\mathrm{O}$ interesse de projeto tratamento de exceções vem sendo abordado em programação orientada a aspectos como um possível candidato a ser modelado com aspectos. Alguns trabalhos recentes [KL99, LL99] têm demonstrado vantagens do uso de programação orientada a aspectos na modelagem deste interesse. Abaixo apresentamos o tratamento de exceções do procedimento GetEventDesc () modelado com aspectos.

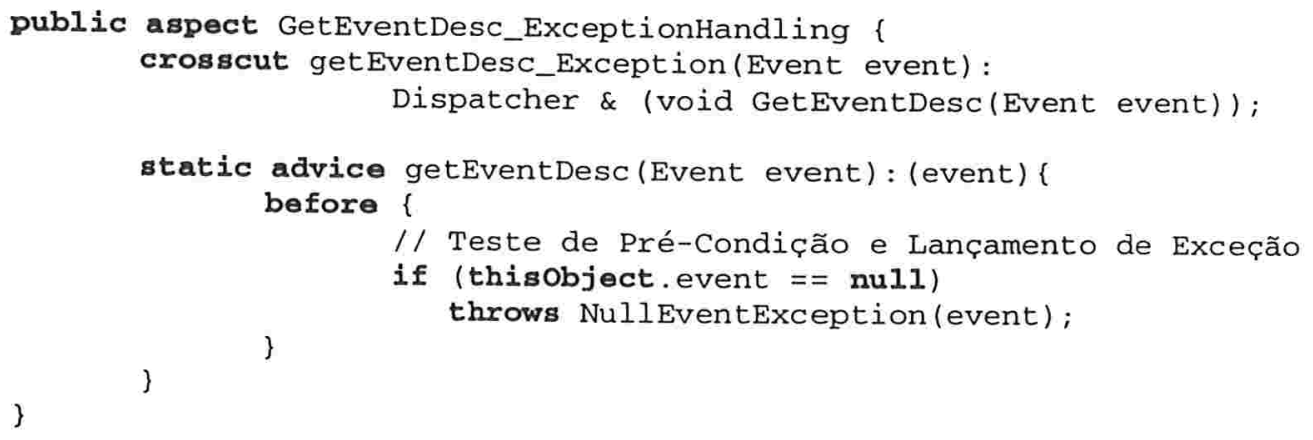

Diversos procedimentos do Dispatcher fazem no início de sua execução o mesmo teste de pré-condição, e em muitos casos realizam operações diferentes (lançamento de exceções, chamada a algum outro procedimento) para tratar a violação àquela précondição. Uma alternativa encontrada para projetar este interesse com programação orientada a aspectos foi elaborar hierarquias de aspectos para tratar as exceções levantadas por muitos dos métodos do Dispatcher a partir do seu teste de pré-condição.

Para tratamento das pré-condições relacionadas ao componente evento foi criado o aspecto abstrato EventContract que define um contrato [Mey97] de pré-condição para este componente. Este aspecto define: (1) o método abstrato evaluate_pre_condition() para verificação da pré-condição do componente evento; (2) o método abstrato pre_condition_false () que será executado caso a pré-condição seja violada; e (3) uma construção advice que será inserida no início dos métodos 
afetados para verificação da pré-condição e a execução da operação de violação da précondição. Subaspectos de EventContract definem: (1) os métodos que serão afetados por um determinado contrato; (2) o contrato de pré-condição, através da implementação do método abstrato herdado evaluate_pre_condition(); e (3) a operação a ser executada nos casos de violação da pré-condição, através da implementação do método abstrato herdado pre_condition_false().

A pré-condição "event. nHandlers $==-1$ " presente em diversos procedimentos do Dispatcher verifica a existência de algum handler instalado junto a um evento específico. A violação desta pré-condição ocasiona a execução de diferentes operações dentro dos procedimentos que a tratam. No exemplo acima duas operações diferentes, presentes no projeto original do Dispatcher, foram consideradas: lançamento de uma exceção e invocação do método RegisterEvent () do Dispatcher.

Para tratamento da pré-condição "event. nHandlers $==-1$ " foi criado o aspecto NoHandlersInstalled (figura 6.8) que herda do aspecto Eventcontract e define o contrato de pré-condição a ser verificado, através da implementação do método abstrato herdado evaluate_pre_condition().

Os subaspectos de NoHandlersInstalled definem a operação que será executada na violação do contrato e os métodos do Dispatcher que terão sua implementação afetada pela pré-condição herdada. O subaspecto RegisterEventAspect ocasiona a chamada ao método RegisterEvent() do Dispatcher caso a pré-condição seja violada, e 0 subaspecto NoHandlersRegistered lança a exceção NoHandlersRegisteredException. A figura 5.10 apresenta um diagrama contendo tais aspectos. Código fonte dos aspectos da figura 5.10 é também apresentado logo a seguir. 


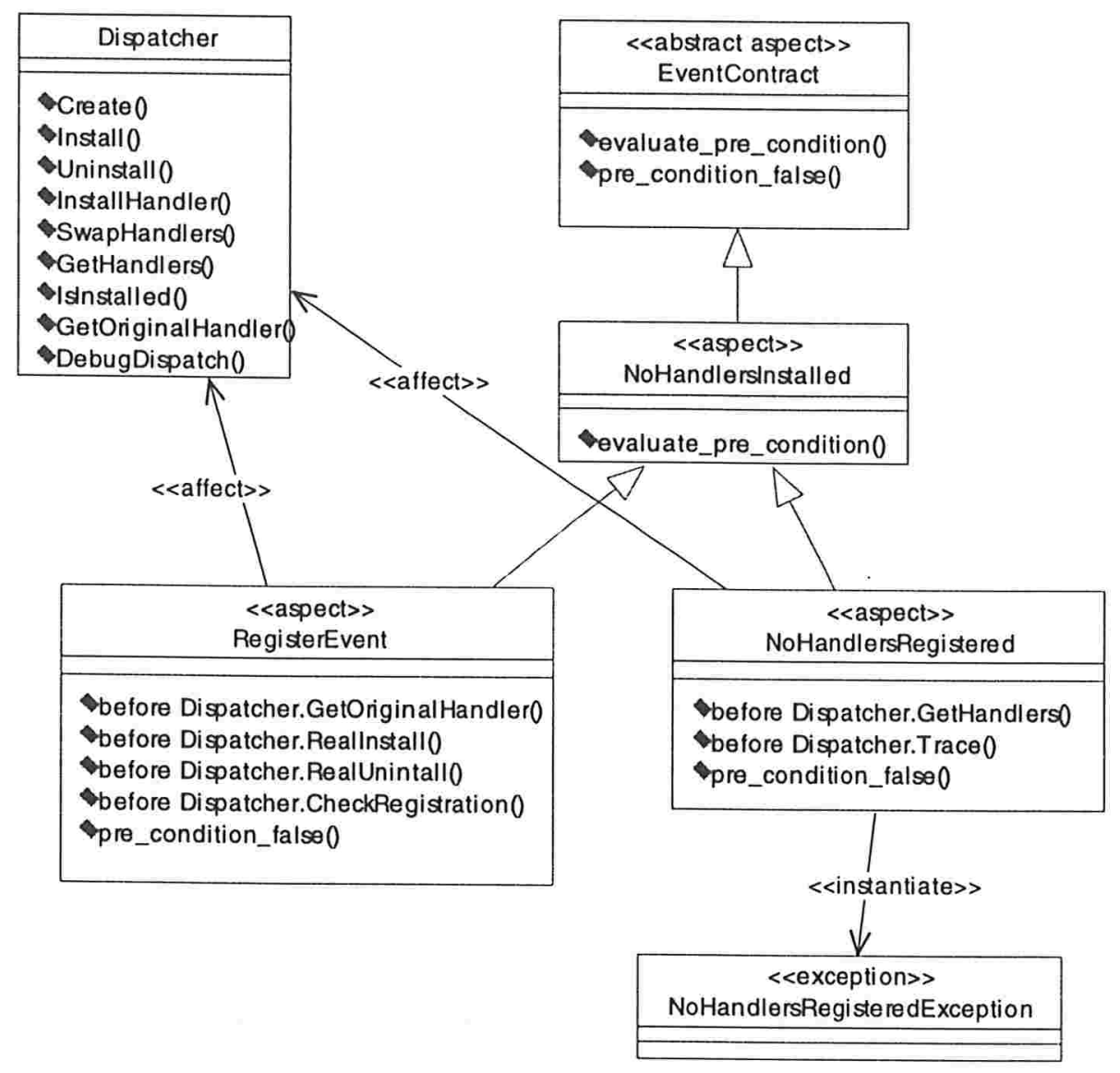

Figura 5.10: Aspecto de Exceção NoHandlersInstalled

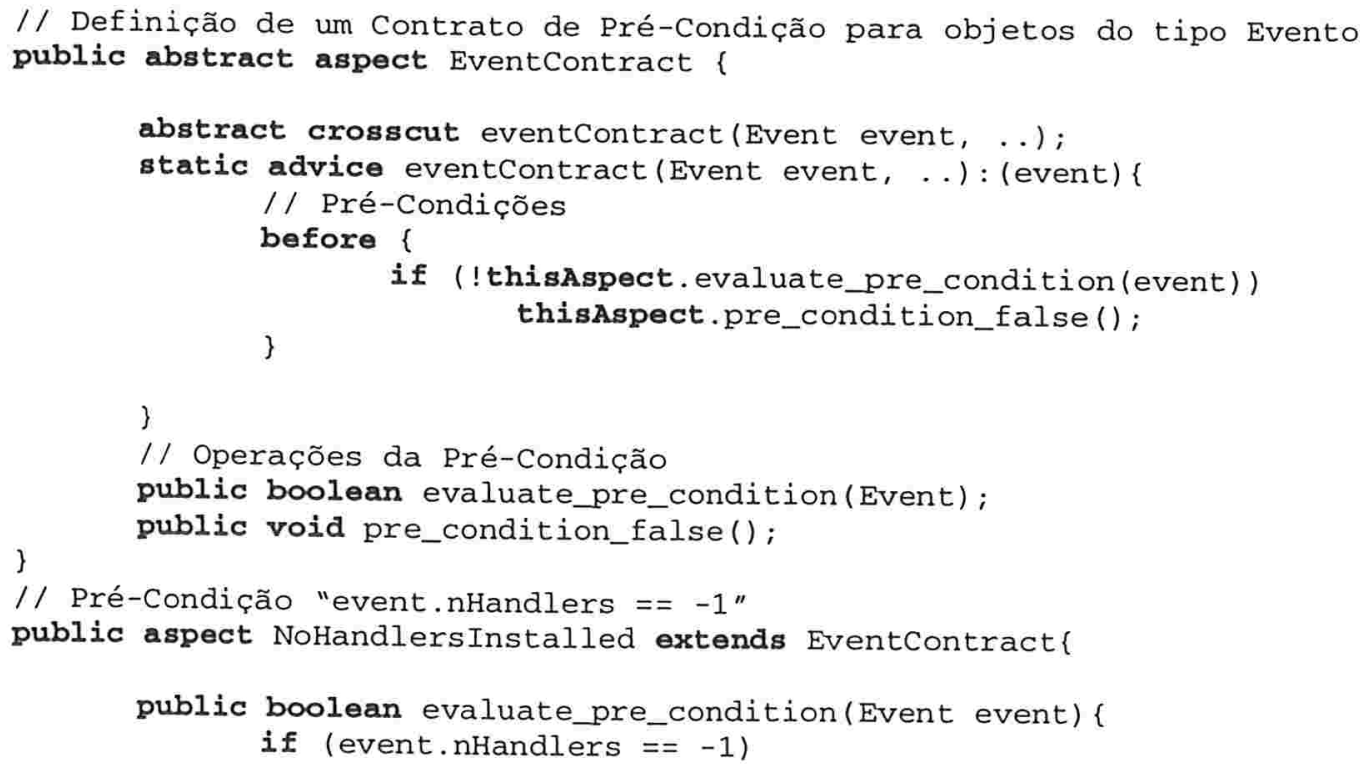




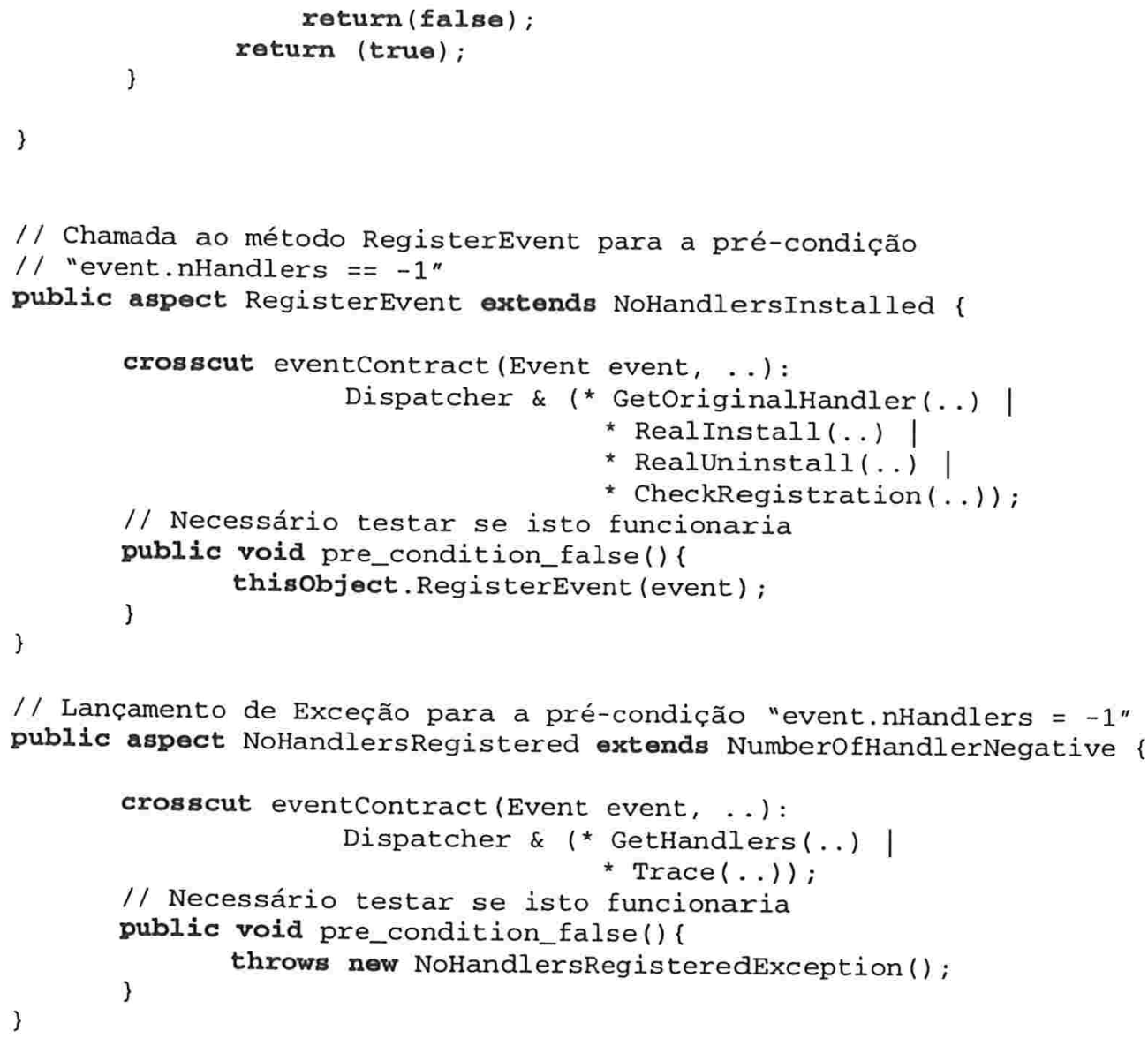

O aspecto EventNull (figura 5.11) trata os métodos do Dispatcher que possuem como pré-condição "event $==$ null". Para implementar tal funcionalidade ele herda do aspecto EventContract e define: (1) a pré-condição a ser verificada; (2) a operação de violação da pré-condição (lançamento da exceção EventNullexception); e (3) os métodos do Dispatcher que serão afetados por tal aspecto. A figura 5.11 apresenta o diagrama que contém o aspecto EventNull. Código fonte deste aspecto é apresentado logo a seguir. 


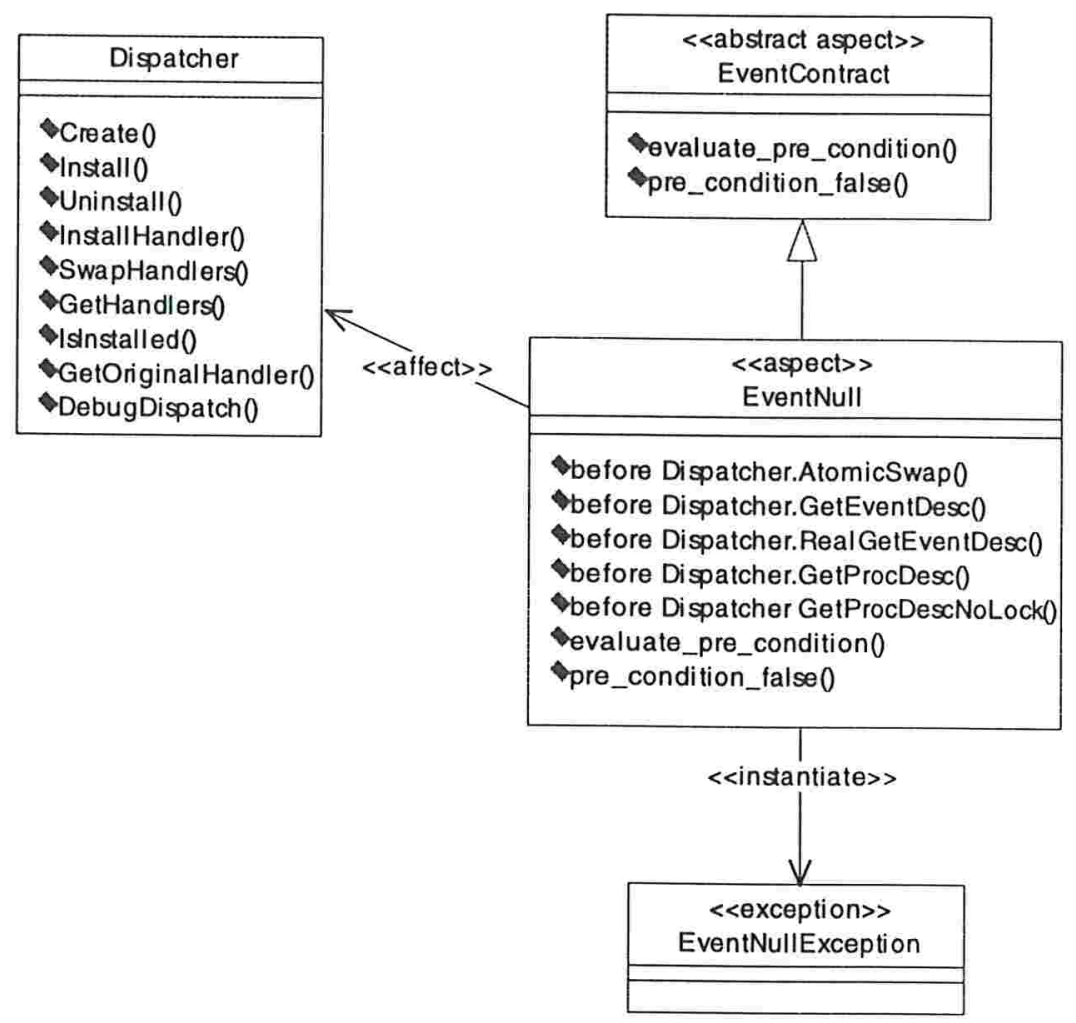

Figura 5.11: Aspecto de Exceção EventNul1

// Lançamento de Exceção para a pré-condição "event = null" public aspect EventNull extends EventContract \{

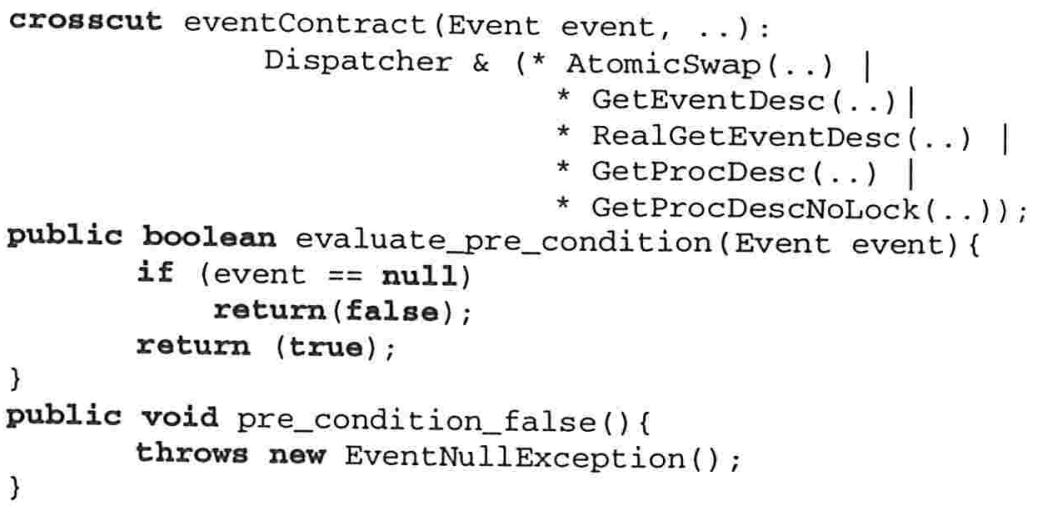

\subsubsection{Rastreamento da Execução do Dispatcher}

É comum dentro do código de sistemas encontrarmos partes referentes a atividades de rastreamento da sua execução. Este código é utilizado com fins de 
depuração, e em geral, envia informações sobre o estado do sistema em execução (valores mantidos por estruturas de dados, métodos ou procedimentos executados) para a tela do computador ou algum arquivo. Apesar de bastante útil durante o desenvolvimento de sistemas, este código de rastreamento é muitas vezes dispensável após a sua utilização e a entrega do sistema, trazendo inclusive alguma sobrecarga ao desempenho quando mantidos internamente.

No Dispatcher foram identificados diversos "pedaços" de código em seus procedimentos que são usados para o rastreamento da execução do sistema. Abaixo apresentamos o exemplo do procedimento Installstub(). Neste procedimento podemos observar o rastreamento da execução do Dispatcher durante o início e final da sua execução.

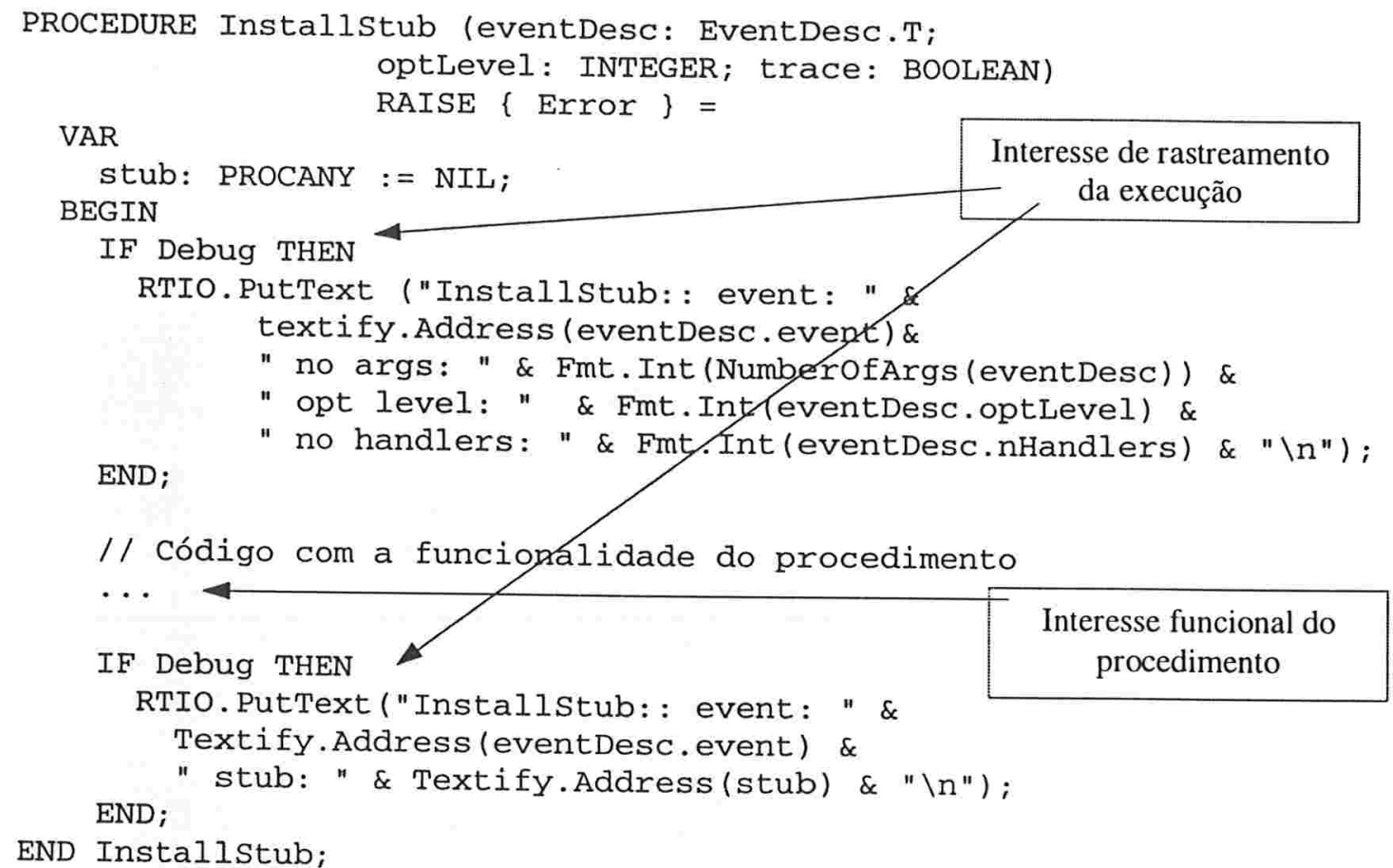

O código de rastreamento da execução de um sistema pode ser projetado e implementado utilizando aspectos. As vantagens do projeto deste interesse com programação orientada a aspectos, são: a especificação separada de quais informações se deseja rastrear em um dado momento (oferecendo flexibilidade para a definição de diversas configurações de rastreamento para o teste de diferentes funcionalidades) e a possibilidade de desacoplar, de forma estática ou dinâmica, os aspectos de rastreamento quando estes não forem mais necessários. A figura 5.12 apresenta um diagrama de aspectos e classes projetado para o tratamento do interesse de rastreamento do procedimento Installstub(). Código do aspecto Tracing, presente no diagrama da figura 5.12, é apresentado a seguir. 


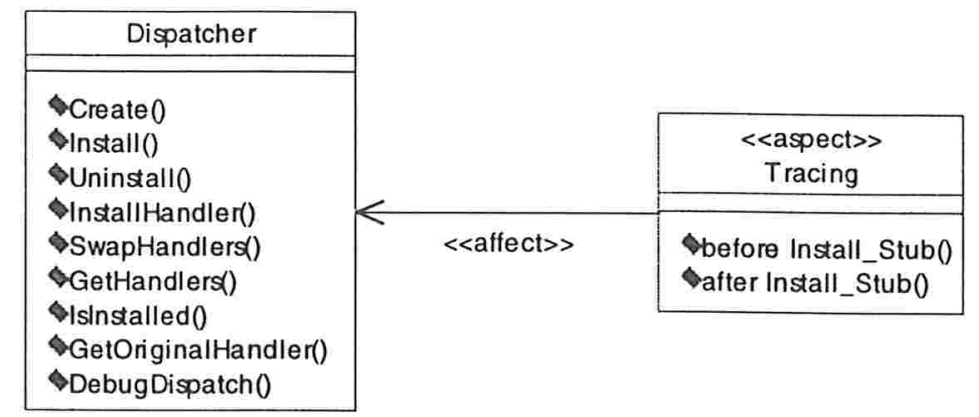

Figura 5.12: Aspecto Tracing (rastreamento do método Install_Stub)

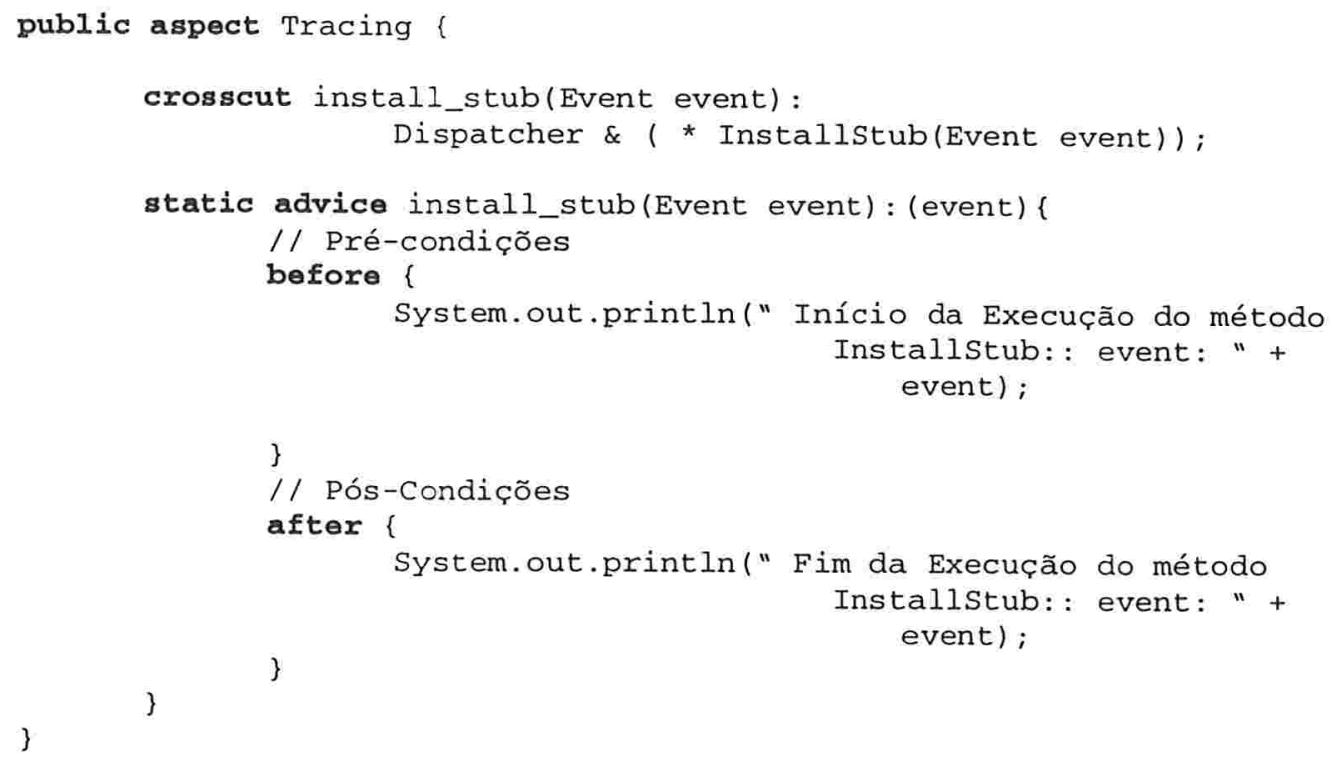

Diversos outros procedimentos presentes no Dispatcher poderiam ter seu interesse de rastreamento de execução endereçado com aspectos. $\mathrm{O}$ aspecto abaixo define cláusulas que serão inseridas em todos os métodos do Dispatcher indicando na tela do computador, a entrada e saída da execução de tais métodos.

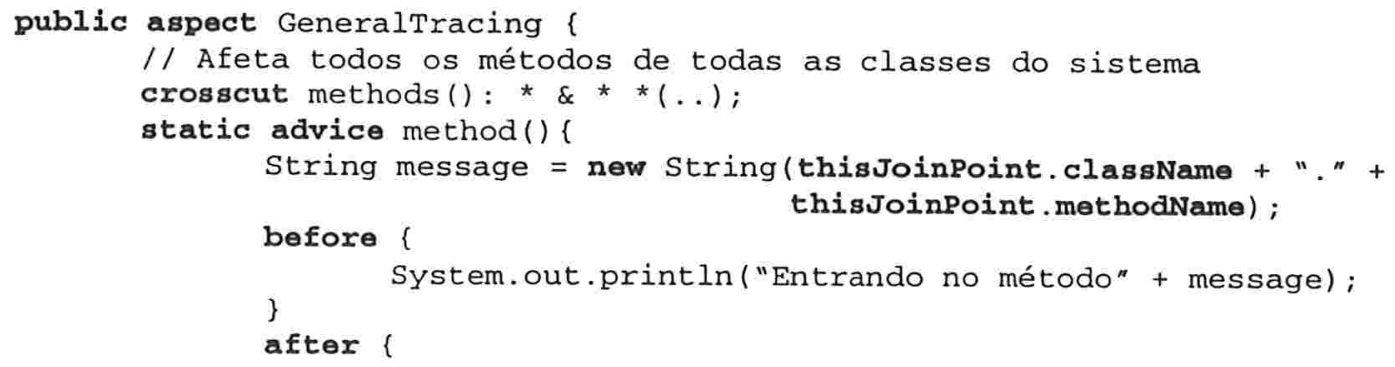




\section{System.out.println("Saindo do método" + message);

\subsubsection{Geração de Stubs}

O Dispatcher é responsável pelo despacho de eventos (chamadas a procedimentos) que ocorrem dentro do kernel do SPIN, podendo influenciar diretamente o desempenho alcançado pelo sistema operacional. Para evitar sobrecarga no sistema, o Dispatcher não intercepta eventos que tenham apenas seu handler original registrado, neste caso a ocorrência do evento ocasiona a execução direta do próprio procedimento que o representa (handler original). Para lidar com a sobrecarga de desempenho no despacho de eventos que possuem vários handlers e guards instalados, o Dispatcher conta com a geração de código em tempo de execução para oferecer versões especializadas e otimizadas (stubs) da rotina de despacho de eventos [PB96].

Durante análise e estudo do código-fonte do Dispatcher foi identificado que diversos procedimentos da sua estrutura estão associados ao interesse de geração de stubs. Além de oferecer diversos procedimentos relacionados ao interesse de geração de stubs, o Dispatcher mantém ainda em sua estrutura, dentro do elemento EventDesc, os próprios stubs gerados para o evento e diversas informações que são utilizadas por tais procedimentos e que são também relacionadas diretamente ao interesse de geração de stubs. Estas informações foram apresentadas na estrutura do Dispatcher (subseção 5.1.1.2).

O Dispatcher permite a geração de diversos tipos de stubs, classificados de acordo com o seu nível de otimização [PB96]. O elemento EventDesc da estrutura original do Dispatcher mantém: (1) um vetor para referenciar os diversos tipos de stubs gerados para o evento; (2) uma referência para o stub corrente, que será utilizado pelo evento durante o seu despacho; (3) a variável optLevel do tipo int, que indica o nível de otimização do stub que será gerado para o evento; e (4) as variáveis booleanas trace e keepstub, que indicam, respectivamente, se o stub terá sua execução rastreada e se o stub mantido para o evento será sempre o de menor nível de otimização.

Os procedimentos relacionados ao interesse de geração de stubs do Dispatcher são a maioria referenciados por outros módulos do kernel do SPIN. Apenas os procedimentos FindoptLevel(), InstallStub() e GetStub() são invocados por procedimentos do próprio Dispatcher.

O procedimento FindoptLevel () é usado por muitos procedimentos relacionados ao próprio interesse de geração de stubs para determinar o nível de otimização do stub que será gerado para um evento. O procedimento Installstub() é usado para a instalação de um stub junto a um dado evento, e é chamado em procedimentos relacionados ao próprio interesse de geração de stubs e dentro do procedimento Activate() do Dispatcher. A responsabilidade do Activate() é atualizar o estado do sistema para as mudanças feitas (instalação e desinstalação de elementos) em um determinado evento, assim sempre que o estado de um evento é modificado, é instalado 
um novo stub para este evento. Finalmente, o procedimento Getstub() é responsável pela obtenção de um stub (com nível de otimização especificado) para um determinado evento, para cumprir sua função ele faz uma chamada ao procedimento clonestub () do módulo stitcher (responsável pela geração de stubs em tempo de execução). O procedimento GetStub() é invocado apenas pelo procedimento Installstub().

Para endereçar o interesse de geração de stubs do Dispatcher no projeto com programação orientada a aspectos, foi criado o aspecto stubconcern, cujas funções são: (1) introduzir na classe Event informações relacionadas a geração de stubs; (2) introduzir métodos no Dispatcher que são diretamente relacionados a geração de stubs; e (3) definir uma construção advice after que afeta o método Activate() do Dispatcher, invocando no final da sua execução o método Installstub(). A figura 5.13 mostra o diagrama do aspecto stubconcern. Código-fonte parcial deste aspecto é apresentado em seguida.

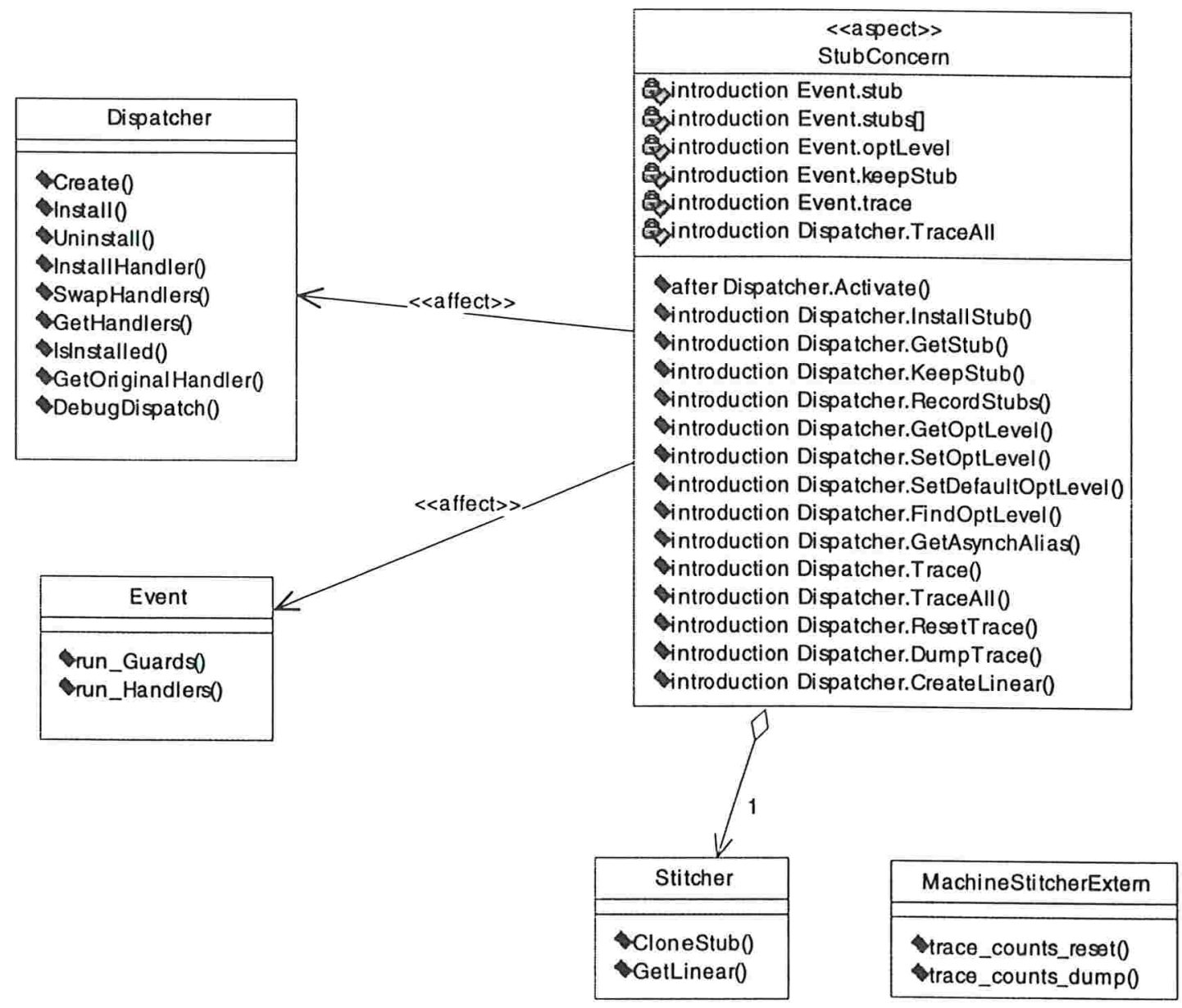

Figura 5.13: Aspecto StubConcern 


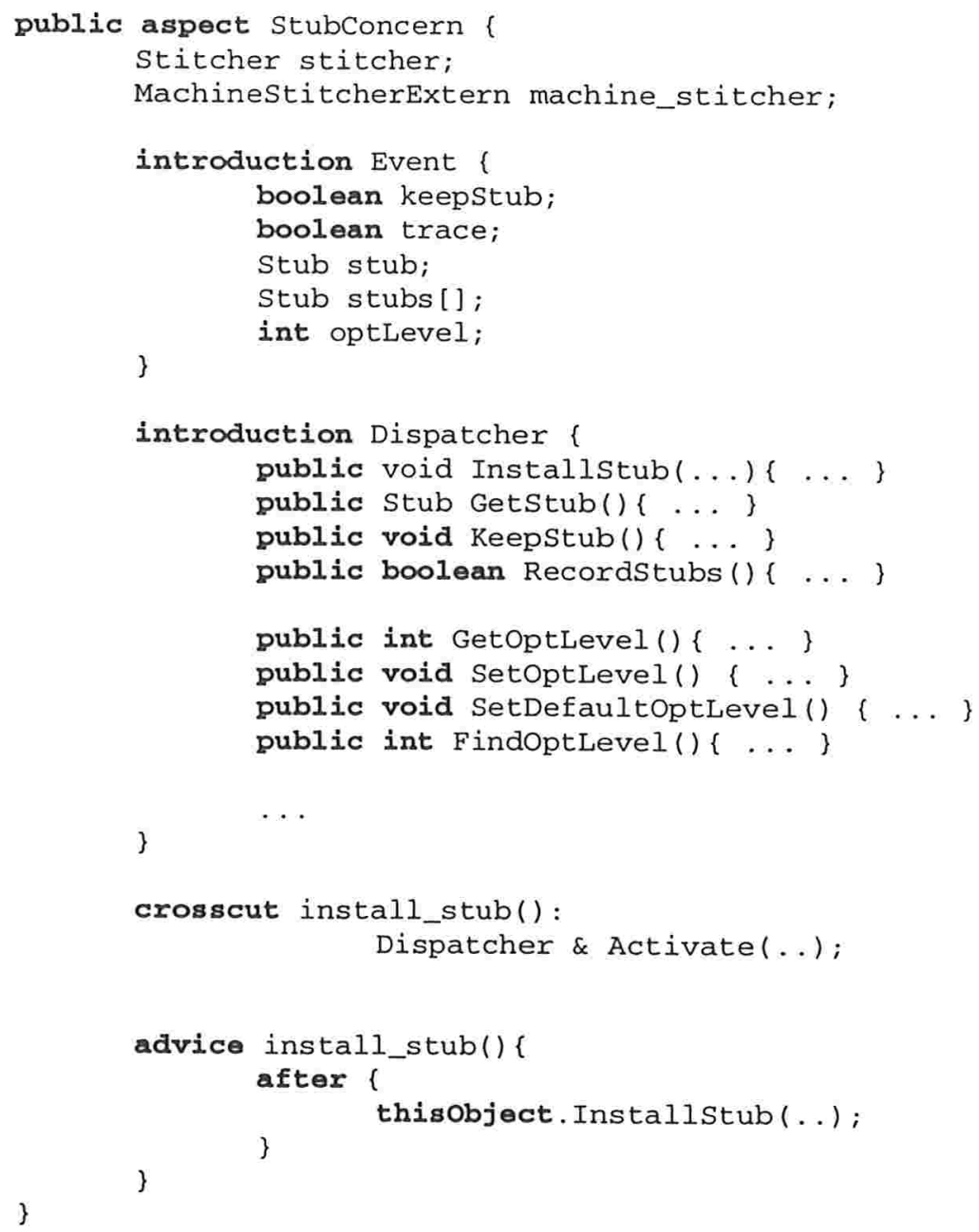

\subsubsection{Análise do Projeto do Dispatcher com Programação Orientada a Aspectos}

O Dispatcher é o módulo do sistema operacional SPIN responsável pela implementação do seu modelo de eventos. Dentro do seu projeto e implementação existem diversos interesses envolvidos, entre eles: (a) instalação de handlers e guards em eventos; (b) despacho de eventos; (c) instalação dinâmica de imposed guards, e handlers default e result; (d) autorização; (e) execução assíncrona; (f) sincronização de acesso a objetos; (g) checagem de tipos; (h) tratamento de exceções; (i) rastreamento da execução do sistema; (j) geração de stubs.

O projeto do Dispatcher com programação orientada a aspectos permitiu o tratamento destes interesses de forma separada. Cada um deles foi especificado separadamente, iniciando pelos interesses funcionais de instalação de handlers/guards e de despacho de eventos, os quais originaram o modelo de componentes funcionais do sistema. E em seguida, diversas hierarquias de aspectos/classes foram projetadas para afetar o modelo de componentes funcionais do Dispatcher e endereçar os seus demais interesses. 
O projeto original do Dispatcher representa seus interesses em uma estrutura monolítica, contendo procedimentos com vários destes interesses entrelaçados e difusos. Já o projeto do Dispatcher com programação orientada a aspectos, promovendo a especificação separada dos interesses, permite um melhor entendimento de como cada um deles é alcançado no sistema e a relação que existe entre os mesmos. A estrutura e comportamento do projeto do Dispatcher com programação orientada a aspectos pode ser entendida e estudada progressivamente, iniciando pelo seu modelo de componentes funcionais, e em seguida, pelas diversas hierarquias independentes que afetam o modelo de componentes e endereçam os demais interesses do sistema. Permitindo um melhor entendimento do projeto e implementação do Dispatcher, a separação de interesses acaba também trazendo facilidades para a sua manutenção.

As hierarquias de aspectos/classes responsáveis por cada interesse podem ser desacopladas do modelo de componentes funcionais do sistema durante sua compilação. Isto traz facilidades para a evolução estática do sistema. Um novo interesse pode ser reprojetado desacoplando a sua hierarquia atual e construindo uma nova hierarquia para o mesmo propósito.

Durante o projeto dos aspectos que afetam o modelo de componentes funcionais do sistema, foi observado que alguns aspectos afetam métodos do Dispatcher que são introduzidos por outros aspectos projetados para o sistema. Dessa forma, durante a geração do sistema é necessário estabelecer uma ordem para compilação dos aspectos juntamente com os componentes funcionais, baseada nas dependências entre os aspectos. $\mathrm{O}$ aspecto Typechecking, por exemplo, só pode ser compilado juntamente com a classe Dispatcher que ele afeta, após esta classe ter sido compilada com o aspecto DynamicManager que introduz os métodos de instalação de imposed guards e handlers result/default, já que estes métodos são afetados por construções do aspecto Typechecking. Para auxiliar neste processo de compilação dos aspectos com os componentes funcionais, os diagramas de aspectos do sistema podem representar as dependências existentes entre aspectos que afetam os mesmos componentes, através do uso de relações de dependência de UML com o estereótipo <<depend >> Na figura 5.14 apresentamos um diagrama que representa as dependências entre os aspectos do projeto do Dispatcher com programação orientada a aspectos.

Pode ser observado no diagrama que apresenta o componente funcional Dispatcher e os aspectos que o afetam com suas respectivas relações de dependência (affect e depend), que devem ser aplicados (e conseqüentemente projetados) inicialmente os aspectos relacionados diretamente com interesses do domínio específico do Dispatcher, tais como, interesse dos elementos dinâmicos (aspecto DynamicManager), interesse de autorização (aspecto InstallAuthorizer), interesse de geração de stubs (aspecto stubConcern) e interesse de checagem de tipos (aspecto Typechecking), e em seguida os aspectos relacionados a interesses independentes do domínio, tais como, interesse de tratamento de exceções (aspecto NoHandlerRegistered), interesse de rastreamento da execução (aspecto Tracing) e interesse de sincronização (aspectos objectSynchronization e ExclusiveMethods). Apesar de não ser representado, todos 
os aspectos apresentados no diagrama da figura 5.14 afetam o componente funcional Dispatcher.

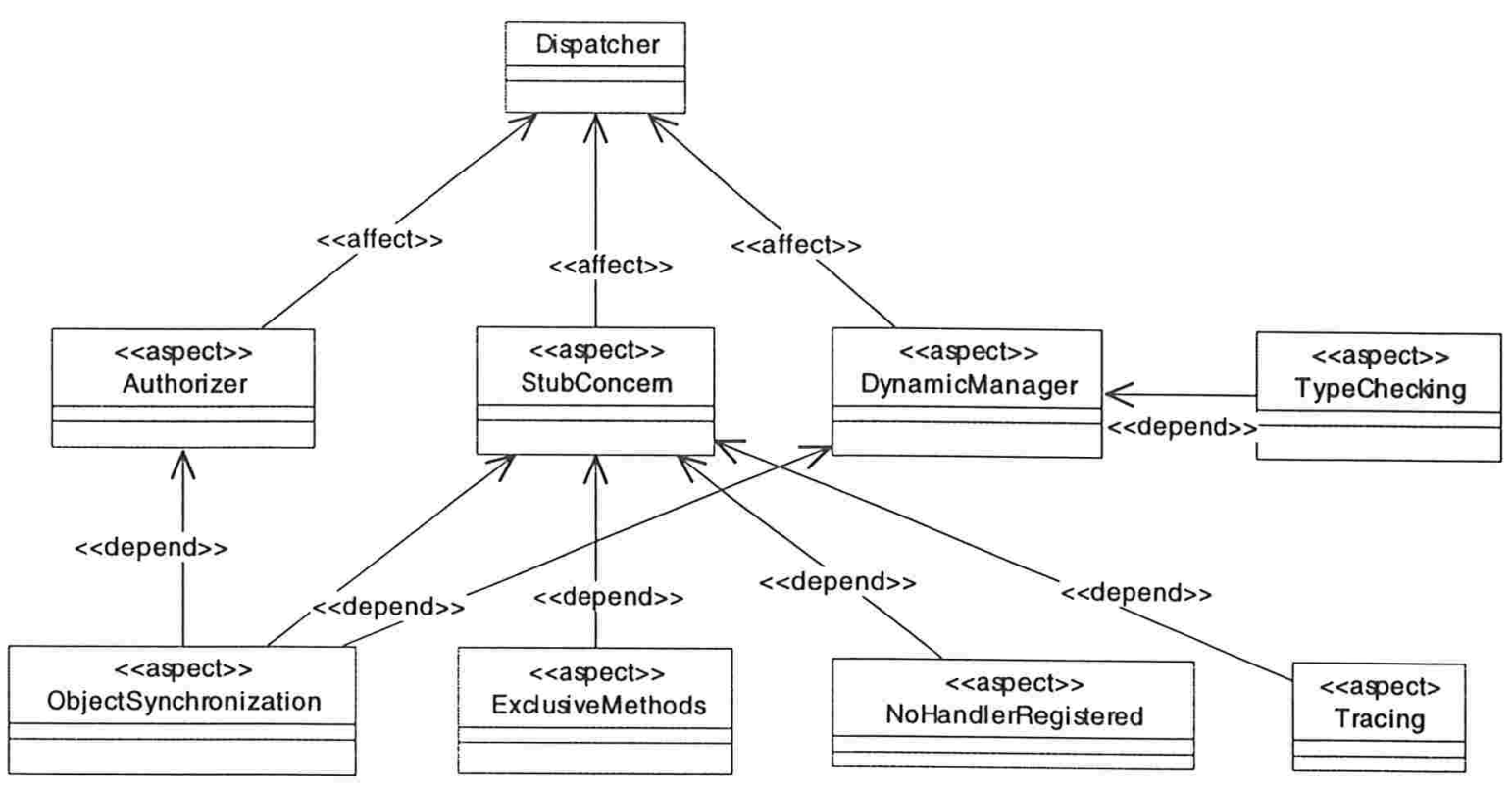

Figura 5.14: Diagrama de Dependência entre Aspectos

$\mathrm{Na}$ tabela abaixo apresentamos a distribuição do código fonte do módulo Dispatcher do SPIN (arquivo Dispatcher.m3) de acordo com o interesse de projeto que cada parte do código atende. Os comentários do código fonte foram eliminados. Esta tabela serve também de motivação para o projeto do Dispatcher com programação orientada a aspectos, porque mostra que cerca de $50 \%$ de seu código é relacionado diretamente com sua funcionalidade e os outros $50 \%$ com interesses não funcionais.

\begin{tabular}{|l|c|c|}
\hline \multicolumn{1}{|c|}{ Interesse de Projeto } & Linhas de Código & Porcentagem \\
\hline Componentes Funcionais & 899 & 49,2 \\
\hline Componentes Dinâmicos & 245 & 13,4 \\
\hline Geração de Stubs & 326 & 17,9 \\
\hline Tratamento de Exceções & 135 & 7,4 \\
\hline Rastreamento da Execução & 95 & 5,2 \\
\hline Checagem de Tipos & 44 & 2,4 \\
\hline Sincronização & 39 & 2,1 \\
\hline Serviço de Autorização & 30 & 1,7 \\
\hline Execução Assíncrona & 13 & 0,7 \\
\hline Total - Interesses Funcionais & $\mathbf{8 9 9}$ & $\mathbf{4 9 , 2}$ \\
\hline Total - Interesses Não-Funcionais & $\mathbf{9 2 7}$ & $\mathbf{5 0 , 8}$ \\
\hline Total - Código Fonte & $\mathbf{1 8 2 6}$ & $\mathbf{1 0 0}$ \\
\hline
\end{tabular}




\subsection{Reengenharia do Projeto do Dispatcher com Programação Adaptativa e Relações de Contexto}

No projeto do Dispatcher com programação adaptativa e relações de contexto, de forma análoga ao JAWS, buscamos: (1) identificar comportamentos colaborativos entre classes, que pudessem ser modelados com as abstrações presentes na técnica de programação adaptativa; e (2) utilizamos relações de contexto para o projeto de aspectos de variação dinâmica encontrados no Dispatcher.

Como as técnicas de programação adaptativa e relações de contexto estendem o modelo convencional de orientação a objetos, durante a reengenharia do projeto do Dispatcher com tais técnicas foi reutilizada a estrutura de componentes funcionais projetada para tal sistema em sua reengenharia com programação orientada a aspectos (apresentada na subseção 5.2.1). Esta estrutura possui características que a tornam um sistema orientado a objetos (OO) mais próximo do modelo convencional $\mathrm{OO}$ do que a estrutura original do Dispatcher, que possui diversas de suas classes mantendo apenas estado sem nenhum comportamento associado.

\subsubsection{Projeto do Dispatcher com Programação Adaptativa}

Nesta subseção apresentamos os comportamentos do Dispatcher que foram projetados usando programação adaptativa.

\subsubsection{Projeto dos Comportamentos da Classe Event}

Os métodos run_Guards() e run_Handlers() da classe Event, que são utilizados pelo Dispatcher durante o despacho de eventos, foram especificados como métodos adaptativos em seu projeto com programação adaptativa.

O método adaptativo run_Guards() utiliza em sua implementação o método traversal traverseGuards () - que percorre os guards instalados para os handlers de um evento específico, e a classe visitor Guardvisitor - que define o comportamento para execução dos guards durante o percurso do método traverseGuards (). Analogamente, o método adaptativo run_Handlers() utiliza a implementação do método traversal traverseHandlers () - que percorre os handlers de um dado evento, e da classe visitor HandlerVisitor - que define o comportamento para execução dos handlers instalados junto a um evento específico durante o percurso do método traverseHandlers ().

Abaixo apresentamos código-fonte da classe Event com os métodos adaptativos run_Guards() e run_Handlers(), e das classes visitors Guardvisitor e HandlerVisitor. 


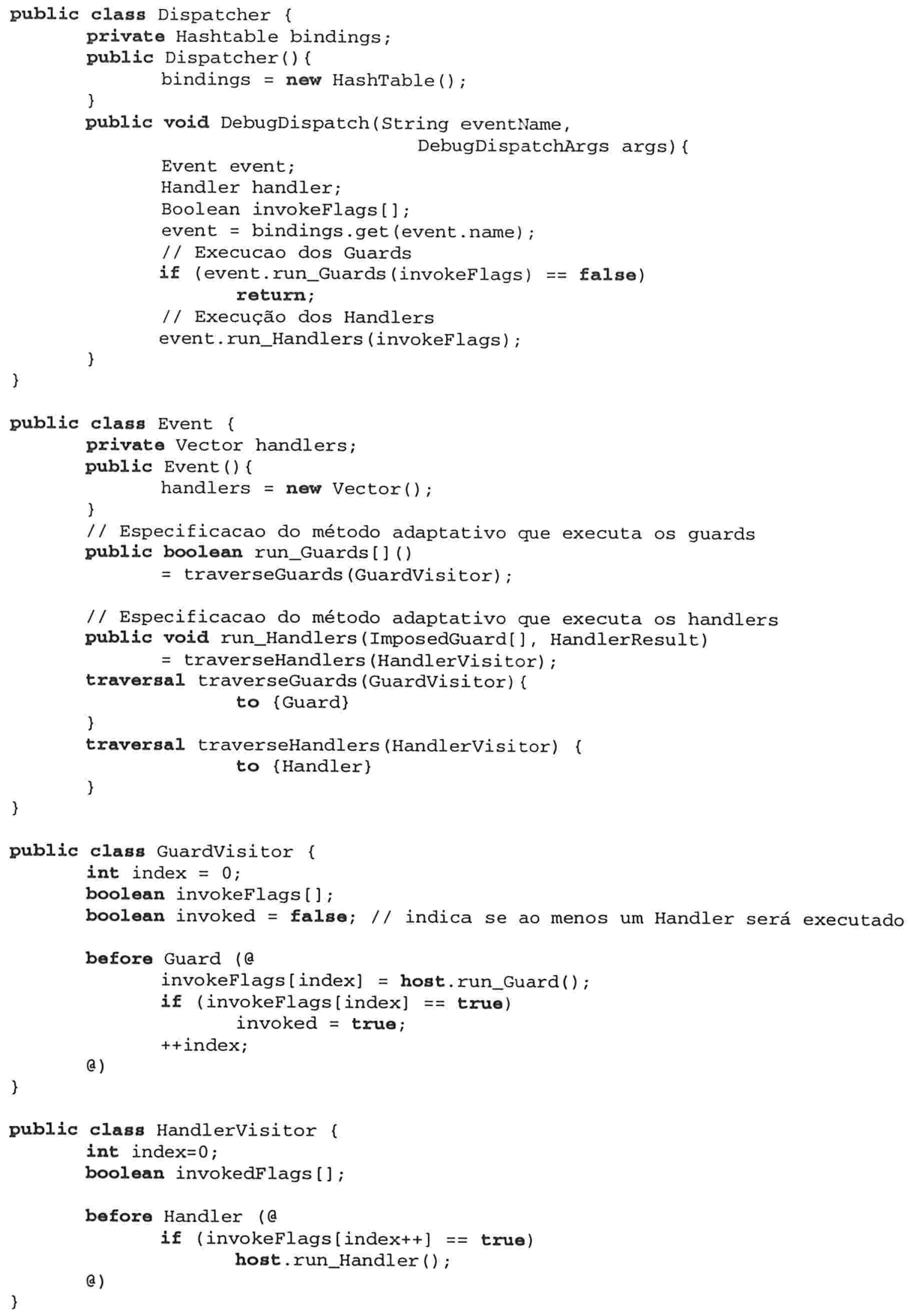




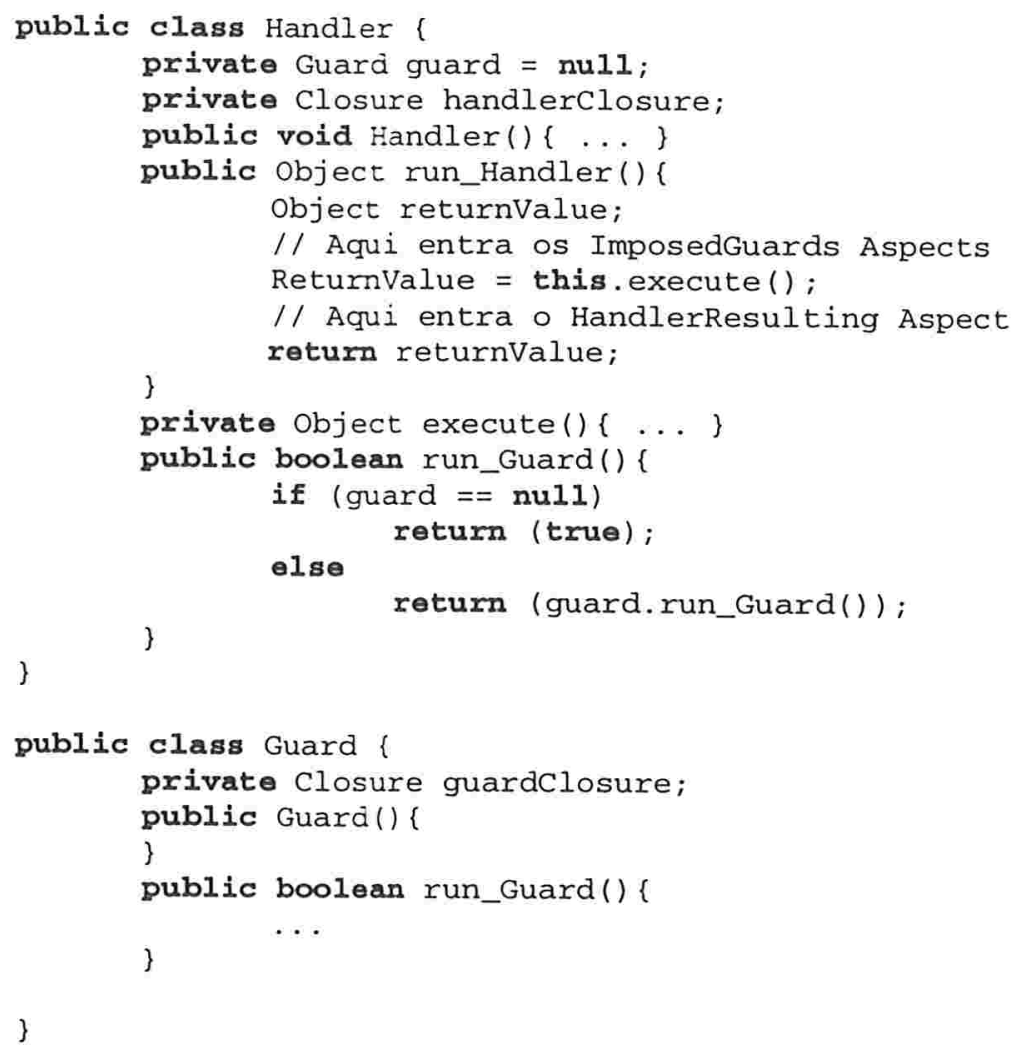

\subsubsection{Projeto de Imposed Guards e Handlers Default/Result}

No projeto do Dispatcher com programação adaptativa, os elementos imposed guards e handlers default e result, presentes no modelo de eventos, foram incorporados a estrutura do Dispatcher da seguinte forma:

(a) O elemento imposed guard é representado pela classe ImposedGuard. A classe Handler passou a agregar os imposed guards que são instalados junto ao mesmo;

(b) O elemento handler default é representado pela classe HandlerDefault. A classe Event passou a agregar um HandlerDefault;

(c) $\mathrm{O}$ elemento handler result é representado pela classe HandlerResult. A classe Event passou a agregar seu HandlerResult.

O comportamento de execução dos elementos imposed guards, handler default e result foram implementados como métodos adaptativos. O comportamento de execução dos imposed guards de cada handler são implementados pelo método adaptativo run_ImposedGuards () definido pela classe Handler. Os comportamentos dos handlers default e result definidos para um evento são implementados, respectivamente, pelos métodos adaptativos run_DefaultHandler () e run_ResultHandler() da classe Event.

A figura 5.15 mostra um diagrama de classes com as extensões no projeto do Dispatcher a partir da incorporação dos elementos acima e logo em seguida código-fonte do comportamento associado a cada um deles. 


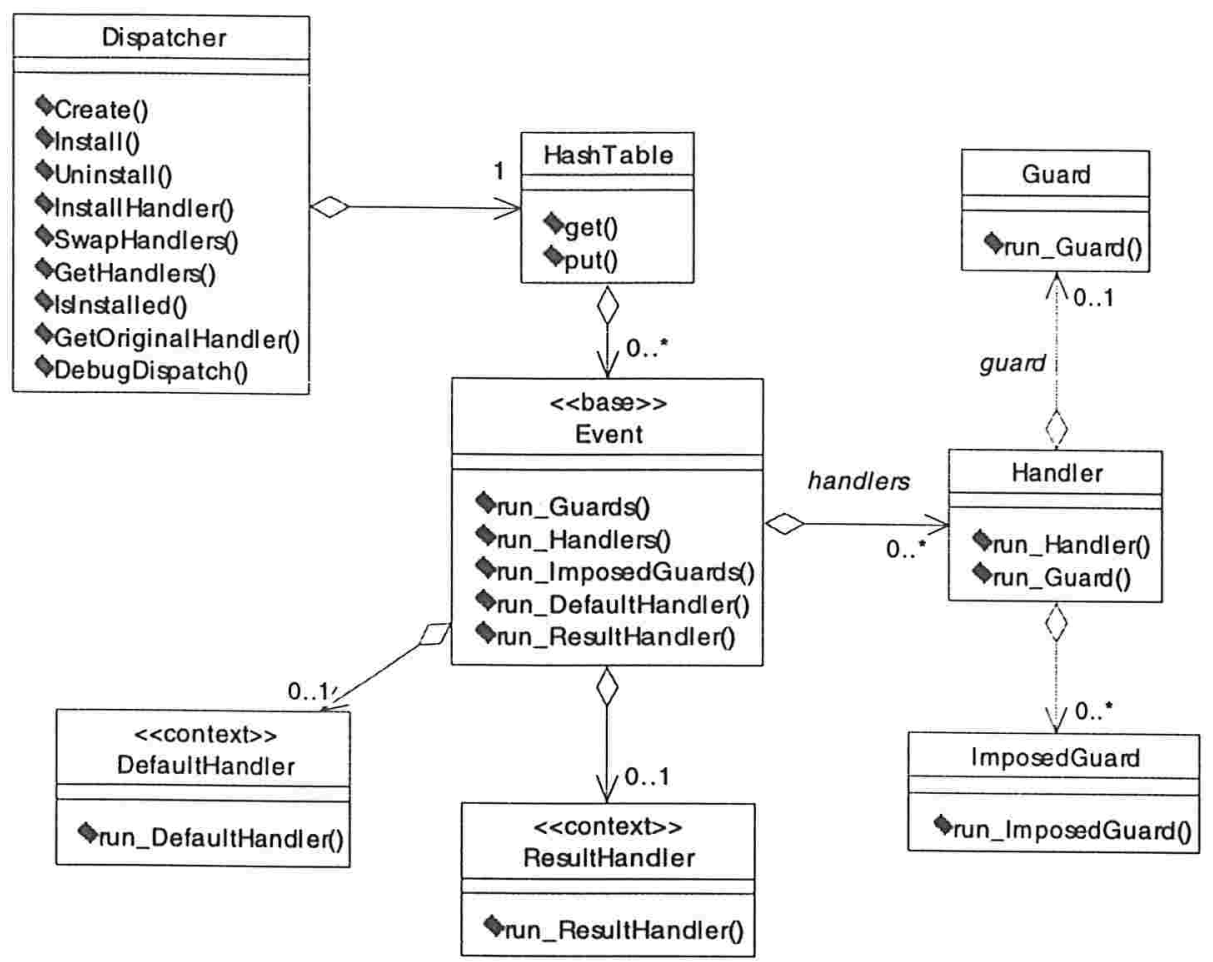

Figura 5.15: Diagrama de classes do Modelo de Componentes Funcionais Extendido

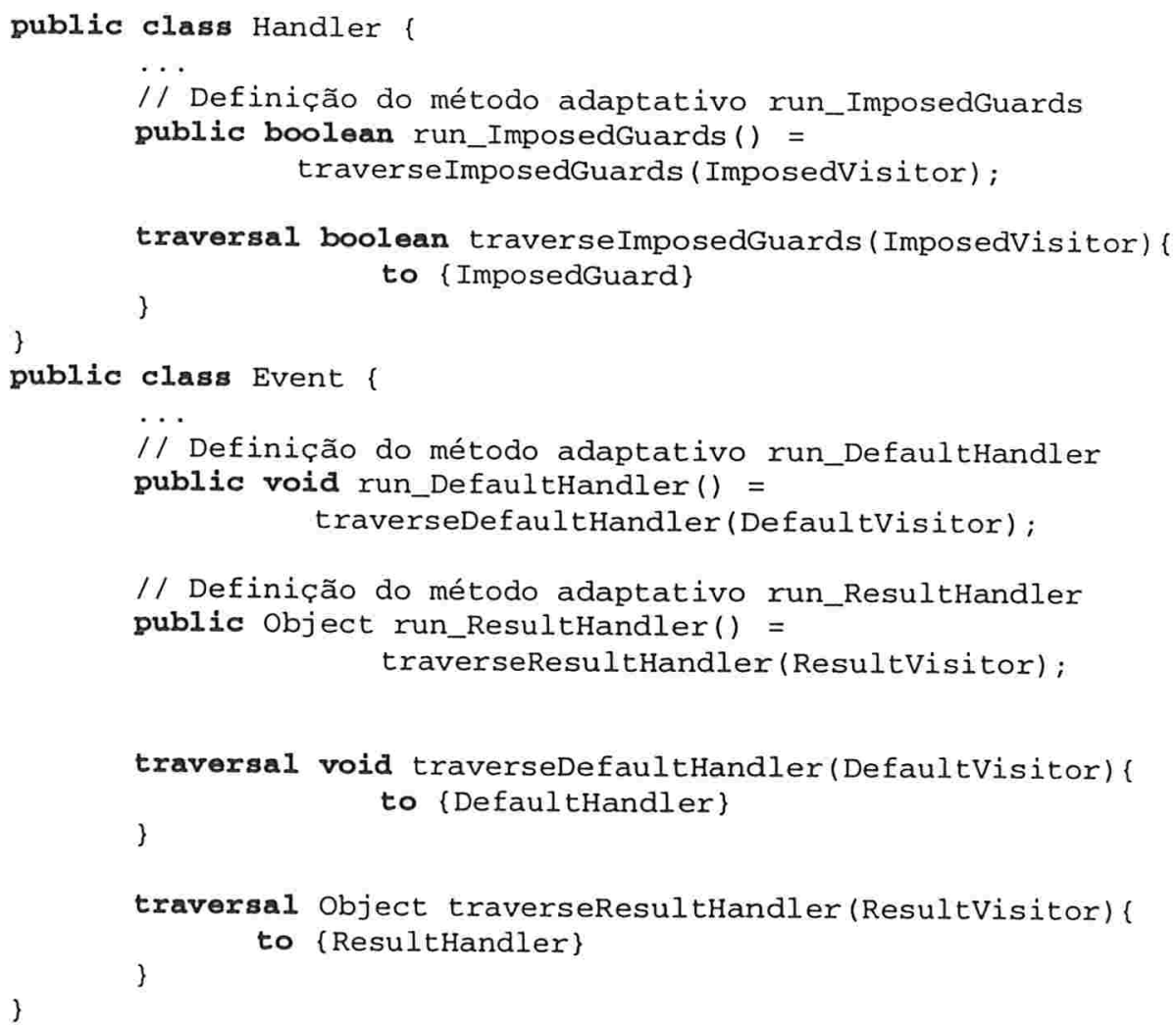




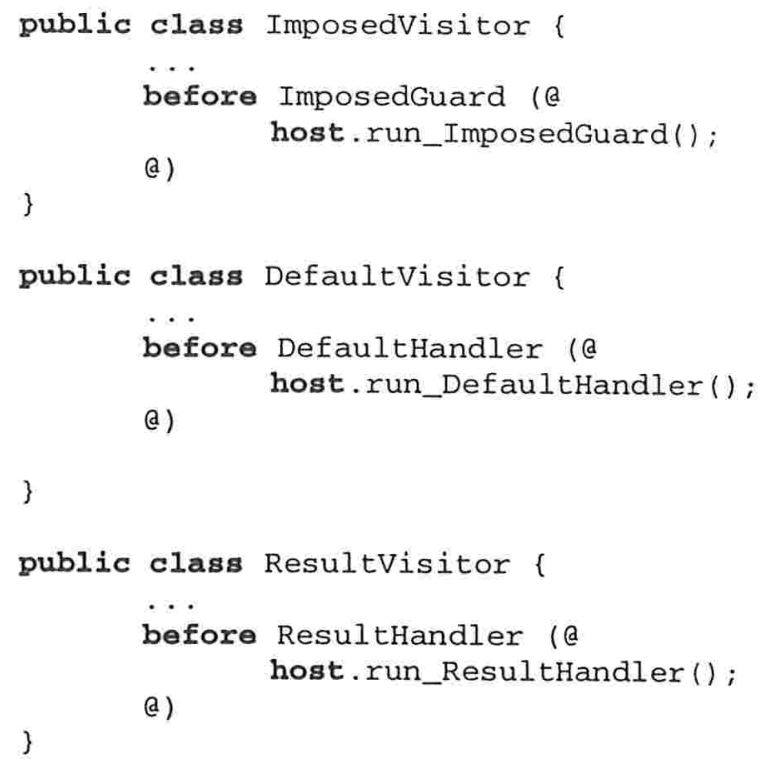

As classes visitors Handlervisitor e GuardVisitor, definidas na subseção anterior, que são usadas na implementação dos métodos adaptativos run_Guards () e run_Handlers (), foram redefinidas para incorporar a execução dos imposed guards e handlers default/result. Abaixo apresentamos o código-fonte destas classes visitors com suas novas extensões.

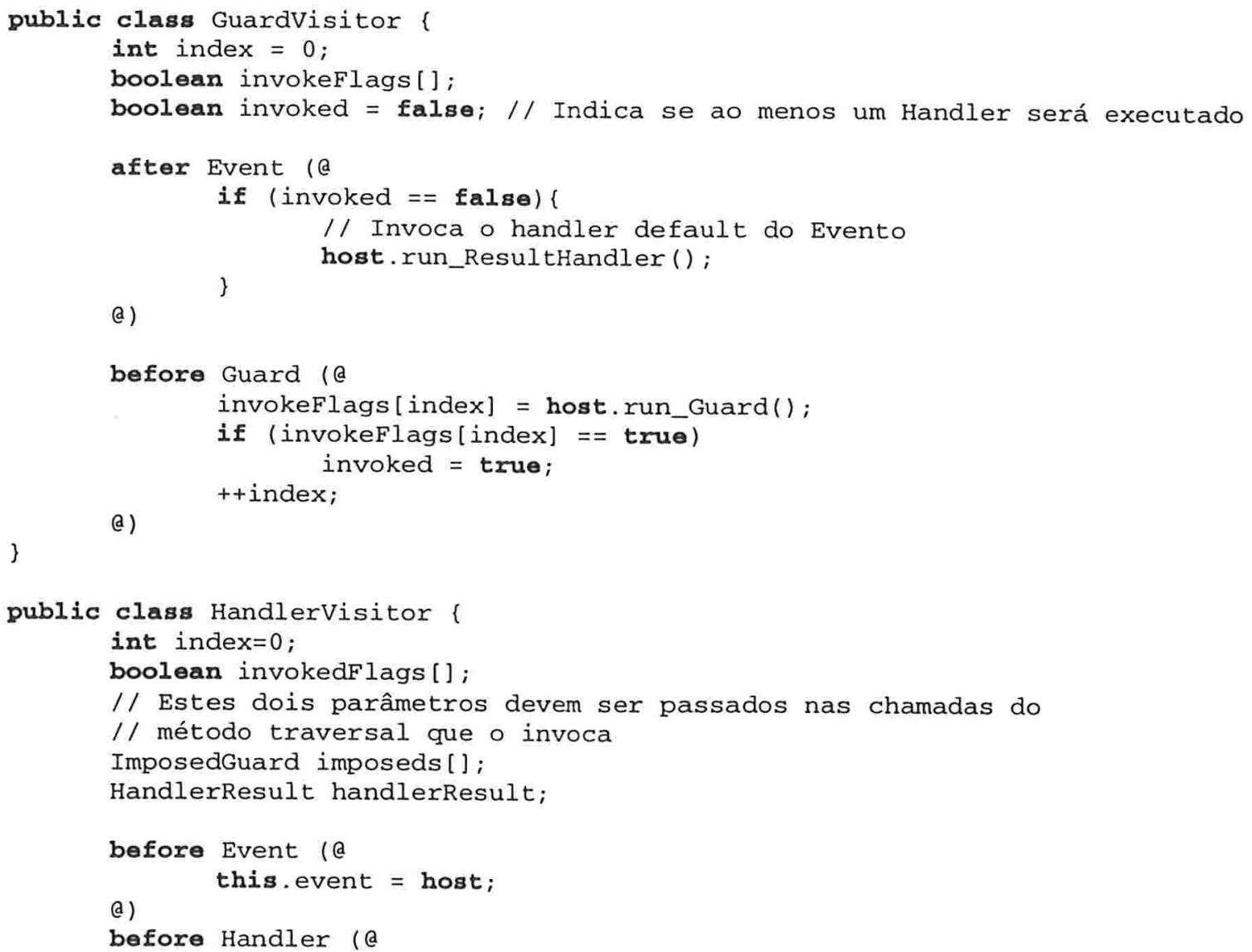




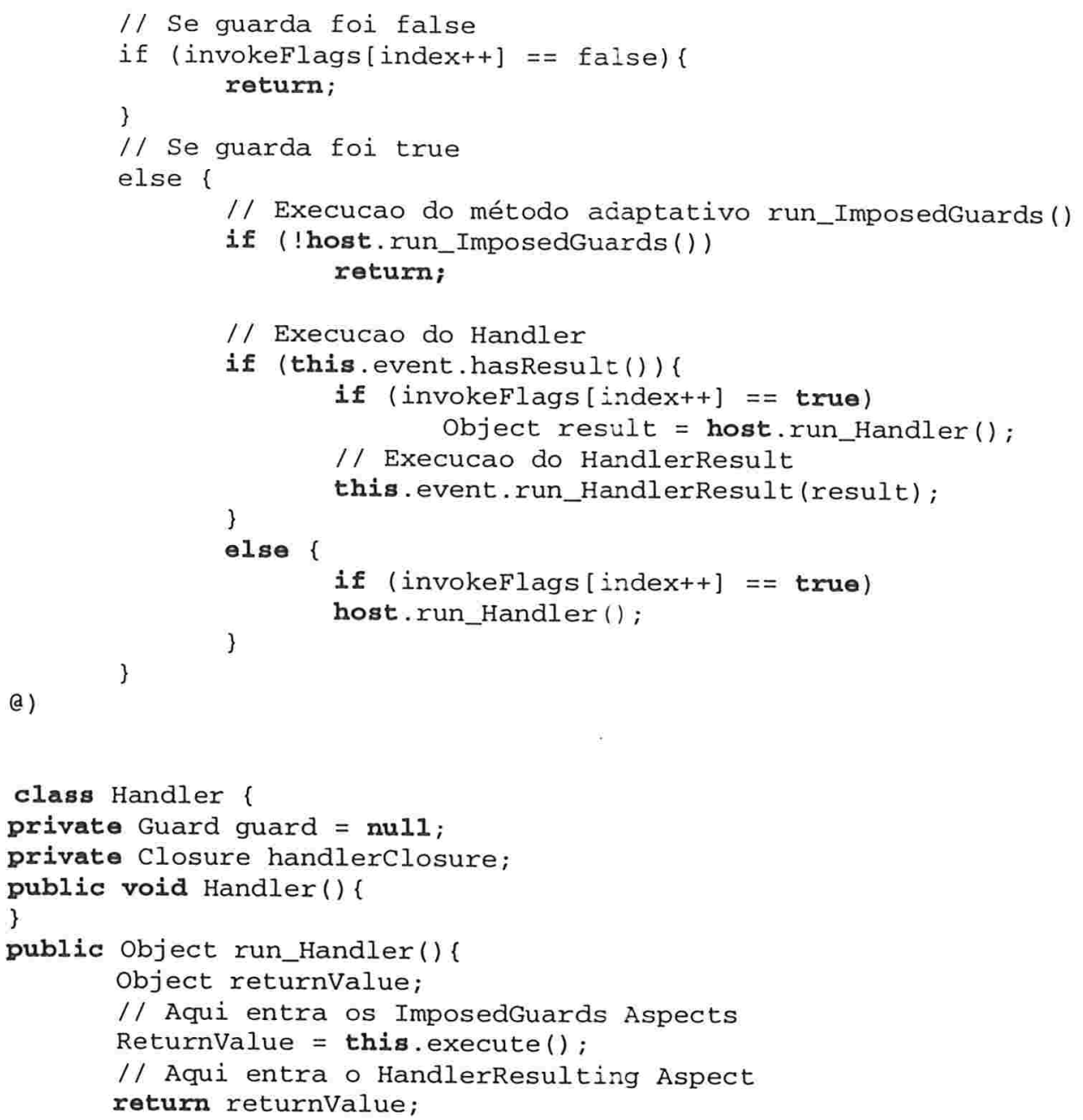

\subsubsection{Projeto do Dispatcher com Relações de Contexto}

No projeto do Dispatcher com relações de contexto foi reconsiderada a sua estrutura de componentes funcionais gerada durante a reengenharia com programação orientada a aspectos. Os elementos handlers default e result foram projetados como classes de contexto que modificam métodos de instância de alguma das classes funcionais do Dispatcher. O projeto de tais elementos com relações de contexto não requereu 
nenhuma modificação nos métodos adaptativos e traversal e classes visitor apresentados na subseção anterior.

O elemento handler default é representado pela classe de contexto DefaultHandler que oferece uma implementação para o método de instância run_DefaultHandler() da classe base Event. O método de instalação deste elemento InstallDefaultHandler() da classe Dispatcher deve agora receber como parâmetro um objeto de contexto que será associado ao respectivo objeto Event no qual o handler default deve ser instalado. O método de instância run_DefaultHandler() da classe Event será chamado durante a execução do método adaptativo run_Guards (), através do comportamento especificado pela classe visitor Guardvisitor.

$\mathrm{O}$ elemento handler result é representado pela classe de contexto ResultHandler. Esta classe oferece uma variação dinâmica para o método de instância run_ResultHandler() da classe Event. O método de instalação deste elemento InstallResultHandler() da classe Dispatcher deve, neste projeto com relações de contexto, receber como parâmetro um objeto de contexto da classe ResultHandler que será associado ao respectivo objeto Event no qual ele está sendo instalado. A classe HandlerVisitor chama o método de instância run_ResultHandler(), durante a execução do método adaptativo run_Handlers () .

O serviço de autorização de eventos, implementado por um objeto do tipo Auth no projeto original do Dispatcher, foi representado em seu projeto com relações de contexto pela classe de contexto Auth da classe base Event. A classe de contexto Auth define uma atualização dinâmica para o método de instância authorize() da classe base Event, além de poder definir seu estado e comportamento próprio utilizado na autorização de handlers sendo instalados no evento. Este método authorize() da classe Event será chamado pelo método AuthCheck() da classe Dispatcher.

A figura 5.16 apresenta diagrama de classes do projeto dos elementos handlers default e result e do serviço de autorização usando relações de contexto. Código-fonte do projeto destes elementos é também apresentado a seguir. 


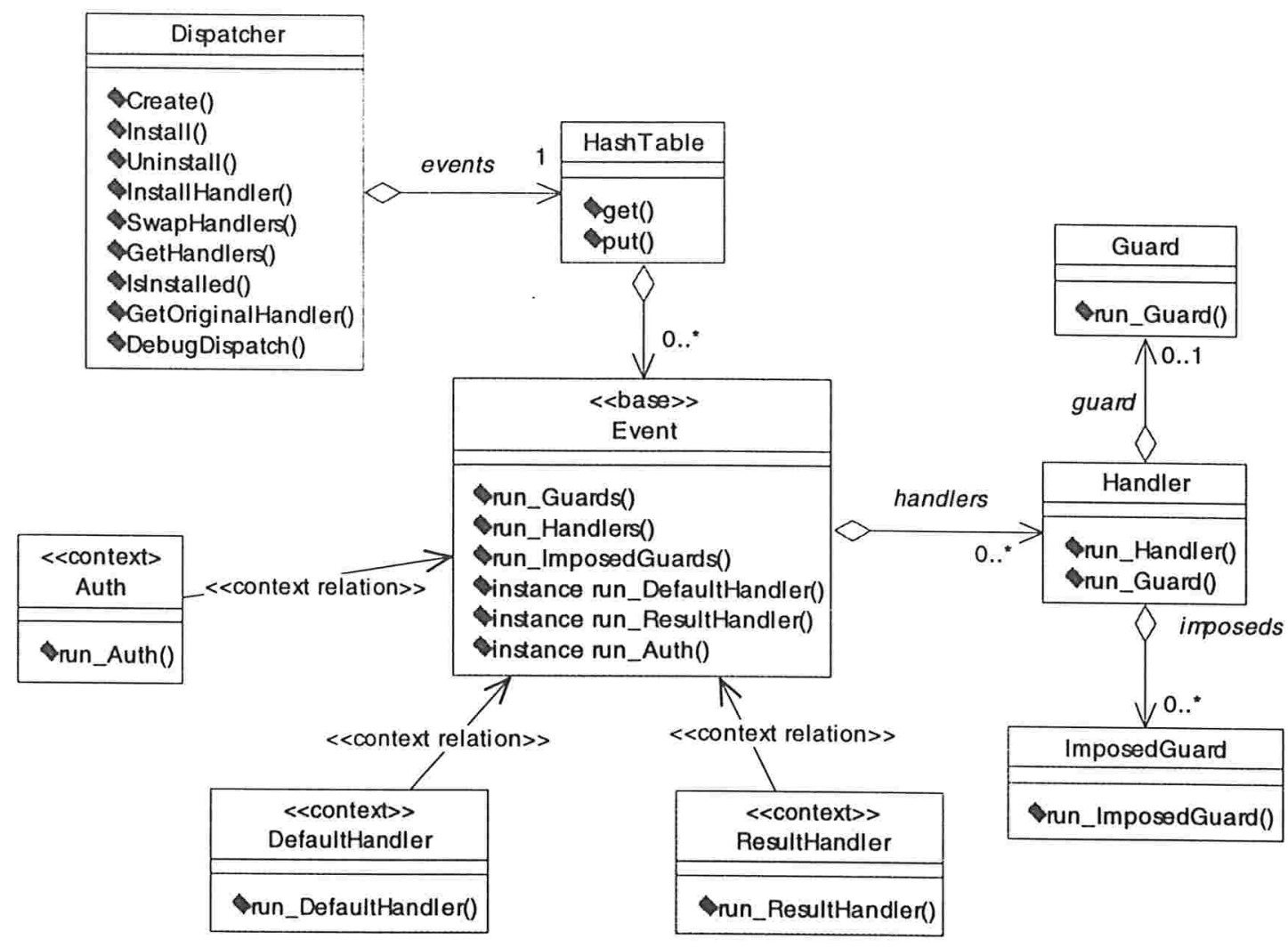

Figura 5.16: Diagrama de classes do Dispatcher com Relações de Contexto

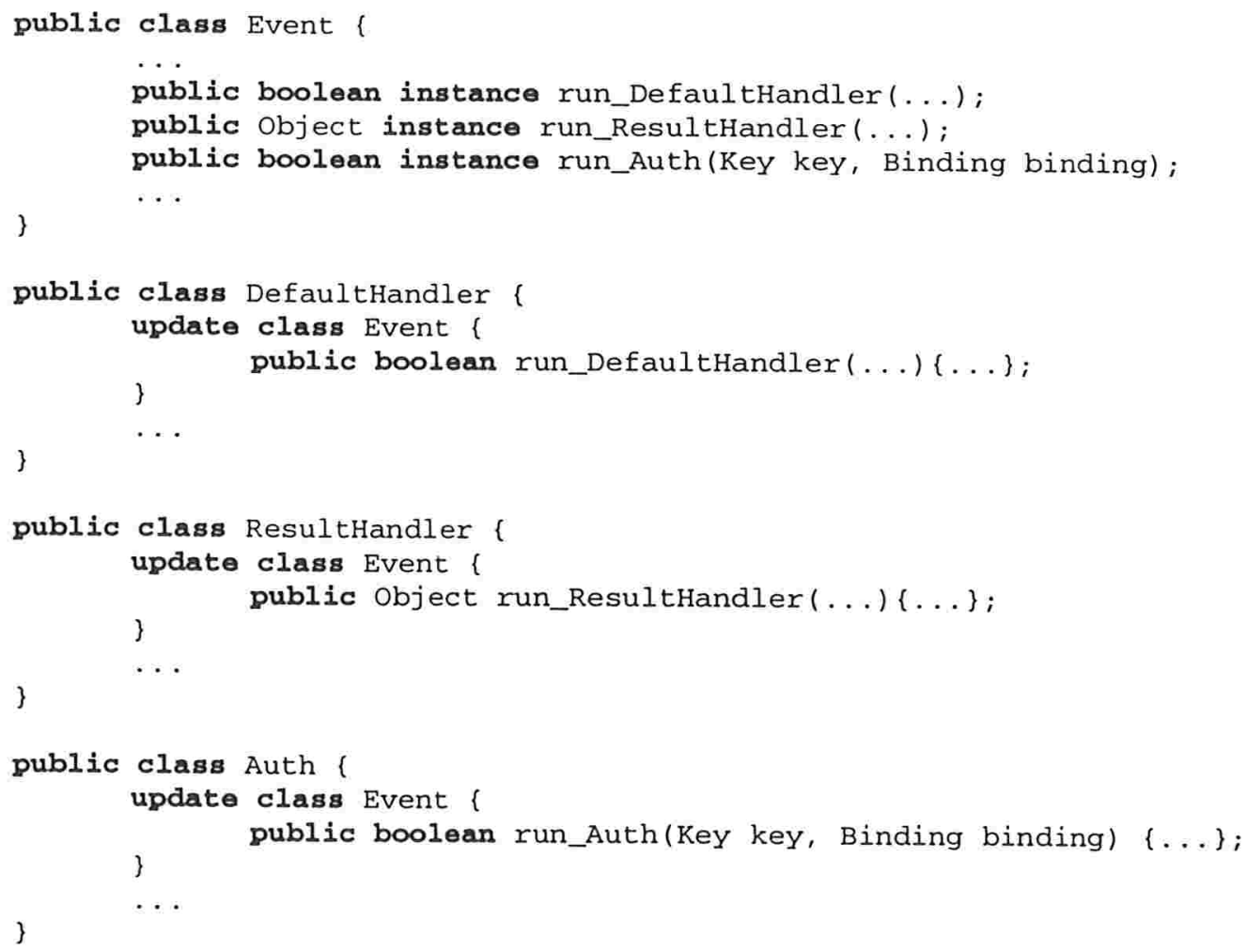




\subsubsection{Análise do Projeto do Dispatcher com Programação Adaptativa e Relações de Contexto}

O projeto do Dispatcher com programação adaptativa possibilitou a especificação dos métodos run_Guards() e run_Handlers() da classe Event como métodos adaptativos. As classes visitor Guardvisitor e HandlerVisitor foram implementadas com o intuito de fornecer o comportamento destes métodos adaptativos. Durante a extensão do modelo de componentes funcionais do Dispatcher, com a inserção das classes ImposedGuard, HandlerDefault e HandlerResult, as classes GuardVisitor e Handlervisitor foram modificadas de forma a incorporar o comportamento para execução dos novos elementos do modelo. Os métodos adaptativos run_Guards () e run_Handlers () não sofreram nenhuma modificação durante a extensão do modelo de componentes funcionais do Dispatcher. Isto revelou a vantagem de concentrar as modificações relacionadas ao comportamento dos métodos adaptativos em suas respectivas classes visitor, demonstrando na prática a capacidade da técnica em separar a especificação da estrutura e comportamento de sistemas orientados a objetos e trazendo facilidades para o seu entendimento e manutenção. Os métodos do Dispatcher que possibilitam a instalação dos elementos funcionais (eventos, handlers e guards) e dinâmicos (imposed guards, handlers default e result) poderiam também ser modelados usando as abstrações da técnica de programação adaptativa.

No projeto do Dispatcher com relações de contexto apenas os elementos dinâmicos handlers default e result e authorizer, foram modelados utilizando abstrações presentes nesta técnica. A maioria dos comportamentos implementados no Dispatcher não oferecem nenhuma forma de variação dinâmica. As vantagens do projeto dos elementos dinâmicos com relações de contexto observadas são: separação do interesse de variação dinâmica nas classes de contexto; facilidades para evolução estática do comportamento dinâmico de sistemas através do fácil desacoplamento de classes de contexto da classe base que elas estão associada; definição de uma nova configuração para o interesse sendo modelado com classes de contexto.

\subsection{Comparação do Estudo de Reengenharias do Dispatcher/SPIN}

As reengenharias do projeto do Dispatcher/SPIN usando as técnicas investigadas na dissertação demonstraram novamente que a técnica de programação orientada a aspectos permite projetar de forma mais clara diferentes interesses não funcionais presentes em um sistema, enquanto que a técnica de programação adaptativa com relações de contexto é útil para o projeto de comportamentos colaborativos (usando as abstrações de programação adaptativa) e para o projeto de comportamentos com variação dinâmica (usando relações de contexto).

A comparação dos projetos do Dispatcher/SPIN com programação orientada a aspectos e relações de contexto, no que se refere aos diferentes tipos de interesses não- 
funcionais projetados com cada uma das técnicas, permitiu a detecção de similaridades e diferenças entre as abstrações presentes (classes de contexto e aspectos) nas mesmas. Classes de Contexto e Aspectos definem ambos modificações em classes ou objetos do sistema, e podem manter estado e comportamento próprio dentro de suas respectivas estruturas. As principais diferenças entre as técnicas de programação orientada a aspectos e relações de contexto estão no tipo de modificações que classes de contexto e aspectos podem definir. Cada classe de contexto pode definir uma implementação alternativa para cada um dos métodos de instância de classes base. Um objeto de contexto (instância de uma classe de contexto) pode ser anexado dinamicamente a um objeto de uma classe base, modificando completamente um ou mais de seus comportamentos (métodos de instância). Os aspectos permitem estender objetos ou classes do sistema, inserindo estaticamente novos estado e comportamento às classes ou estendendo (estatica ou dinamicamente) o comportamento de métodos de objetos ou classes, durante o início (before) ou final (after) da sua execução.

Assim, percebe-se diferenças nos tipos de modificações apoiadas por classes de contexto e aspectos quanto ao elemento afetado (objeto ou classe), estado do sistema que é feita a modificação (estática ou dinamicamente), e finalmente quanto ao tipo (inserção de atributos/métodos ou extensão de métodos) e granularidade da modificação (substituição completa de um método, extensão de métodos durante o início ou final da sua execução). No capítulo 6 oferecemos sugestões para integração dos modelos de relações de contexto e programação orientada a aspectos (abordagem AspectJ). 


\section{Conclusões Gerais do Estudo de Casos}

A análise dos projetos gerados para os sistemas adaptáveis JAWS e Dispatcher/SPIN durante o processo de reengenharia com a utilização das técnicas de programação orientada a aspectos e programação adaptativa com relações de contexto possibilitou a elaboração de conclusões acerca dos benefícios que a aplicação das técnicas pode trazer para o projeto de sistemas e da possibilidade de integração das mesmas. Dentro do processo de reengenharia dos sistemas foram também adotadas algumas diretrizes para facilitar a aplicação das técnicas. Neste capítulo abordamos estas questões relatando as conclusões gerais do estudo de casos e comparando nosso trabalho com outros estudos relacionados.

\subsection{Aplicabilidade de Programação Orientada a Aspectos}

As reengenharias dos projetos do JAWS e Dispatcher usando a técnica de programação orientada a aspectos trouxeram diferentes conclusões a respeito da sua aplicabilidade no projeto de sistemas.

O projeto do JAWS com programação orientada a aspectos demonstrou a aplicabilidade da técnica na elaboração de estruturas (classes e aspectos) para endereçar seus interesses de adaptação estática e dinâmica. Cada um dos interesses de adaptação do JAWS (suas estratégias) foi projetado através de uma hierarquia independente de aspectos/classes que afeta o modelo de componentes funcionais do sistema.

Além disso, o projeto do JAWS com programação orientada a aspectos permitiu tratar do interesse de monitoramento, que não havia sido endereçado em seu projeto original. A técnica de programação orientada a aspectos permite projetar o interesse de monitoramento de um sistema de forma bastante coesa e com fraco acoplamento aos componentes do sistema que serão monitorados. Seguindo o modelo convencional de orientação a objetos (OO), o projeto do interesse de monitoramento de um sistema pode ser realizado através da especificação de uma classe que define o estado de monitoramento e comportamento para atualização deste estado. Dentro dos métodos das classes do sistema que serão monitoradas são inseridas, pelo desenvolvedor, chamadas aos métodos da classe de monitoramento de forma a atualizar seu estado. Com este projeto $\mathrm{OO}$, o interesse de monitoramento não é capturado de forma coesa, apresentandose difundido pelas diversas classes do sistema que serão monitoradas, e não permitindo o seu fácil desacoplamento do sistema. Assim, a pouca coesão e forte acoplamento deste projeto $\mathrm{OO}$ dificultam a manutenção do interesse de monitoramento. O projeto do 
interesse de monitoramento com a técnica de programação orientada a aspectos especifica dentro de uma mesma estrutura (um aspecto): (a) o estado de monitoramento; (b) o comportamento de modificação deste estado; e (c) as extensões que as classes do sistema que serão monitoradas sofrerão. Além disso, projetado com o suporte de AspectJ para a definição de aspectos dinâmicos, o serviço de monitoramento do sistema pode, em tempo de execução, ter seu esquema modificado com a redefinição dos objetos do sistema que serão monitorados.

Para permitir a configuração estática e dinâmica das estratégias do JAWS a partir das informações mantidas pelo aspecto de monitoramento (Monitoring), foi criado o aspecto Configurator. Este aspecto recebe notificações do aspecto Monitoring de atualizações feitas no estado de monitoramento e determina, a partir da mudança deste estado, possíveis configurações estáticas e dinâmicas para as estratégias definidas para o JAWS. Para realizar estas configurações, o aspecto Configurator agrega os aspectos que definem as políticas de configuração para cada uma das estratégias do JAWS e delega para estes, eventuais pedidos de troca de estratégias do sistema.

Esta estrutura, composta pelos aspectos Configurator e Monitoring e pelos aspectos que definem as políticas de configuração das estratégias do JAWS, pode ser reutilizada para o projeto de sistemas que tratem o interesse de configuração de forma semelhante ao JAWS, ou seja, definem estratégias para o sistema que podem ser estática ou dinamicamente substituídas por outras. Estas estratégias não precisam ser necessariamente projetadas usando a abstração de aspectos (tal como na reengenharia do JAWS), elas podem ser representadas seguindo o modelo definido pelo padrão de projeto Strategy [GHJV95] ou até mesmo como objetos de contexto.

A reengenharia do projeto do Dispatcher com programação orientada a aspectos trouxe como principal contribuição um exemplo de sistema que apresenta diversos de seus interesses de projeto entrelaçados e difusos por entre os procedimentos de sua estrutura. O projeto resultante do processo de reengenharia mostrou como esses diferentes interesses podem ser projetados de forma separada da estrutura de componentes funcionais estabelecida para o Dispatcher. O estudo do Dispatcher com programação orientada a aspectos permitiu ainda: (1) reutilizar a biblioteca de aspectos Coolib para endereçar seu interesse de sincronização de objetos; (2) apresentar hierarquias de aspectos para o tratamento de exceções do sistema a partir da violação de contratos; e (3) mostrar a existência de dependências entre aspectos.

De forma geral, os dois estudos de reengenharia usando a técnica de programação orientada a aspectos validaram, em sistemas adaptáveis reais, os benefícios que esta técnica pode trazer para requisitos de manutenibilidade de sistemas, favorecendo a separação de interesses de projetos e a reutilização das estruturas relacionadas a cada interesse, e trazendo facilidades para evolução estática e configuração dinâmica do sistema.

Em [WMH93], são identificadas duas questões-chaves para obtenção de sucesso no processo de manutenção: (1) habilidade de fazer mudanças facilmente; e (2) 
entendimento profundo da estrutura e comportamento do software. Acreditamos que estes dois pontos se apresentam mais fortalecidos nos projetos do JAWS e Dispatcher usando programação orientada a aspectos do que em seus projetos originais. A separação de interesses, através da especificação de cada um dos interesses de projeto do JAWS e Dispatcher em hierarquias distintas de aspectos/classes, trouxe benefícios para o entendimento de como cada um deles é alcançado no sistema. Isto favorece (2), pois permite entender de forma independente a estrutura e comportamento das diferentes hierarquias, e conseqüentemente dos diferentes interesses. Além disso, a distribuição do atendimento dos interesses do sistema em diversas hierarquias distintas e independentes aparentemente diminui a complexidade da estrutura e comportamento do software como um todo. O projeto dos sistemas usando a técnica de programação orientada a aspectos permite entender a sua estrutura e comportamento de forma progressiva iniciando pelo modelo de componentes funcionais definido para o sistema e, em seguida, estudando separadamente cada uma das hierarquias de aspectos que afetam o modelo de componentes funcionais e endereçam os interesses não funcionais do sistema.

A independência entre as diferentes hierarquias que endereçam os interesses do sistema e a sua própria especificação separada facilitam a adequação de mudanças (questão-chave 1) em cada uma delas por limitar o impacto de propagação destas mudanças para o seu escopo (classes e aspectos que fazem parte de cada hierarquia). Entretanto, um novo tipo de dependência surge entre os elementos, classes e aspectos, que formam agora a estrutura do sistema: alguns aspectos dependem das classes que eles afetam e mudanças na estrutura de tais classes (ex: remoção de atributos ou métodos) podem invalidar cláusulas advice que fazem suposições sobre esta estrutura ${ }^{6}$.

\subsubsection{Método para Projeto Orientado a Aspectos}

Algumas diretrizes para projeto orientado a aspectos, apresentadas por Kersten \& Murphy em [KM99], foram usadas com êxito no nosso estudo. De forma similar ao trabalho destes autores, inicialmente mantivemos um modelo de objetos independente que permitiu pensarmos apenas na funcionalidade básica do sistema, e em seguida, foram identificados e projetados os diferentes aspectos que afetavam tal funcionalidade. Foram utilizadas também relações entre aspectos e classes, nas quais apenas os primeiros fazem suposições sobre o funcionamento do outro (class-directional). Este tipo de relação garante a relativa independência entre o modelo de objetos do sistema e as hierarquias de aspectos/classes que projetamos.

O método empregado no reprojeto dos sistemas JAWS e Dispatcher/SPIN com a técnica de programação orientada a aspectos se baseou nos seguintes passos:

(1) projeto dos interesses funcionais - inicialmente foram modelados apenas os componentes funcionais do sistema. Tal modelagem utilizou apenas elementos do modelo tradicional de programação orientada a objetos. Diversas classes e relações presentes no sistema original e que atendiam seus interesses funcionais foram mantidas;

\footnotetext{
${ }^{6}$ Recentes versões de AspectJ forçam os aspectos a definirem explicitamente os atributos (de classes ou objetos que eles afetam) que eles utilizarão em cada uma de suas cláusulas.
} 
em alguns casos foi necessária uma reestruturação destes elementos. Ao final deste passo, tinha-se como resultado diagramas de classes UML que descreviam a estrutura do novo projeto do sistema, assim como a especificação de métodos que descrevessem o seu comportamento;

(2) projeto dos interesses não-funcionais - o segundo passo do reprojeto do sistema era modelar seus interesses não-funcionais. O entendimento da estrutura $\mathrm{e}$ comportamento do sistema original, a detecção de entrelaçamentos de seus interesses (funcionais e não-funcionais) nas classes originais do sistema e a compreensão de aspectos capturados em outros sistemas [KM99, LL99, LK97, Lop97, KL99], comentados na seção 6.4, foram de grande valia para a realização deste passo. Em geral, cada um dos interesses não-funcionais do sistema foi projetado separadamente, e em seguida, se necessário, acoplados entre si. Hierarquias, contendo aspectos e classes, foram utilizadas para modelar tais interesses não funcionais. Os aspectos definem a forma como cada uma destas hierarquias afetam os componentes funcionais do sistema. Em alguns casos foi necessário uma refatoração (refactoring [Opd92, Fow99]) de comportamentos dos componentes funcionais de forma a permitir a acomodação dos aspectos. Os produtos finais deste passo foram: (a) modelos contendo aspectos e classes responsáveis pelo atendimento de um dado interesse não-funcional; e (b) aspectos e classes responsáveis pela implementação de cada um dos modelos.

Também a descoberta de existência de dependências entre aspectos no projeto do Dispatcher com programação orientada a aspectos levou-nos a concluir que no projeto dos interesses não-funcionais do sistema devem ser modelados inicialmente os aspectos relacionados aos interesses do domínio específico do sistema e, em seguida, os aspectos relacionados a interesses gerais do sistema (tratamento de exceções, sincronização de objetos, rastreamento da execução). Isto acontece porque, em geral, os aspectos relacionados a interesses não-funcionais gerais do sistema afetam métodos introduzidos pelos aspectos relacionados a interesses não-funcionais do domínio do sistema.

\subsection{Aplicabilidade de Programação Adaptativa e Relações de Contexto}

A técnica de programação adaptativa promove a especificação separada da estrutura e comportamento do sistema. Durante os estudos de reengenharia do projeto do JAWS e do Dispatcher usando a técnica de programação adaptativa, foram encontrados comportamentos colaborativos que puderam ser projetados usando as abstrações de tal técnica. A principal vantagem trazida pela técnica para a modelagem de comportamentos colaborativos é, além da especificação separada da estrutura e comportamento do sistema, a possibilidade de adaptação automática dos comportamentos especificados anteriormente para mudanças ocorrendo na estrutura de classes do sistema.

Apesar de apenas alguns comportamentos do JAWS e Dispatcher terem sido projetados com programação adaptativa, estes são seus comportamentos principais. No JAWS a configuração e ativação de suas estratégias e a definição do protocolo foram 
especificados com programação adaptativa. No Dispatcher, métodos utilizados para o despacho de eventos foram definidos como métodos adaptativos.

Acreditamos que o projeto adaptativo, privilegiando a especificação separada da estrutura e comportamento do sistema, pode trazer facilidades para o entendimento e implementação daqueles comportamentos que envolvam uma colaboração entre objetos de várias classes da estrutura do sistema. A técnica traz também facilidades para reutilização (de métodos traversal e classes Visitor) e manutenção (definição de subvisitors com novas funcionalidades para os comportamentos do sistema, adaptação automática de comportamentos a modificações na estrutura de classes) do sistema.

A técnica de Relações de Contexto permite o projeto de aspectos de variação dinâmica de uma aplicação, sem a necessidade de utilização de estruturas de classes extras, tais como, as apresentadas pelos padrões de projeto [GHJV95, BMR+96]. Durante a reengenharia do projeto dos sistemas JAWS e Dispatcher, relações de contexto foi utilizada para o projeto dos interesses de adaptação de tais sistemas.

No projeto do JAWS usando relações de contexto, as suas diferentes estratégias adaptativas foram reprojetadas através da especificação de classes base e de contexto. No projeto do Dispatcher com relações de contexto, elementos de caráter dinâmico (handlers default/result, authorizer) foram também projetados usando abstrações da técnica.

Além de definir um projeto mais simples (sem o uso de estruturas de classes adicionais) para endereçar os aspectos de variação dinâmica de um sistema, foram observadas algumas vantagens que relações de contexto pode trazer para o projeto de um sistema, entre elas: separação explícita do interesse de variação dinâmica, facilidades para evolução estática devido ao fraco acoplamento de classes de contexto para classes base e a definição de uma nova configuração para o sistema quando anexando um objeto de contexto a um objeto base.

\subsubsection{Método para Projeto Adaptativo}

O método utilizado para o reprojeto dos sistemas usando a técnica de programação adaptativa com relações de contexto se baseou nos seguintes passos:

(1) projeto de comportamentos colaborativos - após o entendimento da estrutura e comportamento do sistema, foram identificados métodos colaborativos entre suas classes. Estes métodos colaborativos foram então modelados utilizando as abstrações existentes (métodos adaptativos, métodos traversals, classes visitor) em programação adaptativa.

(2) projeto de comportamentos com variação dinâmica - este passo consistiu no entendimento das partes específicas da estrutura do sistema que apresentam alguma forma de adaptação/variação dinâmica. Por exemplo, hierarquias de classes e subclasses, em que as subclasses definem implementações concretas para a interface definida por sua superclasse, e em tempo de execução existe a necessidade de permutação entre instâncias destas subclasses. 


\subsection{Integração das Técnicas}

Programação orientada a aspectos e programação adaptativa com relações de contexto fazem parte de um conjunto de técnicas [KLM+97, TOHS99, HL95], que buscam o favorecimento da manutenibilidade de um sistema, através da especificação separada de seus interesses.

Programação orientada a aspectos propõe a separação dos interesses de um sistema, através da especificação de: componentes - que determinam a funcionalidade inerente do sistema; e aspectos - que representam as propriedades não-funcionais do sistema que afetam o seu desempenho ou a semântica dos seus componentes de uma forma sistemática.

Programação adaptativa propõe a separação dos interesses relacionados a estrutura e comportamento do sistema. Assim, usando a abordagem Demeter/Java desta técnica, um sistema orientado a objetos tem sua estrutura especificada através de dicionários de classes e seu comportamento especificado através da definição de métodos adaptativos, métodos traversal e classes Visitor. Relações de Contexto propõe um novo tipo de relação entre classes que oferece suporte a variações dinâmicas no comportamento de sistemas.

\subsubsection{Integração entre Programação Orientada a Aspectos e Programação Adaptativa}

Apesar de programação orientada a aspectos ter sido proposta pelo grupo de projeto de software do centro de pesquisa da Xerox em Palo Alto, um dos trabalhos primordiais [LK97, Lop97] da abordagem de programação orientada a aspectos foi desenvolvido parcialmente na Northeastern University, dentro das atividades do projeto de pesquisa Demeter, responsável pela técnica de programação adaptativa. Este trabalho propôs um framework de uma linguagem orientada a objetos para programação de aplicações distribuídas [LK97, Lop97], que consiste de: Jcore - uma linguagem para expressão dos componentes funcionais e atividades da aplicação (na verdade um subconjunto da linguagem Java); Cool - uma linguagem de aspectos usada para expressar a coordenação das threads da aplicação; e Ridl - uma linguagem de aspectos que permite especificar estratégias de transferência de dados na especificação de serviços remotos. Ambas as linguagens Cool e Ridl foram incorporadas à ferramenta Demeter/Java, demonstrando desta forma a possibilidade de integração entre as técnicas de programação orientada a aspectos e programação adaptativa. Mais recentemente, o grupo de projeto de software da Xerox vem desenvolvendo a linguagem AspectJ para especificação de aspectos de propósito geral.

\section{Proposta de Integração}

Os projetos do JAWS e Dispatcher/SPIN com a linguagem AspectJ de programação orientada a aspectos e a abordagem Demeter/Java de programação 
adaptativa foram realizados separadamente, ou seja, cada sistema foi projetado separadamente com cada uma das técnicas. Acreditamos, entretanto, que um sistema pode em seu projeto beneficiar-se simultaneamente de ambas as abordagens. Como a abordagem Demeter/Java se refere a especificação dos interesses relacionados a estrutura e comportamento do sistema, ela pode ser usada inicialmente no projeto de sistemas para definir a estrutura e funcionalidade do seu modelo de componentes funcionais. Após a especificação do modelo de componentes funcionais do sistema, poderiam ser construídas as hierarquias de aspectos (de AspectJ) que endereçam os interesses nãofuncionais de seu projeto.

Os projetos do JAWS e do Dispatcher com AspectJ e Demeter/Java mostra a possibilidade de integração das abordagens. No projeto do JAWS com programação adaptativa, os seguintes comportamentos foram projetados usando as abstrações desta técnica: configuração das estratégias, ativação da estratégia de concorrência e definição do comportamento do protocolo. Um projeto usando simultaneamente as abordagens de AspectJ e Demeter/Java, deveria inicialmente definir a estrutura e comportamento do modelo de componentes funcionais do sistema, tal como o obtido na reengenharia do JAWS com programação orientada a aspectos (descrito na subseção 4.2.1). Este modelo de componentes funcionais definido para o JAWS na sua reconstrução com programação orientada a aspectos permite, por exemplo, a definição do método que implementa o comportamento do protocolo HTTP do JAWS (método svc() da classe JAWS_Request_Manager) como um método adaptativo idêntico ao método adaptativo run_protocol () da classe JAWS_Pipeline_Protocol obtido na reengenharia do JAWS com programação adaptativa (subseção 4.3.1.2). Os demais comportamentos do JAWS especificados com programação adaptativa (configuração das estratégias e ativação da estratégia de concorrência) são endereçados pelos aspectos que definem as configurações para as estratégias do JAWS, pois estes permitem um projeto mais coeso (cada configuração é especificada separadamente por um aspecto) e de fácil evolução estática (cada aspecto pode ser estaticamente desacoplado do modelo de componentes funcionais). Também os métodos run_Handlers() e run_Guards() da classe Event definida no modelo de componentes funcionais do projeto do Dispatcher com programação orientada a aspectos (subseção 5.2.1), poderiam ser projetados como métodos adaptativos tal como apresentado no projeto do Dispatcher com programação adaptativa (subseção 5.3.1.1). Foi observado um problema na integração das abordagens: os métodos svc () e run_Handlers (), citados acima, dos respectivos projetos do JAWS e Dispatcher com programação orientada a aspectos foram, durante o projeto dos aspectos dos sistemas, quebrados em dois métodos para acomodar extensões de aspectos que os afetam. Caso estes métodos fossem modelados como métodos adaptativos, alguns métodos das classes visitor, que implementam o comportamento de tais métodos adaptativos, deveriam ser afetados pelos mesmos aspectos que nos projetos dos sistemas com programação orientada a aspectos afetam os métodos svc() e run_Handlers(). Desta forma, torna-se necessário o desenvolvimento de novos estudos a respeito de como proceder na integração das abordagens AspectJ e Demeter/Java. 


\subsubsection{Integração entre Programação Orientada a Aspectos e Relações de Contexto}

O projeto do Dispatcher com relações de contexto revelou diversas similaridades e diferenças entre a abstração de classe de contexto do modelo de relações de contexto e a abstração de aspecto tal como definido em AspectJ. Ambas as abstrações afetam uma classe ou objeto do sistema. No modelo proposto por relações de contexto, entretanto, uma classe pode ter alguns de seus comportamentos modificados dinamicamente, o que não acontece no modelo definido por AspectJ que permite apenas a alteração dinâmica de objetos. Classes de contexto e aspectos podem ambos definir seus atributos e métodos próprios. As abstrações diferem também no que se refere ao tipo e granularidade da modificação feita sobre o elementos afetado. Uma classe de contexto define uma substituição para um método de uma classe ou objeto (construções update). Um aspecto permite inserir novos atributos e métodos em classes do sistema (construções introduction) ou estender um método de uma classe ou objeto (construções advice).

\section{Proposta de Integração}

Nós propomos a integração dos modelos de relações de contexto e da abordagem AspectJ de programação orientada a aspectos, onde o primeiro seria incorporado ao último. Nesta integração cada classe de contexto seria também representada por um aspecto, que por sua vez poderia definir construções update para atualização de métodos de classes ou objetos do sistema. Assim, os aspectos passariam a incorporar modificações estáticas e dinâmicas em classes ou objetos do sistema que oferecessem uma forma de expressar as variações dinâmicas do comportamento destes elementos do sistema. Esta integração dos modelos de relações de contexto e da abordagem AspectJ de programação orientada a aspectos traria também mais facilidades para o desacoplamento das classes de contexto das classes base. Cada classe de contexto, representada na integração dos modelos por um aspecto, poderia definir não apenas construções update para atualizações de métodos, como também introduzir na classe base (a classe afetada pelo aspecto) o próprio método que sofrerá modificações dinâmicas.

\section{Representação de Objetos de Contexto em AspectJ}

O modelo da versão 0.6 de AspectJ usada no nosso estudo permite expressar as Relações de Contexto, mas não com a semântica proposta por seus autores [SPL98]. Para ilustrar esta possibilidade apresentamos a seguir a modelagem do padrão Strategy com AspectJ, do exemplo que foi descrito na subseção 3.2.2.1 usando relações de contexto. Neste exemplo uma classe base composition tinha seu método de instância compose () afetado pelas três classes de contexto simplecompositor, TexCompositor e ArrayCompositor. O projeto deste exemplo com AspectJ, transformaria as três classes de contexto em aspectos que afetariam a classe composition. O aspecto Simplecompositor, tal como no exemplo com relações de contexto, deve oferecer uma implementação default para o método compose() da classe composition, assim ele define um advice after estático que afeta o método compose (), chamando no final da 
sua execução o método compose() definido por ele. Já os aspectos TexCompositor e ArrayCompositor definem um advice dinâmico que afetam o método compose() da classe composition, chamando no início da execução de tal método, os seus respectivos métodos compose(). Os aspectos TexCompositor e Arraycompositor, por definirem um advice dinâmico, devem ser associados, durante a execução do sistema, a um objeto da classe composition de forma a afetar seu método compose (). A seguir apresentamos código-fonte dos aspectos e classe deste exemplo, assim como código de associação (e desassociação) dos aspectos a uma instância da classe composition.

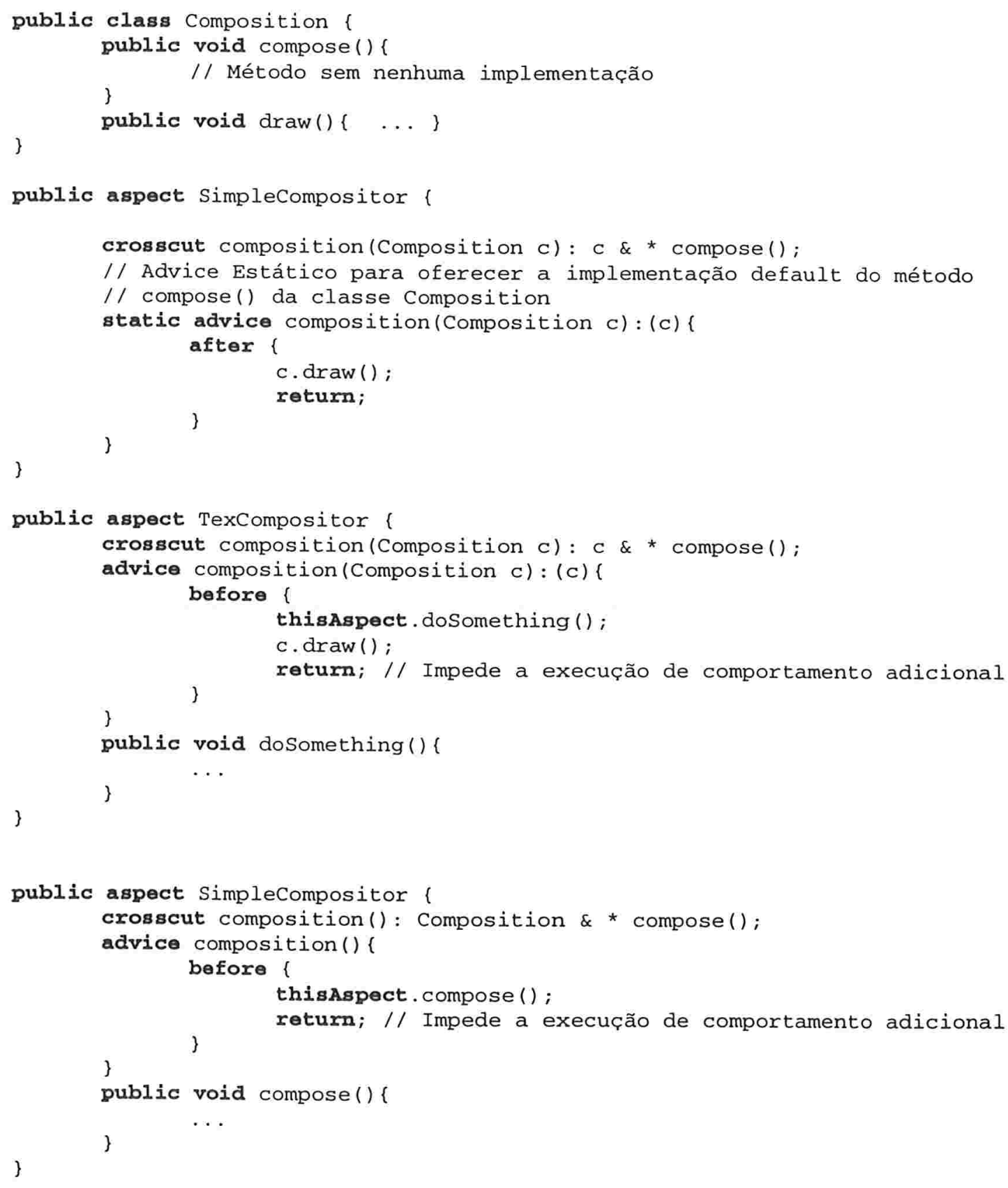




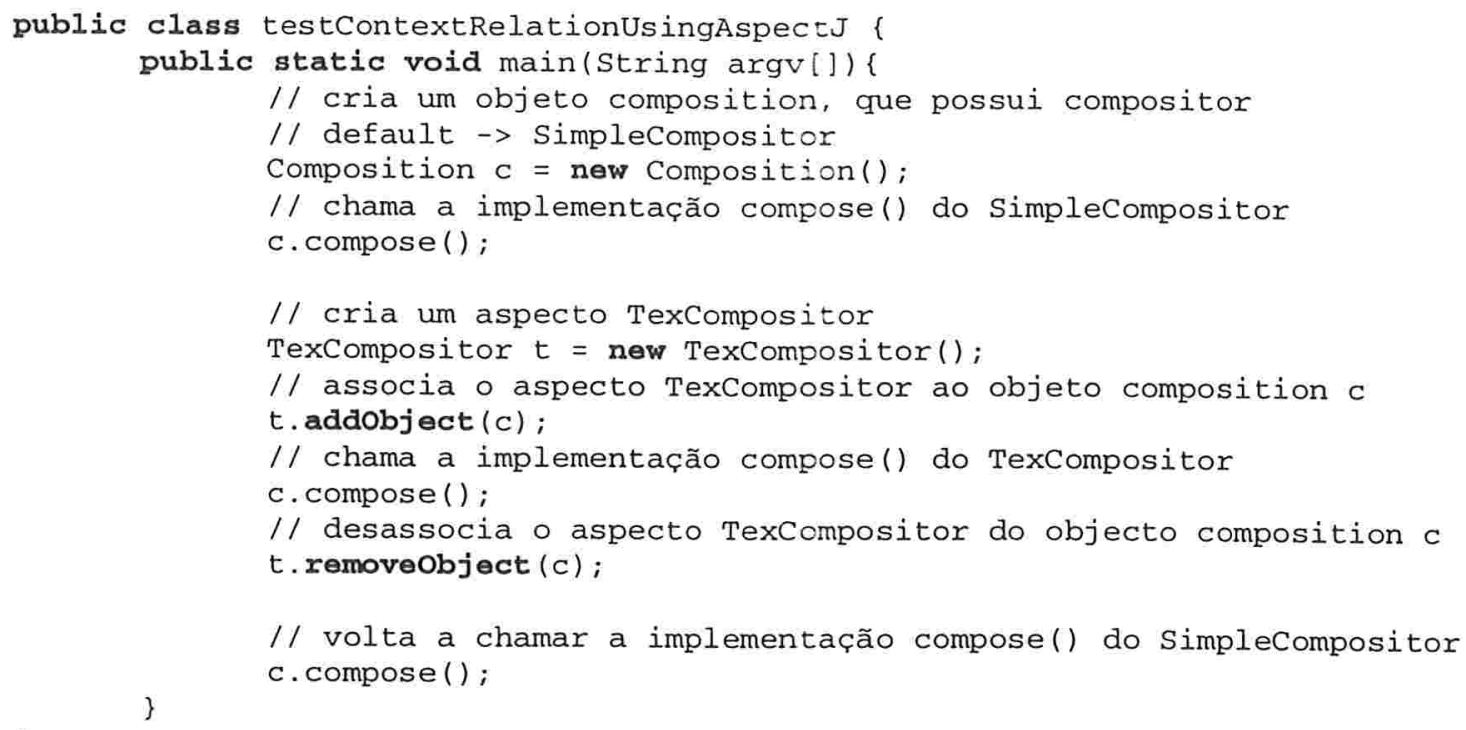

\subsection{Trabalhos Relacionados}

Nesta seção descrevemos outros trabalhos e estudos empíricos desenvolvidos pela comunidade com o intuito de avaliar a utilidade e usabilidade das técnicas de programação orientada a aspectos e programação adaptativa com relações de contexto. Os trabalhos descritos são relacionados com o estudo desenvolvido nesta dissertação, assim como são enfocadas as suas contribuições para a realização das reengenharias dos projetos do JAWS e do Dispatcher/SPIN com as técnicas estudadas.

Os trabalhos de Murphy, Walker \& Baniassad, descritos em [WBM99, MWB99], mostram os resultados obtidos a partir da realização de um estudo de caso e quatro experimentos [Pf194, ZW98] de avaliação da abordagem AspectJ da técnica de programação orientada a aspectos. A versão de AspectJ usada no trabalho destes autores foi a 0.1 (nosso trabalho usou a versão 0.6 de AspectJ); esta versão 0.1 consiste dos mesmos elementos presentes no framework D [LK97, Lop97], ou seja, ela contém a linguagem de componentes JCore e as linguagens de aspectos Cool (para especificar interesses de sincronização) e Ridl (para especificar interesses de distribuição). O estudo de caso do trabalho destes autores teve como principal objetivo avaliar o impacto de AspectJ em trazer facilidades para a escrita e manutenção de programas que tratam interesses de concorrência e distribuição. O estudo foi conduzido através do desenvolvimento de programas distribuídos, por um grupo de estudantes de pósgraduação e graduação com conhecimentos de orientação a objetos, durante um período de 3 meses. Os resultados deste estudo ofereceram evidências qualitativas da utilidade de AspectJ no desenvolvimento de aplicações distribuídas, assim como permitiu identificar dificuldades existentes na expressão de interesses do sistema com o uso de linguagens de aspectos específicas. Já os experimentos tiveram como objetivo investigar como a abordagem AspectJ da técnica de programação orientada a aspectos pode trazer facilidades (ou não) para tarefas específicas da atividade de programação orientada a aspectos em comparação com programação orientada a objetos. Os experimentos foram 
conduzidos através da proposição, para pequenos grupos de estudantes, de problemas similares de construção, depuração e modificação de programas para serem ou que foram escritos em AspectJ e linguagens orientadas a objetos. Por se tratar de experimentos, as sessões para cumprimento das suas atividades foram monitoradas (através de gravações de vídeo) e tiveram diversas informações qualitativas e quantitativas coletadas (tempo para completar a atividade, quantidade de compilações, consulta a diferentes arquivos dos programas, comentários dos participantes). Os resultados obtidos nos experimentos apontam para um melhor entendimento de programas escritos em AspectJ (versão 0.1), principalmente quando os aspectos definidos nesta abordagem afetam os componentes funcionais do sistema em um escopo bem definido, e indicam que a técnica de programação orientada a aspectos pode mudar a estratégia usada por programadores na "captura" dos interesses de projeto do sistema.

O estudo apresentado nesta dissertação se diferencia do trabalho destes autores por ter como objetivo a avaliação do impacto de AspectJ (versão 0.6) no projeto de sistemas com requisitos de adaptação estática e dinâmica. Para alcançar este objetivo, partes específicas do projeto dos sistemas adaptáveis JAWS e SPIN foram reconstruídas utilizando abstrações presentes em AspectJ. Os projetos orientados a aspectos resultantes destes sistemas foram então comparados com seus respectivos projetos originais, em relação a características como separação de interesses e facilidade de entendimento, reutilização, configuração dinâmica e evolução estática do sistema. Este método de comparação [KPP95] com os projeto originais dos sistemas, foi relatado no estudo de Murphy, Walker \& Baniassad [MWB99] como sendo uma forma efetiva para proceder a avaliação de uma técnica.

Em [KM99], Kersten \& Murphy apresentam um estudo de casos de construção de um software de ensino baseado na Web usando programação orientada a aspectos. A versão 0.2 de AspectJ foi utilizada neste estudo. Embora a versão usada no trabalho destes autores não seja a mesma versão usada no nosso estudo, ambas possuem o mesmo caráter de oferecer uma linguagem para especificação de aspectos de propósito geral para a linguagem Java, tendo como principais diferenças apenas questões relacionadas às respectivas sintaxes. O objetivo do estudo foi relatar a experiência do emprego da técnica de programação orientada a aspectos no desenvolvimento de um sistema que privilegia sua qualidade de manutenibilidade. $O$ estudo destes autores apresentou diversas contribuições para a realização do trabalho desta dissertação. Diretrizes para projeto orientado a aspectos apresentadas pelos autores foram usadas com êxito no nosso estudo quando aplicando a técnica de programação orientada a aspectos, conforme descrito na seção 6.1. Foram também utilizadas na reengenharia do projeto do JAWS as chamadas políticas de reassociação (que consistem na alteração de atributos de objetos por um aspecto) para configurar as estratégias do protocolo e de I/O. Finalmente, o trabalho de Kersten \& Murphy ilustra o projeto de hierarquias de aspectos que foram úteis na compreensão da aplicabilidade e utilização da abordagem AspectJ de programação orientada a aspectos na fase inicial do nosso estudo, além de mostrar exemplos concretos do uso de aspectos dinâmicos. 
O estudo desenvolvido por Lippert \& Lopes [LL99] possui similaridades e diferenças em relação ao estudo realizado nesta dissertação. O trabalho destes autores, assim como o conduzido nesta dissertação, realizou uma reengenharia parcial de um sistema existente usando AspectJ (versão 0.4). O sistema usado no estudo foi o framework JWAM [Jwa00] usado para construção de aplicações de negócio interativas. O foco principal do trabalho de Lippert \& Lopes, entretanto, foi analisar a aplicabilidade de AspectJ na especificação separada de interesses de detecção e manipulação de exceções em sistemas. $\mathrm{O}$ estudo apresentou evidências qualitativas das facilidades que AspectJ pode trazer para reutilização, tolerância a mudanças, suporte a diferentes configurações e desenvolvimento incremental do interesse de tratamento de exceções em sistemas. $\mathrm{O}$ fato do framework JWAM ter sido construído em Java possibilitou aos autores reimplementarem trechos de código do framework usando AspectJ e apresentarem evidências quantitativas de redução de código do sistema quando expressando interesses de tratamento de exceções com aspectos. O trabalho contribuiu para ilustração de exemplos de projetos do interesse de tratamento de exceções usando AspectJ; estes exemplos foram úteis para elaborar as hierarquias de aspectos de tratamento de exceções do SPIN (descritas na subseção 5.2.2.5).

Em [Lie00] podem ser encontrados diversos relatos de estudos de casos de utilização da técnica de programação adaptativa em projetos comerciais. Estes relatos apresentam resultados obtidos quando desenvolvendo diversas aplicações comerciais com as abordagens Demeter/Java e Demeter/C++. De forma geral, os projetos comprovam os benefícios que a técnica pode trazer para a manutenibilidade (facilidade de entendimento, adaptação automática de comportamentos quando a estrutura do sistema sofre extensões) e reusabilidade de sistemas orientados a objetos complexos. Os estudos também apontam problemas encontrados na implementação dos sistemas, como por exemplo a necessidade de estabelecimento de critérios para organização dos arquivos que descrevem os comportamentos do sistema e as dificuldades encontradas no projeto de métodos traversal resistentes a mudanças. $\mathrm{O}$ foco do nosso trabalho foi analisar a aplicabilidade da técnica de programação adaptativa no projeto de comportamentos colaborativos presentes em sistemas adaptáveis. As reengenharias do JAWS e do Dispatcher com programação adaptativa mostraram possibilidades para o projeto de diversos comportamentos destes sistemas usando as abstrações da técnica e trazendo facilidades para o entendimento de muitos destes comportamentos, além da possibilidade de adaptação dos mesmos para modificações nas estruturas de classes dos sistemas. Uma diferença relevante entre o estudo conduzido nessa dissertação e os estudos descritos em [Lie00], é que o projeto e implementação dos sistemas que serviram como estudo da aplicabilidade de programação adaptativa nos trabalhos destes autores foi realizado através de vários ciclos iterativos. Este tipo de desenvolvimento, baseado em ciclos iterativos, possibilitou observar a resistência de métodos adaptativos e traversal à mudanças ocorrendo na estrutura do sistema a medida que novas funcionalidades eram introduzidas em cada novo ciclo. $\mathrm{O}$ mecanismo de Relações de Contexto não foi implementado na ferramenta Demeter/Java, e é apresentado e exemplificado apenas em [Sei96, SPL98]. 
Por fim, relatamos que a documentação disponível das técnicas [Asp00, LO00] foi também bastante útil para a compreensão das abstrações presentes nas técnicas e apresentação de exemplos concretos de sua utilização. 


\section{Categorização de Adaptações em Sistemas}

Este capítulo apresenta nossa proposta de uma categorização para tipos de adaptações encontrados em sistemas de software e uma análise do impacto de algumas técnicas de projeto sobre esta categorização.

\subsection{Categorização de Adaptações em Sistemas}

Apesar da comunidade ter apresentado definições para sistemas adaptáveis, motivações para o seu desenvolvimento e características que eles devem apresentar, e terem sido propostas abordagens e técnicas para o desenvolvimento de sistemas que favoreçam a qualidade de adaptabilidade, acreditamos que uma categorização dos tipos de adaptações possíveis em um sistema pode permitir um tratamento mais sistemático do interesse de adaptação em sistemas.

Nossa categorização de adaptações em sistemas se fundamenta no seguinte conceito de adaptação:

\section{"Adaptação - Adequação do sistema à alguma Mudança ocorrida"}

Em outras palavras, adaptação é um ajuste (adição, remoção, substituição, modificação) no sistema ou alguma de suas estruturas, funções, serviços, em resposta a alguma mudança ocorrida.

As adequações feitas no sistema podem variar quanto:

(a) ao estado do sistema em que a adequação é feita;

(b) ao nível do sistema em que a adequação é aplicada;

(c) ao tipo de característica do sistema que está sendo adaptada.

Tipos de mudanças que demandam adequações, são:

(a) mudanças nas tecnologias que interagem com o sistema ou que são utilizadas na sua produção;

(b) mudanças nos requisitos (funcionais e não-funcionais) do sistema;

(c) mudanças no ambiente real de execução do sistema. 


\section{Tipos de Adequações}

(I) Quanto ao estado do sistema em que a adequação é feita.

(a) Adequação Estática - o sistema se adapta a mudanças quando está sendo construído ou sofrendo alguma manutenção;

(b) Adequação Dinâmica - o sistema se adapta a mudanças em tempo de execução.

(II) Quanto ao nível do sistema em que a adequação é aplicada.

(a) Adequação Arquitetural - a arquitetura do sistema suporta a adição, remoção, substituição de algum subsistema ou a forma como os subsistemas se comunicam pode ser alterada;

(b) Adequação no Projeto - o projeto interno dos subsistemas suporta modificações internas, ou seja, os subsistemas ou módulos podem ser alterados sem corromper sua estrutura e funcionamento, e sem propagar mudanças locais para os seus subsistemas ou módulos vizinhos;

(c) Adequação na Implementação - o código fonte do sistema suporta modificações decorrentes de alguma mudança.

Vale ressaltar que adequações no nível Arquitetural implicam em adequações no nível de Projeto e Implementação; adequações no nível de Projeto implicam em adequações no nível de Implementação. Nosso trabalho nesta dissertação enfocou apenas adequações nos níveis de Arquitetura e de Projeto.

(III) Quanto ao tipo de característica do sistema que está sendo adaptada.

(a) Adequação Funcional - o sistema se adapta a inclusão de alguma nova funcionalidade ou possibilita a alteração, remoção de uma funcionalidade existente. Existem dois tipos:

(I) estrutural - a estrutura do sistema (ex: modelo de classes) pode ser ajustada permitindo a inclusão, remoção, substituição ou modificação de entidades e dados, devido à alguma mudança na funcionalidade do sistema;

(II) comportamental - a estrutura do sistema suporta a inclusão de novos comportamentos (funções, serviços) decorrentes de novas funcionalidades necessárias ao sistema ou a alteração, remoção de comportamentos já existentes;

(b) Adequação Não-Funcional - o sistema permite a inclusão, alteração, modificação de alguma(s) de suas características não-funcionais. 


\section{Tipos de Mudanças}

\section{(I) Mudanças nas tecnologias}

(a) Tecnologia de Hardware - mudanças nas características do hardware podem influenciar a forma como o sistema responde ou atende seus serviços, funções, ou podem exigir algum esforço no sentido de manter a portabilidade do sistema;

(b) Tecnologia de Software - mudanças nos sistemas que interagem com o sistema adaptável (por exemplo, sistemas operacionais, sistemas de banco de dados, servidores externos) ou mudanças relacionadas aos sistemas e linguagens que são usados na sua produção (compiladores, ferramentas CASE, linguagens de programação).

\section{(II) Mudanças nos requisitos do sistema}

(a) Requisitos Funcionais - são aqueles relacionados diretamente à funcionalidade do sistema, tais como os serviços ou funções internos e externos que o sistema oferece;

(b) Requisitos Não-Funcionais - são aqueles que se referem a propriedades gerais do sistema ou que impõem restrições na sua funcionalidade. Estes requisitos não-funcionais podem ser divididos basicamente em duas categorias:

(1) os que se referem a estrutura inteira do sistema, como por exemplo, portabilidade, eficiência, reutilização, facilidade de manutenção, confiabilidade;

(2) aqueles que se referem a estruturação e funcionalidade de alguns módulos, subsistemas ou componentes do sistema, como por exemplo, concorrência, tratamento de exceções, tolerância a falhas, reutilização.

\section{(III) Mudanças no ambiente real de execução do sistema}

Mudanças no ambiente real de execução do sistema podem:

(1) demandar a criação de novas funcionalidades ou alteração das existentes;

(2) ocasionar a modificação do sistema para beneficiar alguma(s) de suas propriedades gerais, tais como, distribuição, concorrência, manipulação de falhas, reutilização do sistema ou de algum de seus componentes internos.

Assim, este tipo de mudança pode ocasionar uma série de mudanças nos requisitos funcionais e não-funcionais do sistema. 


\subsubsection{Categorias de Adaptação}

De acordo com as adequações feitas no sistema, decorrentes de algum tipo de mudança, cada categoria de adaptação possui:

(1) estado e nível do sistema em que a adaptação é aplicada;

(2) característica do sistema que está sendo adaptada;

(3) tipo de mudança ocorrida que demandou a adaptação.

Exemplos de categorias válidas, desconsiderando o tipo de mudança que demandou a adaptação e o nível de implementação, seriam:

(I) Adaptação Funcional Estática no nível de Projeto;

(II) Adaptação Não-Funcional Estática no nível de Projeto;

(III) Adaptação Funcional Dinâmica no nível de Projeto;

(IV) Adaptação Não-Funcional Dinâmica no nível de Projeto;

(V) Adaptação Funcional Estática no nível de Arquitetura;

(VI) Adaptação Não-Funcional Estática no nível de Arquitetura;

(VII) Adaptação Funcional Dinâmica no nível de Arquitetura;

(VIII) Adaptação Não-Funcional Dinâmica no nível de Arquitetura.

\subsubsection{Exemplos das Categorias de Adaptação}

Para ilustrar exemplos das categorias de adaptação, consideramos um Sistema de Informação Distribuído de Apuração Eleitoral (SIDAE), cujos requisitos básicos são os seguintes:

- o SIDAE deverá permitir a transmissão de votos apurados em regiões periféricas para uma região central, onde então os votos serão totalizados. Por exemplo, em eleições estaduais os dados serão transmitidos de municípios do estado (regiões periféricas) para a capital (região central);

- o SIDAE fornecerá diferentes visões para diferentes usuários do sistema. Por exemplo, eleitores poderão visualizar os dados de apuração de uma determinada região (cidade, estado ou país) por distribuição de partido, coligação ou de candidato individualmente; os orgãos competentes de cada região terão visões do sistema que os permitirão atualizar os dados de apuração da região em que se encontram;

- o SIDAE se encarregará pela transmissão segura e automática dos dados de apuração total ou parcial de uma região periférica para uma região central.

A figura 7.1 representa a distribuição dos componentes de nosso sistema, considerando a cidade de São Paulo como região central, e as cidades Campinas e Santos como regiões periféricas. Esta configuração poderia ser útil para a apuração dos votos de uma eleição no estado de São Paulo. 


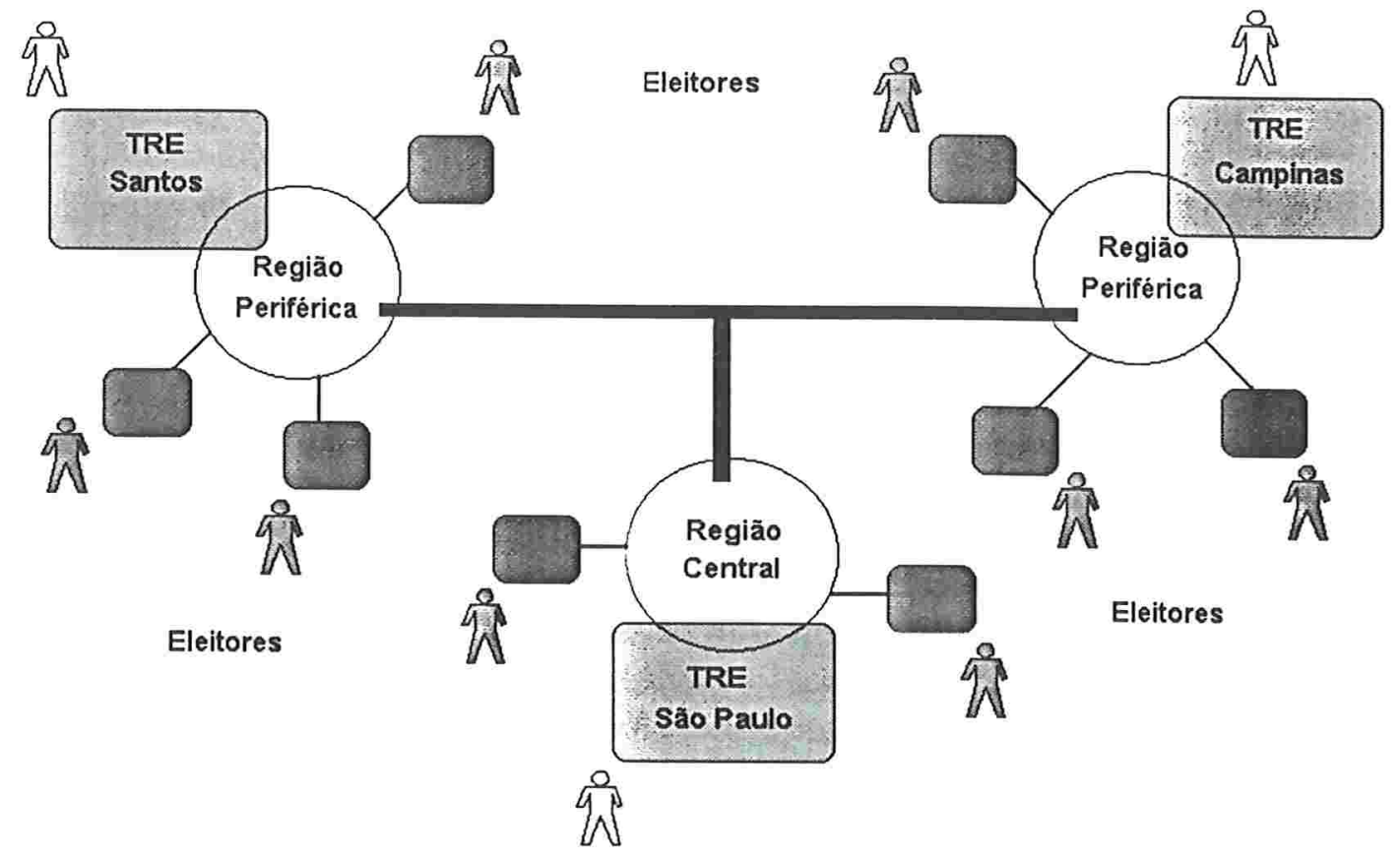

Figura 7.1 - Estrutura dos componentes do SIDAE

(I) Adaptação Funcional Estática no nível de Projeto

O SIDAE poderia possibilitar a adição de nova funcionalidade para avaliar dentro da apuração eleitoral parcial ou total de uma eleição, a distribuição estatística de liderança de cada partido. Por exemplo, em eleições municipais para prefeito, o sistema poderia demandar opções para visualização da distribuição dentro de um estado (ou país) de liderança de cada um dos partidos. A adição desta funcionalidade no SIDAE envolveria adequações funcionais estáticas no nível de projeto devido a mudança nos requisitos funcionais do sistema.

(II) Adaptação Não-Funcional Estática no nível de Projeto

O projeto detalhado do sistema poderia favorecer a independência dos seus principais componentes, tais como, o modelo de dados, a representação gráfica e os mecanismos de comunicação. Isto permitiria a reutilização não apenas da arquitetura do sistema, mas também das estruturas de projeto de cada um de seus componentes que juntas formariam um framework para o desenvolvimento de sistemas similares. Para proceder a obtenção de tais características, o SIDAE poderia sofrer uma adequação estática no nível de projeto que favorecesse a reutilização de seus principais componentes. 
(III) Adaptação Funcional Dinâmica no nível de Projeto

O SIDAE poderia em tempo de execução permitir a permutação de algoritmos de criptografia dos dados eleitorais utilizados para garantir transmissão segura entre os sites responsáveis pela apuração eleitoral. A permutação entre esses algoritmos em tempo de execução poderia ser motivada pela sua capacidade de compressão dos dados ampliando, assim a quantidade de informação transmitida, e pela largura de banda disponível no momento da transmissão. Assim, o projeto do sistema precisa adequar estruturas que permitam a troca dinâmica entre algoritmos relacionados a tal funcionalidade.

(IV) Adaptação Não-Funcional Dinâmica no nível de Projeto

Poderia ser útil em tempo de execução replicar alguns componentes do sistema, devido a sobrecarga em algum dos sites eleitorais periféricos ou central, de forma a beneficiar o tempo de resposta do sistema à solicitação de algum de seus serviços.

(V) Adaptação Funcional Estática no nível de Arquitetura

A arquitetura do SIDAE poderia ser projetada de forma a permitir a criação de novas formas de apresentação dos dados eleitorais para eleitores ou funcionários dos tribunais eleitorais, sem afetar a estrutura atual do sistema. Assim, é preciso haver uma independência entre os subsistemas de apresentação dos dados e os subsistemas responsáveis pela implementação das demais funcionalidade do sistema.

(VI) Adaptação Não-Funcional Estática no nível de Arquitetura

A arquitetura e projeto detalhado do SIDAE poderiam ser desenvolvidos de forma a tornar possível a sua fácil portabilidade para diferentes configurações de rede.

(VII) Adaptação Funcional Dinâmica no nível de Arquitetura

A forma como os sites dos tribunais eleitorais periféricos se comunicam com o site do tribunal eleitoral central poderia ser alterada em tempo de execução no que se refere a mecanismos de comunicação, algoritmo de criptografia dos dados, mudança dinâmica da localização de cada site.

(VIII) Adaptação Não-Funcional Dinâmica no nível de Arquitetura

Um novo requisito que o SIDAE poderia atender seria o de permitir em tempo de execução a adição e remoção de sites de apuração e de conexões de eleitores interessados na apuração de uma eleição. Desta forma o sistema deve ser projetado para lidar com essa mudança dinâmica na configuração dos seus elementos. Devendo portanto, ser adaptável dinamicamente a distribuição dos elementos de sua arquitetura. 


\subsubsection{Tipos de Adaptações do JAWS}

O JAWS, que foi descrito detalhadamente no capítulo 4, é um servidor Web adaptativo que permite que suas estratégias de concorrência, I/O, aceitação de conexões e do seu protocolo possam ser configuradas estática ou dinamicamente. O JAWS pode sofrer adaptações estáticas (através da inclusão de uma nova estratégia concreta ou remoção de uma estratégia concreta existente) ou dinâmicas (através da troca em tempo de execução de alguma de suas estratégias).

As adaptações do JAWS são feitas nas suas estratégias adaptativas. Estas estratégias representam subsistemas da sua arquitetura, caracterizando suas adaptações como sendo aplicadas no nível de arquitetura do sistema. As adaptações das estratégias do JAWS são realizadas no seu projeto detalhado através do uso de relações de herança (classes das estratégias concretas herdam de uma classe-base), o que ilustra como adaptações no nível de arquitetura do sistema são propagadas para o nível de projeto e implementação. Finalmente, as adaptações do JAWS podem ocorrer nas suas características funcionais (inclusão, remoção ou substituição das estratégias concretas de $\mathrm{I} / \mathrm{O}$, aceitação de conexões e do seu protocolo) ou não funcionais (inclusão, remoção ou substituição da estratégia concreta de concorrência).

As mudanças que podem demandar as adaptações do JAWS podem ser: mudanças nas tecnologias de hardware (quantidade de processadores disponíveis) e software (suporte a thread e I/O assíncrono no sistema operacional); e mudanças no ambiente de execução do sistema (carga no servidor - o que acaba afetando e ocasionando mudanças no seu requisito não-funcional de desempenho).

\subsubsection{Tipos de Adaptações do SPIN}

O SPIN, apresentado no capítulo 5, é um sistema operacional extensível que permite que aplicações estendam a interface e implementação do sistema operacional de forma a atender suas necessidades, através da instalação de extensões junto ao kernel.

As adaptações do SPIN (instalação de extensões junto ao kernel) são feitas durante a execução do sistema, caracterizando-as portanto, como sendo dinâmicas. Elas são feitas, em geral, em características funcionais do sistema e podem ser aplicadas no nível de arquitetura (adição, extensão, remoção ou substituição de algum subsistema do sistema operacional) ou de projeto (adição, extensão, remoção ou substituição de alguma função dos subsistemas) do SPIN.

As mudanças que demandam as adaptações do SPIN são as próprias necessidades das aplicações que o utilizam como plataforma de sistema operacional. Este tipo de mudança pode ser caracterizado como uma mudança que ocorre no ambiente de execução do sistema (e que ocasiona mudanças nos requisitos funcionais e não funcionais do SPIN), mas também como uma mudança que ocorre nos requisitos do sistema devido a demanda de seus clientes (aplicações do SPIN). 


\subsubsection{Utilidade da Categorização}

A categorização proposta oferece auxílio para a associação das "mudanças" ocorrendo em um sistema para as "adequações" que precisam ser realizadas sobre o mesmo de forma a contemplar tais "mudanças". Durante o desenvolvimento do software adaptável (nas etapas de sua análise, projeto e implementação) devem ser estabelecidas as associações entre as estruturas do sistema (módulos da arquitetura, projeto e implementação) e os tipos de mudanças a que o sistema está sujeito.

A categorização permite ainda estruturar e organizar os diferentes tipos de adaptações que um sistema pode sofrer. Ela torna possível a análise do impacto de diferentes técnicas de projeto/implementação de sistemas sobre os diferentes tipos de adaptações, permitindo por exemplo, que se favoreça o uso de determinadas técnicas com base nos tipos de adaptações que o sistema deve suportar. A seguir apresentamos uma análise do impacto de algumas técnicas de projeto nas categorias de adaptação.

\subsection{Impacto de Técnicas de Projeto nas Categorias de Adaptação}

Nesta seção apresentamos uma breve análise do impacto das técnicas de padrões (de arquitetura e de projeto), programação adaptativa com relações de contexto e programação orientada a aspectos sobre as categorias de adaptação apresentadas na subseção 7.1.1. Esta análise teve como base o estudo das técnicas realizado durante o desenvolvimento da dissertação e os resultados obtidos no estudo de casos (descritos no capítulo 6).

\subsubsection{Padrões de Arquitetura}

A técnica de padrões arquiteturais oferece alternativas para a formação e construção da arquitetura de um sistema, tendo portanto um forte impacto nas categorias de adaptação que realizam adequações no nível de arquitetura. Padrões arquiteturais refletem estruturas que já foram aplicadas previamente, descrevendo em geral uma análise das conseqüências de adição/remoção estática e dinâmica de algum dos subsistemas. A própria estruturação de um sistema através de um padrão arquitetural auxilia no estudo do impacto de mudanças no sistema neste nível. Muitos desses padrões apresentam uma decomposição funcional do sistema que traz também benefícios para propriedades não-funcionais de interesse do sistema, tais como, reutilização, portabilidade, facilidade de manutenção.

Por exemplo, o padrão Broker [BMR+96] permite a estruturação de um sistema distribuído através da sua decomposição em componentes que interagem através da invocação de serviços remotos. Ele permite a adição/remoção/substituição estática ou dinâmica de componentes clientes e servidores, tornando o sistema mais flexível e de fácil manutenção. O padrão Model-View-Controller (MVC) [BMR+96] permite a 
especificação de aplicações com interfaces gráficas de usuário, mantendo as partes relativas a funcionalidade da aplicação independentes da sua forma de apresentação. Esta forma de estruturar o sistema permite a criação de diferentes visões de um mesmo modelo de classes e dados que podem ser modificadas e destruídas em tempo de execução, além da possibilidade de reutilização dos subsistemas relacionados a parte funcional do sistema (embutidos no componente Modelo), que podem ser também portados para outras plataformas.

Assim, padrões arquiteturais possuem grande impacto nas categorias de adaptação no nível de arquitetura, tanto em características funcionais quanto não-funcionais do sistema, estáticas ou dinâmicas.

\subsubsection{Padrões de Projeto}

Padrões de projeto têm um forte impacto nas categorias de adaptação que aplicam adequações no projeto detalhado do sistema. Cada um dos padrões permite especificar um aspecto de variação do sistema independente dos demais aspectos. Tal aspecto de variação é reflexo do projeto do sistema tendo em vista possíveis mudanças que o sistema poderá sofrer nos seus requisitos atuais ou no atendimento de novos requisitos. Padrões de projeto evitam diversas causas de reconstrução de sistemas [GHJV95], tais como: dependências de plataformas de hardware/software, dependências de algoritmos, forte acoplamento entre classes, extensão da funcionalidade através de subclasses.

Padrões auxiliam na composição de estruturas (conjunto de classes e objetos) que expressam um aspecto de variação do sistema referente a sua funcionalidade. Alguns padrões de projeto têm impacto em adaptações no nível funcional estático e outros no nível funcional dinâmico. O Mediator [GHJV95] permite, em tempo de projeto e codificação, a definição de um objeto que encapsula a forma como um conjunto de objetos se relacionam, mantendo fraco acoplamento entre os mesmos e promovendo assim uma possível reutilização futura de tais objetos. O Strategy [GHJV95] permite, em tempo de execução, a permutação entre algoritmos, de forma independente do objeto cliente que utiliza a implementação de um deles. O Observer [GHJV95] permite definir uma dependência um-para-muitos entre objetos, de forma que quando um deles muda (objeto Subject) em tempo de execução, todos os seus dependentes (objetos Observer) são notificados e atualizados; ele também permite que objetos Observer possam dinamicamente registrar-se ou cancelar seu registro junto ao objeto Subject.

Muitos projetos resultantes da utilização de padrões de projeto apresentam características não-funcionais gerais desejáveis a todo sistema, tais como: reutilização de classes e objetos independentemente ou em conjunto, devido ao fraco acoplamento entre eles; flexibilidade para adição, remoção, alteração, ou substituição de classes e objetos; facilidade de manutenção de aspectos de mudanças previstos e expressos com os padrões.

Alguns padrões de projeto (Mediator, Façade [GHJV95]) são também úteis na especificação das interfaces entre os subsistemas da arquitetura e no projeto de sistemas 
em camadas, tendo portanto, impacto também em adaptações estáticas funcionais no nível de arquitetura.

\subsubsection{Programação Adaptativa}

Programação adaptativa foi desenvolvida com o intuito de facilitar a adaptação de aspectos relacionados ao comportamento do sistema (implementação de métodos) a eventuais evoluções que possam ocorrer no nível de estruturas de classes do sistema. Este tipo de adaptação se encaixa na categoria de adaptação estática funcional no nível de projeto. Programação adaptativa permite também a definição de uma série de comportamentos (métodos adaptativos, classes Visitor) relacionados a uma mesma navegação estrutural comum (método traversal), ampliando desta forma a reutilização no nível de métodos. Os métodos traversal podem inclusive ser utilizados na definição de novos comportamentos decorrentes da evolução do sistema.

O modelo de programação adaptativa foi estendido com o mecanismo de relações de contexto, que permite modelar comportamentos que em tempo de execução podem ser alterados, através da atualização de classes inteiras ou de apenas alguns de seus métodos. Segundo seus autores, relações de contexto permitem modelar aspectos de variação dinâmica do sistema de forma mais elegante e clara que os padrões de Projeto. Assim, programação adaptativa estendida com relações de contexto pode facilitar adaptações dinâmicas funcionais no nível de projeto.

\subsubsection{Programação Orientada a Aspectos}

A técnica de programação orientada a aspectos permite a especificação de propriedades gerais do sistema separada da especificação de sua funcionalidade. Dentro das categorias de adaptação, programação orientada a aspectos parece ter um impacto maior na categoria de adaptação estática não-funcional no nível de projeto, por oferecer linguagens para expressão de aspectos não funcionais do sistema, tais como, concorrência, distribuição, tratamento de exceções. Esta especificação separada pode facilitar a localização e adaptação destes aspectos não funcionais do projeto do sistema. Trabalhos recentes [CBE99] têm mostrado que programação orientada a aspectos pode também causar impacto nas categorias de adaptação dinâmica não-funcional, permitindo modificar em tempo de execução características não funcionais do sistemas, tais como, configuração dinâmica de seus componentes e monitoramento. O projeto do JAWS usando a abordagem AspectJ de programação orientada a aspectos também demonstrou o impacto positivo que esta técnica pode ter nas categorias de adaptação dinâmica não funcionais do sistema. 


\subsubsection{Tabela com o Impacto das Técnicas}

A tabela abaixo resume a discussão da seção anterior, indicando para cada categoria de adaptação as técnicas que causam impacto na realização dos diversos tipos de adequações do sistema.

\begin{tabular}{|l|l|l|l|l|}
\cline { 2 - 5 } \multicolumn{1}{c|}{} & \multicolumn{2}{c|}{ Estática } & \multicolumn{2}{c|}{ Dinâmica } \\
\cline { 2 - 5 } \multicolumn{1}{c|}{} & Funcional & Não Funcional & Funcional & $\begin{array}{l}\text { Não } \\
\text { Funcional }\end{array}$ \\
\hline Arquitetura & PA & PA & PA & PA \\
\hline Projeto Detalhado & PP, PAD & PP, POA & PP, RC & PP, POA \\
\hline
\end{tabular}

Técnicas: Padrões Arquiteturais (PA), Padrões de Projeto (PP), Programação Orientada a Aspecto (POA), Programação Adaptiva (PAD), Relações de Contexto (RC) 


\section{Conclusões e Trabalhos Futuros}

O projeto de software é uma atividade crítica e difícil, e exige das pessoas envolvidas neste processo capacidade criativa e experiência. Métodos e técnicas podem auxiliar no processo de lidar com as dificuldades encontradas nesta atividade e com a complexidade inerente do sistema sendo desenvolvido. As técnicas de projeto investigadas nesta dissertação estendem o modelo convencional de orientação a objetos, preservando as características deste modelo que trazem benefícios para o projeto dos requisitos funcionais do sistema e trazendo novas facilidades para o projeto de seus requisitos não funcionais.

Neste capítulo final da dissertação são enfocadas as contribuições do trabalho e são elaboradas propostas para a realização de trabalhos futuros.

\subsection{Conclusões}

Este trabalho apresentou um estudo comparativo do impacto das técnicas de programação orientada a aspectos e programação adaptativa com relações de contexto no projeto de sistemas adaptáveis. Os projetos do JAWS - um servidor Web adaptativo - e do Dispatcher - o modelo de eventos do sistema operacional extensível SPIN - foram reconstruídos usando os conceitos e abstrações das abordagens AspectJ e Demeter/Java, das técnicas de programação orientada a aspectos e programação adaptativa com relações de contexto, respectivamente. A comparação do projeto original destes sistemas com os novos projetos gerados durante o processo de suas reengenharias revelou diversas vantagens que podem ser alcançadas quando aplicando os preceitos das técnicas sendo investigadas.

A abordagem de AspectJ da técnica de programação orientada a aspectos, possibilitou o alcance das seguintes vantagens:

- separação de interesses - para cada um dos sistemas estudados foi possível especificar separadamente usando a abstração de aspectos, diversos interesses não funcionais que se encontravam no projeto original dos sistemas entrelaçados e difusos ao longo dos componentes funcionais que os representam. O projeto do JAWS usando programação orientada a aspectos permitiu expressar separadamente da sua estrutura de componentes funcionais: as estratégias de concorrência e aceitação de conexões, as configurações estáticas e dinâmicas das suas diferentes estratégias, e o interesse de monitoramento do ambiente de execução e carga no sistema. O projeto do Dispatcher/SPIN usando programação orientada a aspectos permitiu especificar 
separadamente (ou ilustrar alternativas para esta especificação separada) os seguintes interesses não-funcionais deste subsistema: elementos (imposed guards, handlers default e result) que podem ser anexados em tempo de execução aos componentes funcionais, serviço de autorização, sincronização de acesso a objetos, checagem de tipos, tratamento de exceções, rastreamento da execução, e geração de stubs;

- reutilização - a especificação separada dos interesses usando a técnica de programação orientada a aspectos acaba trazendo diversos outros benefícios para 0 projeto de sistemas. Um deles é a facilidade de reutilização tanto da estrutura de componentes funcionais definida para o sistema que evita diversos entrelaçamentos com seus interesses não funcionais, quanto das próprias hierarquias de aspectos definidas para endereçar a modelagem dos seus interesses não funcionais;

- evolução estática - uma outra vantagem trazida pela especificação separada dos interesses é a facilidade de evolução estática dos sistemas. Cada hierarquia de aspectos elaborada para endereçar um interesse específico do projeto dos sistemas pode ser facilmente desacoplada do modelo de componentes funcionais que ela afeta, durante a compilação do sistema. Este fácil desacoplamento permite que cada um dos interesses não funcionais possam ser completamente reelaborados através da concepção de uma nova hierarquia para endereçá-los:

- configuração dinâmica - cada aspecto pode definir uma nova configuração dinâmica para diferentes interesses do sistema, podendo ser dinamicamente "plugado" ou "desplugado" do sistema e afetando assim em tempo de execução o comportamento dos seus componentes funcionais;

- entendimento/desenvolvimento progressivo - cada sistema projetado através de um modelo de componentes funcionais e de um conjunto de hierarquias de aspectos, permite o seu entendimento progressivo iniciando pela funcionalidade inerente do sistema presente no modelo de componentes funcionais e em seguida no entendimento do projeto de cada um de seus demais interesses endereçados pelas hierarquias de aspectos que afetam o modelo de componentes funcionais. Também o método empregado para o processo de reengenharia do projeto dos sistemas usando programação orientada a aspectos privilegiou o seu desenvolvimento progressivo.

A abordagem Demeter/Java da técnica de programação adaptativa possibilitou a especificação separada da estrutura de classes que representa os sistemas e de vários comportamentos que envolvem a colaboração de objetos das classes da sua estrutura. Esta especificação separada traz facilidades para: (1) o entendimento e implementação daqueles comportamentos que envolvam uma colaboração entre objetos de várias classes da estrutura do sistema; (2) a reutilização das abstrações de programação adaptativa (métodos traversal e classes visitor) que representam o comportamento e implementam a funcionalidade do sistema; e (3) a manutenção do sistema permitindo que o comportamento especificado anteriormente possa em muitos casos se adaptar automaticamente a mudanças na estrutura de classes do sistema.

O mecanismo de Relações de Contexto da técnica de programação adaptativa permite definir um projeto mais simples, sem a utilização de estruturas adicionais de herança e composição de classes, para endereçar os aspectos de variação dinâmica de um sistema. Vantagens observadas durante a modelagem de interesses de adaptação dos 
sistemas usando a abstração de classes de contexto foram: (1) separação explícita do interesse de variação dinâmica nas classes de contexto; (2) facilidade de evolução dos interesses de adaptação devido ao fraco acoplamento de classes de contexto para classes base; e (3) a possibilidade de definição de uma nova configuração dinâmica para um interesse de adaptação quando anexando um objeto de contexto a um objeto base.

O estudo de casos permitiu, portanto, a constatação em sistemas reais, das facilidades que as técnicas de programação orientada a aspectos e programação adaptativa com relações de contexto podem trazer para a manutenção de sistemas orientados a objetos, permitindo projetar separadamente seus interesses funcionais e nãofuncionais e trazendo benefícios para a sua evolução estática, configuração dinâmica, reutilização das estruturas de seus interesses não funcionais e entendimento progressivo do sistema. Acreditamos que a especificação separada dos interesses funcionais e não funcionais do sistema em hierarquias de objetos e aspectos relativamente independentes, pode auxiliar no processo de lidar com a inerente complexidade de um sistema, facilitando o desenvolvimento e entendimento de sua estrutura e comportamento.

Foram delineadas diretrizes para a integração das abordagens de AspectJ de programação orientada a aspectos e Demeter/Java de programação adaptativa, assim como foi sugerida a incorporação da abstração de classes de contexto à abstração de aspectos tal como definido em AspectJ (capítulo 7).

Foi também proposta uma categorização para os tipos de adaptações encontrados no desenvolvimento de software. Esta categorização oferece auxílio para um tratamento mais sistemático de mudanças em sistemas, permitindo relacionar as mudanças que um sistema está sujeito às respectivas adequações que devem ser feitas em seu projeto para tolerá-las.

\subsection{Lista de Contribuições}

- estudo de caso: a dissertação apresentou (capítulos 4, 5 e 6) um estudo comparativo do impacto das técnicas de programação orientada a aspectos e programação adaptativa com relações de contexto no projeto de sistemas adaptáveis, com a constatação de benefícios que tais técnicas podem trazer para o projeto e manutenção de sistemas orientados a objetos;

- ilustração de uso e aplicação das técnicas: no estudo de reengenharia do projeto dos sistemas JAWS e Dispatcher/SPIN foram elaborados diversas hierarquias de classes junto com as abstrações presentes nas técnicas investigadas (capítulos 4 e 5). Estas hierarquias são exemplos concretos do uso e aplicação das técnicas no projeto de sistemas. Durante a construção destas hierarquias foram também delineadas diretrizes para aplicação das técnicas (seções 6.1 e 6.2 do capítulo 6);

- integração das técnicas: foram elaboradas propostas para a integração das técnicas de programação orientada a aspectos e programação adaptativa com relações de contexto (seção 6.3 do capítulo 6); 
- categorização de adaptações: no capítulo 7 foi apresentada uma proposta para categorização dos tipos de adaptações encontrados em sistemas de software.

\subsection{Trabalhos Futuros}

Recentemente nas principais conferências relacionadas as áreas de Engenharia de Software e Orientação a Objetos, têm se organizado workshops [WADC00, WMDS99. WMDS00] e se formado uma comunidade de pesquisa que busca a resolução de problemas centrais da área de engenharia de software (notadamente, manutenção e reutilização) através do favorecimento da separação de interesses em sistemas ao longo de todo o ciclo de vida de desenvolvimento de software. Acredita-se que tal favorecimento possa trazer facilidades para lidar com problemas de manutenção, evolução, entendimento e reutilização em sistemas [KLM+97, TOHS99, HL95].

Este trabalho trouxe evidências das facilidades que as abordagens de AspectJ de programação orientada a aspectos e Demeter/Java de programação adaptativa com relações de contexto trazem para o projeto de sistemas, melhorando sua qualidade no que se refere a aspectos como evolução, manutenção, entendimento e reutilização.

A seguir apresentamos propostas para a realização de trabalhos futuros:

- análise do impacto de utilizar as técnicas de programação orientada a aspectos e programação adaptativa no desenvolvimento de frameworks favorecendo a especificação separada de diversos de seus interesses no seu projeto e implementação. Fontoura apresenta em [Fon99] formas de se representar os pontos flexíveis (hot-spots) [Pree95] de um framework usando diferentes técnicas de projeto, incluindo programação orientada a aspectos, padrões e programação orientada a domínio;

- desenvolvimento de novos estudos de casos para comparação e análise da possibilidade da utilização integrada das técnicas investigadas com outras técnicas de projeto, tais como, padrões, programação orientada a domínio e filtros de composição;

- desenvolvimento de novos estudos de casos que enfoquem mais especificamente questões de reutilização em sistemas, usando as abordagens de AspectJ de programação orientada a aspectos e Demeter/Java de programação adaptativa, inclusive de forma integrada;

- elaboração de métodos de desenvolvimento de software e ferramentas que privilegiem a separação dos interesses funcionais e não-funcionais e que forneçam diretrizes para utilização conjunta e integrada das técnicas;

- re-concepção de padrões catalogados pela comunidade [BMR+96, GHJV95] usando o modelo estendido de orientação a objetos da abordagem AspectJ de programação orientada a aspectos;

- construção de bibliotecas de aspectos para domínios específicos (monitoramento, configuração, replicação) ou gerais (tratamento de exceções, execução concorrente, persistência), que possam ser reutilizados na concepção de aplicações orientadas a aspectos. 


\section{Referências Bibliográficas}

[ABSB94] M. Aksit, J. Bosch, W. Sterren, L. Bergmans. "Real-Time Specification Inheritance Anomalies and Real-Time Filters", Proceedings of the ECOOP'94 Conference, LNCS 821, pp. 386-407, Springer Verlag, July 1994.

[ABV92] M. Aksit, L. Bergmans, S. Vural. "An Object-Oriented LanguageDatabase Integration Model: The Composition-Filters Approach", Proceedings of the ECOOP'92 Conference, LNCS 615, Springer Verlag, 1992.

[Arr94] G. Arrango. "Domain Analysis Methods", in Software Reusability, R. Prieto-Díaz, M. Matsumoto (Editors), Ellis Horwood, New York, pp.17-49, 1994.

[Asp00] Aspect J ${ }^{\mathrm{TM}}$ Web Site - [http://www.aspectj.org/], July 2000.

[AT88] M. Aksit, A. Tripathi. "Data Abstractions Mechanisms in Sina/ST", in Proceedings of the OOPSLA'88, ACM SIGPLAN Notices, vol. 23, no. 11, pp. 265-275, 1988.

[AT00] M. Aksit, B. Tekinerdogan, B. "Balancing Design Alternatives", to be published in Software Architectures and Component Technology: The State of the Art in Research and Practice. M. Aksit (Ed.), Kluwer Academic Publishers, 2000.

[Ber94] L. Bergmans. "Composing Concurrent Objects - Applying Composition Filters for the Development and Reuse of Concurrent Object-Oriented Programs", Phd Thesis, Department of Computer Science, University of Twente, The Netherlands, 1994.

[BMR+96] F. Buschmann, R. Meunier, H. Rohnert, P. Sommerlad, M. Stal. A System of Patterns: Pattern-Oriented Software Architecture, John Wiley \& Sons, 1996.

[Boo94] G. Booch. Object-Oriented Analysis and Design with Applications, Benjamin/Cummings, 1994.

[BRJ99] G. Booch, J. Rumbaugh, I. Jacobson. Unified Modeling Language - User Guide, Addison- Wesley, 1999.

[BRL97] L. Buzato, C. Rubira, M. Lisboa. "A Reflective Object-Oriented Architecture for Developing Fault-Tolerant Software". Journal of the Brazilian Computer Society, vol. 4, no. 2, pp.39-48, November 1997. 
[BSP+95] B. Bershad, S. Savage, P. Pardyak, E. Sirer, M. Fiuczynski, D. Becker, S. Eggers, C. Chambers. "Extensibility, Safety and Performance in the SPIN Operating System", in Proceedings of the Fifteenth ACM Symposium on Operating Systems Principles, pp. 267-284, Copper Mountain, CO, December 1995.

[CAB+94] D. Coleman, P. Arnold, S. Bodoff, C. Dollin, H. Gilchrist, F. Hayes, P. Jeremaes. Object-Oriented Development: The FUSION Method, Prentice-Hall, Englewood Cliffs, NJ, 1994.

[CALO94] D. Coleman, D. Ahs, B. Lowther, P. Oman. "Using Metrics to Evaluate Software System Maintainability”, IEEE Computer 24, vol. 27, no. 8, pp. 44-49, August1994.

[CBE99] C. Constantinides, A. Bader, T. Elrad. "A Framework to Address a TwoDimensional Composition of Concerns", Proceedings of the First Workshop on MultiDimensional Separation of Concerns in Object-Oriented Systems, OOPSLA'99, Denver, Nov-1999.

[CRJ87] R. Campbell, V. Russo, G. Johnson. "Choices (Class Hierarchical Open Interface for Custom Embedded Systems)". ACM Operating Systems Review, Vol. 21, No. 3, pp. 9-17, July 1987.

[EGS+94] Y. Endo, J. Gwertzman, M. Seltzer, C. Small, K. Smith, D. Tang, "VINO: The 1994 Fall Harvest", Harvard Computer Center for Research in Computing Technology, Technical Report TR-34-94.

[EKO95] D. Engler, M. Kaashoek, J. O'Toole. "Exokernel: An Operating System Architecture for Application-Level Resource Management", in Proceedings. of the $15^{\text {th }}$ Symposium on Operating Systems Principles. ACM Press, December 1995.

[FC96] M. Fayad, M. Cline. "Aspects of Software Adaptability", Communications of the ACM, Vol. 39, No. 10, pp. 58-59, October-1996.

[FJS99] M Fayad, R. Johnson, D. Schmidt. "Building Application Frameworks: Object-Oriented Foundations of Framework Design”, John-Wiley, 1999.

[FML+97] B. Ford, K. Maren, J. Lepreau, S. Clawson, B. Robinson, J. Turner. "The Flux OS Toolkit: Reusable Components for OS Implementation". In Proc. $6^{\text {th }}$ Workshop on Hot Topics in Operating Systems, May 1997.

[Fon99] M. Fontoura, "A Systematic Approach to Framework Development", Tese de Doutorado, Departamento de Informática, PUC-Rio, 1999.

[Fow99] M. Fowler. Refactoring - Improving The Design of Existing Code, Addison-Wesley, 1999. 
[FS97] M. Fayad, D. Schmidt. "Object-Oriented Application Frameworks", Communications of the ACM, Vol. 40, No. 10, pp. 32-38, October 1997.

[GHJV95] E. Gamma, R. Helm, R. Johnson, J. Vlissides. Design Patterns: Elements of Reusable Object Oriented Software, Addison-Wesley Publishing, 1995.

[GJM91] C. Ghezzi, M. Jazayeri, D. Mandrioli. Fundamentals of Software Engineering, Prentice Hall, 1991.

[Gra94] R. Graddy. "Succesfully Applying Software Metrics", IEEE Computer, vol. 27, no.9, pp.18-25, September-1994.

[HH93] S. Henry, M. Humphrey. "Object-Oriented versus Procedural Programming Languages: Effectiveness in Program Maintenance", J. Object-Oriented Programming, vol. 6, no. 3, pp.41-49, June 1993.

[HL95] W. Hürsch, C. Lopes. "Separation of Concerns", Northeastern University Technical Report NU-CCS-95-03, Boston, February 1995.

[HO93] W. Harrison, H. Ossher. "Subject Oriented Programming (A critique of pure objects) ", in Proceedings of the OOPSLA'93, ACM SIGPLAN Notices, vol. 28, no. 10, pp. 411-428, 1993.

[HS99] J. Hu, D. Schmidt. "JAWS: A Framework for High-performance Web Servers" in Domain-Specific Application Frameworks: Frameworks Experience by Industry, M. Fayad and R. Johnson (Editors), John-Wiley, 1999.

[ICCDS94] Proceedings of the Second International Conference in Configurable Distributed Systems(ICCDS'94). IEEE Computer Society, May 1994.

[ICCDS96] Proceedings of the Third International Conference in Configurable Distributed Systems (ICCDS'96). IEEE Computer Society, May 1996.

[ICCDS98] Proceedings of the Fourth International Conference in Configurable Distributed Systems (ICCDS'98). IEEE Computer Society, May 1998.

[IL+97] J. Irwin, J. Loingtier, et. al. Aspect-Oriented Programming of Sparse Matrix Code, Technical Report, Xerox Palo Alto Research Center, February-1997.

[Is197] N. Islam. "Customizing System Software Using OO Frameworks", IEEE Computer, Vol. 30, No. 2, pp. 69-78, February-1997.

[JCJ92] I. Jacobson, M. Christerson, P. Jonsson, G. Övergaard. Object-Oriented Software Enginnering: a Use Case Driven Approach, Addison Wesley, 1992.

[Jwa00] JWAM framework Web Site, [http://www.jwam.de/], July 2000. 
[KCM+00] F. Kon, R. Campbell, M. Mickunas, K. Nahrstedt, F. Ballesteros. " $2 K$ : A Distributed Operating System for Dynamic Heterogeneous Environments", in Proceedings of the 9th IEEE International Symposium on High Performance Distributed Computing (HPDC'2000), Pittsburgh, August 2000.

[KdRB91] G. Kiczales, J. des Rivieres, D. Bobrow. The Art of the Metaobject Protocol, The MIT Press, 1991.

[KL99] G. Kiczales, C. Lopes. Aspect-Oriented Programming with AspectJ, Tutorial at OOPSLA'99, Nov. 1999.

[KLM+97] G. Kiczales, J. Lamping, A. Mendhekar, C. Maeda, C. Lopes, J. Loingtier, J. Irwin. "Aspect-Oriented Programming". In Proceedings of the ECOOP'97, Finland, June-1997.

[KM85] J. Kramer, J. Magee. "Dynamic Configuration for Distributed Systems", IEEE Transactions on Software Engineering", Vol. 11, No. 4, April-1985.

[KM99] M. Kersten, G. Murphy. "Atlas: A Case Study in Building a Web-based Learning Environment using Aspect-oriented Programming", in Proceedings of the OOPSLA'99, ACM SIGPLAN Notices, vol. 34, no. 10, pp. 340-352, Denver, Nov-1999.

[KPP95] B. Kitchenham, L. Pickard, S. Pleeger. "Case Studies for Method and Tool Evaluation”, IEEE Software, vol. 12, no. 4, pp. 52-62, July 1995.

[Lie96] K. Lieberherr. Adaptive Object-Oriented Software: The Demeter Method with Propagation Patterns, PWS Publishing Company, 1996.

[Lie00] K. Lieberherr. Demeter/Java Experiences, [http://www.ccs.neu.edu/ research/demeter/evaluation/success.html], [http://www.ccs.neu.edu/research/demeter/ evaluation/evaluation-of-adaptive-programming], July 2000.

[LK97] C. Lopes, G. Kiczales. D: A Language Framework for Distributed Programming. Technical Report, Xerox Palo Alto Research Center, February-1997.

[LL95] K. Lieberherr, C. Lopes "Adaptable and Adaptive Software Workshop Report", OOPSLA'95.

[LL99] M. Lippert, C. Lopes. "A Study on Exception Detection and Handling Using Aspect-Oriented Programming", in Proceedings of the ICSE '2000, Limerick, Ireland, June 2000.

[LO00] K. Lieberherr, D. Orleans. Demeter/Java, [http://www.ccs.neu.edu/home/ lieber/Demeter-and-Java.html], July 2000. 
[Lop97] C. Lopes. D: A Language Framework for Distributed Programming, $\mathrm{PhD}$ thesis, Northeastern University, November-1997.

[LS95] R. Lavender, D. Schmidt. "Active Object: an Object Behavioral Pattern for Concurrent Programming", in Pattern Languages of Program Design 2, J. Vlissides, J. Coplien, N. Kerth (editors), Addison-Wesley, 1996.

[LX93] K. Lieberherr, C. Xiao. Object-Oriented Software Evolution, IEEE Software, vol. 19, no. 4, pp.313-343, Abril 1993.

[Mae87] P. Maes. "Concepts and Experiments in Computational Reflection", in Proceedings of the OOPSLA'87, ACM SIGPLAN Notices, Vol. 22, No. 12, pp. 147-155, Orlando-Flórida, October 1987.

[Mey97] B. Meyer. Object-Oriented Software Construction, Prentice-Hall, 1997.

[MK+97] A. Mendhekar, G. Kiczales, et. al., RG: A Case-Study for Aspect-Oriented Programming, Technical Report, Xerox Palo Alto Research Center, February-1997.

[ML98] M. Mezini, K. Lieberherr. "Adaptive Plug-and-Play Components for Evolutionary Software Development", in Proceedings of OOPSLA'98, ACM SIGPLAN Notices, vol. 33, no. 10, pp. 97-116, Vancouver, October-1998.

[MWB99] G. Murphy, R. Walker, E. Baniassad. "Evaluating Emerging Software Development Technologies: Lessons Learned from Assessing Aspect-oriented Programming", IEEE Transactions on Software Engineering, Vol. 25, No. 4, pp. 438455, July/August-1999.

[MY93] S. Matsuoka, A. Yonezawa. "Inheritance Anomaly in Object-Oriented Concurrent Programming Languages", in Research Directions in Concurrent ObjectOriented Programming, G. Agha, P. Wegner, A. Yonezawa (Editors), pp. 107-150, MIT Press, April 1993.

[Ne191] G. Nelson (editor). "System Programming with Modula-3", Prentice-Hall, Englewood Cliffs, NJ, 1991.

[OB98] A. Oliva, L. Buzato. "An Overview of MOLDS: A Meta-Object Library for Distributed Systems". Technical Report IC-98-15, Instituto de Computação, Unicamp, Abril 1998.

[OI94] H. Okamura, Y. Ishikawa. "Object Location Control Using Meta-Level Programming”. In Proceedings of the ECOOP'94, pp. 299-319, Bologna, Italy, July 1994. Springer Verlag, Lecture Notes in Computer Science. Vol. 821. 
[OKH+95] H. Ossher, M. Kaplan, W. Harrison, A. Katz, V. Kruskal. SubjectOriented Compositions Rules, in Proceedings of the OOPSLA'95, ACM SIGPLAN Notices, vol. 30, no. 10, pp. 235-250, 1995.

[Opd92] W. Opdyke. "Refactoring Object-Oriented Frameworks". Phd Thesis, University of Illinois at Urbana-Champaign, 1992.

[OT00] H. Ossher and P. Tarr. "Multi-Dimensional Separation of Concerns and The Hyperspace Approach". In Proceedings of the Symposium on Software Architectures and Component Technology: The State of the Art in Software Development, Kluwer, January-2000.

[PB96] P. Pardyak, B. Bershad. "Dynamic Binding for an Extensible System", Proceedings of the Second USENIX Symposium on Operating Systems Design and Implementation, pp. 201-212, Seattle, WA, October 1996.

[Pf194] S. Pleeger. "Design and Analysis in Software Engineering, Part 1: The Language of Case Studies and Formal Experiments", ACM SIGSOFT Software Engineering Notes, vol. 19, no.4, pp.16-20, October 1994.

[Pree95] W. Pree. "Design Patterns for Object-Oriented Software Development", Addison-Wesley, 1995.

[Pres95] R. Pressman. Engenharia de Software, Makron Books (McGraw Hill), 1995.

[QR97] E. Quadros, C. Rubira. "Construção de um Framework para Sistemas Controladores de Trens utilizando Padrões de Projeto e Metapadrões", Anais do XI Simpósio Brasileiro de Engenharia de Software, Fortaleza, Out-1997.

[RBP+91] J. Rumbaugh, M. Blaha, W. Premerlani, E. Frederick, W. Lorensen. Object-Oriented Modeling and Design, Prentice-Hall, 1991.

[Sch95] D. Schmidt. "Using Design Patterns to Develop Reusable Object-Oriented Communication Software", Communications of the ACM, Vol. 38, No. 10, pp. 65-74, October-1995.

[Sch97a] D. Schmidt. "Applying Design Patterns and Frameworks to Develop Object-Oriented Communication Software", in Handbook of Programming Languages (P. Salus, ed.), MacMillan Computer Publishing, 1997.

[Sch97b] D. Schmidt. "Acceptor and Connector: Design Patterns for Initializing Communication Services", in Pattern Languages of Program Design (editors: R. Martin, F. Buschmann, D. Riehle), Addison-Wesley, 1997. 
[Sch98] S. Schach. Classical and Object-Oriented Software Engineering with UML and C++, McGraw-Hill, 1998.

[SE97] D. Silva, M. Endler. "Configuração Dinâmica de Sistemas", Relatório Técnico, Departamento de Ciência da Computação, Instituto de Matemática e Estatística, Universidade de São Paulo, Agosto 1997.

[Sei96] L. Seiter. Design Patterns for Managing Evolution, $\mathrm{PhD}$ thesis, Northeastern University, September-1996.

[SLMD96] P. Steyaert, C. Lucas, K. Mens, Theo D`Hondt. "Reuse Contracts: Managing the Evolution of Reusable Assets", in Proceedings of the OOPSLA'96, ACM SIGPLAN Notices, Vol.31, No. 10, pp. 268-285, October 1996.

[Som92] I. Sommervile. Software Engineering, Addison-Wesley, 4th edition, 1992.

[SOSP95] XV ACM Symposium on Operating Systems Principles (SOSP'95), 1995.

[SOSP97] XVI ACM Symposium on Operating Systems Principles (SOSP'97), 1997.

[SOSP99] XVII ACM Symposium on Operating Systems Principles (SOSP'99), 1999.

[SPL98] L. Seiter, J. Palsberg, K. Lieberherr. "Evolution of Object Behavior Using Context Relations", IEEE Transactions on Software Engineering, Vol. 24, No. 1, pp. 7992, January 1998.

[SS94] D. Schmidt, T. Suda. "An Object-Oriented Framework for Dynamically Configuring Extensible Distributed Communication Systems", IEEE/BCS Distributed Systems Engineering Journal, vol. 2., Dec.94.

[TA97] B. Tekinorgan, M. Askit. "Adaptability in Object-Oriented Software Development”, ECOOP'96 Workshop Report, in M. Muhlhauser (ed), Special issues in Object-Oriented Programming, Dpunkt, Heidelberg, 1997.

[Tek96] B. Tekinerdogan. "Modeling Adaptability in Object-Oriented Software Development", Adaptability in OO Software Development Workshop, ECOOP '96, Linz, Austria, 1996

[TOHS99] P. Tarr, H. Ossher, W. Harrison, S. Sutton. "N Degrees of Separation: Multi-Dimensional Separation of Concerns", in Proceedings of the ICSE'99, Los Angeles, May 1999.

[vDHT95] L. van Doorn, P. Homburg, A. Tanenbaum. "Paramecium: An extensible object-based kernel", Proceedings of the 5th Hot Topics in Operating Systems (HotOS) Workshop, pp. 86-89, Orcas Island, WA, May 1995. 
[Vli95] J. Vlissides. Visiting Rights, C++ Report, September 1995.

[Vli96] J. Vlissides. The Trouble with Observer, C++ Report, September 1996.

[WADC00] Workshop on Aspects \& Dimensions of Concerns, ECOOP 2000, Cannes, France, June 2000.

[WBM99] R. Walker, E. Baniassad, G. Murphy. "An Initial Assessment of AspectOriented Programming", in Proceedings of the ICSE '99, Los Angeles, May 1999.

[WMDS99] First Workshop on Multi-Dimensional Separation of Concerns in ObjectOriented Systems, OOPSLA'99, Denver, EUA, November 1999.

[WMDS00] Workshop on Multi-Dimensional Separation of Concerns in Software Engineering, ICSE'2000, Limerick, Ireland, June 2000.

[WMH93] N. Wilde, P. Matthews, R. Huitt. "Maintaining Object-Oriented Software", IEEE Software, Vol. 10, No. 1, pp. 75-80, January-1993.

[WY90] T. Watanabe, A. Yonezawa. "Reflection in an Object-Oriented Concurrent Language". In ABCL - An Object-Oriented Concurrent System, A. Yonezawa (editor), chapter 3, pgs. 45-70. The MIT Press, Cambridge, Massachusetts, 1990.

[Yok92] Y. Yokote. "The Apertos Reflective Operating System: the Concept and its Implementation", in Proceedings of the OOPSLA'92, ACM SIGPLAN Notices, vol. 27, no. 10, pp. 414-434, October 1992.

[ZW98] M. Zelkowitz, D. Wallace. "Experiment Models for Validating Technology", Computer, vol. 31, no.5, pp. 23-31, May 1998. 